\title{
Clinical implications of acute exacerbations in COPD
}

Citation for published version (APA):

Groenewegen-Sipkema, K. H. (2008). Clinical implications of acute exacerbations in COPD. [Doctoral Thesis, Maastricht University]. s.n.]. https://doi.org/10.26481/dis.20080625kg

Document status and date:

Published: 01/01/2008

DOI:

$10.26481 /$ dis.20080625kg

Document Version:

Publisher's PDF, also known as Version of record

\section{Please check the document version of this publication:}

- A submitted manuscript is the version of the article upon submission and before peer-review. There can be important differences between the submitted version and the official published version of record.

People interested in the research are advised to contact the author for the final version of the publication, or visit the DOI to the publisher's website.

- The final author version and the galley proof are versions of the publication after peer review.

- The final published version features the final layout of the paper including the volume, issue and page numbers.

Link to publication

\footnotetext{
General rights rights.

- You may freely distribute the URL identifying the publication in the public portal. please follow below link for the End User Agreement:

www.umlib.nl/taverne-license

Take down policy

If you believe that this document breaches copyright please contact us at:

repository@maastrichtuniversity.nl

providing details and we will investigate your claim.
}

Copyright and moral rights for the publications made accessible in the public portal are retained by the authors and/or other copyright owners and it is a condition of accessing publications that users recognise and abide by the legal requirements associated with these

- Users may download and print one copy of any publication from the public portal for the purpose of private study or research.

- You may not further distribute the material or use it for any profit-making activity or commercial gain

If the publication is distributed under the terms of Article $25 \mathrm{fa}$ of the Dutch Copyright Act, indicated by the "Taverne" license above, 


\section{Clinical implications of acute exacerbations in COPD}


The studies described in this thesis were supported by research grants from AstraZeneca BV and GlaxoSmithKline BV.

Publication of this thesis was financially supported by AstraZeneca BV,

GlaxoSmithKline BV and Chiesi Pharmaceuticals BV.

(C) Copyright Karin Groenewegen, 2008

Every part of this book may be reproduced in any form (e.g. print, microfilm, photo print or other wise) with the condition that the source is credited for reproduction.

Isbn: 978-90-9023145-7

Lay out: Helga de Graaf, Studio Eye Candy, Groningen (www.proefschrift.info). Printed by: Ipskamp PrintPartners Enschede, the Netherlands. 


\title{
Clinical implications of acute exacerbations in COPD
}

\section{PROEFSCHRIFT}

\author{
ter verkrijging van de graad van doctor \\ aan de Universiteit Maastricht \\ op gezag van \\ prof. mr. G.P.M.F. Mols, Rector Magnificus, \\ volgens het besluit van het College van Decanen, \\ in het openbaar te verdedigen \\ op woensdag 25 juni 2008 om 14.00 uur
}

door

Karin Groenewegen-Sipkema 


\section{Promotor:}

Prof. dr. E.F.M. Wouters

\section{Beoordelingscommissie:}

Prof. dr. A. Masclee

Prof. dr. H.A.M. Kerstjens

Prof. dr. R. Louis

Dr. E. Stobberingh

Dr. G.P.M. ten Velde (voorzitter)

(Rijksuniversiteit Groningen)

(CHU Sart-Tilman, Liege) 


CONTENTS

Chapter 1 General Introduction 9

Chapter 2 Bacterial infections in acute exacerbations 53 of COPD; a one-year prospective study

Chapter 3 Longitudinal follow-up of systemic

69

inflammation after acute exacerbations of COPD

Chapter $4 \quad$ Increased systemic inflammation is a risk 85 factor for COPD exacerbations

Chapter 5 Elevated plasma homocysteine levels in 101 stable COPD patients

Chapter 6 Low serum MBL levels offer no increased 117 risk for acute exacerbations of COPD

Chapter 7 Systemic inflammation in COPD: the role 135 of acute exacerbations

Chapter 8 Mortality and mortality-related factors 159 after acute exacerbations of COPD

Chapter 9 General Discussion and summary

Curriculum Vitae 205

Dankwoord 206 

CHAPTER 1

General introduction 


\section{General introduction}

\section{Introduction}

Chronic obstructive pulmonary disease (COPD) is defined according to the recently updated GOLD guidelines as "a preventable and treatable disease with some significant extrapulmonary effects that may contribute to the severity in individual patients. Its pulmonary component is characterized by airflow limitation that is not fully reversible. The airflow limitation is usually progressive and associated with an abnormal inflammatory response of the lung to noxious particles or gases. The chronic airflow limitation characteristic of COPD is caused by a mixture of small airway disease (obstructive bronchiolitis) and parenchymal destruction (emphysema), the relative contributions of which vary from person to person"[1]. The clinical manifestations of COPD include dyspnea, cough, sputum production and impaired exercise tolerance. The clinical course of COPD is generally one of gradual progressive impairment, which may eventually lead to respiratory failure. Periods of relative clinical stability are interrupted by recurrent exacerbations. An acute worsening of respiratory symptoms is often described as an exacerbation. The definition of an acute exacerbation of COPD (AECOPD) is generally based on varying combinations of symptoms as an increase in cough or sputum production, worsening of dyspnea or changes in sputum purulence. However, no complete, clear and standardized definition of an exacerbation currently exists. In 1999 a working definition of an exacerbation was proposed : a sustained worsening of the patient's condition, from the stable state and beyond normal day-to-day variations, that is acute in onset and necessitates a change in regular medication in a patient with underlying COPD[2]. In the 2006 GOLD guidelines, acute exacerbations were defined as an event in the natural course of the disease characterized by a change in the patient's baseline dyspnoea, cough, and/or sputum that is beyond day-to-day variations, is acute in onset and may warrant a change in regular medication in a patient with underlying COPD[1]. However, these episodes of acute exacerbation can vary considerably in severity: part of these exacerbations remain unreported while some episodes are complicated by respiratory failure and require therefore hospital admission. Rodriguez-Roisin et al suggested to stage COPD exacerbations based on healthcare utilisation. They defined 3 levels of severity: mild, moderate and severe.

During a mild exacerbation, patient has an increased need for medication, which he/she can manage in their own normal environment. Patients with a moderate exacerbation have an increased need for medication and need to seek additional medical assistance; during a severe exacerbation, the patient recognizes obvious and/or rapid deterioration in condition, requiring hospitalization[2]. However, such operational definitions of severity of exacerbations are possibly dependent on the local health care organisation.

On average, patients with COPD have one to four exacerbations a year with important complications for consumption of health care resources. A prospective 
study performed in the United States in 1995, involving more than 1000 adults admitted to hospital for an acute exacerbation of COPD found the median length of hospital stay was 9 days and hospital readmissions were very common[3]. In the Netherlands, more than $50 \%$ of direct medical costs are related to hospital admissions for acute periods of COPD: reductions of the number of exacerbations may have important implications in direct medical costs. It has been shown that costs vary considerably with the severity of the exacerbation as well as with the severity of COPD[4]. Exacerbations are not only important events in the natural history of COPD because they pose a considerable economic burden but more importantly because repeated exacerbations of COPD lead to deteriorating healthrelated quality of life[5] and when associated with ventilatory failure to premature death[6]. Exacerbations of COPD are therefore of major importance in terms of the prolonged detrimental effect on patients. Furthermore the frequency of exacerbations contributes to the long term decline in lung function in patients with moderate to severe COPD[7].

However, largely as a consequence of the demographic developments in the western world, significant increases in the number of hospitalizations can be expected as long as no marked changes in the system of health care delivery are realised [8].

The presently used definition of acute exacerbations of COPD, largely based on experienced symptomatology by the patient without measurable parameters in order to define severity or outcome, interferes with a systematic approach of this acute disease condition as well as development of adequate strategies in order to prevent or manage this important medical problem.

\section{Risk factors for AECOPD}

Despite the clinical impact of AECOPD for the patient and the community, only limited studies are reported assessing possible risk factors for the development of AECOPD itself: most studies evaluated factors predicting hospitalization for acute exacerbation in patients with COPD. In one study, daily wheeze and bronchitic symptoms contributed to a higher frequency of AECOPD [5]. Another study reported that the risk of hospitalization was higher in the patients with more severe airflow limitation[9]. However, others did not find an association between hospitalization risk and the degree of airflow limitation[10, 11], although there is growing evidence that exacerbation frequency increases with disease severity. Frequent past exacerbations as well as quality of life have also been related to a higher frequency of exacerbations $[8,10]$. Regarding physiological parameters, in one report muscle weakness was associated with high use of health services for COPD[12].

The role of smoking has only been limitedly addressed: smoking habits had no 


\section{General introduction}

significant impact on the risk of hospitalization[10]. Among other external factors, influenza vaccination has been shown to reduce the risk of admission [13]. High levels of air pollution are also related to a higher risk for admission[14]. In a small number of chronic hypercapnic patients, Vitacca et al. reported that basal body weight, the decline in $\mathrm{FEV}$, and the rate of deterioration of arterial blood gases were related to the necessity of ICU admission for acute exacerbations[15]. The same group reported some years later that underlying general condition manifested by malnutrition and APACHE II score, a widely applied prognostic score including 12 physiological variables, was an important determinant of outcome for AECOPD and that flow limitation as assessed by the forced expiratory manoeuvre provides additional information[16].

Kessler et al reported data on predictive factors of hospitalization in a series of 64 patients with COPD followed during a period of at least 2.5 years[10]. In this study, the risk of being hospitalized was significantly increased in patients with a low body mass index and in patients with a limited 6-min walking distance. But above all, the risk of hospitalization for acute exacerbation was significantly increased by gas exchange impairment and pulmonary haemodynamic worsening: by multivariate analysis only arterial carbon dioxide tension $\left(\mathrm{PaCO}_{2}\right)$ and mean pulmonary arterial pressure were independently related to the risk of hospitalization for AECOPD. It is noteworthy that in this study neither the severity of airways obstruction nor the degree of hypoxemia was a predictive factor of hospitalization.

In a study by Garcia-Aymerich, the association between modifiable and nonmodifiable potential risk factors of exacerbation and the admission for a COPD exacerbation was estimated in a case-controlled approach[17]. Among a wide variety of potential risk factors, it was demonstrated that previous admissions, lower FEV, and underprescription of long-term oxygen therapy were independently associated with a higher risk of admission for COPD exacerbation. A recent study from the same group demonstrated a lower risk of admission in COPD patients who perform some level of physical activity[18].

A recent study reported low BMI, a high number of concomitant diagnoses, a high number of respiratory medications and a low Baseline Dyspnoea Index (BDI) as independent risk factors for hospital admission[19]. Furthermore a number of studies investigated the risk factors for re-admission after an acute exacerbation of COPD. In a small study, low BMI on admission and weight loss during hospitalisation were related to an increased risk of re-admission[20]. These findings were confirmed by a more recent study from Sweden, which found that weight loss during the follow-up period and low BMI were predictive for new episodes of exacerbation[21]. A retrospective study conducted in Hong Kong identified previous hospital admission, total length of stay more than 5 days, nursing home residency, dependency in self-care, right heart strain on ECG, high dose of inhalation corticosteroids, and bicarbonate level more than $25 \mathrm{mmol} / \mathrm{l}$ as independent risk factors for hospital readmission[22]. A prospective study from 
the Spanish group showed the following risk factors: 3 or more readmissions for COPD in the year before recruitment, $\mathrm{FEV} 1, \mathrm{pO}_{2}$, and taking anti-cholinergic drugs, while a higher level of physical activity was a protective factor for readmission[23]. Another recent Spanish study found the combination of quality of life, hospitalization for COPD in the previous year and hypercapnia at discharge as predictors for readmission[24]. A Swedish group reported that walking distance is an independent predictor of readmission for acute exacerbations[25].

Patients that are readmitted also seem to have lower health status and a higher level of anxiety[26].

Further research is needed to prevent or relieve exacerbations and to reduce the risk of hospitalization. Longitudinal studies with optimal phenotyping of patients are needed to identify disease-related risk factors. The health care system needs to overcome already identified modifiable care-associated risk factors. At least current evidence indicates that this phenotyping needs to include the total respiratory impairment as well as the extrapulmonary characteristics of the disease.

\title{
Physiological consequences of AECOPD
}

\begin{abstract}
Increased sensation of dyspnea is a common and characteristic finding in AECOPD. Clearly, the sensation of breathlessness is a complex sensory
\end{abstract} phenomenon depending on the central processing of both respiratory-related and non-respiratory neural activity arising from other CNS structures [27]. The mass, strength, length, coordination and endurance capacity of the respiratory muscles, the impedance of the ventilatory pump, and gas exchange efficiency are interdependent factors controlling ventilation and contribute to the sensation of dyspnea and effort[28]. The quality and quantity of sensory information associated with dyspnea during AECOPD is poorly documented and generally not considered in daily clinical practice. However, when it is generally assumed that the load opposing the muscles during AECOPD is increased, effort as well as dyspnea both increase[28]. Similar changes in effort and dyspnea can be expected as ventilation increases or as the respiratory muscles are weakened. Currently available data from patients requiring mechanical ventilation indicates the presence of increased central drive, dyspnoea, tachypnoea, reduced tidal volume and development of hypercapnic respiratory failure, while ventilation/perfusion matching seems to be relatively preserved[29, 30].

Dynamic hyperinflation (DH) is generally considered as an important factor of exercise related breathlessness in COPD[31]. Most studies about dynamic hyperinflation have been performed in patients undergoing mechanical ventilation for acute respiratory failure as a consequence of AECOPD. As a result of dynamic hyperinflation, tidal breathing becomes shifted upwards on the pressure-volume curve, closer to TLC[32]. In this situation, increased pressure must be generated 


\section{General introduction}

to maintain tidal volume. Dynamic lung compliance becomes reduced as a result of the accompanying tachypnoea and reduced inspiratory time and, in conjuction with the increased airway resistance, contributes importantly to the increased dynamic respiratory work[32] .

Acute dynamic hyperinflation furthermore shortens the inspiratory muscles, particularly the diaphragm and causes functional muscle weakness.[32] The accessory muscles of breathing are maximally recruited and inspiratory threshold loads increase significantly. This has been suggested to account for nearly $60 \%$ of the increased static inspiratory work of breathing during an exacerbation[32]. Two studies have evaluated lung mechanics, including spirometry, inspiratory capacity and dyspnoea during recovery from an exacerbation[33, 34]. In both studies, the $\mathrm{FEV}_{1}$ /forced vital capacity (FVC) ratio and expiratory flow limitation changed relatively little throughout the study period. Both studies demonstrated that changes in lung volume rather than airflow resistance predominated. Hypoxemia is a common problem in AECOPD. V/Q inequality is the most important determinant of hypoxemia under these conditions although low mixed venous oxygen tension $\left(\mathrm{PvO}_{2}\right)$ is a contributing factor [29]. Lower $\mathrm{PvO}_{2}$ can be explained by an increased oxygen utilization due to the increased work of breathing as well as by inadequate cardiac compensating capacity to increase cardiac output. Oxygen therapy in these conditions may have unintended deleterious effects: hypercapnia induced by oxygen therapy is a common problem in the management of AECOPD. The most important mechanisms are a reduction in ventilation associated with removal of the hypoxic stimulus and increase in the ventilationperfusion inequality as a consequence of the hypoxic vasoconstriction. Indeed, an increased dispersion of blood flow due to release of hypoxic vasoconstriction is demonstrated after 100\% oxygen breathing during AECOPD but is not significantly different between $\mathrm{CO}_{2}$ retainers and non- $\mathrm{CO}_{2}$-retainers [35]. However, oxygeninduced hypercapnia was characterised by an overall reduction in ventilation during oxygen breathing suggesting that a change in ventilatory control is the major discriminating factor between retainers and non-retainers. In addition, $\mathrm{CO}_{2}$ retainers manifested a significant increase in true alveolar dead space: this substantial increase in alveolar dead space clearly leads to more wasted ventilation and increase in carbon dioxide retention[35]. Increases in physiologic dead space were previously reported by others[36-38]. Few studies have attempted to relate the changes in physiology to changes in the inflammatory process. One study reported an association between serum levels of IL-8 and LTB4 and the magnitude of dyspnoea, respiratory rate and inspiratory capacity[39].

However, precise analysis of pathophysiological changes during AECOPD is scarce, resulting in an imprecise, broad and unfocused treatment strategy in clinical practice, ignoring the clinically important pathophysiological mechanisms. An exacerbation of COPD appears to be characterized by increased central drive, decreased inspiratory capacity and decreased inspiratory muscle force. 


\section{Diagnosis and assessment of AECOPD}

Diagnosis of AECOPD is still largely based on medical history. The three major symptoms are increased dyspnea, increased sputum volume and increased sputum purulence[40]. Exacerbations may also be accompanied by fever, wheezing, chest tightness and number of non-specific complaints. An increase in sputum volume and purulence can be indicative for a bacterial cause, as well as a prior history of chronic sputum production[40, 41].

Medical history can direct the diagnosis to other disease conditions, manifested by AECOPD related symptoms. Many of these disease conditions are regularly considered as secondary causes of AECOPD. In fact, these diseases have to be considered as separate disease entities in order to avoid further confusion and in order to determine more precisely the pathogenesis and pathophysiology of AECOPD.

\section{Differential diagnosis of AECOPD}

Pneumonia

Pulmonary embolism

Pneumothorax

Pleural effusion

Rib fractures/Chest trauma

Right and/or left heart failure or arrythmias

Inappropriate use of sedatives

Gastro-oesopheagal reflux and/or aspiration

Bronchus carcinoma

Assessment of severity of an AECOPD is based on patient's medical history before the exacerbation, symptoms, physical examination, lung function tests, arterial blood gas measurements, and other laboratory tests[42, 43].

The history of the previous stable condition provides a comparable measure of the performance of the patient during daily living activities. The duration of the episode and the progression of symptoms are also important parameters in the assessment of the severity of the AECOPD. Sleeping and eating difficulties have to be assessed very carefully. Specific information is also required on the frequency of attacks and the level of dyspnoea has to be noted. When the patient is unable to complete one sentence, the AECOPD is considered severe. However, the most important sign is the change in the alertness of the patient.

Important signs at physical examination are the use of accessory respiratory muscles, paradoxical chest movements, central cyanosis, oedema, haemodynamic instability and signs of cor pulmonale. A body temperature $>38.5 \mathrm{C}$, a respiratory 


\section{General introduction}

rate $>25$ breaths/min and a heart rate $>110$ beats $>$ min are arbitrary cut-off points indicating severe exacerbation [43].

\begin{tabular}{ll}
\hline Medical history and signs of severity of AECOPD \\
\hline Medical history & Signs of severity \\
$\begin{array}{l}\text { Duration or worsening of new } \\
\text { symptoms }\end{array}$ & Use of accessory respiratory muscles \\
$\begin{array}{l}\text { Number of previous episodes } \\
\text { (exacerbations/hospitalizations) }\end{array}$ & Paradoxical chest wall movements \\
Present treatment regimen & Worsening or new onset central cyanosis \\
& Development of peripheral oedema \\
& Hemodynamic instability \\
& Signs of right heart failure \\
& Reduced alertness \\
\hline
\end{tabular}

Available prior measures of lung function and blood gases are extremely useful for comparison with those during the acute episode. However, admission for an AECOPD is many times the first time that patients are referred to evaluate their respiratory condition. During AECOPD even simple lung function tests can be difficult to perform properly, and their routine use is not recommended according to the latest GOLD guidelines[1].

In the hospital, measurement of arterial blood gases is essential to assess the severity of an exacerbation. Arterial oxygen tension $\left(\mathrm{PaO}_{2}\right)<8.0 \mathrm{kPa}$ and $/$ or an arterial oxygen saturation $\left(\mathrm{SaO}_{2}\right)<90 \%$ when breathing room air indicate respiratory failure. In addition, $\mathrm{PaO}_{2}<5.3 \mathrm{kPa}, \mathrm{PaCO}_{2}>8.0 \mathrm{kPa}$ and $\mathrm{pH}<7.25$ are generally accepted criteria for ICU admission of AECOPD[1].

Chest radiographs are useful in identifying alternative diagnoses that can mimic the symptoms of an exacerbation. However, data on the diagnostic accuracy of chest x-rays during acute exacerbations are lacking. An ECG may help in the diagnosis of right heart hypertrophy, arrhytmias or ischemic episodes. Further technical investigations or imaging techniques have to be considered when other diagnoses are suspected.

Laboratory investigations can reveal specific abnormalities. Whole blood count may identify polycythaemia. Sputum stain and culture are useful in identifying bacterial infections and directing antimicrobial therapy. Biochemical analysis can reveal electrolyte disturbances contributing to muscle weakness like hypophophataemia or can be indicative for systemic inflammation as manifested by increased levels of acute phase proteins like C- reactive protein.

In general, it can be assumed that criteria reflecting the severity of the disease or of disease related complications as AECOPD are used in order to guide clinical decision making as to decide if there are indications for hospitalization for these 
patients. The GOLD document [1] identified indications for hospital assessment or admission for AECOPD.

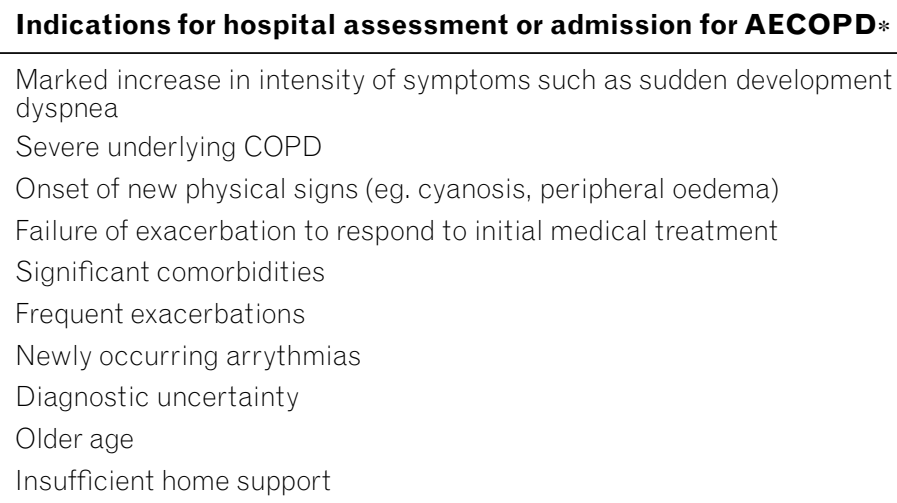

*Local resources need to be considered

Remarkably, many of the formulated criteria are related to facilities for health care delivery or to criteria derived from medical history from the patient and his/her relatives. Furthermore, growing development of monitoring facilities even at home will blur the dissociation between hospital managed and home managed acute exacerbations.

Indications for ICU admission of patients with AECOPD are defined more strictly, as recently summarised in the GOLD document [1]:

\section{Indications for ICU admission of patients with AECOPD*}

Severe dyspnea that responds inadequately to initial emergency therapy

Change in mental status (confusion, lethargy, coma)

Persistent or worsening hypoxemia $(\mathrm{PaO} 2<5.3 \mathrm{kPa}, 40 \mathrm{~mm} \mathrm{Hg})$, and /or severe/ worsening hypercapnia ( $\mathrm{pCO} 2>8.0 \mathrm{kPa}, 60 \mathrm{~mm} \mathrm{Hg}$, and /or severe/worsening respiratory acidosis $(\mathrm{pH}<7.25)$ despite supplemental oxygen and noninvasive ventilation

Failure of exacerbation to respond to initial medical treatment

Need for invasive mechanical ventilation

Hemodynamic instability-need for vasopressors

* Local resources need to be considered 


\section{General introduction}

\section{Causal aspects of AECOPD}

Bacteria, viruses and environmental agents account for the vast majority of episodes of exacerbations, although many patients suffer from exacerbations, where no specific cause can be identified[44].

\section{Bacterial infections}

The role of bacterial infection in COPD is still a matter of debate despite decades of investigation. Murphy et al summarised the different obstacles to define the role of bacteria in COPD in general, and their role in causing exacerbations in particular. First, the lower airways in COPD patients are colonised by bacteria even in the absence of symptoms of an exacerbation. Second, patients with COPD as well as exacerbations of the disease are highly heterogeneous, and, as a result, bacteria may vary from patient to patient and are likely to play different roles in different patients. Third, the information obtained from cultures of expectorated sputum samples is limited since these samples do not reliably reflect conditions in the lower airways. Fourth, the three bacteria most strongly implicated in causing exacerbations (non-typeable Haemophilus influenzae, Moraxella catarrhalis, and Streptococcus pneumoniae) are exclusively human pathogens, limiting the use of animal models [45].

Patients with COPD have a number of predisposing factors for bacterial infection, such as impaired mucociliary clearing and impaired neutrophil function leading to abnormal inflammatory airway responses[46, 47].

An assessment of the microbiological studies indicates that conventional bacterial respiratory pathogens are absent in about $50 \%$ of acute exacerbations in COPD.

The percentage of positive sputum cultures using protected specimen brushes to define the microbial flora of the distal airways varies between 50 and $72 \%$ [48-50]. Monso et al found positive bacterial cultures in $52 \%$ of outpatients with AECOPD. In that study, only $25 \%$ of the outpatients in stable condition had a significant concentration (> $1000 \mathrm{cfu} / \mathrm{mL}$ ) of bacteria recovered by the protected- specimen brush technique from the lower airways, while $52 \%$ of patients with exacerbation had this amount of bacteria present, suggesting that bacteria are present in the lower airways during exacerbations in concentrations sufficient to cause invasive infection [49].

Fagon et al found evidence of bacterial infection in $50 \%$ of patients who required mechanical ventilation [48]. In contrast to these data, Soler et al found $72 \%$ of positive cultures in ventilated patients for AECOPD [51]. In this study, gramnegative enteric bacteria and Pseudomonas or Stenotrophomonas represented $39 \%$ of potential pathogens.

A shift in the type of micro-organism isolated was reported in patients with more severely compromised lung function $[52,53]$. Indeed, both studies reported in patients with lower FEV a higher incidence of Pseudomonas and 
Enterobacteriaceae in their sputum. They hypothesized a possible relationship between the decline in lung function and occurrence of Pseudomonas and other Gram negative species in sputum.

The hypothesis of an etiological role of bacterial pathogens in AECOPD can be supported by presence of greater neutrophilic airway inflammation in pathogenpositive than in pathogen-negative exacerbations. Soler et al reported that the presence of potentially pathogenic micro-organisms in their study was significantly associated with higher percentages of neutrophils and TNF-alpha concentration in broncho-alveolar lavage fluid[51]. Sethi et al tested this hypothesis by comparing levels of interleukin (IL)-8, tumor necrosis factor (TNFalpha) and neutrophil elastase (NE) in 81 sputum samples obtained from 45 patients with AECOPD. $\mathrm{H}$. influenzae exacerbations were associated with significantly higher sputum IL-8, TNF-alpha, and NE. M. catarrhalis exacerbations demonstrated significantly higher sputum TNF-alpha and NE when compared to pathogen-negative exacerbations.

$H$. parainfluenzae-associated exacerbations had an inflammatory profile similar to pathogen-negative exacerbations. This increased airway inflammation associated with isolation of $\mathrm{H}$. influenzae and $\mathrm{M}$. catarrhalis supports an etiological role of those pathogens in AECOPD [54]. Furthermore, bacterial strains of $\mathrm{H}$. influenzae isolated from patients with acute exacerbation cause more airway inflammation in a mouse model than bacterial strains from patients isolated when no symptoms are present [55]. Recently, a number of studies have investigated the role of nontypeable Haemophilus Influenzae (NTHI) in acute exacerbations. Bandi et al. found NTHI intracellulary in the lower airways in $87 \%$ of patients with acute exacerbation, compared to $33 \%$ in stable patients and none in healthy controls, suggesting a role for intracellular infection by NTHI in the pathogenesis of exacerbations[56].

Earlier studies of immune response to Haemophilus influenzae after acute exacerbations of COPD have contradictory results, mostly due to limitation in study design and a failure to detect strain-specific immune responses[57]. More recent studies have shown that immune response to bacterial pathogens after acute exacerbations of COPD is characterized by considerable strain specificity, suggesting the importance of differentiation among strains of bacterial pathogens isolated over time from patients with COPD. A longitudinal cohort study in COPD patients with repeated sputum sampling and molecular strain differentiation showed that the acquisition of a new bacterial strain (one that the patient had not been infected with earlier) was associated with significantly increased risk of exacerbation[57]. Furthermore, it was demonstrated that patients develop a strain-specific antibody response after acute exacerbations, that has only limited bactericidal ability for heterologous strains, leaving the patient susceptible to reinfection by these heterologous strains of $\mathrm{H}$. influenzae[58].

Although most studies of immune response to respiratory pathogens have focused on antibody production, lymphocyte proliferative response is also important. Abe 


\section{General introduction}

et al. examined the lymphocyte response to OMP (outer membrane protein) P6 of $\mathrm{H}$. influenzae in COPD patients who had experienced a $\mathrm{H}$. influenzae exacerbation in the past 12 months, patients without such an exacerbation and healthy controls. They demonstrated that susceptibility to $\mathrm{H}$. influenzae exacerbation was associated with a specific decrease in T-lymphocyte proliferation to P6[59].

Hill et al confirmed that bacterial load and species contribute to airway inflammation in patients with stable chronic bronchitis [6o]. They demonstrated that airway bacterial load correlated with sputum myeloperoxidase level, an indirect measure of neutrophil activation and number, with sputum neutrophil chemoattractants as IL-8 and leukotriene B4 level, with sputum leukocyte elastase activity as well as with albumin leakage from serum to sputum. Markers of inflammation increased at bacterial loads of $10 * 6$ to $10 * 7$ colony-forming units per milliliter and increased progressively with increasing bacterial load. The bacterial species influenced airway inflammation. Sputum myeloperoxidase activity was greater in patients colonized with Pseudomonas aeruginosa than in patients colonized with non-typeable $\mathrm{H}$. influenzae, which in turn was greater than those colonized with Moraxella catarrhalis.

In contrast, a study of Aaron et al. did not show greater increases in sputum inflammatory cytokines MPO, TNF- $\alpha$ and IL- 8 during exacerbations in patients with documented bacterial or viral infection compared with patients without infection [61].

White et al. conducted a longitudinal study of bacterial cultures and sputum markers of inflammation[62]. After acute exacerbation, the concentration of sputum MPO and LTB4 was lower in patients in whom bacteria were eradicated than in those with persistent bacteria, suggesting that resolution of bronchial inflammation after acute exacerbation is related to bacterial eradication.

Combined assessment of bacterial load and inflammatory profiles in longitudinal as well in well conducted prospective antibiotic intervention studies may contribute to unravel the exact role of bacteria in AECOPD and to understand the pattern of inflammation and spectrum of mediators in exacerbations due to different causal mechanisms.. Host factors as alterations in the innate immunity are likely to be of substantial importance, but have not yet been investigated in a systematic manner. Based on current understanding, bacteria are an important cause of exacerbations of COPD.

\section{Viral infections}

Estimates of the proportion of COPD exacerbations associated with viral infections range considerably. Based on the highest quality studies the proportion of exacerbations attributed to viral illness ranges from 18 to $34 \%$. Influenza, parainfluenza, and coronavirus were the most frequent pathogens to be significantly associated with exacerbations $[63,64]$. Interestingly, Smith et al. reported that Haemophilus influenzae and Streptococcus pneumoniae were isolated more than 
twice as often as expected following influenza virus infection [64].

Greenberg and colleagues recently studied viral etiologies of COPD exacerbations and found that $27 \%$ of COPD exacerbations were associated with respiratory viruses, based on viral cultures and serology,[65] whereas in $44 \%$ of acute respiratory illnesses in control subjects were assciated with viruses. In the patients with COPD, rhinoviruses accounted for $43 \%$ of the virus infections and were thus responsible for a total of $12 \%$ of the exacerbations[65].

The availability of PCR techniques for viral detections allows for a more detailed investigation of the role of virus in COPD exacerbations. Recent studies have shown that about $50 \%$ of COPD exacerbation is associated with viral infections, the majority of which are rhinovirus[66-69]. Rohde et al. showed that viral respiratory pathogens can be recovered from sputum more often than from nasal aspirates during exacerbations[67]. The most commonly detected viruses in that study were picornaviruses (including rhinovirus, $36 \%$ ), influenza A (25\%), and respiratory syncytial virus (RSV, 22\%).

In a study by Seemungal et al., rhinovirus was detected by PCR in induced sputum and nasal aspirates in $23 \%$ of COPD exacerbations. Rhinovirus was associated with a greater rise in lower airway IL-6 levels and a higher symptom score[69]. The same authors have shown that respiratory virus infections are associated with more severe and frequent exacerbations of COPD and may cause chronic infection in COPD patients[68]. In this study the majority of viruses detected was rhinovirus; other detected viruses were coronaviruses, influenza A and B, parainfuenza and Respiratory Syncytial Virus (RSV). Furthermore, a recent study by Wilkinson showed that persistent detection of this RSV in COPD patients was associated with greater airway inflammation and more accelerated decline in $\mathrm{FEV}_{1}[70]$. Interestingly, frequent exacerbators (i.e. those with an exacerbation frequency greater than the median) experience significantly more common colds than infrequent exacerbators, whereas the likelihood of an exacerbation during a cold is unaffected by exacerbation frequency[66].

A few studies have investigated the effect of interactions between lower airway bacterial and viral infections. Wilkinson et al. showed that COPD exacerbations in which both rhinovirus and $\mathrm{H}$. influenzae were present, had higher bacterial load and higher serum levels of IL-6[71]. In a study by Papi et al, patients with exacerbations with co-infections had more marked lung function impairment and longer hospitalisations[44]. In that study, sputum eosinophilia was associated with viral exacerbations.

Further studies are needed to get information how often bacterial infection in AECOPD follows an inciting viral infection and what the relation is to the clinical and inflammatory response in acute exacerbations of COPD. In a study of viral-induced asthma exacerbations, it was shown that rhinovirus infection of respiratory epithelial cells increased VCAM-1 surface expression via NF- B and GATA-mediated transcriptional upregulation. VCAM- 1 and the NF-אB and CATA 


\section{General introduction}

transcription families may be potential therapeuric targets for virus induced exacerbations[72, 73].

\section{Atypical infections}

Considerable confusion exists in the literature regarding the significance of atypical pathogens in acute exacerbations of COPD.[74] This is partly due to differences in the techniques used to detect the presence of atypical infections. When a fourfold increase in antibody titer or a positive culture or RT-PCR is used, M. Pneumoniae and Legionella are rare and C. Pneumoniae infection may be involved in up to $9 \%$ of COPD exacerbations[64, 75-77]. Moreover, chronic colonization with C. Pneumoniae may be associated with a higher rate of COPD exacerbations. C. Pneumonia infection can amplify inflammation in the airways of COPD patients by stimulating the production and expression of cytokines, chemokines and adhesion molecules[78, 79]. However, clear evidence showing a direct relationship between increased inflammation and C. Pneumoniae infection during COPD exacerbations is yet lacking.

\section{Air pollution}

Different studies have reported excess hospitalizations related to air pollution. These studies indicate that about $5 \%$ of episodes of AECOPD might be related to air pollution. These effects are demonstrable at pollution levels below current air-quality standards[80, 81]. In a study in several European cities, different air pollutants were significantly associated with admissions for COPD independent of environmental characteristics[82]. In this study, the most consistent effects were for ozone, but significant effects were also found for $\mathrm{SO}_{2}, \mathrm{NO}_{2}$ and measures of particles (total suspended particles $=$ TSP and black smoke $=\mathrm{BS}$ ).

Particularly concentrations of particulate matter under 10 microns in diameter (PM10) are associated with acute admissions for COPD[83]. PM10 has free radical activity and can enhance inflammatory response in the airways by activating transcription factors AP-1 and NF-KB and inducing the expression of IL-8, particularly when airway epithelial cells have been infected with adenovirus [84]. PM10 may also increase proinflammatory activity in airway epithelial cells via alteration in the balance between histone acetylation and deacetylation[85]. Several studies and meta-analyses have shown that exacerbations in severe COPD are particularly related to ozone $\left(\mathrm{O}_{3}\right)[86,87]$.

\section{Pulmonary embolism}

In patients who were admitted for an acute exacerbation of COPD with unknown origin, the prevalence of pulmonary embolism was $25 \%$, according to a recent study[88]. Malignant disease, history of thrombo-embolism, and a decrease in $\mathrm{PaCO}_{2}$ from baseline were risk factors for PE in this study. 


\section{Local inflammation in AECOPD}

In recent years, there is a growing interest in the local as well as systemic inflammatory consequences of AECOPD. Airway inflammation is presumed to play an important role in the pathogenesis of worsening of airflow obstruction seen during acute exacerbations of COPD. Several studies have demonstrated an increase in local airway inflammation during acute exacerbations.

Saetta et al reported in lobar bronchial biopsies obtained during acute exacerbations a 30 -fold increase in eosinophils during exacerbation than under baseline conditions. The numbers of neutrophils, T-lymphocytes, VLA-1 positive cells and TNF-alpha positive cells were also increased during exacerbations.

Eosinophils were also increased in sputum of subjects with exacerbations when compared with those examined under basal conditions $[89,90]$. The study by Zhu demonstrated that the eosinophilia is associated with increased expression of CCL5 (also known as RANTES)[91].

There is an upregulation of leucocyte adhesion molecules like E- selectin, which are involved in the recruitment of cells to inflammatory sites, in the bronchial mucosa of stable COPD patients, suggesting a role for these molecules in the pathogenesis of COPD.[92] Also during exacerbations, upregulation of E-selectin has been found[93]. Others suggested that plasma levels of endothelial adhesion molecule ICAM-1 are reduced in COPD patients, both in the stable situation and during exacerbation, indicating some form of epithelial dysfunction in these patients[94]. Balbi et al [95] analysed airway inflammation in patients with and without an exacerbation of bronchitis using BAL. Compared with patients under baseline conditions, chronic bronchitis patients with an exacerbation had increased numbers of BAL neutrophils and of BAL eosinophils. Remarkably, patients with an exacerbation had significantly increased BAL levels of granulocyte/ macrophage colony-stimulating factor (GM-CSF) as well as increased serum levels of GM-CSF, suggesting a role of this cytokine in the inflammatory processes of chronic bronchitis. This cytokine stimulates differentiation of granulocytes and macrophages and can activate them directly.

Aaron et al reported data on granulocyte inflammatory markers and airway infection at baseline, during AECOPD and after convalescence in patients with COPD by induced sputum[61]. TNF- $\alpha$ and IL-8 were significantly elevated in the sputum of patients during acute COPD exacerbation compared with the stable disease state. Concentrations of these cytokines declined significantly 1 month after the exacerbation. In only 3 of the 14 patients a bacterial or viral respiratory tract infection could be confirmed, suggesting that the acute inflammatory airway response occurs independently of a demonstrable viral or bacterial airway infection. In addition, Papi et al. demonstrated that acute exacerbations are associated with increased sputum neutrophilia, independent of association with viral and/or bacterial infection, and also with increased sputum eosinophilia, in 


\section{General introduction}

case of virus-associated exacerbations[44].

Interesting data are reported on endothelin- (ET-1) levels in sputum during exacerbation. ET-1 is a potent vasoconstrictive and bronchoconstrictive peptide. ET-1 has been shown to stimulate mucus secretion, airway oedema, smooth muscle mitogenesis, and also bronchial hyperresponsiviness and has important pro-inflammatory effects in the airways $[96,97]$. Sputum ET-1 levels significantly rise during AECOPD and this increase in sputum ET-1 levels correlated with the increase in plasma ET-1 levels and sputum IL-6 levels [76]. Airway inflammation was also assessed in relation to the frequency of exacerbations in patients with COPD. Sputum concentrations of individuals with COPD who suffer from three or more exacerbations per year have higher sputum concentrations of IL- 6 and IL-8 in the stable state than those who have less frequent exacerbations[98]. Patients with more frequent exacerbations have also lower sputum values of secretory leukoproteinase inhibitor (SLPI)[99]. SLPI not only acts as a protease inhibitor but also has antiviral and antibacterial activity[100, 101].

Patterns of inflammatory response in a subset of COPD patients can also been studied in this way. Hill et al studied the inflammatory nature of acute bacterial exacerbations of COPD in subjects with alpha1-antitrypsine (AAT) deficiency [102]. It was found that at the start of an exacerbation, patients with AAT deficiency had lower sputum AAT and SLPI with higher elastase activity compared with COPD patients without deficiency. Both groups had a comparable acute phase response as assessed by C-reactive protein but the AAT deficient patients had a minimal rise in serum AAT. After treatment with antibiotics, in patients with AAT deficiency, there were significant changes in many sputum proteins including a rise in SLPI levels and a reduction in myeloperoxidase and elastase activity[102].

An increase in the concentration of the elastolytic enzyme matrix metalloproteinase-9 (MMP-9) and a decrease of its major inhibitor, tissue inhibitor of metalloproteinase-1, is also reported in sputum during exacerbations[103].

This is consistent with an increase in urinary desmosine, which is an indicator of elastolysis. This may provide a causal link between exacerbations and accelerated decline in lung function.

Further studies are needed to explore the cellular and molecular mechanisms involved in exacerbations.

\section{Systemic inflammation in AECOPD}

Growing evidence is present in the literature that acute exacerbations are associated not only with inflammatory changes in the airway, but also with a systemic inflammatory response. Next to an increase in sputum endothelin, increases in plasma endothelin levels are reported during AECOPD.[76] In the same study it was demonstrated that baseline endothelin levels under stable 
conditions were inversely related with baseline forced expiratory volume in one second and forced vital capacity[76]. Increases in plasma fibrinogen levels were also reported during AECOPD. There was a relation between the changes in fibrinogen at exacerbation and IL-6 levels[104]. It can be hypothesised that these transient acute increases in plasma fibrinogen may contribute to an increase in exacerbation-related cardiovascular morbidity and mortality in COPD patients. Other authors reported increases in acute phase response as well as moderate changes in both soluble TNF-receptors p55 and p75[105, 106]. In the latter study, significant increases in the anti-inflammatory mediator, soluble interleukin 1 receptor II were reported[106].

Hurst et al. recently evaluated the relation between systemic and upper and lower airway inflammation during acute exacerbations of COPD[107]. Exacerbations of COPD were associated with greater nasal, sputum and serum inflammation than the stable state. The degree of systemic inflammation, as expressed by serum IL- 6 and C-reactive protein, was correlated with the degree of lower airway inflammation as expressed by sputum IL-8. Furthermore systemic inflammation was greater in the presence of a bacterial pathogen[108].

A recent report measured systemic cytokine levels during acute exacerbations in relation to symptoms and lung function parameters[39]. At admission for acute exacerbation, there was increase in levels of plasma IL-6, IL-8 and LTB4, compared to recovery, but no change in levels of TNF- $\alpha$ and SLPI. Furthermore, there was a correlation between systemic inflammatory markers IL- 6 and IL-8 and dyspnea levels and between levels of IL- 6 and TNF- $\alpha$ and changes in FEV [39]. A recent study by Hurst et al. explored the diagnostic value of 36 different biomarkers at exacerbation of COPD[109]. To confirm the diagnosis of exacerbation, the most selective biomarker was CRP. Besides CRP, only levels of IL-6, myeloid progenitor inhibitory factor-1 (MPIF-1), pulmonary and activationregulated chemokine (PARC), adiponectin (ACRP-30) and soluble intercellular adhesion molecule- (SICAM-1) were significantly different between baseline and exacerbation. Systemic biomarkers were not helpful in predicting exacerbation severity[109]. A recent meta-analysis involving many clinical, cytological and biochemical variables in COPD, could also not show any relationship of systemic markers with exacerbation severity[110]. Recently, copeptin, a precursor of vasopressin, was suggested as prognostic biomarker for AECOPD[111]. In summary, markers of systemic inflammation that are upregulated in acute exacerbations as compared to the stable state include CRP[106, 112], IL-8[39], TNF- $\alpha$ [113] and its soluble receptors[105, 106], leptin [105, 113], endothelin-1[76], eosinophil cationic protein [114], myeloperoxidase [114], fibrinogen [104], IL-6 [104], $\alpha-1$ antitrypsin [102], leukotriene E4 [115] and leukotriene B4 [39], MPIF-1, PARC, ACRP-30 and SICAM-1[109].

It is clear that systemic inflammation is upregulated in acute exacerbations of COPD. This systemic inflammatory response may be related to the local 


\section{General introduction}

inflammatory response in the airways, possibly in the presence of bacterial or viral infection, but the exact mechanisms are unknown. To date, none of the systemic inflammatory markers is able to show a relationship with exacerbation severity and the majority of tested biomarkers do not appear capable of enlightening clinical judgment. This can partially be related to the selection of biomarkers and the heterogeneity of acute exacerbations.

\section{Oxidative stress in AECOPD}

Cigarette smoke is an important source of oxidants. Furthermore COPD patients have an increased number of activated neutrophils and macrophages in their airways that produce reactive oxygen species, leading to increased oxidative stress. There are a number of studies that demonstrate this increased oxidative stress in COPD patients especially during exacerbations. Circulating neutrophils of COPD patients show an enhanced repiratory burst in reaction to pro-inflammatory stimuli[116].

The concentration of exhaled $\mathrm{H}_{2} \mathrm{O}_{2}$, a reactive oxygen species, is also elevated in patients with stable COPD and increases even further during an exacerbation[117]. Urinary levels of IsoprostaneF2 $\alpha$ III, a product of lipid peroxidation, and therefore a marker for oxidative stress, are elevated in patients with an acute exacerbation and decline after treatment[118]. During acute exacerbations there is not only evidence for an increase in oxidants, but also for a decrease in antioxidant capacity. Total plasma antioxidant capacity (TEAC) is reduced in patients with acute exacerbation of COPD, and returns to normal values during the course of treatment[119].

A recent report showed that 8-isoprostane levels are also increased in exhaled breath condensate of COPD patients during exacerbations while levels of the antioxidant enzyme glutathione(CSH) in bronchoalveolar lavage fluid are decreased [120, 121]. Oxidative stress may be closely associated to increased systemic inflammation during exacerbations[120, 122, 123].

\section{Clinical consequences of AECOPD}

\section{Health status}

Using disease specific instruments such as St. George Respiratory Questionnaire, Chronic Respiratory Questionnaire, Baseline and Transitional Dyspnoea Index, it has been shown that acute exacerbations of COPD have a significant impact on the patient's health related quality of life[5, 124-128]. The impact on health status during and shortly after hospitalization for an acute exacerbation was studied recently[125]. This study showed that all COPD patients hospitalized for 
an acute exacerbation suffer a serious deterioration in health status, regardless of severity based on $\mathrm{FEV}_{[}[125]$. Although health status improved during admission, it deteriorated in the 3 months post-discharge. In an interview based study to determine the importance and consequences of exacerbations on patient's every day lives, it was shown that exacerbations have a significant impact on the patient's physical and psychological well being, with common symptoms like tiredness, malaise and low-mood[126].

\section{Muscle function and activity pattern}

Changes in skeletal and respiratory musle metabolism are also present in COPD patients[129]. In skeletal muscle of COPD patients, there is a change in fiber composition towards a predominance of anaerobic type 2 muscle fibers while in the diaphragm an increase in type 1 fibers occurs[130, 131]. However, few data are available on how and if muscle metabolism changes during acute exacerbations. One study reported that peripheral muscle weakness is significantly increased during an acute exacerbation of COPD, when compared to patients with stable disease[132]. Quadriceps muscle force was further reduced during the hospital stay and was only partially recovered 3 months after discharge from the hospital. In this study, peripheral muscle force was related to systemic levels of interleukin-8 (IL-8) and insulin-like growth factor-1 (IGF-1), suggesting these cytokines may be involved in peripheral muscle weakness in hospitalized patients with COPD.

In COPD patients, time spent outdoors declines over time and deteriorates acutely during an exacerbation[133]. In addition, patients with frequent exacerbations

recover their physical activity level to a lesser extent than patients without frequent exacerbations. These results were confirmed by Pitta et al[134]. Furthermore it was shown that patients with hospitalization for an AECOPD in the previous year had a lower activity level than patients without a recent hospitalization. Furthermore, patients with a lower activity level one month after discharge were more likely to be readmitted. In another study by Garcia-Eymerich et al, it was demonstrated that COPD patients who perform some level of physical activity have a lower risk of COPD admission and mortality[18].

\section{Metabolic changes}

COPD is characterized by complex metabolic disturbances. Weight loss and in particular depletion of fat-free mass is a common finding in COPD patients[135]. Weight loss is mainly a result of a disturbed balance between energy expenditure and energy intake. In COPD patients total daily energy expenditure is high as a result of decreased mechanical efficiency.[136]. There is also evidence in a subset of patients, that increased resting energy expenditure may be related to systemic inflammation[137].

During acute exacerbation, there is an impaired energy balance, caused by a decreased dietary intake, especially in the first few days of the exacerbation and an 


\section{General introduction}

increased resting energy expenditure[138]. Limited information is available about the underlying mechanisms of this impaired energy balance.

Recent research indicates that the hormone leptin is involved in body weight and energy balance homeostasis. During acute exacerbations of COPD, increased leptin concentration were found, decreasing again after treatment[105]. These elevated leptin concentrations may be induced by the systemic inflammatory response as well as by glucocorticoid treatment and contribute to the impaired energy balance during acute exacerbations.

\section{Prevention strategies for AECOPD}

\section{Vaccination}

At present, the value of influenza vaccination in patients with COPD is well documented and all patients with COPD are recommended to receive influenza vaccination over a yearly basis. Nichol et al [13, 139] demonstrated the efficacy and cost effectiveness of influenza vaccination: vaccination was associated with a $30 \%$ to $40 \%$ reduction in the rate of hospitalization for all acute and chronic respiratory conditions. The estimates of vaccine efficacy for preventing respiratory illness, hospitalization and death were 56\%, 50\% and 68\% respectively. The value of pneumococcal vaccination for COPD patients is more controversial. Two randomized controlled trials evaluating the efficacy of pneumococcal vaccination among patients with COPD do not show statistically significant protective benefits [140, 141]. One recent Spanish randomized controlled trial showed that pneumococcal vaccination is effective in preventing community acquired pneumonia in patients with COPD aged less than 65 years and in those with severe airflow obstruction. No differences were found among the other groups of patients with COPD [142]. A recent meta-analysis concluded that evidence from randomized controlled trials shows no significant effect of pneumococcal vaccination on morbidity and mortality in patients with COPD[143].

\section{Maintenance therapy with bronchodilating agents}

Both inhaled beta-2- agonists and anticholinergic medications are considered as initial bronchodilator therapy for patients with COPD. In a 16-week study, it was found that salmeterol (42 or 84 microgr) inhaled twice daily significantly reduced the number of exacerbations besides improvement in daytime and nighttime symptom scores, dyspnea ratings following the 6-min walk test, use of bronchodilators, patient/physician assessment and days unable to perform work compared to placebo [144]. It has been suggested that additional effects of long acting bronchodilating agents, salmeterol and formoterol, on neutrophils, pulmonary epithelium, airway smooth muscle, and respiratory muscles may contribute to the overall clinical efficacy in COPD and may therefore reduce the 
number of exacerbations and particularly decrease the severity [145].

In a 3-month, randomized, double-blind, placebo-controlled, multicentre study, Casaburi et al compared the bronchodilator efficacy and safety of tiotropium bromide, a long-acting anticholinergic agent, and placebo. They reported a trend for fewer COPD exacerbations in the tiotropium group (16\% vs $21.5 \%$ ) but this difference was not significant. Tiotropium was demonstrated to provide superior efficacy relative to placebo for both in-clinic spirometry and daily measurements of peak flow and these observations were accompanied by better symptom control and subjective global assessments[146].

Several long term studies investigating the effects of tiotropium have determined the incidence of acute exacerbations as a secondary end-point[147-149]. Patients receiving tiotropium consistently experienced 20 to $30 \%$ fewer exacerbations and hospitalizations than patients in the placebo or ipratropium study arms[147149]. The differences between tiotropium and salmeterol were not statistically significant[147]. Recently two randomized controlled trials have specifically investigated the prevention of acute exacerbations of COPD with tiotropium[150, 151]. In a large prospective study in 1829 patients with moderate to severe COPD, tiotropium significantly reduced the percentage of patients experiencing one or more exacerbations, compared to placebo. The number of hospitalizations due to AECOPD was also reduced with tiotropium, although this difference was not statistically significant $(p=0.056)$. As secondary endpoints, the time to first exacerbation, health care resource for acute exacerbations (including frequency of hospitalizations and unscheduled clinic visits) and treatment days were also reduced with tiotropium[151]. In a French randomized controlled trial, tiotropium significantly reduced time to first exacerbation, the proportion of patients experiencing at least one exacerbation and the number of exacerbations and exacerbations days[150]. Addition of salmeterol or fluticasone-salmeterol to tiotropium therapy did not statistically influence rates of COPD exacerbation but did improve hospitalization rates in patients with moderate to severe COPD, in a recent randomized double blind controlled trial. [152]

\section{Maintenance therapy with inhaled steroids}

The efficacy of inhaled steroids in the treatment of COPD remains controversial. Although inhaled steroids do not modify disease progression in COPD [42], there is increasing evidence that they reduce the number of exacerbations, especially inpatients with more severe disease. Paggiaro et al compared the effect of inhaled fluticasone propionate (500 microgram twice daily) with placebo in the treatment of patients with COPD [153]. They reported that the total number of exacerbations was lower after treatment with fluticasone propionate and the distribution of number of exacerbations per patient was lower in the fluticasone group. although not significantly. Significantly more exacerbations in the placebo group were defined as moderate or severe than in the fluticasone group. Exacerbations in 


\section{General introduction}

that study were defined as worsening of COPD symptoms, requiring changes to normal treatment, including antimicrobial therapy, short courses of oral steroids, and other bronchodilator therapy. Moderate exacerbations were those requiring treatment by a family physician or as a hospital outpatient; severe exacerbations resulted in admission to hospital.

The Isolde trial studied the effect of long term inhaled corticosteroids on lung function, exacerbations, and health status in patients with moderate to severe COPD [154]. In that study, there was no significant difference in the annual rate of decline in $\mathrm{FEV}_{\text {; }}$, however, median exacerbation rate was reduced by $25 \%$ from 1.32 a year on placebo to 0.99 a year on with fluticasone proprionate. The effects of fluticasone propionate on exacerbations were seen predominantly in patients with $\mathrm{FEV}_{1}<50 \%$ predicted.[155] During the Isolde run-in the withdrawal of inhaled corticosteroids was associated with an increased likelihood of an exacerbation,suggesting that these drugs do modify the risk of symptomatic deterioration in COPD [156]. A recent Cochrane meta-analysis of 47 trials including over 13000 patients showed that inhalation steroids were beneficial in reducing the frequency of acute exacerbations[157].

Furthermore, statistical modelling showed that the beneficial effect of fluticasone on deterioration in health status to be largely due to its effect on exacerbation frequency[158].

Discontinuation of inhaled steroids was associated with a more rapid onset and higher recurrence rate of aute exacerbations in one study.[159]

\section{Maintenance therapy with combination therapy}

Several studies have investigated the effect of combination therapy of longacting $\beta$-2 agonists with inhaled steroids on acute exacerbations. The Tristan study was designed to evaluate combination therapy of long-acting $\beta$-2 agonist salmeterol and inhalation corticosteroid fluticasone versus each component alone or placebo.[160] Each of the active treatments reduced exacerbation frequency to a similar degree in this study[160]. In a study comparing the combination of formoterol and budesonide versus each component alone or placebo, the combination therapy reduced the mean number of severe exacerbations per patient per year by $24 \%$ versus placebo and by $23 \%$ versus formoterol alone[161]. In the recently published TORCH study, a large randomized double blind trial designed to measure the effect of combination therapy fluticasone and salmeterol on survival in COPD, the combination therapy also significantly reduced the annual rate of exacerbations, while the effect on survival was not statistically significant[162]. However, in this study, the probability of having pneumonia reported as an adverse event was higher among patients receiving medications containing fluticasone propionate $(19.6 \%$ in the combination-therapy group and $18.3 \%$ in the fluticasone group) than in the placebo group (12.3\%, $\mathrm{P}<0.001$ for comparisons between these treatments and placebo). 
Withdrawal of fluticasone in patients using the combination fluticasone/salmeterol has been shown to result in acute and persistent deterioration in lung function and dyspnoea and an increase in mild exacerbations.[163]

The most recent Cochrane review showed a signicant reduction in morbidity and mortality from combination therapy with inhaled steroids and LABA compared with inhaled steroids alone[164].

It is not well understood why patients with COPD benefit from inhalation corticosteroids, but a number of studies have shown a reduction in local inflammation[165-169].

\section{Mucolytic drugs and anti-oxidants}

A recent systematic review of the available literature showed that oral mucolytic drugs have significant effect on exacerbation rates in people with chronic bronchitis and COPD: mucolytic treatment was associated with a reduction of $20 \%$ in number of exacerbations per patient per year[170]. Mucolytic therapy significantly reduced the number of days of illness per subject per month and the number of days that subjects took antibiotics. None of the studies reported the effect of treatment with mucolytics on hospital admission for AECOPD.[170] Acetylcysteine was used in most of these studies suggesting that the beneficial results in this review were largely related to this drug. Acetylcysteine has mucolytic and antioxidant effects, although the mucolytic activity of acetylcysteine is not well documented in chronic bronchitis [171]. Another mechanism might be the antioxidative effect as one of its metabolites is a free thiol. Isobutyrylcysteine, a derivative of acetylcysteine with higher levels of free thiols did not, however, have any effects on the number of exacerbations[172].

Disappointingly, a large recent randomized controlled trial, designed to investigate the effect of $\mathrm{N}$-acetylcysteine on outcomes in COPD, was not able to detect a difference in the number of exacerbations per year between $\mathrm{N}$-acetylcysteine and placebo[173].

Subgroups of patients with more severe COPD or patients who have frequent or prolonged exacerbations may probably benefit more of this regular treatment[170] .

\section{Additional strategies}

Collet et al reported data of a double-blind placebo controlled randomized clinical trial to study the effect of an immunostimulating agent OM-85 BV to prevent acute respiratory exacerbation in patients with COPD [9]. OM-85 BV is an immunostimulating agent made from eight different species of bacteria that are frequently present in the lower respiratory tract. The mechanism of action of OM-85 BV seems to be related to direct activation of lung macrophages and enhancement of antigen presentation to T- lymphocytes. These authors demonstrated that the total number of days of hospitalization for a respiratory problem was $55 \%$ less in the group treated with OM-85 BV than in the placebo group; the risk of being 


\section{General introduction}

hospitalised for a respiratory problem was $30 \%$ lower in the treated group than in the placebo group. In a recent double blind study in patients with chronic bronchitis or mild COPD, the beneficial effect of OM-85 in reducing the frequency of acute exacerbations was confirmed[174]. However, a meta-analysis in which 13 trials were included, found a non-statistically significant trend in favour of OM-85 BV [175]. A trial with another immunomodulating agent, $\mathrm{AM}-3$ found an improvement in quality of life, but no difference in exacerbation frequency[176]. Further trials are required to properly define the potential role of these immunomodulatory agents prevention of AECOPD.

\section{Pulmonary rehabilitation}

In stable COPD patients, a 6 week pulmonary rehabilitation programme has been shown to reduce the number of days in hospital over one year by 11 days compared with a control group, who received standard medical care.[177] One study by Guell et. al found a significant reduction in the number of acute exacerbations, but not hospitalizations in stable COPD patients undergoing an outpatient rehabilitation program[178].

A recent meta-analysis showed that pulmonary rehabilitation after acute exacerbations of COPD significantly reduces the risk of unplanned hospital admissions with a pooled relative risk of $0.26[179]$. The recently published evidence based clinical guidelines on pulmonary rehabilitation from the American College of Chest Physicians state that pulmonary rehabilitation improves dyspnoea and quality of life and reduces the number of hospital days and other measures of health care utilization in COPD patients[180].

\section{Management of AECOPD}

Hospital management of acute exacerbations of COPD has been summarized in the GOLD document [1].

\section{Oxygen}

Oxygen therapy is the cornerstone of hospital treatment for AECOPD. Supplemental oxygen should be titrated to improve the patient's hypoxemia. Adequate levels of oxygenation ( $\mathrm{PaO}_{2}>8.0 \mathrm{kPa}, 60 \mathrm{mmHg}$, or $\mathrm{SaO}_{2}>90 \%$ ) are easy to achieve in uncomplicated exacerbations, but $\mathrm{CO}_{2}$ retention can occur insidiously with little change in symptoms. Once oxygen is started, arterial blood gases should be checked 30-30 minutes later to ensure satisfactory oxygenation without $\mathrm{CO}_{2}$ retention or acidosis[1].

\section{Bronchodilator therapy}

Short acting inhaled $\beta 2$ agonists and anticholinergic agents are the main treatment 


\section{Management of severe but not life-threatening exacerbations of COPD in the} emergency department or the hospital*

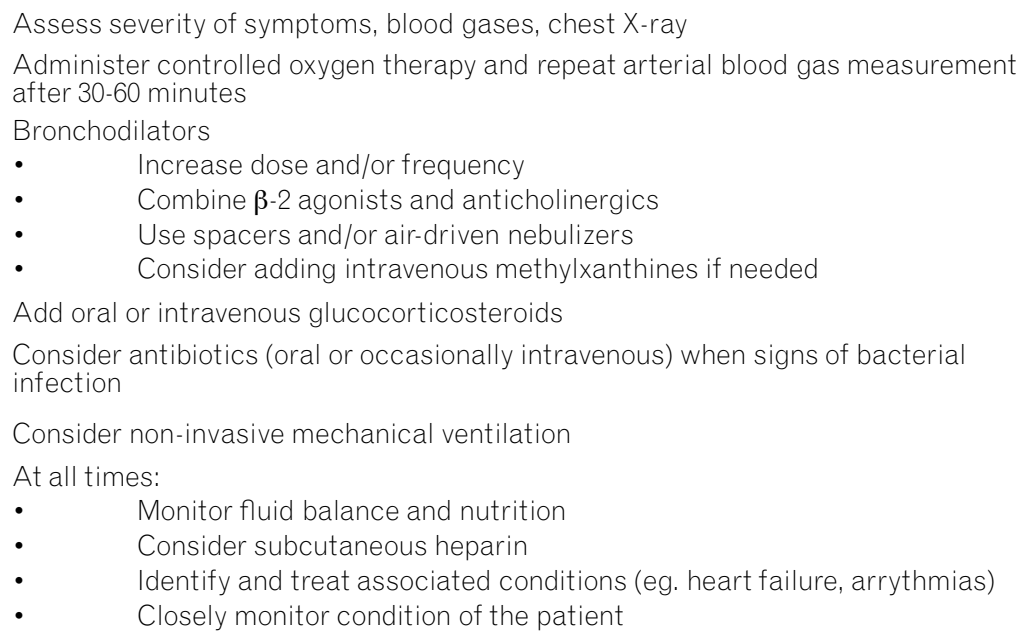

* local resources need to be considered

modality for AECOPD as they relieve symptoms and improve airflow obstruction. Short acting $\beta$-2 agonists such as salbutamol and terbutalin act by increasing the concentration of cyclic adenosine monophosphate (c-AMP), while anticholinergics such as ipratropium and oxitropium bromide are non-selective muscarinic antagonists. Although there are no trials of short acting bronchodilator agents, their use in acute exacerbations is unquestioned[181]. There are no clinical studies that have evaluated the use of inhaled long-acting bronchodilators (either $\beta_{2}$ agonists or anticholinergics) with or without inhaled glucocorticosteroids during AECOPD[1].

\section{Glucocorticosteroids}

Oral or intravenous corticosteroids are recommended in treating patients with AECOPD in addition to other treatments[182, 183].

Two large randomized controlledtrials examining the role of systemic steroids in COPD exacerbations have been reported. Niewoehner et al [183] conducted a double blind, randomised trial of systemic glucocorticosteroids or placebo in addition to other therapies for exacerbation of COPD. The primary end point was treatment failure, defined as death from any cause or the need for intubation and mechanical ventilation, readmission to the hospital for COPD, or intensification of drug therapy. Patients were assigned to three treatment groups: group 1 received eight weeks of glucorticoid therapy; group 2 received two weeks of glucocorticoids 


\section{General introduction}

and the third group received placebo. Rates of treatment failure were significantly higher in the placebo group than in the two glucocorticoid groups combined at 30 days and at 90 days. Systemic glucocorticoids were associated with a shorter initial hospital stay and with a small improvement in $\mathrm{FEV}_{1}$ on the first day . Significant treatment benefits were no longer evident at six months and the 8-week regimen was not superior to the 2-week regimen. Davies et al [182] investigated the role of oral corticosteroids in treating patients with AECOPD requiring hospital admission. Patients were randomly assigned to oral prednisolone 30 mg once daily, or identical placebo for 14 days in addition to standard therapy. FEV, after bronchodilation increased more rapidly and to a greater extent in the corticosteroid treated group. Up to day 5 of hospital stay, daily increases in FEV, after bronchodilation were statistically significant. Hospital stays were also shorter in the corticosteroid-treated group.

The exact dose of corticosteroids that should be recommended is not known, but high doses are associated with a significant risk of side effects. 30 to $40 \mathrm{mg}$ of oral prednisolone daily for 7-10 days is effective and safe. [184] Prolonged treatment does not result in greater efficacy and increases the risk of side effects[184].

\section{Methylxanthins}

The role of methylxanthins (theophylline and aminophylline) in the treatment of exacerbations is controversial. The available data do not support the use of methylxanthines for the treatment of exacerbations of chronic obstructive pulmonary disease. Potential benefits of methylxanthines for lung function and symptoms could not be confirmed in meta-analysis of available trials, whereas the potentially important adverse events of nausea and vomiting were significantly increased in patients receiving methylxanthines[185]. Another recent randomized controlled trial also found no evidence for any clinically important additional effect of aminophylline treatment when used with high dose nebulised bronchodilators and oral corticosteroids[186].

They are currently considered as second-line intravenous therapy, in patients with inadequate or insufficient response to short-acting bronchodilators [181].

\section{Antibiotics}

The use of antibiotics in AECOPD remains unsettled despite their extensive use. The role of bacterial infections in AECOPD has been described above.

The best randomized controlled trial of antibiotic use for AECOPD was performed by Anthonisen et al.[40]. In that study, antibiotics led to an earlier resolution of all three symptoms defining an acute exacerbation (increased dyspnoea, increased sputum volume, and increased sputum purulence). Stockley et al. showed a relationship between sputum purulence and the presence of bacteria, suggesting that patients with purulent sputum should be treated with antibiotics, if they also have at least one of the other symptoms (dyspnoea or increased sputum volume)[41]. 
In a retrospective cohort analysis of visits for AECOPD, Adams et al demonstrated that patients, treated with antibiotics had significantly lower relapse rates than those who did not receive antibiotics; relapse from AECOPD was not related to the severity of underlying disease or to the severity of the AECOPD. It was found that the specific choice of antibiotic is important because those treated with amoxicillin had the highest relapse rates of all groups, suggesting that the choice of antibiotic should probably based on the resistance profiles to antibiotics [187].

There have been a number of systematic reviews of the use of antibiotic treatment in patients with AECOPD[188-190]. The most recent included 13 randomized controlled trials of antibiotic use in AECOPD[188]. The conclusion was that antibiotics effectively reduce the risk of treatment failure and mortality in severe exacerbations of COPD, but for patients with mild to moderate exacerbations, further research is needed in order to guide antibiotic prescription[188].

The current GOLD guidelines recommend the use of antibiotics in patients with all three major symptoms (increased dyspnoea, increased sputum volume and increased sputum purulence), to patients with two major symptoms if one of them is increased sputum purulence, and to patients with a severe exacerbation requiring mechanical ventilation[1].

\section{Ventilatory support}

The primary objectives of mechanical ventilatory support in AECOPD are to decrease mortality and morbidity and to relieve symptoms[1].

Ventilatory support can be delivered non-invasively or invasively (conventionally) using different modes that are, in essence, positive pressure devices for noninvasive ventilation using either a nasal or a facial mask, or via an endotracheal tube or a trachostomy for invasive ventilation.

Non-invasive ventilation has been studied in several randomized controlled trials in patients with acute respiratory failure,consistently providing positive results with success rates of 80-85\%[191-193]. NIV decreases mortality, the need for endotracheal intubation and treatment failure. Moreover, NIV increases $\mathrm{pH}$, reduces hypercapnia and respiratory rate and shortens length of hospital stay by more than 3 days and decreases complication rate[192, 193]. It is cost-effective compared with usual therapeutic care alone[194].

Indications and contraindications for the use of NIV were published in the GOLD guidelines[1].

Indications for invasive mechanical ventilation in AECOPD have already been mentioned. NIV has been used to shorten the period of invasive ventilation in cases of weaning failure and in those with a long stay in the intensive care unit[195, 196]. However, it was not effective in avoiding reintubation and did not reduce mortality[197].

In a recent study among patients with chronic hypercapnic COPD that had been 


\section{General introduction}

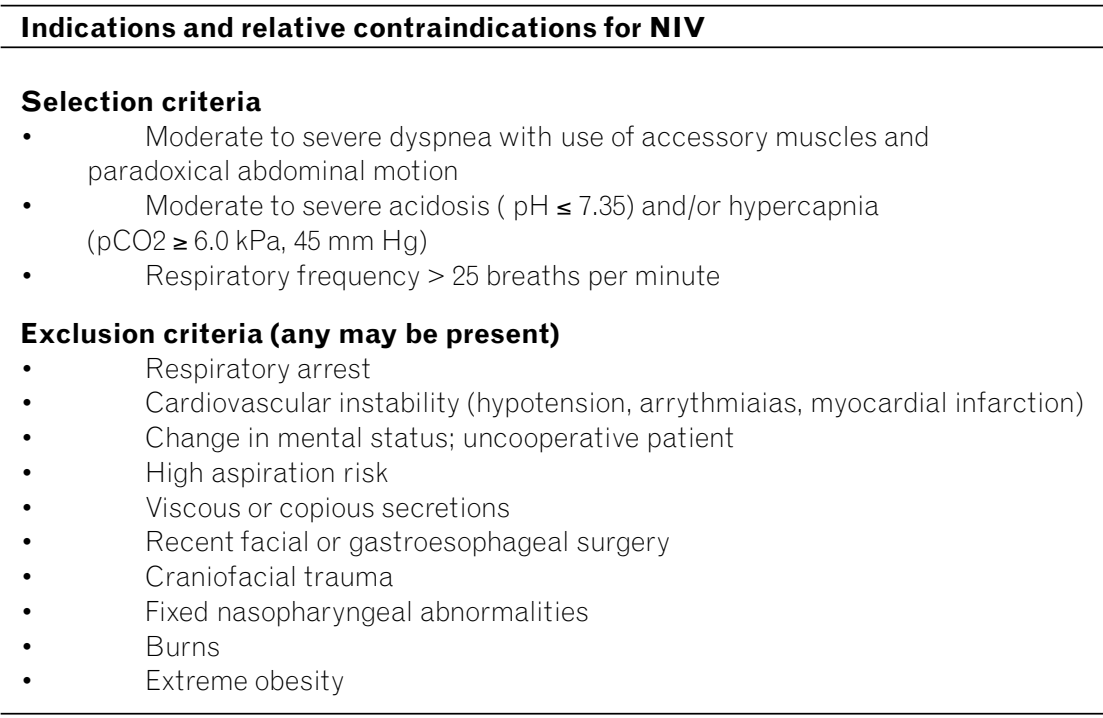

discharged from the hospital with NIV, mortality was $16 \%$ after 1 year, $35 \%$ after 2 years and $75 \%$ after 5 years[198]. Independent predictors of mortality were nutritional status, hyperinflation and base excess. In patients at risk, a reduction of these risk factors after initiation of NIV was associated with improved survival[198].

\section{Outcome and prognosis of AECOPD}

Outcome and prognosis of AECOPD are still poorly documented. However, especially patients with more frequent exacerbations have a worse health status compared to COPD patients with fewer exacerbations (o to 2 exacerbations/ year) [5]. The same authors reported that although lung function changes during AECOPD may be small, they can be persistent and in some cases lung function and symptoms did not recover to baseline values even at 3 months. Therefore, closer monitoring of patients may be useful and all patients should be followed after an exacerbation until recovery has occurred [199].

Several studies have investigated predictive factors related to an increased COPD related mortality risk. Patient characteristics that have been reported to influence survival in stable COPD patients include FEV, [200-202], age [200, 202], arterial carbon dioxide tension $\left(\mathrm{PaCO}_{2}\right)$ [201], cardiac factors [201], diffusion capacity[201] and $\mathrm{BMI}[2 \mathrm{O} 3,204]$.

Other studies have investigated more specifical factors related to mortality after acute exacerbations of COPD. Factors that have been reported as risk factors 
for mortality after exacerbation are $\mathrm{PaCO}_{2}$, oxygen saturation and resting oxygen consumption [205], low BMI [6, 203], older age [6, 206, 207], cardiac factors $[6,206,207]$ and other co-morbidity [207], severity of illness, serum albumin, functional status and arterial oxygen tension $\left(\mathrm{PaO}_{2}\right)[6]$.

A prospective cohort study of 1016 adult patients admitted to hospital for AECOPD described the outcomes of patients hospitalised with AECOPD and the determinants related to survival in that cohort [3]. The in-hospital mortality in that study was $11 \%$; at 6 months, $34.7 \%$ of patients died. Survival time was independently related to severity of illness, body mass index, age, prior functional status, $\mathrm{PaO} / \mathrm{FlO}_{2}$, congestive heart failure, serum albumin, and the presence of cor pulmonale. The authors concluded that patients as well as caregivers should be aware of the likelihood of poor outcomes following hospitalization for exacerbation of COPD, particularly associated with hypercapnia.

More recent studies have documented similar outcomes. A Turkish study in 205 patients, hospitalised for acute exacerbation of COPD showed an inhospital mortality of $8.3 \%$, with 1-,2- and 3-year mortality rates of 33, 43 and $49 \%$ respectively[208]. In this study, long term mortality was associated with longer disease duration, lower serum albumin, lower $\mathrm{PaO}_{2}$, and lower $\mathrm{BMI}[208]$. A Spanish study among 304 patients reported a mortality of $55.2 \%$ after 5 years of follow-up, but this study also included patients who were treated as outpatients[209]. It was shown that besides older age and $\mathrm{PaCO}_{2}$, severe (requiring hospital management) acute exacerbations are an independent predictor of mortality. Patients with more than 3 exacerbations and patients requiring admission had higher mortality rates[209].

Similar results were reported about hospital and 1-year survival of patients admitted to ICU with AECOPD [210]. Hospital mortality was $24 \%$; mortality rates were $41 \%$ at 90 days after discharge, $47 \%$ at 180 days and $59 \%$ at 1 year. Median survival for all patients was 224 days. These figures should be considered when making decisions or evaluating therapies. Generally, it is believed that patients admitted to ICU with acute respiratory failure due to acute exacerbations of COPD have a worse outcome. Recent retrospective reports have also shown that outcome for these patients is similar to patients treated for an acute exacerbation without the need for intubation [211, 212].

Further prospective studies of outcome of AECOPD, based on adequate staging of the disease process, are urgently needed in order to support adequate decision making in the management of AECOPD.

\section{Conclusive remarks}

The definition of acute exacerbation of COPD is generally based on medical symptoms like dyspnoea, cough and sputum production. The majority of acute 


\section{General introduction}

exacerbations is related to bacterial infection, viral infection and/or air pollution, although exact causal relationships have not been established. Acute exacerbations are not only associated with local inflammation in the airways, but there is growing evidence that systemic inflammation is upregulated as well during AECOPD. Acute exacerbations have an important detrimental impact on patient's quality of life and activity pattern. Prevention of these episodes is therefore an important goal in COPD management. Influenza vaccination, maintenance therapy with bronchodilating agents, inhalation steroids and anti-oxidants and pulmonary rehabilitation are to some extent beneficial in reducing the number of exacerbations.

Treatment of acute exacerbations consists of bronchodilating agents, oral or intravenous glucocorticosteroids, and antibiotics in case of severe exacerbations. In patients with respiratory failure due to acute exacerbations, non invasive or invasive ventilatory support may be indicated.

Acute exacerbations of COPD still have a high mortality rate. Future research should focus on phenotyping of patients and reducing modifiable risk-factors.

\section{Aims and outline of the thesis}

As discussed in chapter 1 of this thesis, the general introduction, acute exacerbations of COPD are very heterogeneous and not well characterized. In general, this thesis aims at assessing the clinical implications and the involvement of systemic processes in the pathophysiology of of acute exacerbations of COPD, in order to better characterize these episodes.

To gain more insight in clinical outcomes of acute exacerbation, two studies are performed in patients hospitalized for an acute exacerbation. These studies are described in chapters 2 and 8 of this thesis.

Further studies are aimed at investigating systemic inflammation and its relation to acute exacerbations. These studies are performed in hospitalized patients (described in chapter 3) and outpatient populations. (chapter 4, 5 and 6)

In chapter 2, the contribution of respiratory bacterial infections to acute exacerbations of COPD is studied. The specific aims of this study are to investigate the frequency of respiratory bacterial infections in hospitalized patients, admitted for an acute exacerbation of COPD, to identify the responsible pathogens by sputum culture and to assess patient characteristics in relation to sputum culture results.

The study described in chapter 3 of this thesis is aimed to further characterize the systemic inflammation during acute exacerbation and in the stable state. The course of different systemic inflammatory and anti-inflammatory parameters 
during hospitalization and in the follow-up period, when patients were clinically stable, is assessed.

The next studies are performed in COPD patients in the clinically stable state to investigate systemic levels of different inflammatory cytokines as well as markers of haemostasis and the innate immune system, and to identify a possible relation of these markers with the occurrence of acute exacerbations.

In chapter 4, different systemic inflammatory parameters in a large cohort of COPD patients, who were clinically stable, are studied, to determine if an elevated systemic inflammatory status at baseline is related to the number of moderate and severe exacerbations during a one year follow-up period. In this study, risk factors for an acute exacerbation are identified, particularly in relation to parameters of systemic inflammation and haemostasis.

The study described in chapter 5 of this thesis was set up to investigate systemic levels of different markers of inflammation and haemostasis in clinically stable COPD patients. In these patients, systemic levels of hs-CRP, total plasma homocysteine (tHcy) and fibrinogen are determined and a possible relation of these markers to clinical characteristics is studied.

In chapter 6 , the contributing role of $\mathrm{MBL}$, a key component of the innate immune system, to the development of acute exacerbations is evaluated.

The aim of this study is to determine if serum MBL levels, measured at baseline, are related to the occurrence of moderate and severe exacerbations of COPD.

In chapter 7 , the current knowledge regarding systemic inflammation and its effects during acute exacerbations is extensively reviewed, in order to outline the context of our results.

The aim of the study described in chapter 8 of this thesis is to investigate mortality and risk factors for mortality in patients admitted for an acute exacerbation of COPD during a one-year follow-up period.

Finally, chapter 9 comprises the general discussion and summary. 


\section{General introduction}

\section{References}

1. COLD executive commitee BAC. Global Strategy for the Diagnosis, Management, and Prevention of Chronic Obstructive Pulmonary Disease. wwwgoldcopdcom. 2006.

2. Rodriguez Roisin R. Toward a consensus definition for COPD exacerbations. Chest. 2000;117(5 Suppl 2):398s-401s.

3. Connors AF, Jr., Dawson NV, Thomas C, Harrell FE, Jr., Desbiens N, Fulkerson WJ, et al. Outcomes following acute exacerbation of severe chronic obstructive lung disease. The SUPPORT investigators (Study to Understand Prognoses and Preferences for Outcomes and Risks of Treatments). Am J Respir Crit Care Med. 1996 Oct;154(4 Pt 1):959-67.

4. Andersson F, Borg S, Jansson SA, Jonsson AC, Ericsson A, Prutz C, et al. The costs of exacerbations in chronic obstructive pulmonary disease (COPD). Respir Med. 2002 Sep;96(9):700-8.

5. Seemungal TAR, Donaldson GC, Paul EA, Bestall JC, Jeffries DJ, Wedzicha JA. Effect of exacerbation on quality of life in patients with chronic obstructive pulmonary disease. Am J Resp Crit Care Med. 1998;157(5)):1418-22.

6. Connors AF, Jr., Dawson NV, Thomas C, Harrell FE, Jr., Desbiens N, Fulkerson WJ, et al. Outcomes following acute exacerbation of severe chronic obstructive lung disease. The SUPPORT investigators (Study to Understand Prognoses and Preferences for Outcomes and Risks of Treatments). Am J Respir Crit Care Med. 1996;154(4 Pt 1):959-67.

7. Donaldson GC, Seemungal TA, Bhowmik A, Wedzicha JA. Relationship between exacerbation frequency and lung function decline in chronic obstructive pulmonary disease. Thorax. 2002 Oct; $57(10): 847-52$.

8. Rutten van Molken MP, Postma MJ, Joore MA, Van Genugten ML, Leidl R, Jager JC. Current and future medical costs of asthma and chronic obstructive pulmonary disease in The Netherlands. Respir Med. 1999;93(11):779-87.

9. Collet JP, Shapiro P, Ernst P, Renzi T, Ducruet T, Robinson A. Effects of an immunostimulating agent on acute exacerbations and hospitalizations in patients with chronic obstructive pulmonary disease. The PARIIIS Study Steering Committee and Research Group. Prevention of Acute Respiratory Infection by an Immunostimulant. Am I Respir Crit Care Med. 1997;156(6):1719-24.

10. Kessler R, Faller M, Fourgaut G, Mennecier B, Weitzenblum E. Predictive factors of hospitalization for acute exacerbation in a series of 64 patients with chronic obstructive pulmonary disease. Am J Respir Crit Care Med. 1999;159(1):158-64.

11. Osman IM, Godden DJ, Friend JA, Legge JS, Douglas JG. Quality of life and hospital readmission in patients with chronic obstructive pulmonary disease. Thorax. 1997 Jan;52 (1):6771.

12. Decramer M, Gosselink R, Troosters T, Verschueren M, Evers G. Muscle weakness is related to utilization of health care resources in COPD patients. Eur Respir ). 1997;10(2):417-23.

13. Nichol KL, Margolis KL, Wuorenma J, Von Sternberg T. The efficacy and cost effectiveness of vaccination against influenza among elderly persons living in the community. N Engl J Med. 1994 Sep 22;331 (12):778-84.

14. Anderson HR, Katsouyanni K, Spix C. Air pollution and daily admissions for chronic obstructive pulmonary disease in six European cities: results from the APHEA project - Reply. Eur Respir ). 1998;11 (4)):993-.

15. Vitacca M, Foglio K, Scalvini S, Marangoni S, Quadri A, Ambrosino N. Time course of pulmonary function before admission into ICU. A two-year retrospective study of COLD patients with hypercapnia. Chest. 1992 Dec;102(6):1737-41.

16. Vitacca M, Clini E, Porta R, Foglio K, Ambrosino N. Acute exacerbations in patients with COPD: predictors of need for mechanical ventilation. Eur Respir J. 1996;9(7):1487-93.

17. Garcia-Aymerich J, Monso E, Marrades RM, Escarrabill J, Felez MA, Sunyer J, et al. Risk factors for hospitalization for a chronic obstructive pulmonary disease exacerbation. EFRAM 
study. Am J Respir Crit Care Med. 2001;164(6):1002-7.

18. Garcia-Aymerich J, Lange P, Benet M, Schnohr P, Anto JM. Regular physical activity reduces hospital admission and mortality in chronic obstructive pulmonary disease: a population based cohort study. Thorax. 2006 Sep;61 (9):772-8.

19. Oostenbrink JB, Rutten-van Molken MP. Resource use and risk factors in high-cost exacerbations of COPD. Respir Med. 2004 Sep;98(9):883-91.

20. Pouw EM, Ten Velde GP, Croonen BH, Kester AD, Schols AM, Wouters EF. Early non-elective readmission for chronic obstructive pulmonary disease is associated with weight loss. Clin Nutr. 2000;19(2):95-9.

21. Hallin R, Koivisto-Hursti UK, Lindberg E, Janson C. Nutritional status, dietary energy intake and the risk of exacerbations in patients with chronic obstructive pulmonary disease (COPD). Respir Med. 2006 Mar;100(3):561-7.

22. Lau AC, Yam LY, Poon E. Hospital re-admission in patients with acute exacerbation of chronic obstructive pulmonary disease. Respir Med. 2001 Nov;95(11):876-84.

23. Garcia-Aymerich J, Farrero E, Felez MA, Izquierdo J, Marrades RM, Anto JM. Risk factors of readmission to hospital for a COPD exacerbation: a prospective study. Thorax. 2003 Feb;58(2):100-5.

24. Almagro P, Barreiro B, Ochoa de Echaguen A, Quintana S, Rodriguez Carballeira M, Heredia $J L$, et al. Risk factors for hospital readmission in patients with chronic obstructive pulmonary disease. Respiration. 2006;73(3):311-7.

25. Emtner MI, Arnardottir HR, Hallin R, Lindberg E, Janson C. Walking distance is a predictor of exacerbations in patients with chronic obstructive pulmonary disease. Respir Med. $2006 \mathrm{Nov}$ 3.

26. Gudmundsson G, Gislason T, Janson C, Lindberg E, Hallin R, Ulrik CS, et al. Risk factors for rehospitalisation in COPD: role of health status, anxiety and depression. Eur Respir J. 2005 Sep;26(3):414-9.

27. Adams L. Reflex Respiration Stimulation and Respiratory Sensation; 1996.

28. Killian KJ, Gandevia, SC. Sense of Effort and Dyspnea; 1996.

29. Barbera JA, Roca J, Ferrer A, Felez MA, Diaz O, Roger N, et al. Mechanisms of worsening gas exchange during acute exacerbations of chronic obstructive pulmonary disease. Eur Respir J. 1997;10(6):1285-91.

30. Diaz O, Iglesia R, Ferrer M, Zavala E, Santos C, Wagner PD, et al. Effects of noninvasive ventilation on pulmonary gas exchange and hemodynamics during acute hypercapnic exacerbations of chronic obstructive pulmonary disease. Am J Respir Crit Care Med. 1997 Dec;156(6):1840-5.

31. O'Donnell DE, Webb KA. Exertional breathlessness in patients with chronic airflow limitation. The role of lung hyperinflation. Am Rev Respir Dis. 1993 Nov;148(5):1351-7.

32. O'Donnell DE, Parker CM. COPD exacerbations . 3: Pathophysiology. Thorax. 2006 Apr;61 (4):354-61.

33. Parker CM, Voduc N, Aaron SD, Webb KA, O'Donnell DE. Physiological changes during symptom recovery from moderate exacerbations of COPD. Eur Respir ). 2005 Sep;26(3):42O8.

34. Stevenson NJ, Walker PP, Costello RW, Calverley PM. Lung mechanics and dyspnea during exacerbations of chronic obstructive pulmonary disease. Am J Respir Crit Care Med. 2005 Dec 15;172(12):1510-6.

35. Robinson TD, Freiberg DB, Regnis JA, Young IH. The role of hypoventilation and ventilationperfusion redistribution in oxygen-induced hypercapnia during acute exacerbations of chronic obstructive pulmonary disease. Am J Respir Crit Care Med. 2000;161 (5):1524-9.

36. Aubier M, Murciano D, Milic-Emili J, Touaty E, Daghfous J, Pariente R, et al. Effects of the administration of $\mathrm{O}_{2}$ on ventilation and blood gases in patients with chronic obstructive pulmonary disease during acute respiratory failure. Am Rev Respir Dis. 1980 Nov;122 (5):74754 . 


\section{General introduction}

37. Dick CR, Liu Z, Sassoon CS, Berry RB, Mahutte CK. O2-induced change in ventilation and ventilatory drive in COPD. Am J Respir Crit Care Med. 1997 Feb;155(2):609-14.

38. Sassoon CS, Hassell KT, Mahutte CK. Hyperoxic-induced hypercapnia in stable chronic obstructive pulmonary disease. Am Rev Respir Dis. 1987 Apr;135(4):907-11.

39. Pinto-Plata VM, Livnat G, Girish M, Cabral H, Masdin P, Linacre P, et al. Systemic cytokines, clinical and physiological changes in patients hospitalized for exacerbation of COPD. Chest. $2007 \operatorname{Jan} ; 131(1): 37-43$.

40. Anthonisen NR, Manfreda J, Warren CP, Hershfield ES, Harding GK, Nelson NA. Antibiotic therapy in exacerbations of chronic obstructive pulmonary disease. Ann Intern Med. 1987;106(2):196-204.

41. Stockley RA, O'Brien C, Pye A, Hill SL. Relationship of sputum color to nature and outpatient management of acute exacerbations of COPD. Chest. 2000;117(6):1638-45.

42. Pauwels RA, Buist AS, Ma P, Jenkins CR, Hurd SS. Global strategy for the diagnosis, management, and prevention of chronic obstructive pulmonary disease: National Heart, Lung, and Blood Institute and World Health Organization Global Initiative for Chronic Obstructive Lung Disease (GOLD): executive summary. Respir Care. 2001 Aug;46(8):798825 .

43. Siafakas NM, Vermeire P, Pride NB, Paoletti P, Gibson J, Howard P, et al. Optimal assessment and management of chronic obstructive pulmonary disease (COPD). The European Respiratory Society Task Force. Eur Respir J. 1995;8(8):1398-420.

44. Papi A, Bellettato CM, Braccioni F, Romagnoli M, Casolari P, Caramori G, et al. Infections and airway inflammation in chronic obstructive pulmonary disease severe exacerbations. Am J Respir Crit Care Med. 2006 May 15;173(10):1114-21.

45. Murphy TF, Sethi S, Niederman MS. The role of bacteria in exacerbations of COPD. A constructive view. Chest. 2000;118(1):204-9.

46. Oldenburg FA, Jr., Dolovich MB, Montgomery JM, Newhouse MT. Effects of postural drainage, exercise, and cough on mucus clearance in chronic bronchitis. Am Rev Respir Dis. 1979 Oct; $120(4): 739-45$.

47. Wanner A. Clinical aspects of mucociliary transport. Am Rev Respir Dis. 1977 Jul;116(1):73125 .

48. Fagon JY, Chastre J, Trouillet JL, Domart Y, Dombret MC, Bornet M, et al. Characterization of distal bronchial microflora during acute exacerbation of chronic bronchitis. Use of the protected specimen brush technique in 54 mechanically ventilated patients. Am Rev Respir Dis. 1990;142(5):1004-8.

49. Monso E, Ruiz J, Rosell A, Manterola J, Fiz J, Morera J, et al. Bacterial infection in chronic obstructive pulmonary disease. A study of stable and exacerbated outpatients using the protected specimen brush. Am / Respir Crit Care Med. 1995;152 (4 Pt 1):1316-20.

50. Soler N, Torres A, Ewig S, Gonzalez J, Celis R, ElEbiary M, et al. Bronchial microbial patterns in severe exacerbations of chronic obstructive pulmonary disease (COPD) requiring mechanical ventilation. Am J Respir Crit Care Med. 1998;157(5)):1498-505.

51. Soler N, Ewig S, Torres A, Filella X, Gonzalez J, Zaubet A. Airway inflammation and bronchial microbial patterns in patients with stable chronic obstructive pulmonary disease. Eur Respir J. 1999;14(5):1015-22.

52. Eller ), Ede A, Schaberg T, Niederman MS, Mauch H, Lode H. Infective exacerbations of chronic bronchitis: Relation between bacteriologic etiology and lung function. Chest $1998 ; 113(6)): 1542-8$.

53. Miravitlles M, Espinosa C, Fernandez Laso E, Martos JA, Maldonado JA, Gallego M. Relationship between bacterial flora in sputum and functional impairment in patients with acute exacerbations of COPD. Chest 1999;116(1)):40-6.

54. Sethi S, Muscarella K, Evans N, Klingman KL, Grant B), Murphy TF. Airway Inflammation and Etiology of Acute Exacerbations of Chronic Bronchitis. Chest. 2000;118(6):1557-65.

55. Chin CL, Manzel L), Lehman EE, Humlicek AL, Shi L, Starner TD, et al. Haemophilus 
influenzae from patients with chronic obstructive pulmonary disease exacerbation induce more inflammation than colonizers. Am J Respir Crit Care Med. 2005 Jul 1;172(1):85-91.

56. Bandi V, Apicella MA, Mason E, Murphy TF, Siddiqi A, Atmar RL, et al. Nontypeable Haemophilus influenzae in the lower respiratory tract of patients with chronic bronchitis. Am J Respir Crit Care Med. 2001 Dec 1;164(11):2114-9.

57. Sethi S, Evans N, Grant BJ, Murphy TF. New strains of bacteria and exacerbations of chronic obstructive pulmonary disease. N Engl J Med. 2002 Aug 15;347(7):465-71.

58. Sethi S, Wrona C, Grant BJ, Murphy TF. Strain-specific immune response to Haemophilus influenzae in chronic obstructive pulmonary disease. Am J Respir Crit Care Med. 2004 Feb 15;169(4):448-53.

59. Abe Y, Murphy TF, Sethi S, Faden HS, Dmochowski J, Harabuchi Y, et al. Lymphocyte proliferative response to $\mathrm{P} 6$ of Haemophilus influenzae is associated with relative protection from exacerbations of chronic obstructive pulmonary disease. Am J Respir Crit Care Med. 2002 Apr 1;165(7):967-71.

6o. Hill AT, Campbell EJ, Hill SL, Bayley DL, Stockley RA. Association between airway bacterial load and markers of airway inflammation in patients with stable chronic bronchitis. Am J Med. 2000 Sep;109(4):288-95.

61. Aaron SD, Angel JB, Lunau M, Wright K, Fex C, Le Saux N, et al. Granulocyte Inflammatory Markers and Airway Infection during Acute Exacerbation of Chronic Obstructive Pulmonary Disease. Am J Respir Crit Care Med. 2001;163(2):349-55.

62. White AJ, Gompertz S, Bayley DL, Hill SL, O'Brien C, Unsal I, et al. Resolution of bronchial inflammation is related to bacterial eradication following treatment of exacerbations of chronic bronchitis. Thorax. 2003 Aug;58(8):680-5.

63. Gump DW, Phillips CA, Forsyth BR, McIntosh K, Lamborn KR, Stouch WH. Role of infection in chronic bronchitis. Am Rev Respir Dis. 1976;113(4):465-74.

64. Smith CB, Golden CA, Kanner RE, Renzetti AD, Jr. Association of viral and Mycoplasma pneumoniae infections with acute respiratory illness in patients with chronic obstructive pulmonary diseases. Am Rev Respir Dis. 1980;121 (2):225-32.

65. Creenberg SB, Allen M, Wilson J, Atmar RL. Respiratory viral infections in adults with and without chronic obstructive pulmonary disease. Am J Respir Crit Care Med. 2000;162(1):16773.

66. Hurst JR, Donaldson GC, Wilkinson TM, Perera WR, Wedzicha JA. Epidemiological relationships between the common cold and exacerbation frequency in COPD. Eur Respir ). 2005 Nov; $26(5): 846-52$.

67. Rohde G, Wiethege A, Borg I, Kauth M, Bauer TT, Gillissen A, et al. Respiratory viruses in exacerbations of chronic obstructive pulmonary disease requiring hospitalisation: a casecontrol study. Thorax. 2003 Jan;58(1):37-42.

68. Seemungal T, Harper-Owen R, Bhowmik A, Moric I, Sanderson G, Message S, et al. Respiratory Viruses, Symptoms, and Inflammatory Markers in Acute Exacerbations and Stable Chronic Obstructive Pulmonary Disease. Am J Respir Crit Care Med. 2001;164(9):161823.

69. Seemungal TA, Harper Owen R, Bhowmik A, Jeffries DJ, Wedzicha JA. Detection of rhinovirus in induced sputum at exacerbation of chronic obstructive pulmonary disease. Eur Respir $)$. 2000;16(4):677-83.

70. Wilkinson TM, Donaldson GC, Johnston SL, Openshaw PJ, Wedzicha JA. Respiratory syncytial virus, airway inflammation, and $\mathrm{FEV}_{1}$ decline in patients with chronic obstructive pulmonary disease. Am J Respir Crit Care Med. 2006 Apr 15;173(8):871-6.

71. Wilkinson TM, Hurst JR, Perera WR, Wilks M, Donaldson GC, Wedzicha JA. Effect of interactions between lower airway bacterial and rhinoviral infection in exacerbations of COPD. Chest. 2006 Feb;129(2):317-24.

72. Papi A, Johnston SL. Respiratory epithelial cell expression of vascular cell adhesion molecule1 and its up-regulation by rhinovirus infection via NF-kappaB and GATA transcription factors. 


\section{General introduction}

J Biol Chem. 1999 Oct 15;274(42):30041-51.

73. Papi A, Johnston SL. Rhinovirus infection induces expression of its own receptor intercellular adhesion molecule 1 (ICAM-1) via increased NF-kappaB-mediated transcription. J Biol Chem. 1999 Apr 2;274(14):9707-20.

74. Tsoumakidou M, Siafakas NM. Novel insights into the aetiology and pathophysiology of increased airway inflammation during COPD exacerbations. Respir Res. 2006;7:80.

75. Blasi F, Legnani D, Lombardo VM, Negretto GG, Magliano E, Pozzoli R, et al. Chlamydia pneumoniae infection in acute exacerbations of COPD. Eur Respir J. 1993;6(1):19-22.

76. Roland M, Bhowmik A, Sapsford RJ, Seemungal TA, Jeffries DJ, Warner TD, et al. Sputum and plasma endothelin- levels in exacerbations of chronic obstructive pulmonary disease. Thorax. 2001;56(1):30-5.

77. Mogulkoc N, Karakurt S, Isalska B, Bayindir U, Celikel T, Korten V, et al. Acute purulent exacerbation of chronic obstructive pulmonary disease and Chlamydia pneumoniae infection. Am J Respir Crit Care Med. 1999;160(1):349-53.

78. von Hertzen LC. Chlamydia pneumoniae and its role in chronic obstructive pulmonary disease. Ann Med. 1998;30(1):27-37.

79. Clementsen P, Permin H, Norn S. Chlamydia pneumoniae infection and its role in asthma and chronic obstructive pulmonary disease. J Investig Allergol Clin Immunol. 2002;12(2):739 .

80. Schikowski T, Sugiri D, Ranft U, Gehring U, Heinrich J, Wichmann HE, et al. Long-term air pollution exposure and living close to busy roads are associated with COPD in women. Respir Res. 2005;6:152.

81. Levy D, Gent M, Newhouse MT. Relationship between acute respiratory illness and air pollution levels in an industrial city. Am Rev Respir Dis. 1977 Aug;116(2):167-73.

82. Anderson HR, Spix C, Medina S, Schouten JP, Castellsague J, Rossi G, et al. Air pollution and daily admissions for chronic obstructive pulmonary disease in 6 European cities: results from the APHEA project. Eur Respir J. 1997 May;10(5):1064-71.

83. Wordley J, Walters S, Ayres JG. Short term variations in hospital admissions and mortality and particulate air pollution. Occup Environ Med. 1997 Feb;54(2):108-16.

84. Gilmour PS, Rahman I, Hayashi S, Hogg JC, Donaldson K, MacNee W. Adenoviral E1A primes alveolar epithelial cells to PM(10)-induced transcription of interleukin-8. Am J Physiol Lung Cell Mol Physiol. 2001 Sep;281 (3):L598-606.

85. Gilmour PS, Rahman I, Donaldson K, MacNee W. Histone acetylation regulates epithelial IL8 release mediated by oxidative stress from environmental particles. Am / Physiol Lung Cell Mol Physiol. 2003 Mar;284(3):L533-40.

86. Health effects of outdoor air pollution. Committee of the Environmental and Occupational Health Assembly of the American Thoracic Society. Am J Respir Crit Care Med. 1996 Jan;153(1):3-50.

87. Desqueyroux H, Pujet JC, Prosper M, Le Moullec Y, Momas I. Effects of air pollution on adults with chronic obstructive pulmonary disease. Arch Environ Health. 2002 NovDec;57(6):554-60.

88. Tillie-Leblond I, Marquette $\mathrm{CH}$, Perez T, Scherpereel A, Zanetti C, Tonnel AB, et al. Pulmonary embolism in patients with unexplained exacerbation of chronic obstructive pulmonary disease: prevalence and risk factors. Ann Intern Med. 2006 Mar 21;144(6):390-6.

89. Saetta M, Di Stefano A, Maestrelli P, Turato G, Ruggieri MP, Roggeri A, et al. Airway eosinophilia in chronic bronchitis during exacerbations [see comments]. Am J Respir Crit Care Med. 1994;150(6 Pt 1):1646-52.

9o. Saetta M, Di Stefano A, Turato G, Facchini FM, Corbino L, Mapp CE, et al. CD8+ Tlymphocytes in peripheral airways of smokers with chronic obstructive pulmonary disease. Am J Respir Crit Care Med. 1998;157(3 Pt 1):822-6.

91. Zhu J, Qiu YS, Majumdar S, Gamble E, Matin D, Turato G, et al. Exacerbations of Bronchitis: bronchial eosinophilia and gene expression for interleukin-4, interleukin-5, and eosinophil 
chemoattractants. Am J Respir Crit Care Med. 2001 Jul 1;164(1):109-16.

92. Di Stefano A, Maestrelli P, Roggeri A, Turato G, Calabro S, Potena A, et al. Upregulation of adhesion molecules in the bronchial mucosa of subjects with chronic obstructive bronchitis. Am J Respir Crit Care Med. 1994;149(3 Pt 1):803-10.

93. Riise GC, Larsson S, Lofdahl CG, Andersson BA. Circulating cell adhesion molecules in bronchial lavage and serum in COPD patients with chronic bronchitis. Eur Respir ). 1994;7(9):1673-7.

94. Noguera A, Busquets X, Sauleda J, Villaverde JM, MacNee W, Agusti AC. Expression of adhesion molecules and $\mathrm{G}$ proteins in circulating neutrophils in chronic obstructive pulmonary disease. Am J Respir Crit Care Med. 1998;158 (5 Pt 1):1664-8.

95. Balbi B, Bason C, Balleari E, Fiasella F, Pesci A, Chio R, et al. Increased bronchoalveolar granulocytes and granulocyte/macrophage colony-stimulating factor during exacerbations of chronic bronchitis. Eur Respir J. 1997;10(4):846-50.

96. Hay DW. Putative mediator role of endothelin-1 in asthma and other lung diseases. Clin Exp Pharmacol Physiol. 1999 Feb;26(2):168-71.

97. Mullol J, Baraniuk JN, Logun C, Benfield T, Picado C, Shelhamer JH. Endothelin-1 i nduces GM-CSF, IL-6 and IL-8 but not G-CSF release from a human bronchial epithelial cell line (BEAS-2B). Neuropeptides. 1996 Dec;30(6):551-6.

98. Bhowmik A, Seemungal TA, Sapsford RJ, Wedzicha JA. Relation of sputum inflammatory markers to symptoms and lung function changes in COPD exacerbations. Thorax. 2000;55(2):114-20.

99. Compertz S, Bayley DL, Hill SL, Stockley RA. Relationship between airway inflammation and the frequency of exacerbations in patients with smoking related COPD. Thorax. 2001;56(1):36-41.

100. Stockley RA, Burnett D. Alpha,-antitrypsin and leukocyte elastase in infected and noninfected sputum. Am Rev Respir Dis. 1979 Nov;120(5):1081-6.

101. Tomee JF, Koeter GH, Hiemstra PS, Kauffman HF. Secretory leukoprotease inhibitor: a native antimicrobial protein presenting a new therapeutic option? Thorax. 1998 Feb;53(2):114-6.

102. Hill AT, Campbell E), Bayley DL, Hill SL, Stockley RA. Evidence for Excessive Bronchial Inflammation during an Acute Exacerbation of Chronic Obstructive Pulmonary Disease in Patients with alpha(1)-Antitrypsin Deficiency (PiZ). Am J Respir Crit Care Med. 1999;160(6):1968-75.

103. Mercer PF, Shute JK, Bhowmik A, Donaldson GC, Wedzicha JA, Warner JA. MMP-9, TIMP-1 and inflammatory cells in sputum from COPD patients during exacerbation. Respir Res. 2005;6:151.

104. Wedzicha JA, Seemungal TA, MacCallum PK, Paul EA, Donaldson GC, Bhowmik A, et al. Acute exacerbations of chronic obstructive pulmonary disease are accompanied by elevations of plasma fibrinogen and serum IL-6 levels. Thromb Haemost. 2000;84(2):210-5.

105. Creutzberg EC, Wouters EF, Vanderhoven Augustin IM, Dentener MA, Schols AM. Disturbances in leptin metabolism are related to energy imbalance during acute exacerbations of chronic obstructive pulmonary disease. Am J Respir Crit Care Med. 2000;162(4 Pt 1):1239-45.

106. Dentener MA, Creutzberg EC, Schols AM, Mantovani A, van't Veer C, Buurman WA, et al. Systemic anti-inflammatory mediators in COPD: increase in soluble interleukin 1 receptor II during treatment of exacerbations. Thorax. 2001 Sep;56(9):721-6.

107. Hurst JR, Wilkinson TM, Perera WR, Donaldson GC, Wedzicha JA. Relationships among bacteria, upper airway, lower airway, and systemic inflammation in COPD. Chest. 2005 Apr;127(4):1219-26.

108. Hurst JR, Perera WR, Wilkinson TM, Donaldson GC, Wedzicha JA. Systemic, Upper and Lower Airway Inflammation at Exacerbation of COPD. Am J Respir Crit Care Med. 2005 Sep 22.

109. Hurst JR, Donaldson GC, Perera WR, Wilkinson TM, Bilello JA, Hagan GW, et al. Use of 


\section{General introduction}

plasma biomarkers at exacerbation of chronic obstructive pulmonary disease. Am J Respir Crit Care Med. 2006 Oct 15;174(8):867-74.

110. Franciosi LG, Page CP, Celli BR, Cazzola M, Walker MJ, Danhof M, et al. Markers of exacerbation severity in chronic obstructive pulmonary disease. Respir Res. 2006;7:74

111. Stolz D, Christ-Crain M, Morgenthaler NG, Leuppi J, Miedinger D, Bingisser R, et al. Copeptin, C-reactive protein, and procalcitonin as prognostic biomarkers in acute exacerbation of COPD. Chest. 2007 Apr;131 (4):1058-67.

112. Dev D, Wallace E, Sankaran R, Cunniffe J, Govan JRW, Wathen CG, et al. Value of C-reactive protein measurements in exacerbations of chronic obstructive pulmonary disease. Respir Med. 1998;92(4)):664-7.

113. Calikoglu M, Sahin G, Unlu A, Ozturk C, Tamer L, Ercan B, et al. Leptin and TNF-alpha levels in patients with chronic obstructive pulmonary disease and their relationship to nutritional parameters. Respiration. 2004 Jan-Feb;71 (1):45-50.

114. Fiorini G, Crespi S, Rinaldi M, Oberti E, Vigorelli R, Palmieri G. Serum ECP and MPO are increased during exacerbations of chronic bronchitis with airway obstruction. Biomed Pharmacother. 2000 Jun;54(5):274-8.

115. Shindo K, Hirai Y, Fukumura M, Koide K. Plasma levels of leukotriene E4 during clinical course of chronic obstructive pulmonary disease. Prostaglandins Leukot Essent Fatty Acids. 1997;56(3):213-7.

116. Noguera A, Batle S, Miralles C, Iglesias ), Busquets X, MacNee W, et al. Enhanced neutrophil response in chronic obstructive pulmonary disease. Thorax. 2001 Jun;56(6):432-7.

117. Dekhuijzen PN, Aben KK, Dekker I, Aarts LP, Wielders PL, van Herwaarden CL, et al. Increased exhalation of hydrogen peroxide in patients with stable and unstable chronic obstructive pulmonary disease. Am J Respir Crit Care Med. 1996;154(3 Pt 1):813-6.

118. Pratico D, Basili S, Vieri M, Cordova C, Violi F, Fitzgerald GA. Chronic obstructive pulmonary disease is associated with an increase in urinary levels of isoprostane F2 alpha III, an index of oxidant stress. Am J Resp Crit Care Med 1998;158(6)):1709-14.

119. Rahman I, MacNee W. Oxidant/antioxidant imbalance in smokers and chronic obstructive pulmonary disease. Thorax. 1996;51 (4):348-50.

120. Drost EM, Skwarski KM, Sauleda J, Soler N, Roca J, Agusti A, et al. Oxidative stress and airway inflammation in severe exacerbations of COPD. Thorax. 2005 Apr;60(4):293-300.

121. Biernacki WA, Kharitonov SA, Barnes PJ. Increased leukotriene B4 and 8-isoprostane in exhaled breath condensate of patients with exacerbations of COPD. Thorax. 2003 Apr;58(4):294-8.

122. Tkacova R, Kluchova Z, Joppa P, Petrasova D, Molcanyiova A. Systemic inflammation and systemic oxidative stress in patients with acute exacerbations of COPD. Respir Med. 2007 Aug;101 (8):1670-6.

123. Tsoumakidou M, Tzanakis N, Chrysofakis G, Siafakas NM. Nitrosative stress, heme oxygenase-1 expression and airway inflammation during severe exacerbations of COPD. Chest. 2005 Jun;127(6):1911-8.

124. Wilkinson TM, Donaldson CC, Hurst JR, Seemungal TA, Wedzicha JA. Early therapy improves outcomes of exacerbations of chronic obstructive pulmonary disease. Am J Respir Crit Care Med. 2004 Jun 15;169(12):1298-303.

125. O'Reilly J F, Williams AE, Rice L. Health status impairment and costs associated with COPD exacerbation managed in hospital. Int J Clin Pract. 2007 Jul;61 (7):1112-20.

126. Kessler R, Stahl E, Vogelmeier C, Haughney J, Trudeau E, Lofdahl CG, et al. Patient understanding, detection, and experience of COPD exacerbations: an observational, interview-based study. Chest. 2006 Jul;130(1):133-42.

127. Doll H, Miravitlles M. Health-related QOL in acute exacerbations of chronic bronchitis and chronic obstructive pulmonary disease: a review of the literature. Pharmacoeconomics. $2005 ; 23(4): 345-63$.

128. Miravitlles M, Ferrer M, Pont A, Zalacain R, Alvarez-Sala JL, Masa F, et al. Effect of 
exacerbations on quality of life in patients with chronic obstructive pulmonary disease: a 2 year follow up study. Thorax. 2004 May;59(5):387-95.

129. Gosker HR, Wouters EF, van der Vusse G), Schols AM. Skeletal muscle dysfunction in chronic obstructive pulmonary disease and chronic heart failure: underlying mechanisms and therapy perspectives. Am I Clin Nutr. 2000;71 (5):1033-47.

130. Levine S, Kaiser L, Leferovich J, Tikunov B. Cellular adaptations in the diaphragm in chronic obstructive pulmonary disease. N Engl J Med. 1997 Dec 18;337(25):1799-806.

131. Satta A, Migliori GB, Spanevello A, Neri M, Bottinelli R, Canepari M, et al. Fibre types in skeletal muscles of chronic obstructive pulmonary disease patients related to respiratory function and exercise tolerance. Eur Respir J. 1997 Dec;10(12):2853-60.

132. Spruit MA, Gosselink R, Troosters T, Kasran A, Gayan-Ramirez G, Bogaerts P, et al. Muscle force during an acute exacerbation in hospitalised patients with COPD and its relationship with CXCL8 and IGF-I. Thorax. 2003 Sep;58(9):752-6.

133. Donaldson CC, Wilkinson TM, Hurst JR, Perera WR, Wedzicha JA. Exacerbations and time spent outdoors in chronic obstructive pulmonary disease. Am J Respir Crit Care Med. 2005 Mar 1;171 (5):446-52.

134. Pitta F, Troosters T, Probst VS, Spruit MA, Decramer M, Gosselink R. Physical activity and hospitalization for exacerbation of COPD. Chest. 2006 Mar;129(3):536-44.

135. Schols A, Mostert R, Soeters P, Greve LH, Wouters EF. Inventory of nutritional status in patients with COPD. Chest. 1989;96(2):247-9.

136. Baarends EM, Schols AM, Akkermans MA, Wouters EF. Decreased mechanical efficiency in clinically stable patients with COPD. Thorax. 1997 Nov;52(11):981-6.

137. Schols AM, Buurman WA, Staal van den Brekel AJ, Dentener MA, Wouters EF. Evidence for a relation between metabolic derangements and increased levels of inflammatory mediators in a subgroup of patients with chronic obstructive pulmonary disease. Thorax. 1996;51 (8):81924.

138. Vermeeren MA, Schols AM, Wouters EF. Effects of an acute exacerbation on nutritional and metabolic profile of patients with COPD. Eur Respir ). 1997;10(10):2264-9.

139. Nichol KL, Baken L, Wuorenma J, Nelson A. The health and economic benefits associated with pneumococcal vaccination of elderly persons with chronic lung disease. Arch Intern Med. 1999 Nov 8;159(20):2437-42.

140. Davis AL, Aranda CP, Schiffman G, Christianson LC. Pneumococcal infection and immunologic response to pneumococcal vaccine in chronic obstructive pulmonary disease. A pilot study. Chest. 1987 Aug;92(2):204-12.

141. Leech JA, Gervais A, Ruben FL. Efficacy of pneumococcal vaccine in severe chronic obstructive pulmonary disease. Cmaj. 1987 Feb 15;136(4):361-5.

142. Alfageme I, Vazquez R, Reyes N, Munoz J, Fernandez A, Hernandez M, et al. Clinical efficacy of anti-pneumococcal vaccination in patients with COPD. Thorax. 2006 Mar;61 (3):189-95.

143. Granger R, Walters J, Poole PJ, Lasserson TJ, Mangtani P, Cates C), et al. Injectable vaccines for preventing pneumococcal infection in patients with chronic obstructive pulmonary disease. Cochrane Database Syst Rev. 2006(4):CDoo1390.

144. Boyd G, Morice AH, Pounsford JC, Siebert M, Peslis N, Crawford C. An evaluation of salmeterol in the treatment of chronic obstructive pulmonary disease (COPD). Eur Respir ). 1997 Apr;10(4):815-21.

145. Johnson M, Rennard S. Alternative mechanisms for long-acting beta(2)-adrenergic agonists in COPD. Chest. 2001 Jul;120(1):258-70.

146. Casaburi R, Briggs DD, Jr., Donohue JF, Serby CW, Menjoge SS, Witek TJ, Jr. The spirometric efficacy of once-daily dosing with tiotropium in stable COPD: a 13-week multicenter trial. The US Tiotropium Study Group. Chest. 2000 Nov;118(5):1294-302.

147. Brusasco V, Hodder R, Miravitlles M, Korducki L, Towse L, Kesten S. Health outcomes following treatment for six months with once daily tiotropium compared with twice daily salmeterol in patients with COPD. Thorax. 2003 May;58(5):399-404. 


\section{General introduction}

148. Vincken W, van Noord JA, Greefhorst AP, Bantje TA, Kesten S, Korducki L, et al. Improved health outcomes in patients with COPD during 1 yr's treatment with tiotropium. Eur Respir I. 2002 Feb;19(2):209-16.

149. Casaburi R, Mahler DA, Jones PW, Wanner A, San PG, ZuWallack RL, et al. A long-term evaluation of once-daily inhaled tiotropium in chronic obstructive pulmonary disease. Eur Respir J. 2002 Feb;19(2):217-24.

150. Dusser D, Bravo ML, lacono P. The effect of tiotropium on exacerbations and airflow in patients with COPD. Eur Respir J. 2006 Mar;27(3):547-55.

151. Niewoehner DE, Rice K, Cote C, Paulson D, Cooper JA, Jr., Korducki L, et al. Prevention of exacerbations of chronic obstructive pulmonary disease with tiotropium, a once-daily inhaled anticholinergic bronchodilator: a randomized trial. Ann Intern Med. 2005 Sep 6;143(5):31726.

152. Aaron SD, Vandemheen KL, Fergusson D, Maltais F, Bourbeau J, Goldstein R, et al. Tiotropium in combination with placebo, salmeterol, or fluticasone-salmeterol for treatment of chronic obstructive pulmonary disease: a randomized trial. Ann Intern Med. $2007 \mathrm{Apr}$ $17 ; 146(8): 545-55$.

153. Paggiaro PL, Dahle R, Bakran I, Frith L, Hollingworth K, Efthimiou J. Multicentre randomised placebo-controlled trial of inhaled fluticasone propionate in patients with chronic obstructive pulmonary disease. Lancet 1998;351(9105)):773-80.

154. Burge PS, Calverley PM, Jones PW, Spencer S, Anderson JA, Maslen TK. Randomised, double blind, placebo controlled study of fluticasone propionate in patients with moderate to severe chronic obstructive pulmonary disease: the ISOLDE trial. BMJ. 2000;320(7245):1297-303.

155. Jones PW, Willits LR, Burge PS, Calverley PM. Disease severity and the effect of fluticasone propionate on chronic obstructive pulmonary disease exacerbations. Eur Respir ). 2003 Jan;21 (1):68-73.

156. Jarad NA, Wedzicha JA, Burge PS, Calverley PM. An observational study of inhaled corticosteroid withdrawal in stable chronic obstructive pulmonary disease. ISOLDE Study Group. Respir Med. 1999;93(3):161-6.

157. Yang IA, Fong KM, Sim EH, Black PN, Lasserson TJ. Inhaled corticosteroids for stable chronic obstructive pulmonary disease. Cochrane Database Syst Rev. 2007(2):CDo02991.

158. Spencer S, Calverley PM, Burge PS, Jones PW. Impact of preventing exacerbations on deterioration of health status in COPD. Eur Respir J. 2004 May;23(5):698-702.

159. van der Valk P, Monninkhof E, van der Palen J, Zielhuis G, van Herwaarden C. Effect of discontinuation of inhaled corticosteroids in patients with chronic obstructive pulmonary disease: the COPE study. Am J Respir Crit Care Med. 2002 Nov 15;166(10):1358-63.

160. Calverley P, Pauwels R, Vestbo J, Jones P, Pride N, Gulsvik A, et al. Combined salmeterol and fluticasone in the treatment of chronic obstructive pulmonary disease: a randomised controlled trial. Lancet. 2003 Feb 8;361 (9356):449-56.

161. Szafranski W, Cukier A, Ramirez A, Menga G, Sansores R, Nahabedian S, et al. Efficacy and safety of budesonide/formoterol in the management of chronic obstructive pulmonary disease. Eur Respir J. 2003 Jan;21 (1):74-81.

162. Calverley PM, Anderson JA, Celli B, Ferguson CT, Jenkins C, Jones PW, et al. Salmeterol and fluticasone propionate and survival in chronic obstructive pulmonary disease. N Engl ) Med. 2007 Feb 22;356(8):775-89.

163. Wouters EF, Postma DS, Fokkens B, Hop WC, Prins J, Kuipers AF, et al. Withdrawal of fluticasone propionate from combined salmeterol/fluticasone treatment in patients with COPD causes immediate and sustained disease deterioration: a randomised controlled trial. Thorax. 2005 Jun;60(6):480-7.

164. Nannini LJ, Cates C), Lasserson TJ, Poole P. Combined corticosteroid and long-acting betaagonist in one inhaler versus inhaled steroids for chronic obstructive pulmonary disease. Cochrane Database Syst Rev. 2007(4):CDoo6826.

165. Barnes NC, Qiu YS, Pavord ID, Parker D, Davis PA, Zhu J, et al. Antiinflammatory effects of 
salmeterol/fluticasone propionate in chronic obstructive lung disease. Am J Respir Crit Care Med. 2006 Apr 1;173(7):736-43.

166. Hattotuwa KL, Gizycki M), Ansari TW, Jeffery PK, Barnes NC. The effects of inhaled fluticasone on airway inflammation in chronic obstructive pulmonary disease: a double-blind, placebo-controlled biopsy study. Am J Respir Crit Care Med. 2002 Jun 15;165(12):1592-6.

167. Ozol D, Aysan T, Solak ZA, Mogulkoc N, Veral A, Sebik F. The effect of inhaled corticosteroids on bronchoalveolar lavage cells and IL-8 levels in stable COPD patients. Respir Med. 2005 Dec;99(12):1494-500.

168. Gizycki M), Hattotuwa KL, Barnes N, Jeffery PK. Effects of fluticasone propionate on inflammatory cells in COPD: an ultrastructural examination of endobronchial biopsy tissue. Thorax. 2002 Sep;57(9):799-803.

169. Verhoeven GT, Hegmans JP, Mulder PG, Bogaard JM, Hoogsteden HC, Prins JB. Effects of fluticasone propionate in COPD patients with bronchial hyperresponsiveness. Thorax. 2002 Aug;57(8):694-700.

170. Poole PJ, Black PN. Mucolytic agents for chronic bronchitis or chronic obstructive pulmonary disease. Cochrane Database Syst Rev. 2006;3:CDoo1287.

171. Houtmeyers E, Gosselink R, Gayan-Ramirez G, Decramer M. Effects of drugs on mucus clearance. Eur Respir ). 1999 Aug;14(2):452-67.

172. Ekberg Jansson A, Larson M, MacNee W, Tunek A, Wahlgren L, Wouters EFM, et al. Nisobutyrylcysteine, a donor of systemic thiols, does not reduce the exacerbation rate in chronic bronchitis. Eur Respir J. 1999;13(4)):829-34.

173. Decramer M, Rutten-van Molken M, Dekhuijzen PN, Troosters T, van Herwaarden C, Pellegrino R, et al. Effects of $\mathrm{N}$-acetylcysteine on outcomes in chronic obstructive pulmonary disease (Bronchitis Randomized on NAC Cost-Utility Study, BRONCUS): a randomised placebo-controlled trial. Lancet. 2005 Apr 30-May 6;365(9470):1552-60.

174. Soler M, Mutterlein R, Cozma G. Double-blind study of OM-85 in patients with chronic bronchitis or mild chronic obstructive pulmonary disease. Respiration. 2007;74(1):26-32

175. Sprenkle MD, Niewoehner DE, MacDonald R, Rutks I, Wilt T). Clinical efficacy of OM-85 BV in COPD and chronic bronchitis: a systematic review. COPD. 2005 Mar;2 (1):167-75.

176. Alvarez-Mon M, Miravitlles M, Morera ), Callol L, Alvarez-Sala JL. Treatment with the immunomodulator $\mathrm{AM}_{3}$ improves the health-related quality of life of patients with COPD. Chest. 2005 Apr;127(4):1212-8.

177. Griffiths TL, Burr ML, Campbell IA, Lewis-Jenkins V, Mullins ), Shiels K, et al. Results at 1 year of outpatient multidisciplinary pulmonary rehabilitation: a randomised controlled trial. Lancet. 2000 Jan 29;355(9201):362-8.

178. Guell R, Casan P, Belda J, Sangenis M, Morante F, Guyatt GH, et al. Long-term effects of outpatient rehabilitation of COPD: A randomized trial. Chest. 2000;117(4):976-83.

179. Puhan MA, Scharplatz M, Troosters T, Steurer J. Respiratory rehabilitation after acute exacerbation of COPD may reduce risk for readmission and mortality -- a systematic review. Respir Res. 2005;6:54.

180. Ries AL, Bauldoff GS, Carlin BW, Casaburi R, Emery CF, Mahler DA, et al. Pulmonary Rehabilitation: Joint ACCP/AACVPR Evidence-Based Clinical Practice Guidelines. Chest. 2007 May;131(5 Suppl):4S-42S.

181. Rodriguez-Roisin R. COPD exacerbations.5: management. Thorax. 2006 Jun;61 (6):535-44.

182. Davies L, Angus RM, Calverley PMA. Oral corticosteroids in patients admitted to hospital with exacerbations of chronic obstructive pulmonary disease: a prospective randomised controlled trial. Lancet. 1999;354(9177)):456-60.

183. Niewoehner DE, Erbland ML, Deupree RH, Collins D, Gross NJ, Light RW, et al. Effect of systemic glucocorticoids on exacerbations of chronic obstructive pulmonary disease. New Engl J Med. 1999;340(25)):1941-7.

184. Niewoehner DE. Systemic corticosteroids for chronic obstructive pulmonary disease: benefits and risks. Monaldi Arch Chest Dis. 1999;54(5):422-6. 


\section{General introduction}

185. Barr RG, Rowe BH, Camargo CA, Jr. Methylxanthines for exacerbations of chronic obstructive pulmonary disease: meta-analysis of randomised trials. BMJ. 2003 Sep 20;327(7416):643.

186. Duffy N, Walker P, Diamantea F, Calverley PM, Davies L. Intravenous aminophylline in patients admitted to hospital with non-acidotic exacerbations of chronic obstructive pulmonary disease: a prospective randomised controlled trial. Thorax. 2005 Sep;60(9):713-7.

187. Adams SG, Melo J, Luther M, Anzueto A. Antibiotics are associated with lower relapse rates in outpatients with acute exacerbations of COPD. Chest. 2000;117(5):1345-52.

188. Puhan MA, Vollenweider D, Latshang T, Steurer J, Steurer-Stey C. Exacerbations of chronic obstructive pulmonary disease: when are antibiotics indicated? A systematic review. Respir Res. 2007;8:30.

189. Ram FS, Rodriguez-Roisin R, Granados-Navarrete A, Garcia-Aymerich J, Barnes NC. Antibiotics for exacerbations of chronic obstructive pulmonary disease. Cochrane Database Syst Rev. 2006(2):CDoo4403.

190. Saint S, Bent S, Vittinghoff E, Grady D. Antibiotics in chronic obstructive pulmonary disease exacerbations. A meta-analysis. JAMA. 1995 Mar 22-29;273(12):957-60.

191. Brochard L, Mancebo J, Wysocki M, Lofaso F, Conti G, Rauss A, et al. Noninvasive ventilation for acute exacerbations of chronic obstructive pulmonary disease. N Engl J Med. 1995 Sep 28;333(13):817-22.

192. Lightowler JV, Wedzicha JA, Elliott MW, Ram FS. Non-invasive positive pressure ventilation to treat respiratory failure resulting from exacerbations of chronic obstructive pulmonary disease: Cochrane systematic review and meta-analysis. BMJ. 2003 Jan 25;326(7382):185.

193. Ram FS, Picot J, Lightowler J, Wedzicha JA. Non-invasive positive pressure ventilation for treatment of respiratory failure due to exacerbations of chronic obstructive pulmonary disease. Cochrane Database Syst Rev. 2004(3):CDo04104.

194. Plant PK, Owen JL, Parrott S, Elliott MW. Cost effectiveness of ward based non-invasive ventilation for acute exacerbations of chronic obstructive pulmonary disease: economic analysis of randomised controlled trial. BMJ. 2003 May 3;326(7396):956.

195. Nava S, Ambrosino N, Clini E, Prato M, Orlando G, Vitacca M, et al. Noninvasive mechanical ventilation in the weaning of patients with respiratory failure due to chronic obstructive pulmonary disease. A randomized, controlled trial. Ann Intern Med. 1998 May 1;128(9):721-8.

196. Ferrer M, Esquinas A, Arancibia F, Bauer TT, Gonzalez G, Carrillo A, et al. Noninvasive ventilation during persistent weaning failure: a randomized controlled trial. Am J Respir Crit Care Med. 2003 Jul 1;168(1):70-6.

197. Esteban A, Frutos-Vivar F, Ferguson ND, Arabi Y, Apezteguia C, Gonzalez M, et al. Noninvasive positive-pressure ventilation for respiratory failure after extubation. $\mathrm{N}$ Engl ) Med. 2004 Jun 10;350(24):2452-60.

198. Budweiser S, Jorres RA, Riedl T, Heinemann F, Hitzl AP, Windisch W, et al. Predictors of Survival in COPD Patients With Chronic Hypercapnic Respiratory Failure Receiving Noninvasive Home Ventilation. Chest. 2007 Jun;131(6):1650-8.

199. Seemungal TA, Donaldson CC, Bhowmik A, Jeffries DJ, Wedzicha JA. Time course and recovery of exacerbations in patients with chronic obstructive pulmonary disease. Am J Respir Crit Care Med. 2000;161 (5):1608-13.

200. Anthonisen NR, Wright EC, Hodgkin JE. Prognosis in chronic obstructive pulmonary disease. Am Rev Respir Dis. 1986;133(1):14-20.

201. Burrows B, Earle RH. Prediction of survival in patients with chronic airway obstruction. Am Rev Respir Dis. 1969;99(6):865-71.

202. Traver GA, Cline MG, Burrows B. Predictors of mortality in chronic obstructive pulmonary disease. A 15-year follow-up study. Am Rev Respir Dis. 1979;119(6):895-902.

203. Gray Donald K, Gibbons L, Shapiro SH, Macklem PT, Martin JG. Nutritional status and mortality in chronic obstructive pulmonary disease. Am J Respir Crit Care Med. 1996;153(3):961-6.

204. Schols A, Slangen J, Volovics L, Wouters EFM. Weight loss is a reversible factor in 
the prognosis of chronic obstructive pulmonary disease. Am / Resp Crit Care Med. 1998;157(6)):1791-7.

205. Sukumalchantra Y, Dinakara P, Williams MH, Jr. Prognosis of patients with chronic obstructive pulmonary disease after hospitalization for acute ventilatory failure: a three-year follow-up study. Am Rev Respir Dis. 1966;93(2):215-22.

206. Fuso L, Incalzi RA, Pistelli R, Muzzolon R, Valente S, Pagliari G, et al. Predicting mortality of patients hospitalized for acutely exacerbated chronic obstructive pulmonary disease. Am J Med. 1995;98(3):272-7.

207. Incalzi RA, Fuso L, DeRosa M, Forastiere F, Rapiti E, Nardecchia B, et al. Co-morbidity contributes to predict mortality of patients with chronic obstructive pulmonary disease. Eur Respir J. 1997;10(12)):2794-800.

208. Gunen H, Hacievliyagil SS, Kosar F, Mutlu LC, Gulbas G, Pehlivan E, et al. Factors affecting survival of hospitalised patients with COPD. Eur Respir ). 2005 Aug;26 (2):234-41.

209. Soler-Cataluna J), Martinez-Carcia MA, Roman Sanchez P, Salcedo E, Navarro M, Ochando R. Severe acute exacerbations and mortality in patients with chronic obstructive pulmonary disease. Thorax. 2005 Nov;60(11):925-31.

210. Seneff MG, Wagner DP, Wagner RP, Zimmerman JE, Knaus WA. Hospital and 1-year survival of patients admitted to intensive care units with acute exacerbation of chronic obstructive pulmonary disease. JAMA. 1995;274(23):1852-7.

211. Ai-Ping C, Lee KH, Lim TK. In-hospital and 5-year mortality of patients treated in the ICU for acute exacerbation of COPD: a retrospective study. Chest. 2005 Aug;128(2):518-24.

212. Breen D, Churches T, Hawker F, Torzillo PJ. Acute respiratory failure secondary to chronic obstructive pulmonary disease treated in the intensive care unit: a long term follow up study. Thorax. 2002 Jan;57(1):29-33. 

CHAPTER 2

Bacterial infections in acute exacerbations of COPD; a one-year prospective study

Respiratory Medicine 2003 Jul;97 (7): 770-777

KH Groenewegen

AM Schols

EFM Wouters 


\section{Abstract}

\section{Study objective}

to investigate the frequency of respiratory bacterial infections in hospitalized patients, admitted with an acute exacerbation of COPD, to identify the responsible pathogens by sputum culture and to assess patient characteristics in relation to sputum culture results.

\section{Methods}

We prospectively evaluated clinical data and sputum culture results of 171 patients, admitted to the pulmonology department of the University Hospital Maastricht with an acute exacerbation of COPD from January 1st 1999 until December 31st 1999.

\section{Results}

85 patients (50\%) had positive sputum cultures, indicating the presence of bacterial infection. Pathogens most frequently isolated were: H.influenzae (45\%), S. pneumoniae (27\%), and P. aeruginosa ( $15 \%)$.

Patients with more severely compromised lung function had a higher incidence of bacterial infections $(p=0.026)$. There were no significant differences in age, lung function parameters, blood gas results and length of hospital stay between patients with and without bacterial infection. There were no correlations between the type of bacteria isolated and clinical characteristics.

\section{Conclusion}

Incidence of bacterial infection during acute exacerbations of COPD is about $50 \%$. Patients with and without bacterial infection are not different in clinical characteristics or in outcome parameters. Patients with lower FEV, have a higher incidence of bacterial infections, but there is no difference in the type of bacterial infection.

In the future the pathogenic role of bacterial infection in exacerbations of COPD should be further investigated, especially the role of bacterial infection in relation to local and systemic inflammation. 


\section{Introduction}

Chronic obstructive pulmonary disease (COPD) comprises a heterogeneous group of conditions, characterized by varying degrees of expiratory flow limitation. Exacerbations punctuate the clinical course of COPD in many patients. These episodes of acute exacerbation can vary considerably in severity: part of the exacerbations will remain unreported while some episodes require hospital admission. Hospital admission for acute exacerbations forms the major component of the economical burden of COPD in western countries [1]. These exacerbations are characterized by varying combinations of symptoms as increase in cough, sputum production, worsening of dyspnea or changes in sputum purulence.

Recent studies have indicated that health status of patients with COPD has been influenced by the presence and frequency of these acute exacerbations [2,3]. The exact role of periods of acute exacerbations in the pathogenesis of COPD remains unclear, especially the relationship between bronchial inflammation and lung defense during these possible noxious events [4]. Some studies have indicated that recurrent exacerbations may be associated with increased airway inflammation although many factors may influence the state of inflammation in the airways [5]. Recent data also suggest presence of decreased antiproteinase activity in sputum of patients with recurrent exacerbations [4].

Exacerbations are not only heterogeneous in severity and symptom characteristics but are also in nature. Although several events may lead to acute exacerbations, respiratory tract infections are often considered as the initiating event contributing to the deterioration in the clinical condition. Especially the role of bacterial infections and the value of antibiotic therapy have been a matter of debate for many decades [6-8].

An important problem in defining the role of bacteria in these episodes of acute exacerbation is the bacterial colonization of the lower airways even in the absence of symptoms of an exacerbation [7]. Careful investigations have reported presence of bacterial pathogens in only about $50 \%$ of exacerbations [9-15]. However, these studies have been performed in different populations of COPD patients, and most frequently in outpatients.

Recently two studies have investigated the type of bacterial pathogens isolated in sputum of COPD patients, hospitalized for an acute exacerbation $[12,13]$. In these studies a correlation was found between lung function and the type of bacteria isolated: patients with more compromised lung function had a higher incidence of infections with Pseudomonas aeruginosa and other Gram-negative bacteria isolated from their sputum. These findings suggested that patients with more advanced lung disease may need a different pharmacological therapy than patients with milder disease.

The generalisation of these findings as well as the interpretation of them as 


\section{Bacterial infections in acute exacerbations of COPD}

disease-specific findings are hampered by limited availability of data on distribution of bacterial flora in COPD patients from different geographical areas as qualitative differences in bacterial flora can be related to many other factors. Therefore it seems interesting to investigate prospectively the prevalence of acute bacterial infections during these episodes of hospital admission as well as if specific patient profiles are related to a different pattern of micro-organisms in patients admitted for an acute exacerbation of the disease.

Furthermore, we questioned if presence of bacterial infection influences the clinical outcome of hospital admissions for acute exacerbations.

\section{Material and Methods}

\section{Study population and study design}

All patients, admitted with an acute exacerbation of COPD to the pulmonology ward of the University Hospital Maastricht, between January 1st 1999 and December 31st 1999, were prospectively evaluated. All patients were diagnosed as having COPD, according to the criteria of the American Thoracic Society [16]. Acute exacerbation was defined by the presence of an increase in at least two of the three following symptoms: dyspnoea, cough and sputum purulence.

Admission to the hospital was deemed necessary based on the clinical situation of the patient or the presence of complicating factors as respiratory failure. In all cases the need for admission was decided by a senior chest physician, experienced in the management of COPD patients. Chest X-rays were performed in each patient on admission and patients with lobar infiltrates or radiologic signs of pneumonia on chest X-ray were excluded from the study.

Patients were included only once in the study even if hospitalized more frequently. For all included patients the following data were assessed: medical history, lung function measurements, blood gases, duration of hospital stay, previous treatment, chronic corticosteroid use and results of sputum cultures. Medical history, previous treatment and use of corticosteroids were recorded from the patients charts on standardized forms. Chronic use of oral corticosteroids was defined as the use of daily oral corticosteroids for at least one year in a dosage of at least $5 \mathrm{mg}$ Prednisolone or equivalent. On admission, arterial bloodgases at rest were assessed by puncture of the radial artery during room air breathing. Patients were discharged from the pulmonary ward by decision of a senior chest physician, unaware of the goals of the present study. Total duration of hospital stay was recorded, counting from the first day of admission before $0.00 \mathrm{hrs}$. until the day of discharge.

Patients were treated with a standard protocol consisting of intravenous administration of corticosteroids and theophylline and nebulisation of salbutamol and ipratropiumbromide as bronchodilating agents. $\mathrm{O}_{2}$ was titrated by follow- 
up of blood gas values as well as continuous monitoring of oxygen saturation. Antibiotics were not prescribed until the results of the sputum cultures were available, unless the clinical condition of the patient necessitated early intervention based on documented resistance pattern of isolated microorganisms.

\section{Lung function data}

Spirometries were performed daily during admission for the exacerbation. Spirometries were performed using the portable pneumotachograph from Jaeger pulmonary function equipment (Würzburg, Germany). The value after recovery, prior to discharge from the hospital was used in the analyses. Based on the ATS criteria [16], lung function was rated in 3 stages of severity: stage I: FEV 1 of $\geq 50 \%$ predicted, stage II: FEV 1 between 35 and $50 \%$ predicted, stage III: $F E V_{1} \leq 35 \%$ predicted.

\section{Sputum cultures}

At least one sample of spontaneously expectorated sputum for microbiologic evaluation was obtained in all patients during admission. This is part of common medical practice in the our hospital for patients admitted for an acute exacerbation, and also it is recommend in the recently published GOLD guidelines for the management of COPD [17]. Samples were collected in sterile sputum cups and sent to the laboratory within 1 hour after expectoration.

A Gram stain of the sputum in the area of maximal purulence was examined for polymorphonuclear leukocytes and epithelial cells. The number of leukocytes was semiquantitatively described as: none, sporadic, few, moderate or many. A sputum sample was considered representative if many leukocytes were present in the absence of epithelial cells. Another portion of a the documented purulent material was used for microbiological analysis. Sputa were processed according to standard microbiological methods [18]. A sputum culture was considered as positive (proving bacterial infection) if significant bacterial growth was present as defined by the number of bacteria (higher than $10^{5}$ colony forming units $=\mathrm{cfu}$ ) in a representative sample. Identified bacteria were classified into 3 groups : group 1 included H.influenzae and M. catarrhalis, group 2 included S.pneumoniae and other Gram positive cocci and group 3 included Pseudomonas and other Gram negative micro-organisms. Other identified bacteria are considered non-pathogenic micro-organisms (NPM's), belonging to the oropharyngeal or gastrointestinal flora.

A microbial resistance pattern was available for all pathogens. For all pathogens resistance patterns were determined for Amoxicillin, Amoxicillin/Clavulanic acid, Doxycyclin and Co-trimoxazole. In case of isolation of Pseudomonas and other Gram negative species resistance patterns to Gentamycin, Piperacillin, Ciprofloxacine, Ofloxacine and Cefuroxim were determined additionally. 


\section{Statistical analysis}

The statistical analyses were performed using the Statistical Products and Service Solutions (SPSS;Chicago,IL,USA) for Windows Package. Groups were compared by analysis of variance. (ANOVA). The $X^{2}$ test was used to compare categorical variables. Results are presented as mean \pm SD unless stated otherwise.

\section{Results}

\section{Patient characteristics}

Between January 1st 1999 and December 31st 1999171 patients were included with acute exacerbation of COPD. Characteristics of the study population are summarized in table 1 . Most patients were elderly with severely impaired lung function (mean FEV, was $0.84 \mathrm{~L}$ or $34.6 \%$ predicted).

Hypoxia as well as hypercapnia were very common findings on admission; 141 (= $85 \%$ ) of the patients had arterial oxygen tension $\leq 8.7 \mathrm{kPa}$, arterial carbon dioxide tension higher than $5.9 \mathrm{kPa}$ was measured in 93 patients (= $55 \%)$.

63 Patients $(=37 \%)$ had been treated with antibiotics prior to admission to the hospital. Prescribed antibiotics by general practitioners were: Doxycycline $(37 \%)$, Amoxicillin (21\%), Amoxicillin/Clavulanic acid (29\%) and Azithromycine (10\%). Information concerning the remaining $3 \%$ could not be retrieved. $43 \%$ of the patients had also received a boost of oral corticosteroids prior to admission. Mean hospital stay was 11.7 days and median hospital stay was 10 days. 13 Patients died during their hospital stay, resulting in an in-hospital mortality of $8 \%$.

17 Patients were admitted to ICU because of progressive respiratory failure: In 15 patients failure of conservative treatment in the first 48 hours necessitated referral to the ICU; In 2 patients clinical condition deteriorated after initial improvement. Intubation and mechanical ventilation was necessary in 10 patients, 4 patients received non-invasive ventilation (BiPAP) and in 3 patients conservative treatment could be continued under close supervision. Patients transferred to ICU had a longer duration of hospital stay ( $p=0.005$; mean 17.3 days, median 15 days). One patient died during ICU admission (6\%).

\section{Microbiological analysis}

Sputum cultures could be obtained in 142 patients. ( = 83\%). Other patients were unable to expectorate sputum spontaneously during hospitalization. Samples were considered not representative based on microbiological criteria in 54 cases. In 85 of the 88 representative samples (97\%) a significant bacterial growth was reported; in 61 samples ( $72 \%$ ) there was growth of one single species in significant concentrations, in 22 samples $(26 \%)$ there was growth of 2 different species in significant concentrations and in 4 samples (5\%) growth of 3 different species in significant concentrations was present. 
Table 1. Clinical characteristics of the COPD population and the patients with and without bacterial infection.

\begin{tabular}{|c|c|c|c|c|}
\hline & $\begin{array}{l}\text { whole } \\
\text { group } \\
(n=171)\end{array}$ & $\begin{array}{c}\text { negative } \\
\text { sputum culture } \\
(n=86)\end{array}$ & $\begin{array}{c}\text { positive } \\
\text { sputum culture } \\
(n=85)\end{array}$ & $\begin{array}{c}\mathrm{p}- \\
\text { value }\end{array}$ \\
\hline Age (years) & $70.6 \pm 8.6$ & $71.7 \pm 7.8$ & $69.5 \pm 8.9$ & 0.023 \\
\hline $\mathrm{FEV}_{1}(\mathrm{I}, \%$ pred $)$ & $34.6 \pm 12.6$ & $34.1 \pm 13.3$ & $35.2 \pm 1.9$ & NS \\
\hline $\mathrm{PaO}_{2}(\mathrm{kPa})$ & $7.49 \pm 2.2$ & $7.16 \pm 2.0$ & $7.82 \pm 2.5$ & NS \\
\hline $\mathrm{PaCO}_{2}(\mathrm{kPa})$ & $6.74 \pm 2.1$ & $6.12 \pm 2.1$ & $6.66 \pm 2.2$ & NS \\
\hline hospital stay (days) & $11.7 \pm 8.8$ & $10.5 \pm 5.6$ & $12.9 \pm 10.8$ & NS \\
\hline $\operatorname{Sex}(M / F)$ & $104 / 67$ & $50 / 36$ & $54 / 31$ & NS \\
\hline $\begin{array}{l}\text { Pretreatment with } \\
\text { antibiotics }(y / n)\end{array}$ & $63 / 108$ & $30 / 56$ & $33 / 52$ & NS \\
\hline $\begin{array}{l}\text { Pretreatment with } \\
\text { corticosteroids }(y / n)\end{array}$ & $73 / 98$ & $29 / 57$ & $31 / 54$ & NS \\
\hline $\begin{array}{l}\text { Chronic corticosteroids } \\
(y / n)\end{array}$ & $17 / 154$ & $8 / 78$ & $9 / 76$ & NS \\
\hline ICU admission (y/n) & $17 / 154$ & $10 / 76$ & $7 / 78$ & NS \\
\hline $\begin{array}{l}\text { Died during admission } \\
(y / n)\end{array}$ & $13 / 158$ & $6 / 80$ & $7 / 77$ & NS \\
\hline
\end{tabular}

The most frequently isolated species were Haemophilus influenzae (23 cases as single pathogen, 15 cases in combination with other pathogens, overall $38 / 85$ cases or $45 \%$ ) and Streptococcus pneumoniae ( 9 cases as single pathogen, 15 cases in combination with other pathogens, overall $24 / 85$ cases or $28 \%)$.

Pseudomonas aeruginosa was isolated in $13 / 85$ cases (15\%). Other bacteria isolated were: Moraxella catarrhalis ( 3 cases as single pathogen, 2 cases in combination, overall $5 / 85$ cases or $6 \%$ ), and Klebsiella pneumoniae ( 1 case as single pathogen, 3 cases in combination, overall $4 / 85$ cases or $5 \%$ ). In $14 / 85$ cases (16\%) non-pathogenic microorganisms (NPM's) were found. These data are schematically presented in figure 1 .

No resistant strains of $\mathrm{S}$. pneumoniae to Amoxicillin were isolated. For $\mathrm{H}$. influenzae as well as for $\mathrm{M}$. catarrhalis $2 \beta$-lactamase producing strains were identified. No resistant Pseudomonas strains were isolated in the studied population. No significant differences were found in mean $\mathrm{FEV}_{1}, \mathrm{PaO}_{2}$ and $\mathrm{PaCO}_{2}$ between the patients with and without positive sputum culture (table 1). 


\section{Bacterial infections in acute exacerbations of COPD}

Figure 1. Types of isolated micro-organisms found during acute exacerbations of COPD.

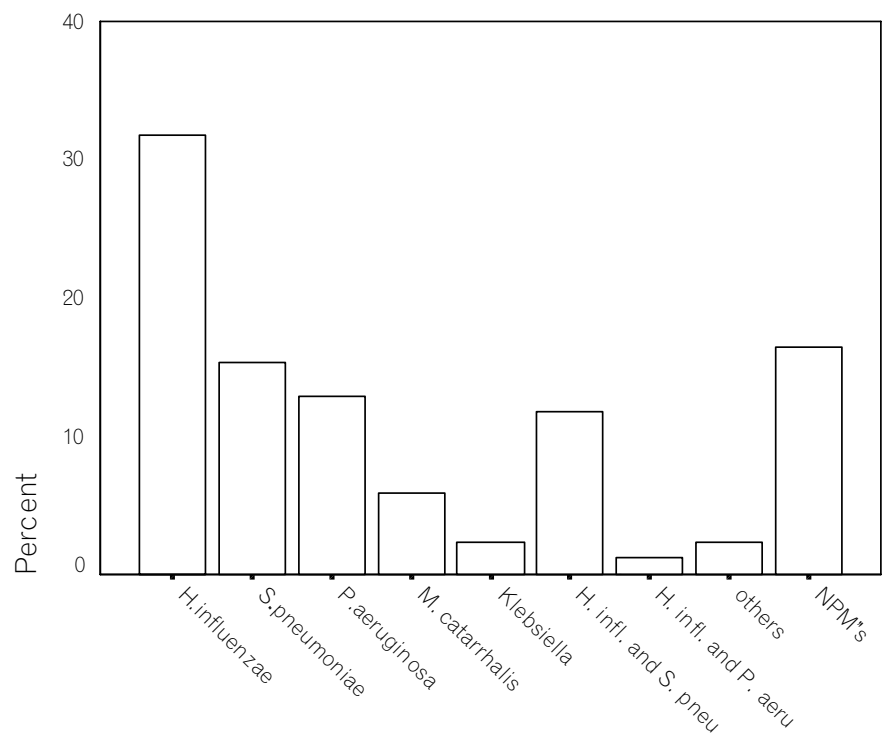

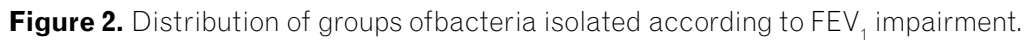

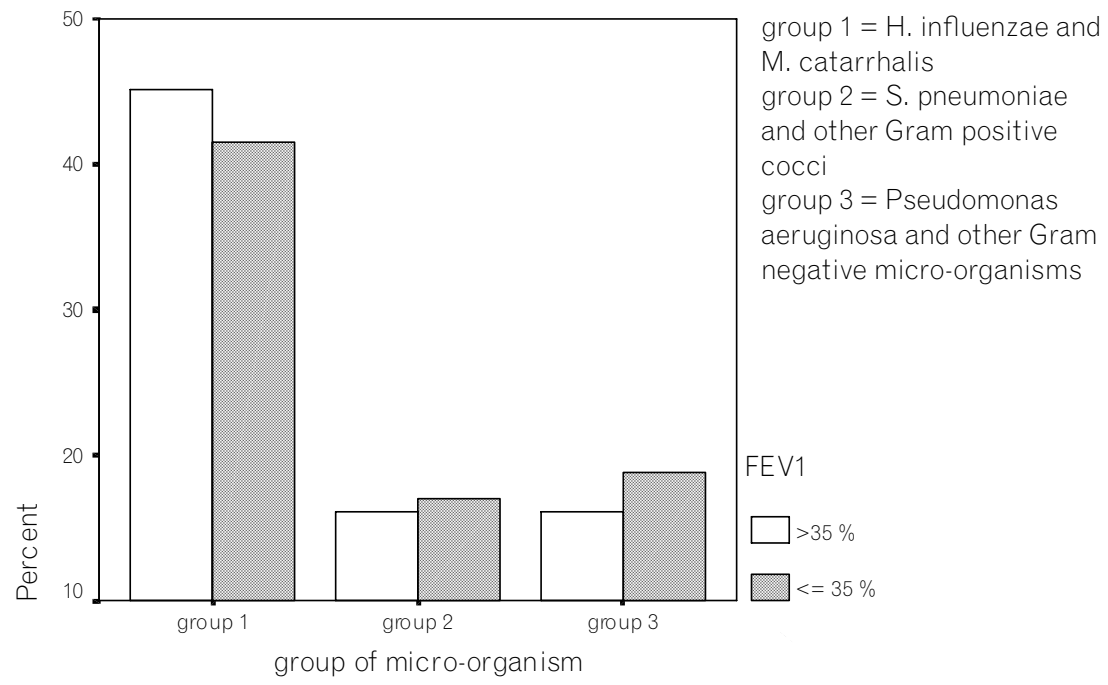


Figure 3. Positive sputum cultures after stratification for FEV

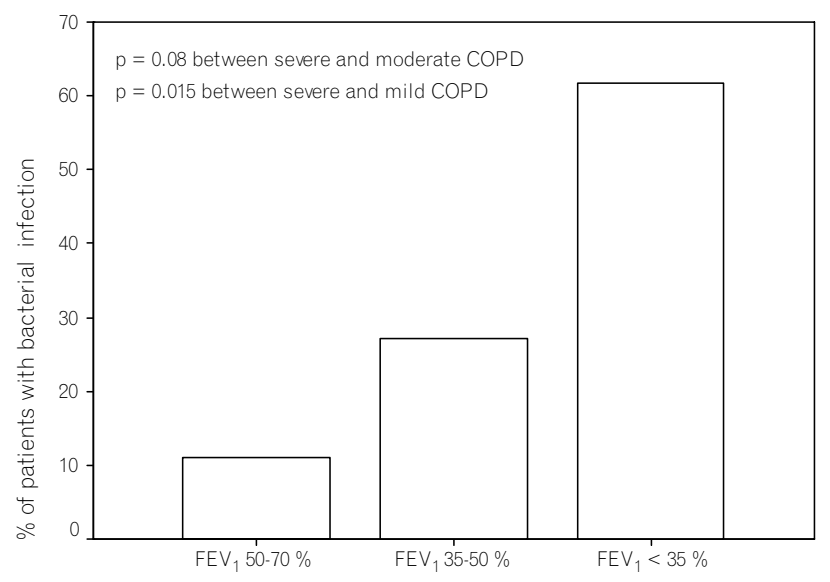

A course of antibiotics or a boost of corticosteroids, prescribed prior to admission, did not influence the outcome of sputum cultures. $52.4 \%$ of patients who had received antibiotics and $51.7 \%$ of patients who had received a boost of corticosteroids prior to admission had bacterial infection.

No difference in duration of hospitalization could be demonstrated between patients with and without bacterial infection on admission.

In the group of patients with positive sputum culture $(n=85)$, 10 patients were transferred to ICU of whom 5 patients were intubated for mechanical ventilation while in the negative sputum culture group $(n=86) 7$ patients were transferred to ICU of whom 4 required mechanical ventilation.

Admission to ICU was not related to the presence and type of bacterial infection during exacerbation.

In comparison of patients with Pseudomonas infection to those with $\mathrm{H}$. influenzae or S. pneumoniae infections, it was demonstrated that the former group was significantly older; other parameters were not different between these groups.

\section{Lung function parameters}

Based on lung function data obtained prior to discharge from the hospital, marked airflow obstruction was present in the majority of the patients: 81 patients $(47 \%)$ had severe COPD 55 patients (32\%) had moderate COPD and 22 patients ( 13 $\%)$ had mild COPD, according to ATS staging. In 12 patients, no spirometric data could be obtained during hospital stay. 10 of these patients had an established diagnosis of severe COPD based on clinical records. In 2 patients, the diagnosis of COPD was established on clinical grounds and the information regarding medical 


\section{Bacterial infections in acute exacerbations of COPD}

history as obtained by their general practitioner.

The incidence of bacterial infection was significantly related to the degree of airflow limitation (figure 3): patients with severe COPD had significantly more bacterial infections than patients classified as moderate $(p=0.015)$ or mild COPD. $(p=0.08)$ However, the type of bacteria isolated was not related to the degree of airflow limitation (figure 3).

\section{Discussion}

The present study confirms previous data reporting a higher incidence of bacterial infections in patients with a severe impairment in lung function during hospital admissions for acute exacerbations. However, no relationship between the type of bacteria isolated and the degree of lung function impairment could be demonstrated. Presence of bacterial pathogens was found in $50 \%$ of all admitted patients. No differences in clinical characteristics could be demonstrated between patients with and without isolation of bacterial pathogens neither with the type of bacterial pathogens. Micro-organisms most frequently isolated were Haemophilus influenzae (45\%) and Streptococcus pneumoniae (27\%). Other pathogens isolated were Pseudomonas aeruginosa (15\%), Moraxella catarrhalis (6\%) and Klebsiella pneumoniae (5\%). Presence of bacterial pathogens did not influence the clinical outcome defined by the length of hospital stay and the need for ICU admission.

One of the most important findings in the present study is the relation between the occurrence bacterial infections and the degree of airflow limitation: patients with a lower FEV, had a higher incidence of bacterial infection. This is in line with previous studies on the prevalence of bacteria in stable COPD patients [8]. However, opposite to previously reported data we found no shift in the type of micro-organism isolated in patients with more severely compromised lung function $[12,13]$. Indeed, both Eller and Miravitlles reported in patients with lower $\mathrm{FEV}_{1}$ a higher incidence of Pseudomonas and Enterobacteriacae in their sputum. They hypothesized a possible relationship between the decline in lung function and occurrence of Pseudomonas and other Gram negative species in sputum. Our data were even obtained in patients with more severely compromised lung function.

The incidence of Pseudomonas infections in our study was comparable with the data reported by Miravitlles, but markedly lower than in the study of Eller. Further data with more specific characterization of the patients suffering from acute exacerbations will be required in order to relate these findings to the disease condition itself. Presence of bronchiectasis [19], nutritional status [20], as well as previous use of antibiotics [21] can influence the type and frequency of colonization of the airways in COPD. 
Remarkably, the incidence of positive sputum cultures in half of our patient population was quite similar to previous data $[2,10,14,15]$. In exacerbated outpatients, prevalence of positive bacterial cultures, obtained by protected specimen brush, was $51.6 \%$ [10]. In a bronchoscopic study of 54 mechanically ventilated patients with acute exacerbation of COPD, bacterial infection was found in $50 \%$ of patients [14]. In another study among mechanically ventilated patients using protected specimen brush, Fagon et al. reported distal bronchial infection in $50 \%$ of patients during acute exacerbation [22]. In a large study of 1016 in-patients with acute exacerbation respiratory infection was found in $47 \%$ of sputum cultures [15]. Therefore, it seems a consistent finding that bacterial infection is present in 50 $\%$ of exacerbations, in hospital as well as in outpatient populations.

However, it remains difficult to distinguish bacterial colonization of the lower airways from an actual bacterial infection. In a bronchoscopic study among 18 stable COPD patients, using protected specimen brush samples, Cabello et al. found that the distal airways were colonized (defined as $>=10^{2} \mathrm{cfu} / \mathrm{ml}$ ) in $83 \%$ of COPD patients [11]. Quantitative cultures of BAL samples in the same patient group remained negative in $88 \%$, suggesting colonization rather than infection. In another study using protected specimen brush samples, Monso et. al found positive cultures in $25 \%$ of stable COPD patients and $52 \%$ of exacerbated COPD patients [10]. In the stable COPD patients, concentrations of bacteria were much lower, again indicating colonization instead of bacterial infection.

Besides differences in quantity of isolated micro-organisms, recent studies suggest differences in the level of inflammation in stable COPD patients as well as during exacerbations between both conditions of presence of bacteria in the airways. Bresser et al. demonstrated that persisting strains of $\mathrm{H}$. influenzae induce a weaker inflammatory response than non-persisting strains [23], while the local airway inflammation in COPD patients clinically infected with $\mathrm{H}$. influenzae is much more pronounced [24]. Sethi et al demonstrated that exacerbated chronic bronchitis patients with $\mathrm{H}$.influenzae and $\mathrm{M}$. catharralis isolated from sputum had increased airway inflammation when compared to pathogen-negative exacerbations [25]. Other studies indicate that bacterial infection contributes significantly to the inflammatory process in the airways. In acute exacerbations of COPD associated with $\mathrm{H}$. influenzae infection, an increase in sputum IL-8, TNF- $\alpha$ and neutrophil elastase was found in contrast to exacerbations without bacterial infection, indicating increased airway inflammation in the presence of $\mathrm{H}$. influenzae [26]. This inflammatory process in the airway continues despite antibiotic and steroid therapy for exacerbations, as was demonstrated by unchanging sputum cell counts during the course of an exacerbation [27].

However, the possible role of bacterial infections in the pathogenesis of acute exacerbations is still incompletely understood.

In the present study, the outcomes in terms of hospital stay or subsequent need for ICU admission were not related to the presence or the type of bacterial 


\section{Bacterial infections in acute exacerbations of COPD}

infections. Our findings are in line with the disputed role of antibiotics in the treatment of acute exacerbations. Studies concerning the effect of antibiotic treatment have shown either no benefit or minimal clinical benefit from antibiotic treatment [7]. Meta-analysis of randomized controlled clinical trials demonstrated a clinically unimportant improvement in patients receiving antibiotics [28]. A recently performed meta-analysis on antibiotic treatment in acute exacerbations concluded that patients with more severe exacerbations are more likely to benefit from antibiotic treatment [29].

A recent study in exacerbated outpatients by Adams et al. demonstrated lower relapse rates in outpatients treated with antibiotics, compared to patients untreated with antibiotics, but even higher relapse rates in patients treated with Amoxicillin [9]. These results indicate that type of antibiotics used to treat acute exacerbations have an impact on the failure rate.

In this respect it is interesting to compare exacerbations of COPD to ventilatorassociated pneumonia (VAP), a combination of clinical parameters in mechanically ventilated patients, that is presumed to be caused by bacteria and treated with antibiotics. In a recent bronchoscopic study among VAP patients, using protected specimen brush and BAL samples, bacterial infection was not proven in $43 \%$ of patients and withholding antibiotics in these patients had no effect on outcomes [30]. In another bronchoscopic study of VAP patients, the bacterial burden was not correlated with inflammatory mediators or with patient outcome [31].

Some limitations of the present study need further discussion. Spontaneously expectorated sputum was used for microbiological sampling, in contrast to for example induced sputum or bronchoscopic sampling. The suitability of sputum samples to analyze bacterial infection is a matter of debate. Recently a good concordance between the results of two sampling methods, valid sputum samples and quantitative protected specimen brush, was shown [32]. At present, especially in patients with severe COPD, spontaneously expectorated sputum seems a clinically reliable method to assess presence and type of bacterial infections when other methods have to be avoided.

The present study has not included data on viral infections or infections with atypical organisms like Chlamydia and Mycoplasma. The presence of viral infection and Mycoplasma and Chlamydia during COPD exacerbations has been evaluated in different studies. In an outpatient population of mild to moderate COPD exacerbations, incidence of Chlamydia pneumoniae was found to be $4 \%$ [33]. In a study of mechanically ventilated patients with acute exacerbations of COPD, an incidence of $\mathrm{C}$. pneumoniae of $18 \%$ was found [14]. The same study found no evidence for Mycoplasma pneumoniae infection and an incidence of $16 \%$ for respiratory viruses. In a Turkish study of outpatients with acute exacerbation, incidence of C. pneumoniae was $22 \%$ and $\mathrm{M}$. pneumoniae incidence was $6 \%$ [34]. So far, most studies concerning respiratory pathogens have been performed in either outpatient populations with mild exacerbation, or mechanically ventilated 
patients with severe exacerbations in an ICU setting. Neither of these populations can be considered representative for the majority of admissions for COPD exacerbations in a clinical setting, as in the present study. Therefore, the role of these non-bacterial pathogens in the pathogenesis of COPD exacerbations needs further exploration.

The present study indicates that the role of bacterial infections in the complex pathogenesis of COPD exacerbations as well as its clinical significance needs further evaluation in the near future and can not be restricted to the limited discussion of the role of antibiotic treatment in the management of these acute events in the clinical course of patients with acute exacerbations. Especially, the role of bacterial infections in relation to the local and systemic inflammatory response has to be unraveled. The impact of acute exacerbations on the socioeconomic burden of this disease as well as on the health status of the individual patient urgently needs to prioritize acute exacerbations in order to better understand the natural course of COPD. 


\section{References}

1. Rutten - van Molken MPH, Postma MJ, van Genugten MLL, Joore MA, Leidl R, Jager JC. Current and future medical costs of asthma and chronic obstructive pulmonary disease in the Netherlands. Respir Med 1999;93:779-787

2. Seemungal TAR, Donaldson GC, Paul EA, Bestall JC, Jeffries DJ, Wedzicha JA. Effect of exacerbation on quality of life in patients with chronic obstructive pulmonary disease. Am J Resp Crit Care Med 1998;157: 1418-1422

3. Burge PS, Calverley PMA, Jones PW, Spencer S, Anderson JA, Marlen TK. Randomized, double blind, placebo controlled study of fluticasone propionate in patients with moderate to severe chronic obstructive pulmonary disease: the ISOLDE trial. BMJ 2000;320:1297-1303

4. Compertz S, Bayley DL, Hill SL, Stockley RA. Relationship between airway inflammation and the frequency of exacerbations in patients with smoking related COPD. Thorax 2001;56:36-41

5. Bhowmik A, Seemungal TAR, Sapsford RJ, Wedzicha JA. Relation of sputum inflammatory markers to symptoms and lung function changes in COPD exacerbations. Thorax 2000;55:114-120

6. Murphy TF, Sethi S. Bacterial infection in Chronic Obsructive Pulmonary Disease. Am Rev Resp Dis 1992;46: 1067-1083

7. Hirschmann JV. Do bacteria cause exacerbations of COPD? Chest 2000:118:193-203

8. Murphy TF, Sethi S, Niederman MD. The role of bacteria in exacerbations of COPD. Chest 2000;118:204-209

9. Adams SG, Melo J, Luther MS, Anzueto A. Antibiotics are associated with lower relapse rates in outpatients with acute exacerbations of COPD. Chest 2000;117:1345-1352

10. Monso E, Ruiz J, Manterola J, et al. Bacterial infection in Chronic Obstructive Pulmonary Disease. A study of stable and exacerbated outpatients using the protected specimen brush. Am J Resp Crit Care Med 1995;152:1316-20

11. Cabello H, Torres A, Celis R, et al. Bacterial colonization of distal airways in healthy subjects and chronic lung disease: a bronchoscopic study. Eur Resp | 1997;10:1137-1144

12. Eller J, Ede A, Schaberg T, Niederman MS, Mauch H, Lode H. Infective exacerbations of chronic bronchitis. Relation between bacterial etiology and lung function. Chest 1998;113:1542-48

13. Miravitlles M, Espinosa C, Fernandez-Laso E, Martos JA, Maldonado JA, Gallego M. Relationship between bacterial flora in sputum and functional impairment in patients with acute exacerbations of COPD. Chest 1999;116:40-46

14. Soler N, Torres A, Ewig S, et al. Bronchial microbial patterns in severe exacerbations of Chronic Obstructive Pulmonary Disease (COPD) requiring mechanical ventilation. Am J Resp Crit Care Med 1998;157:1498-1505.

15. Connors AF, Dawson NV, Thomas C, et al. Outcomes following acute exacerbation of severe chronic obstructive lung disease. Am J Resp Crit Care Med 1996;154:959-67

16. American Thoracic Society. Standards for the diagnosis and care of patients with chronic obstructive pulmonary disease. Am Rev Respir Dis 1995; 152:S78-83.

17. Global Initiative for Chronic Obstructive Pulmonary Disease. Global Strategy for the Diagnosis, Management and Prevention of Chronic Obstructive Pulmonary Disease. NHLBI/ WHO Workshop Report.

18. Isenberg HD, Baron EJ, Damato RF, et al. Recommendations for the isolation of bacteria from clinical specimens. In: Balows A, Hausler WJ Jr, Herrmann KL et al, eds. Manual of clinical microbiology. Washington, DC: American Society for Microbiology, 1991:231-37

19. Pang JA, Cheng A, Chan HS, Poon D, French G. The bacteriology of bronchiectasis in Hong Kong investigated by protected catheter brush and bronchoalveolar lavage. Am Rev Resp Dis 1989;139 (1):14-17

20. Niederman MS, Mantovani R, Schoch P, Papas J, Fein AM. Patterns and routes of tracheobronchial colonization in mechanically ventilated patients. The role of nutritional 
status in colonization of the lower airway by Pseudomonas species. Chest 1989;95:155-161

21. Vincent JL. Microbial resistance: lessons from the EPIC study. Intensive Care Med 2000; 26 : S3-S8

22. Fagon J-Y, Chastre J, Trouillet J-L, et al. Characterization of distal bronchial microflora during acute exacerbation of chronic bronchitis. Am Rev Resp Dis 1990;142:1004-1008

23. Bresser $P$, van Alphen L, Habets FJM, et al. Persisting Haemophilus influenzae strains induce lower levels of interleukin- 6 and interleukin-8 in $\mathrm{H}_{2} 92$ lung epithelial cells than nonpersisting strains. Eur Resp | 1997;10:2319-2326

24. Bresser P, Out T, van Alphen L, Jansen HM, Lutter R. Airway inflammation in nonobstructive and obstructive chronic bronchitis with chronic Haemophilus influenzae airway infection. Am J Resp Crit Care Med 2000;162:947-852

25. Sethi S, Muscarella K, Evans N, Klingman KL, Grant BJ, Murphy TF. Airway inflammation and etiology of acute exacerbations of chronic bronchitis. Chest 2000;118:1557-1565

26. Sethi S, Evans N, Wrona C, Murphy TF. Airway inflammation in COPD: effects of clinical status and bacterial infection. ATS 2000 A 815.

27. Downey D, Brockbank S, Ennis M, Elborn S. The effect of infective exacerbations on chronic obstructive pulmonary disease on sputum cell counts. ATS 2000 A 821.

28. Saint S, Bent S, Vittinghoff E, Grady D. Antibiotics in chronic obstructive pulmonary disease exacerbations:a meta-analysis. JAMA 1995;273:957-960

29. Bach PB, Brown C, Gelfand SE et al. Management of acute exacerbations of chronic obstructive pulmonary disease: a summary and appraisal of published evidence. Ann Int Med 2001; 134 (7):600-20

30. Bonten MJM, Bergmans DCJJ, Stobberingh EE, et al. Implementation of bronchoscopic techniques in the diagnosis of ventilator- associated pneumonia to reduce antibiotic use. Am J Resp Crit Care Med 1997;156:1920-1824

31. Froon AHM, Bonten MJM, Gaillard CA, et al. Prediction of clinical severity and outcome of ventilator-associated pneumonia. Am / Resp Crit Care Med 1998;158:1026-1031

32. Soler N, Torres A, Celis R, et al. Bronchial microbial patterns in non-severe exacerbations of COPD: a bronchoscopic study. ATS 2000

33. Blasi F, Legnani D, Lombardo VM, et al. Chlamydia pneumoniae infection in acute exacerbations of COPD. Eur Resp / 1993;6:19-22

34. Mogulkoc N, Karakurt S, Isalska B, et al. Acute purulent exacerbation of Chronic Obstructive Pulmonary Disease and Chlamydia pneumoniae infection. Am J Resp Crit Care Med 1999;160:349-353 

CHAPTER 3

Longitudinal follow-up of systemic inflammation after acute exacerbations of COPD

Respiratory Medicine 2007: 101 (17):2409-2415

KH Groenewegen

MA Dentener

EFM Wouters 


\section{Abstract}

\section{Background}

Acute exacerbations are important in the clinical course of COPD, yet the underlying mechanisms are poorly understood. Systemic inflammation is now considered as an important component in the disease process. In this study we evaluated longitudinally the systemic inflammation during hospital treatment for acute exacerbation and after clinical recovery.

\section{Methods}

Blood was collected on day 0, 1, 4 and 8 in 21 patients admitted for an acute exacerbation of COPD and at 1 month, 3 months and 6 months after discharge. Systemic inflammation was determined by measurement of the pro-inflammatory markers interleukin (IL)-6, soluble tumor necrosis factor (TNF) receptors STNFR55 and STNFR75, the anti-inflammatory mediator sIL-1RII, and Bactericidal Permeability Increasing protein (BPI) as a marker of neutrophil activation. In addition, plasma level of Trolox antioxidant capacity (TEAC) was determined. Healthy age-matched controls were measured for the same markers at one timepoint.

\section{Results}

All inflammatory markers analyzed were elevated on first day of admission for exacerbation of COPD, as compared to healthy controls. During treatment, levels of IL-6, and STNFR75 rapidly decreased, whereas STNFR55 and BPI remained elevated. Moreover, sIL-1RII and TEAC increased during first 8 days of treatment. In the stable condition all inflammatory markers returned to values comparable to healthy controls, with the exception of BPI which remained persistently elevated compared to healthy controls.

\section{Conclusion}

This study clearly demonstrates upregulation of systemic inflammation in acute exacerbations of COPD. Attenuation of systemic inflammation offers new perspectives in the management of COPD patients and to reduce the burden of exacerbations. 


\section{Introduction}

Chronic obstructive pulmonary disease (COPD) is a major cause of morbidity and mortality throughout the world. Hospital admission for acute exacerbations forms the major component of the economical burden of COPD in western countries[1]. Generally, acute exacerbations are characterized by varying combinations of symptoms as increase in cough, sputum production, worsening of dyspnoea or changes in sputum purulence. Despite the important role of these acute exacerbations in the clinical course of COPD, underlying pathogenic mechanisms are poorly understood.

Inflammation is a prominent feature of COPD as shown by the presence in the airways of activated neutrophils and macrophages and increased numbers of inflammatory mediators $[2,3]$. Exacerbations of COPD are generally considered to reflect a flare-up of these underlying inflammatory processes, although information about the inflammatory response in the lungs, particularly during severe exacerbations, is still limited. Recent studies showed increased airway inflammation during exacerbations, as measured by increased sputum neutrophil, eosinophil and lymphocyte counts, increased sputum myeloperoxidase (MPO) and IL-8, and activation of NF-kappa B in sputum macrophages, compared to the stable phase[4-7]. Besides the abnormal local inflammatory response, systemic inflammation is now considered an important component in the disease process. This systemic inflammation is related to the systemic consequences of COPD, including involuntary weight loss, muscle dysfunction and wasting, and increased cardiovascular morbidity[8]. Increased systemic inflammation during acute exacerbations of COPD is indicated by increased levels of the acute phase proteins C-Reactive Protein (CRP) and fibrinogen, elevated levels of cytokines as IL-6, and the neutrophil marker MPO[1] [-1 In addition, the anti-inflammatory mediator SIL-1RII was shown to increase progressively during treatment of exacerbation [12]. Recently Hurst et al. published an extensive evaluation of a panel of potential biomarkers at exacerbation, from which CRP was the most selective biomarker[13]. Moreover, a decreased plasma anti-oxidant capacity was observed during exacerbations[14]. Most of the presently available data are obtained in cross-sectional studies not taking into account the time to recovery to the baseline stable state. The aim of our study was to evaluate longitudinally the course of a panel of systemic inflammatory mediators, and the anti-oxidant capacity, during hospital treatment for acute exacerbation and after clinical recovery, in patients with severe COPD, as a control group healthy age-matched control subjects were analysed. Our hypothesis was demonstration of a differential time response pattern of a panel of inflammatory mediators as well as of anti-oxidative capacity during and in the recovery phase of acute exacerbations and assessment of COPD related disease marker in the stable disease condition. 


\section{Material and Methods}

\section{Study population \\ Patients with acute exacerbation}

The study population consisted of 21 patients consecutively admitted to the University Hospital Maastricht for an acute exacerbation of COPD. COPD was defined as forced expiratory volume in one second $\left(\mathrm{FEV}_{1}\right)<80 \%$ predicted for age and height, $\beta 2$ agonist reversibility of $<11 \%$ of predicted and airflow obstruction evidenced by a ratio of $\mathrm{FEV}_{1}$ to forced vital capacity $(\mathrm{FVC})$ of $<0.70$ of predicted according to ATS criteria[15]. Patients with important co-morbid conditions as malignancies, diabetes mellitus, thyroid and cardiovascular diseases were excluded from the study in order to avoid non-COPD related interfering factors. Patients already treated with antibiotics and/or corticosteroid therapy on admission were also excluded from the study. Furthermore, if patients had a recurrent exacerbation within the follow-up period of 6 months, they were excluded from the study. The presence of an acute exacerbation was defined as the presence of one or more the following symptoms: (1) increased cough and sputum volume, (2) increased sputum purulence, and (3) increased dyspnea. All 21 patients were classified as a type 1 exacerbation, based on the Anthonisen criteria[16]. The patients were treated according to a standard protocol with nebulized salbutamol and ipratropiumbromide, intravenous prednisolone in a dosage of $0.5 \mathrm{mg} / \mathrm{kg}$. Duration of intravenous therapy was 4 days, on day 4 patients were switched to an oral tapering schedule of prednisolone. Specific antibiotic treatment was administered to patients in case of positive sputum cultures. A sputum culture was considered as positive (proving bacterial infection) if significant bacterial growth was present as defined by the number of bacteria (higher than 105 colony forming units = $\mathrm{cfu}$ ) in a representative sample. Antibiotic treatment was based on resistance assessment of identified bacteria. Patients were evaluated for inflammatory markers on day o (admission) before start of treatment, day 1 , day 4 and day 8 of hospitalisation for acute exacerbation. Patients were discharged based on clinical judgment of an experienced, independent chest physician.

After discharge, patients were evaluated after 1 month, 3 months and 6 months. Patients with symptoms of acute exacerbation, based on the Anthonisen criteria, were excluded from the study. The study was approved by the medical ethical committee of the University hospital Maastricht and all participants have given their written informed consent.

\section{Healthy controls}

The healthy control group consisted of 20 subjects who were age and gender matched and without any evidence of COPD based on questionnaires and lung function tests. Control subjects without manifested morbid conditions were chosen to find out COPD related changes in systemic mediators during the 
recovery period and after the supervised 6 month period when the disease was considered stable.

\section{Lung function measurements}

On admission for an acute exacerbation, arterial blood gases at rest were assessed by puncture of the radial artery during room air breathing. On days 1, 4 and 8 of admission and 1, 3 and 6 months after discharge, forced expiratory volume in 1 second $\left(F E V_{1}\right)$ and inspiratory vital capacity (IVC) were calculated from the flow-volume curve, using a portable pneumotachograph (Jaeger instruments, Würzburg, Germany). Flow-volume curves were performed at a standardized time point, one hour after medication. Lung function values were expressed as a percentage of the reference values.

\section{Measurement of inflammatory parameters and TEAC in plasma}

Blood was collected in EDTA containing tubes. (Sherwood Medical, St. Louis, MO, US) The blood samples were put on ice immediately and kept on ice during the entire preparation. Plasma was separated by centrifugation at $167 \mathrm{~g}$ for 10 minutes at $4^{\circ} \mathrm{C}$ and two aliquots were centrifuged at $3000 \mathrm{rpm}$. Supernatants were collected and stored at $-70^{\circ} \mathrm{C}$ until analysis for cytokines and anti-oxidants. Inflammatory mediators were measured in plasma by sandwich enzyme-linked immunosorbent assay (ELISA), as described previously[12]. Briefly, for detection of STNFR55 and sTNFR75, monoclonal antibodies MR1-1 and MR2-2 were used for coating and specific biotin labelled polyclonal rabbit anti-human (h)-sTNF-R IgG as detector reagents. For sIL-1RII measurements, plates were coated with monoclonal antibody 8.5 against shIL-1RII and detection was carried out with a biotinylated polyclonal rabbit anti-shIL-1RII IgG. For IL- 6 and BPI measurements, plates were coated with murine monoclonal antibody $5 \mathrm{E} 1$ and human $\mathrm{BPI}$ specific monoclonal antibody $4 \mathrm{E} 3$, respectively. Biotinylated polyclonal rabbit anti-human IL-6 antiserum and biotinylated polyclonal rabbit anti-human BPI IgC were used as detection antibodies. All plasma samples were measured in the same run. For analysis of TEAC, plasma was deproteinized. An aliquot of 150 microliters of plasma was deproteinized by mixing with an equal volume of 10\% (w/v) TCA, and after centrifugation for 5 min at 14,000 rpm the supernatant was used for spectrophotometrical analysis. TEAC was determined enzymatically (Sigma) as described by Van den Berg et al[17].

\section{Statistics}

Differences in parameters within an individual patient between two time points were compared using Wilcoxon matched pairs signed rank test. Because we have performed planned comparisons in a relatively small small sample size, no multiple comparisons tests were performed[18]. Differences between patients 
and controls were measured using the Mann-Whitney $U$ test. Significance was determined at the $5 \%$ level. Data were analyzed using the SPSS for Windows statistical package (version 12.0, SPSS Inc, Chicago, IL, US). Data were expressed as mean $( \pm S D)$.

\section{Results}

\section{Clinical parameters}

The characteristics of the COPD patients on admission for an acute exacerbation and healthy controls are summarized in table 1. On average, the duration of admission was 9.4 days (range 5-14). There was a small improvement in FEV, during the clinical course of acute exacerbation, which was not statistically significant. (from $0.90 \mathrm{~L} \pm 0.03 \mathrm{~L}$ on admission to $0.97 \mathrm{~L} \pm 0.04 \mathrm{~L}$ on day 8; $p=$ 0.19 ) There was a significant improvement in $\mathrm{PaO}_{2}$ during admission (from 53.9 $\mathrm{mm} \mathrm{Hg} \pm 10.2 \mathrm{~mm} \mathrm{Hg}$ on admission to $64.7 \mathrm{~mm} \mathrm{Hg} \pm 8.7 \mathrm{~mm} \mathrm{Hg}$ on day 8; $p=$ $0.001) . \mathrm{PaCO}_{2}$ values did not change significantly (data not shown).

12 of 21 patients had a positive sputum culture, 9 patients with 1 micoorganism and 3 patients with 2 micro-organisms. Micro-organisms cultured were S. pneumonia (6 patients), H. influenzae (8 patients), Moraxella catarrhalis (1 patient). 3 patients had both $\mathrm{H}$. influenzae and $\mathrm{S}$. pneumoniae cultured from their sputum. No differences existed in any of the measured parameters between patients with and without positive bacteriological sputum cultures.

\section{Inflammatory markers}

Figure 1 shows the time course of the inflammatory mediators on day $0,1,4$ and 8 during admission for an acute exacerbation of COPD and at 1 month, 3 months and 6 months after discharge. As comparison, levels were also measured in healthy controls. The cytokine IL- 6 was not detectable in the healthy control subjects with the assay used, therefore, detection limit of the assay $(20 \mathrm{pg} / \mathrm{ml}$ ) was indicated in the figure. On day of admission, IL-6 was significantly enhanced in patients as compared to healthy controls $(p=0.033)$. After one day of treatment levels dropped strongly (day o to day $1: p=0.043$ ) and were no longer different from control subjects. Surprisingly, enhanced levels of IL-6 were seen 1 month after discharge, however this enhancement was not significant. Likewise, the STNFR75 was enhanced at admission of exacerbation, and declined thereafter (day 0 to day $1: p=0.01$; day 1 to day 4 : $p=0.019$ ). After 1 months of discharge increased levels of sTNFR75 were observed (day 8 to month 1: $p=0.028$ ), and declined thereafter (month 1 to month 6: $p=0.013$ ). Soluble TNFR55 was elevated during all time points of acute exacerbation of COPD, with exception of the day 4 time point (day 1 to day 4: $p=0.004$ ). After 1,3 and 6 months levels were no longer different as compared to healthy controls. The anti-inflammatory marker 
Table 1. Characteristics of COPD patients with acute exacerbation and healthy controls.

Values of patients are values on admission. Data are presented as mean \pm SD.

\begin{tabular}{lccc}
\hline & $\begin{array}{c}\text { Patients } \\
(\mathbf{n = 2 1 )}\end{array}$ & $\begin{array}{c}\text { Controls } \\
(\mathbf{n = 2 0})\end{array}$ & p-value \\
\hline Age yrs & $66.7 \pm 9.0$ & $60.6 \pm 3.4$ & $\mathrm{NS}$ \\
Sex F/M & $6 / 15$ & $6 / 14$ & $\mathrm{NS}$ \\
$\mathrm{BMI}(\mathrm{kg} / \mathrm{m} 2)$ & $23.5 \pm 4.7$ & $25.9 \pm 2.7$ & $\mathrm{NS}$ \\
FEV1\% pred & $35.0 \pm 14.4$ & $108.2 \pm 14.2$ & 0.0001 \\
IVC \% pred & $62.9 \pm 22.9$ & $114.8 \pm 12.4$ & 0.0001 \\
Smokers current/ex/none & $7 / 13 / 1$ & $1 / 11 / 8$ & $\mathrm{NS}$ \\
Packyears & $40 \pm 20$ & $20 \pm 15$ & 0.0001 \\
Inhaled steroids Y/N & $19 / 2$ & $0 / 20$ & 0.0001 \\
Bacterial infection $\mathrm{Y} / \mathrm{N}$ & $12 / 9$ & $\mathrm{NA}$ & \\
PaO2 mm Hg & $53.2 \pm 10.5$ & $\mathrm{NA}$ & \\
PaCO2 mm Hg & $47.2 \pm 16.5$ & $\mathrm{NA}$ & \\
\hline
\end{tabular}

Figure 1. Course of cytokines during and after acute exacerbation of COPD.
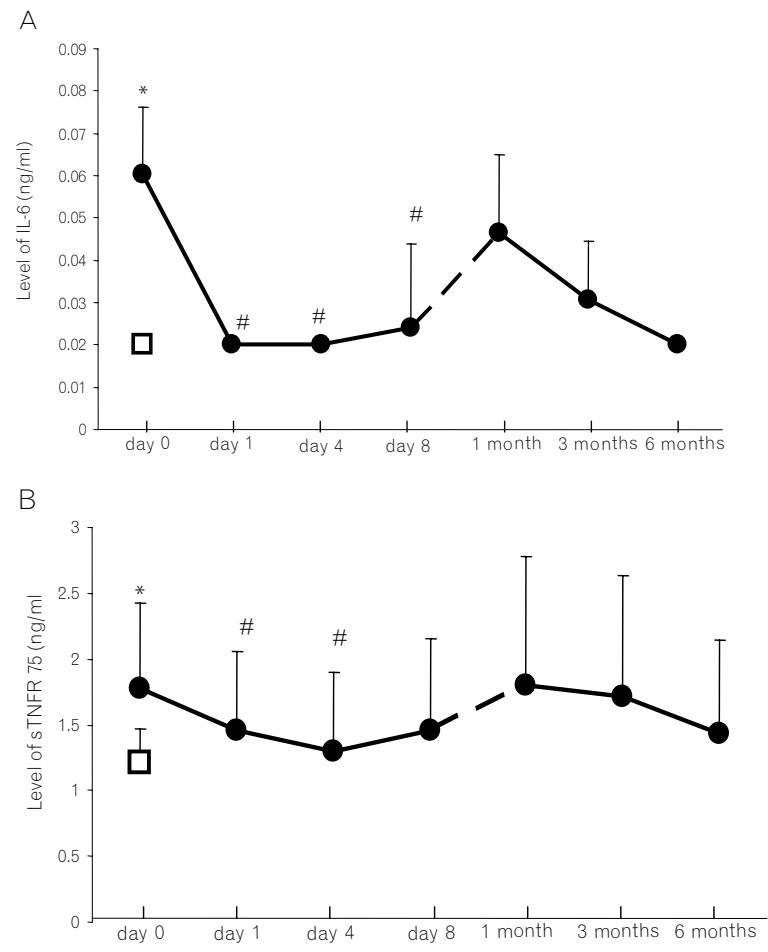
Figure 1. Continued.
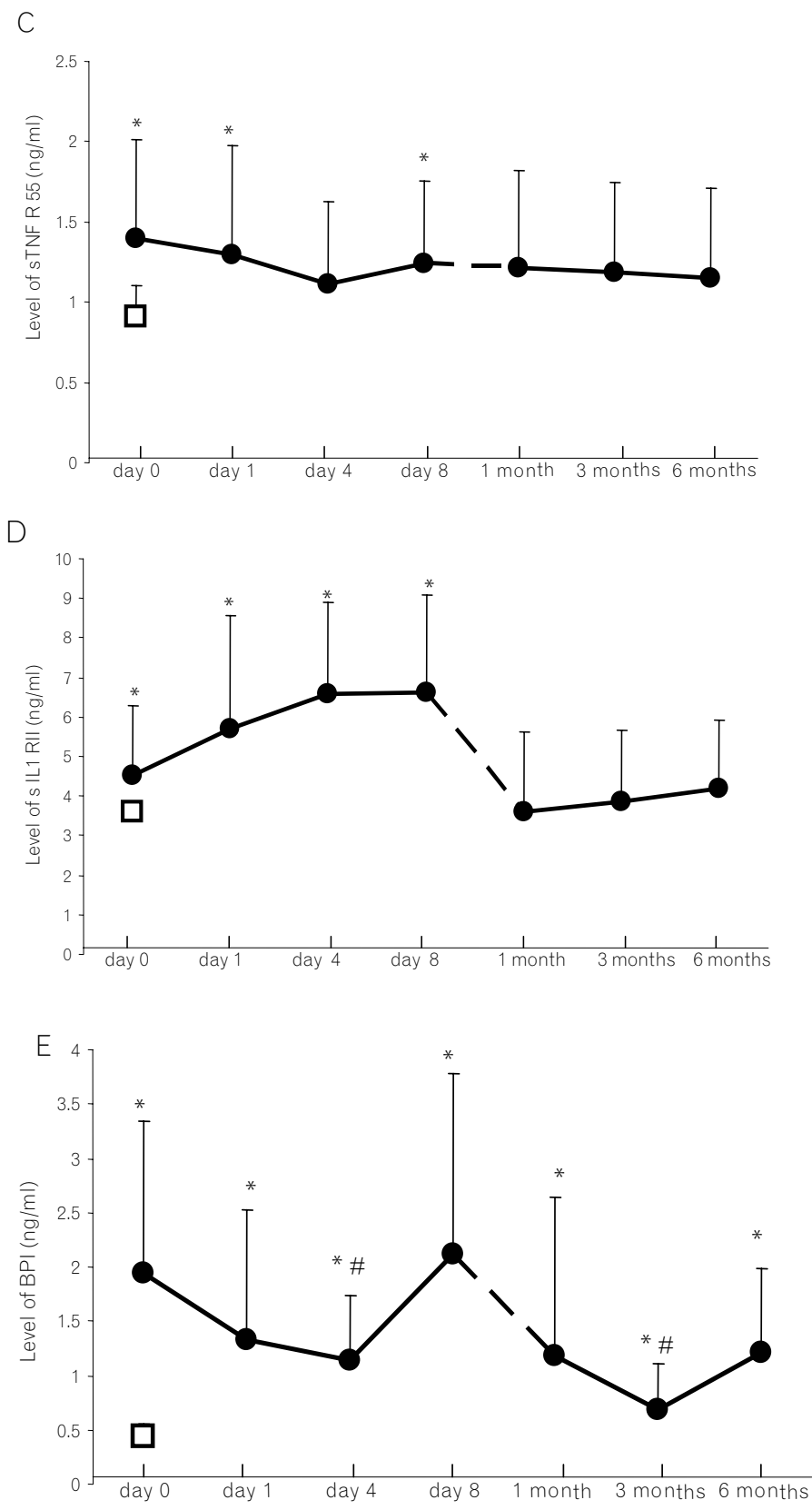
Figure 2. Course of TEAC during and after acute exacerbations of COPD.

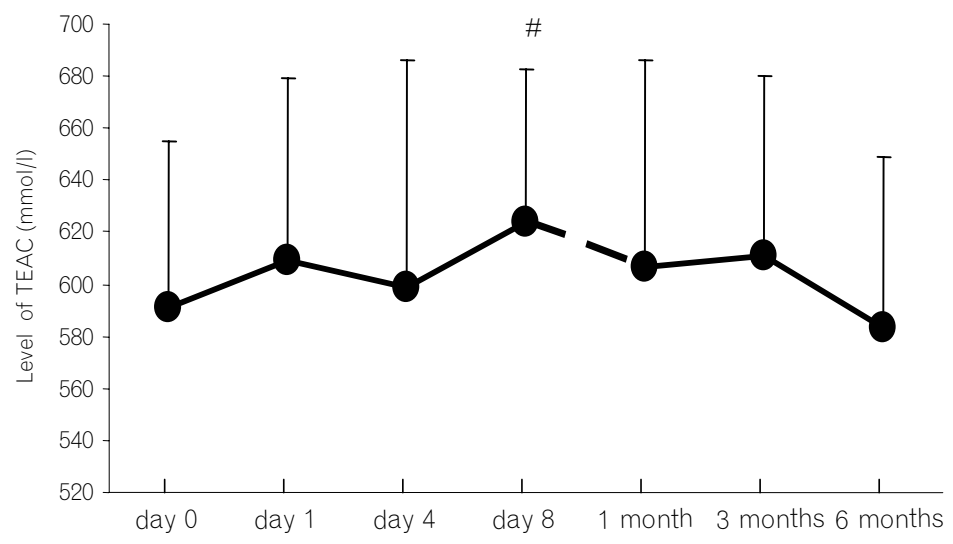

SIL-1RII was significantly increased on the day of admission and increased further during treatment of exacerbation (day o to day $1: p=0.031$; day 1 to day $4: p=$ $0.038)$. In the recovery period SIL-1RII decreased to levels comparable to healthy controls (day 8 to 1 month; $p=0.004$ ). Also the neutrophil marker BPI was elevated on admission $(p=0.0001$ ), and remained elevated during and after recovery of exacerbation, as compared to control subjects. Highest BPI levels were seen on day 8 and lowest at 3 months after exacerbation (day 8 to month $3: p=0.01$ ).

\section{Anti-oxidant capacity}

The change in levels of systemic anti-oxidant TEAC during treatment of acute exacerbation and after recovery is shown in figure 2 . There was a significant increase in TEAC levels during treatment of acute exacerbation, compared to admission values (day o to day 8: $p=0.003$ ). After discharge levels decreased significantly (month 3 to month $6: p=0.017$ ).

\section{Discussion}

This study showed elevated levels of systemic inflammatory markers IL-6, sTNFR55, sTNFR75, and sIL-1RII as well as neutrophil protein BPI, on admission for acute exacerbation of COPD. During treatment, there was a rapid decrease in IL-6, and sTNFR75, whereas in contrast sTNFR55 and BPI remained elevated. Moreover, sIL-1RII and TEAC increased during first 8 days of treatment. In the stable condition, inflammatory markers returned to values comparable to healthy 
controls, with the exception of BPI which remained persistently elevated compared to healthy controls.

Growing evidence exists about the upregulation of systemic inflammation, as manifested by an elevated acute phase response, as part of the underlying pathogenetic processes ongoing during acute exacerbations[19]. In this study elevated levels of IL- 6 were found on admission for an acute exacerbation, compared to healthy controls. During recovery and follow-up, IL-6 is in the same range as in healthy controls, suggesting a short flare-up of systemic inflammation at the beginning of the exacerbation. IL- 6 is the most important cytokine in the hepatic synthesis of acute phase proteins. Moreover, IL-6 is important in regulating levels of fibrinogen, the precursor to fibrin in the coagulation cascade. Elevated fibrinogen levels and IL- 6 are associated with increased cardiovascular mortality and morbidity[20, 21]. It has already been demonstrated that during acute exacerbation levels of fibrinogen and IL-6 rise further[22]. In this way, increased systemic inflammation can predispose to cardiovascular events.

TNF $\alpha$ is a pro-inflammatory cytokine, which has been found in increased levels in airways and circulation of COPD patients[23-25]. TNF $\alpha$ mediates intracellular signaling via two receptors: a $55 \mathrm{kDa}$ receptor (TNFR55) and a $75 \mathrm{kDa}$ receptor (TNFR75). A variety of inflammatory stimuli, including endogenous TNF $\alpha$ formation is known to induce proteolytic shedding of the extracellular cytokinebinding domains of the TNF receptors[26]. Therefore soluble TNF receptors are considered as pro-inflammatory markers. Earlier studies of our group have shown an increase in soluble TNF receptors during treatment of acute exacerbation[27]. In this study we found that on admission for acute exacerbation, before start of treatment, levels of both sTNF-receptors were elevated. During treatment sTNFR75 levels rapidly decreased whereas STNFR55 remained elevated. One, 3 and 6 months after acute exacerbation, levels of both TNF receptors were not different from healthy controls.

Beside monitoring of the changes in inflammatory mediators to predict diagnosis, outcome and prognosis of acute exacerbations, further studies are needed to integrate these findings in order to better understand ongoing processes during exacerbations of COPD. Acute phase responses are involved in activation of the classical component pathway. Biochemical markers as CRP, IL- 6 and TNF$\alpha$ are generally considered as biochemical markers of endothelial dysfunction; particularly CRP represents one of the strongest independent predictors of vascular morbidity and mortality[28, 29]. The role of systemic inflammation to shift the hemostatic balance to favour the activation of coagulation during acute exacerbation remains largely unexplored during acute exacerbations of COPD[30]. $\mathrm{IL}-1$ is a pro-inflammatory cytokine, and has two receptors: type I receptor which mediates cellular activation and type II receptor which acts as a decoy receptor[12]. Both IL-1 receptors are present in soluble forms and the soluble receptors inactivate sIL-1. In patients with stable COPD normal levels of sIL-1RII have been 
found, which increase during treatment of acute exacerbations, indicating that an upregulation of anti-inflammatory cytokines is present during treatment of COPD exacerbations[12]. In this study we have confirmed and expanded those findings. We found elevated levels of SIL-1 RII on admission for acute exacerbation, before start of treatment. These levels increased further during treatment. This supports the hypothesis that recovery of acute exacerbations is associated with an increase in anti-inflammatory capacity. After a follow-up period of 1,3 and 6 months, sILIRII levels are comparable to healthy controls. Future studies should include the course of other anti-inflammatory mediators such as IL-10 in the course of acute exacerbation. Modulation of anti-inflammatory effects can contribute to fasten the recovery after acute exacerbations.

BPI is stored within the azurophilic granules of neutrophils and can be released upon direct stimulation of the neutrophil by bacterial endotoxins, but also by inflammatory stimuli like TNF- $\alpha$ [31]. Therefore it can be used as a marker for neutrophilic activation. So far no data exist on BPI levels in COPD patients. We demonstrated increased systemic levels of BPI in COPD patients with an acute exacerbation in comparison to healthy control subjects. These data suggest ongoing neutrophilic activation in COPD patients, in clinically stable patients and during acute exacerbations. This is in line with other reports indicating that recruitment and activation of neutrophils is an important event in the pathogenesis of COPD[3, 32]. Elevated levels of serum MPO and serum ECP have been found during exacerbations indicating neutrophilic and eosinophilic activation[9]. Noguera et al. reported that circulating neutrophils from COPD patients produced more reactive oxygen species and the level of expression of several surface adhesion molecules in circulating neutrophils is higher in stable COPD patients than in healthy controls. Interestingly, this difference disappeared during acute exacerbations, suggesting neutrophil sequestration in the pulmonary circulation [33]. A recent study found activated neutrophils in the circulation of stable COPD patients, which correlated with disease severity[34]

The question is whether and to what extent the course of inflammatory parameters was influenced by the anti-inflammatory treatment our patients received. Corticosteroids are potent immunosuppressive agents that are known to affect T-cell mediated inflammation by the inhibition of proliferation and cytokine production, as well as the immuno-stimulatory function of monocytes and macrophages[35]. Moreover, in vitro experiments have shown that exposure of cells to the steroid analogue dexamethasone resulted in enhanced membrane expression of IL-1RII followed by augmented release of the receptor over a period of 18-24 hours[36]. Treatment with systemic steroids thus may be partially responsible for the course of systemic inflammatory mediators that we have observed after admission. In line herewith, studies in cardiac surgery patients have shown a decrease in circulating levels of TNF and IL-6 after treatment with corticosteroids[37, 38]. Since our patients did not receive corticosteroids before 
admission, the enhanced levels of inflammatory parameters observed on day o cannot be attributed to treatment effects. Steroid treatment of patients was, according to a standard schedule, tapered after 4 days during a period of 15 days. Interpretation of the course of systemic inflammatory parameters in the recovery period is therefore also most likely not influenced by steroid therapy.

A number of studies have demonstrated an increased oxidative stress in COPD patients, especially during exacerbations $[14,39,40]$. Our study demonstrates an increase in total anti-oxidant capacity during treatment of acute exacerbation, suggesting that improvement in antioxidant capacity may be a contributing factor in recovery from acute exacerbations.

These results were found in a group of patients with severe COPD, admitted for an acute exacerbation, who remained stable during 6 months of follow-up. We realize this is probably a selected population, since patients with exacerbations in the follow-up period and patients with cardiovascular co-morbidity were excluded. Therefore these results are probably not generally applicable in all populations of COPD patients. Otherwise, our results after the 6 month follow-up period clearly illustrate the importance of careful assessment and monitoring of the clinical condition in the evaluation of inflammatory systemic mediators. This will be particularly important when systemic inflammation will be evaluated as part of the phenotyping of COPD.

In conclusion, this study clearly demonstrated upregulation of systemic inflammation in acute exacerbations of COPD. During recovery pro-inflammatory markers declined whereas levels of sIL-1RII and TEAC increased. In stable state inflammatory markers were no longer enhanced with the exception of neutrophil marker BPI. Attenuation of systemic inflammation offers new perspectives in the management of COPD patients and to reduce the burden of exacerbations. 


\section{References}

1. Rutten van Molken MP, Postma MJ, Joore MA, Van Genugten ML, Leidl R, Jager JC. Current and future medical costs of asthma and chronic obstructive pulmonary disease in The Netherlands. Respir Med. 1999;93(11):779-87.

2. Bhowmik A, Seemungal TA, Sapsford RJ, Wedzicha JA. Relation of sputum inflammatory markers to symptoms and lung function changes in COPD exacerbations. Thorax. 2000;55(2):114-20.

3. Keatings VM, Barnes PJ, Schellenberg D, Pare PD, Weir TD, Spinelli J), et al. Granulocyte activation markers in induced sputum: comparison between chronic obstructive pulmonary disease, asthma, and normal subjects

4. Mercer PF, Shute JK, Bhowmik A, Donaldson GC, Wedzicha JA, Warner JA. MMP-9, TIMP-1 and inflammatory cells in sputum from COPD patients during exacerbation. Respir Res. 2005;6:151.

5. Papi A, Bellettato CM, Braccioni F, Romagnoli M, Casolari P, Caramori G, et al. Infections and airway inflammation in chronic obstructive pulmonary disease severe exacerbations. Am J Respir Crit Care Med. 2006 May 15;173(10):1114-21.

6. Tsoumakidou M, Siafakas NM. Novel insights into the aetiology and pathophysiology of increased airway inflammation during COPD exacerbations. Respir Res. 2006;7:80.

7. Caramori G, Romagnoli M, Casolari P, Bellettato C, Casoni G, Boschetto P, et al. Nuclear localisation of $\mathrm{p} 65$ in sputum macrophages but not in sputum neutrophils during COPD exacerbations. Thorax. 2003 Apr;58(4):348-51.

8. Wouters EF. Chronic obstructive pulmonary disease. 5: systemic effects of COPD. Thorax. 2002 Dec;57(12):1067-70.

9. Fiorini G, Crespi S, Rinaldi M, Oberti E, Vigorelli R, Palmieri G. Serum ECP and MPO are increased during exacerbations of chronic bronchitis with airway obstruction. Biomed Pharmacother. 2000 Jun;54(5):274-8.

10. Schols AM, Buurman WA, Staal van den Brekel A), Dentener MA, Wouters EF. Evidence for a relation between metabolic derangements and increased levels of inflammatory mediators in a subgroup of patients with chronic obstructive pulmonary disease. Thorax. 1996;51 (8):81924.

11. Wedzicha JA, Seemungal TA, MacCallum PK, Paul EA, Donaldson GC, Bhowmik A, et al. Acute exacerbations of chronic obstructive pulmonary disease are accompanied by elevations of plasma fibrinogen and serum IL-6 levels. Thromb Haemost. 2000;84(2):210-5.

12. Dentener MA, Creutzberg EC, Schols AM, Mantovani A, van't Veer C, Buurman WA, et al. Systemic anti-inflammatory mediators in COPD: increase in soluble interleukin 1 receptor II during treatment of exacerbations. Thorax. 2001;56(9):721-6.

13. Hurst JR, Donaldson GC, Perea WR, Wilkinson TM, Bilello JA, Hagan GW, et al. Utility of Plasma Biomarkers at Exacerbation of Chronic Obstructive Pulmonary Disease. Am J Respir Crit Care Med. 2006 Jun 23.

14. Rahman I, Skwarska E, MacNee W. Attenuation of oxidant/antioxidant imbalance during treatment of exacerbations of chronic obstructive pulmonary disease. Thorax. 1997;52(6):5658.

15. ATS. Standards for the diagnosis and care of patients with chronic obstructive pulmonary disease (COPD) and asthma. This official statement of the American Thoracic Society was adopted by the ATS Board of Directors, November 1986. Am Rev Respir Dis. 1987;136(1):22544.

16. Anthonisen NR, Manfreda J, Warren CP, Hershfield ES, Harding GK, Nelson NA. Antibiotic therapy in exacerbations of chronic obstructive pulmonary disease. Ann Intern Med. 


\section{Longitudinal follow-up of systemic inflammation after acute exacerbations of COPD}

1987;106(2):196-204.

17. VandenBerg RHG VH, Bast A. Applicability of an improved Trolox equivalent antioxidant capacity (TEAC) assay for evaluation of antioxidant capacity measurements of mixtures. Food Chemistry. 1999;66:511-7.

18. Rothman KJ. No adjustments are needed for multiple comparisons. Epidemiology. 1990 Jan; $1(1): 43-6$.

19. Dev D, Wallace E, Sankaran R, Cunniffe J, Govan JRW, Wathen CG, et al. Value of C-reactive protein measurements in exacerbations of chronic obstructive pulmonary disease. Respir Med. 1998;92(4)):664-7.

20. Cesari M, Penninx BW, Newman AB, Kritchevsky SB, Nicklas BJ, Sutton-Tyrrell K, et al. Inflammatory markers and cardiovascular disease (The Health, Aging and Body Composition [Health ABC] Study). Am J Cardiol. 2003 Sep 1;92 (5):522-8.

21. Tracy RP. Epidemiological evidence for inflammation in cardiovascular disease. Thromb Haemost. 1999 Aug;82 (2):826-31.

22. Seemungal TA, Donaldson GC, Bhowmik A, Jeffries DJ, Wedzicha JA. Time course and recovery of exacerbations in patients with chronic obstructive pulmonary disease. Am J Respir Crit Care Med. 2000;161(5):1608-13.

23. Aaron SD, Angel JB, Lunau M, Wright K, Fex C, Le Saux N, et al. Granulocyte Inflammatory Markers and Airway Infection during Acute Exacerbation of Chronic Obstructive Pulmonary Disease. Am J Respir Crit Care Med. 2001;163(2):349-55.

24. Keatings VM, Collins PD, Scott DM, Barnes PJ. Differences in interleukin-8 and tumor necrosis factor-alpha in induced sputum from patients with chronic obstructive pulmonary disease or asthma. Am J Respir Crit Care Med. 1996;153(2):530-4.

25. Takabatake N, Nakamura H, Abe S, Inoue S, Hino T, Saito H, et al. The relationship between chronic hypoxemia and activation of the tumor necrosis factor-alpha system in patients with chronic obstructive pulmonary disease. Am J Respir Crit Care Med. 2000;161 (4 Pt 1):1179-84.

26. Lantz M, Malik S, Slevin ML, Olsson I. Infusion of tumor necrosis factor (TNF) causes an increase in circulating TNF-binding protein in humans. Cytokine. 1990 Nov;2 (6):402-6.

27. Creutzberg EC, Wouters EF, Vanderhoven Augustin IM, Dentener MA, Schols AM. Disturbances in leptin metabolism are related to energy imbalance during acute exacerbations of chronic obstructive pulmonary disease. Am J Respir Crit Care Med. 2000;162(4 Pt 1):1239-45.

28. Dentener MA, Francot G), Hiemstra PS, Tool AT, Verhoeven AJ, Vandenabeele P, et al. Bactericidal/permeability-increasing protein release in whole blood ex vivo: strong induction by lipopolysaccharide and tumor necrosis factor-alpha. / Infect Dis. 1997 Jan;175(1):108-17.

29. Saetta M, Baraldo S, Corbino L, Turato G, Braccioni F, Rea F, et al. CD8+ve cells in the lungs of smokers with chronic obstructive pulmonary disease. Am J Respir Crit Care Med. 1999;160(2):711-7.

30. Noguera A, Busquets X, Sauleda J, Villaverde JM, MacNee W, Agusti AG. Expression of les and $\mathrm{G}$ proteins in circulating neutrophils in chronic obstructive pulmonary disease. Am J Respir Crit Care Med. 1998;158(5 Pt 1):1664-8.

31. Oudijk EJ, Nijhuis EH, Zwank MD, van de Graaf EA, Mager HJ, Coffer PJ, et al. Systemic inflammation in COPD visualised by gene profiling in peripheral blood neutrophils. Thorax. 2005 Jul; 60 (7):538-44.

32. Newton R, Hart LA, Stevens DA, Bergmann M, Donnelly LE, Adcock IM, et al. Effect of on interleukin-1beta-(IL-1beta)-induced nuclear factor-kappaB (NF-kappaB) and kappaBdependent transcription in epithelial cells. Eur J Biochem. 1998 May 15;254(1):81-9.

33. Orlando S, Sironi M, Bianchi G, Drummond AH, Boraschi D, Yabes D, et al. Role of metalloproteases in the release of the IL-1 type II decoy receptor. I Biol Chem. 1997 Dec 12;272(50):31764-9. 
34. Bourbon A, Vionnet M, Leprince P, Vaissier E, Copeland J, McDonagh P, et al. The effect of methylprednisolone treatment on the cardiopulmonary bypass-induced systemic inflammatory response. Eur J Cardiothorac Surg. 2004 Nov;26(5):932-8.

35. Celik JB, Gormus N, Okesli S, Gormus ZI, Solak H. Methylprednisolone prevents inflammatory reaction occurring during cardiopulmonary bypass: effects on TNF-alpha, IL-6, IL-8, IL-10. Perfusion. 2004 May;19(3):185-91.

36. Dekhuijzen PN, Aben KK, Dekker I, Aarts LP, Wielders PL, van Herwaarden CL, et al. Increased exhalation of hydrogen peroxide in patients with stable and unstable chronic obstructive pulmonary disease. Am J Respir Crit Care Med. 1996;154(3 Pt 1):813-6.

37. Drost EM, Skwarski KM, Sauleda J, Soler N, Roca J, Agusti A, et al. Oxidative stress and airway inflammation in severe exacerbations of COPD. Thorax. 2005 Apr;60(4):293-300. 

CHAPTER 4

Increased systemic inflammation is a risk factor for COPD exacerbations

Chest 2008 Feb;133:350-357

KH Groenewegen
DS Postma
WC Hop
PLML Wielders
N Schlösser
EFM Wouters
for the COSMIC study group 


\section{Abstract}

\section{Background}

Chronic obstructive pulmonary disease (COPD) is characterized by episodic increases in respiratory symptoms, so called exacerbations. COPD exacerbations are associated with an increase in local and systemic inflammation.

Data of a previously published study in a well-characterized COPD cohort were analysed to define predictive factors of acute exacerbations, particularly focussing on systemic inflammation.

\section{Objective}

To determine if an elevated systemic inflammatory status measured at baseline is related to the occurrence of acute exacerbations in COPD.

\section{Methods}

The occurrence of moderate (requiring oral prednisolone) and severe exacerbations (requiring hospitalisation) was prospectively recorded during one year. At the beginning of the study lung function values (FEV, FVC, FRC and DLCO) and serum levels of CRP, fibrinogen, LBP, TNF- $\alpha$ and its soluble receptors STNFR55 and STNFR75 as markers of systemic inflammation were determined.

\section{Results}

277 person-years of follow-up were analyzed in the total group of 374 patients: 186 patients were responsible for 411 exacerbations (374 moderate and 37 severe). Multivariate analyses showed that a higher initial fibrinogen level and a lower FEV, predicted a higher rate of both moderate and severe exacerbations. Additional independent predictors of a severe exacerbation were a higher number of prestudy severe exacerbations and lower DLCO. A higher number of prestudy moderate exacerbations was the only additional independent risk factor for the rate of moderate exacerbations.

\section{Conclusion}

This study demonstrates that besides lung function impairment systemic inflammation manifested by elevated fibrinogen levels is an independent risk factor for exacerbations of COPD. Attenuation of systemic inflammation may offer new perspectives in the management of COPD patients to reduce the burden of exacerbations. 


\section{Introduction}

Chronic obstructive pulmonary disease (COPD) is characterized by episodic increases in respiratory symptoms, so called exacerbations. These episodes contribute considerably to the increased morbidity, mortality and health care costs associated with this disease condition[1-4].

The definition of acute exacerbation of COPD is largely based on reported symptomatology by the patient, mostly an increase in dyspnea, cough and sputum production.

Different studies have reported that airway inflammation increases in acute exacerbations[5-8].

Besides an increase in airway inflammation, COPD exacerbations are associated with an increase in systemic inflammation. It has been established that stable COPD is associated with low grade systemic inflammation as demonstrated by an increase in blood leukocytes [6], acute phase proteins C-reactive protein (CRP)[6] and fibrinogen [7], and inflammatory cytokines[2, 8].

During acute exacerbations of COPD, higher levels of IL- 6 as well as acute phase proteins CRP, fibrinogen and lipopolysaccharide binding protein (LBP) have been demonstrated, declining again during recovery[7, 9].

It is now recognized that exacerbations are an important outcome in COPD, as patients prone to frequent exacerbations have impaired health status [3], reduced physical activity levels [10], increased lower airway bacterial colonization [11] and accelerated lung function decline[12, 13].

Thus, identification of patients at risk for development of acute exacerbations is important since it could lead to more appropriate therapeutic interventions or more specific treatment of identifiable risk factors. A number of risk factors for acute exacerbations have been described, i.e. hypercapnia [14, 15], previous hospital admissions [3, 14], current smoking [14], impaired health status [3, 16], pulmonary hypertension [15] and hypoxia [14], low BMI [17] and low FEV [14]. Most of these factors have been identified in COPD patients who were hospitalized for an acute exacerbation.

However, limited prospective data are available on patients who have moderate exacerbations with treatment out of hospital.

We hypothesized that besides lung function characteristics an elevated systemic inflammatory status is related to the occurrence of acute exacerbations in COPD. We analysed data of a one-year prospective study in a well-characterized COPD cohort to define predictive factors of acute exacerbations, including both moderate and severe exacerbations, particularly focussing on systemic inflammation. 


\section{Material and Methods}

\section{Study design}

This study is a secondary study of the COSMIC (COPD and Seretide: a MultiCenter Intervention and Characterization) study, a multicenter trial to investigate the effects of steroid withdrawal in comparison with combination therapy (long acting beta-2 agonist salmeterol and inhaled steroid fluticasone) during a one year follow-up period[18].

The COSMIC study had a multi-center, randomized, double blind, parallel-group design. All patients received combined salmeterol 50 $\mathrm{\mu g}$ and fluticasone $500 \mathrm{\mu g}$ (Seretide $₫ 50 / 500$ ) twice daily (in the morning and evening) via the Diskus $\AA$ inhaler during a three-month run-in period. Thereafter patients were randomized to a 12-month treatment with either salmeterol/fluticasone (SFC) or salmeterol (S) alone. Inhaled salbutamol was used as relief medication and anticholinergics and methylxanthines in constant dose were allowed throughout the study. After the 3 month run-in period at the randomisation visit, systemic inflammatory parameters were measured next to previously described clinical parameters[18].

\section{Patients}

Inclusion and exclusion criteria have been previously described[18]. In short, entry criteria were: age 40-75 years, established history of COPD, current or ex-smokers with at least 10 pack years, pre-bronchodilator $\mathrm{FEV}_{1} 30-70 \%$ of predicted, $\mathrm{FEV}_{1} /$ FVC $<88 \%$ for men and $<89 \%$ for women, and reversibility $400 \mu \mathrm{g}$ with salbutamol $<10 \%$ of $\mathrm{FEV}_{1}$ predicted. Importantly, all patients had a history of at least two documented COPD exacerbations in the year preceding the study inclusion. Patients requiring systemic corticosteroids or antibiotics or hospitalization for lower respiratory tract infection and/or COPD exacerbation in the 3-month run-in period were also excluded. 314 of the randomized patients were included in this substudy. Approval from ethics committees at each participating site and written informed consent from all patients was obtained.

\section{Measurements}

\section{Static and dynamic lung volumes}

$\mathrm{FEV}_{1}$, forced vital capacity (FVC), peak expiratory flow (PEF) were calculated from the flow volume curve using a spirometer (Masterlab $₫$, Jaeger, Würzburg, Germany). The Tiffeneau-index was calculated as $\mathrm{FEV}_{1} / \mathrm{FVC}$. Lung function parameters were expressed as percentage of reference values [19]. After stopping of short-acting bronchodilating medication for 6 hours and long acting beta-agonists and study medication for 12 hours, reversibility was assessed by inhaling $400 \mu \mathrm{g}$ salbutamol using a Volumatic $®$ spacer; reversibility was expressed as percentage 
of the predicted $\mathrm{FEV}_{\uparrow}$ values. Dynamic lung volumes were measured before and 10 minutes after administration of salbutamol. Functional residual capacity (FRC) was determined by the closed circuit multi breath Helium dilution method. CO diffusion capacity (DLCO) was measured using the single breath method and corrected for $\mathrm{Hb}$ by the equation given by Cotes.[20]

\section{Exacerbations}

All exacerbations were recorded prospectively during the 12-month follow-up period. Symptoms and use of additional medication and/or hospital admission were recorded in the patient's chart by the study physician.

An exacerbation was defined as: worsening of the patient's symptoms of cough, sputum production and/or breathlessness requiring a change in medication. Exacerbations were classified according to severity in moderate or severe. In case of a moderate exacerbation, treatment with a standardised course of prednisolone tablets of $30 \mathrm{mg} /$ day for 10 days was indicated. At the discretion of the physician a moderate exacerbation was additionally treated with a 10-day course of antibiotics. Severe exacerbations required hospitalization of the patient, based on the discretion of the physician.

\section{Inflammatory markers}

Blood was collected in an evacuated tube containing EDTA (Sherwood Medical, St Louis, Missouri, USA) and immediately placed on melting ice. Plasma was separated from blood cells by centrifugation for 10 minutes within 2 hours after collection in a refrigerated centrifuge (speed between 3000 and $5000 \mathrm{rpm}$ ), without use of the brake. The separated plasma was centrifuged for 5 minutes, with use of the brake. Plasma samples were stored at $-70^{\circ} \mathrm{C}$ until analysis.

High-sensitivity (hs) CRP was assessed by a particle-enhanced immunonephelometry on the BN Prospec from Dade-Behring (Liederbach, Germany). The detection limit for hs-CRP was $0.175 \mathrm{mg} / \mathrm{L}$, with a range of 0.175 $1100 \mathrm{mg} / \mathrm{L}$, depending on the dilution (Dade Behring, Liederbach Germany, N Hs CRP, cat no OQIY 13; supplement reagent OUMU). Reference values were 0.267.24 mg/L.[21] Fibrinogen was assessed on Sysmex (Dade-Behring, Liederbach, Germany) CA-70oo coagulation analyzer according to the Clauss method and calculated from EDTA to citrate plasma values. The measuring range was 0.3-10.0 $\mathrm{g} / \mathrm{L}$ and the reference range was $1.7-4.0 \mathrm{~g} / \mathrm{L}$. Lipopolysaccharide (LPS) binding protein (LBP) and the soluble tumor necrosis factor receptors 55 and 75 (sTNFR55, sTNFR75) were measured by enzyme-linked immunosorbent assay (ELISA), as described previously.[22] Lower detection limits for the assays were $1 \mathrm{ng} / \mathrm{ml}$ for LBP, $40 \mathrm{ng} / \mathrm{ml}$ for STNFR55 and $70 \mathrm{ng} / \mathrm{ml}$ for STNF75. Tumor necrosis factor alpha (TNF- $\alpha$ ) was determined with the Quantikine ${ }^{\circledR}$ high sensitivity ELISA from R\&D systems (Minneapolis, USA) with a lower detection limit of $0.5 \mathrm{pg} / \mathrm{ml}$ for total TNF- $\alpha$. 


\section{Statistical analysis}

The predictive value of inflammatory parameters, gender, smoking status (current/former), pack years and lung function parameters $\mathrm{FEV}_{1}, \mathrm{DLCO}$ and FRC (all expressed as \% pred) was analysed separately for severe and moderate exacerbations. Also the documented number of moderate and severe exacerbations during the year before entry into the study was analysed for their predictive value. Definition of these exacerbations was the same as for the followup period.

As there were few patients $(n=5)$ with more than one severe exacerbation, Kaplan-Meier curves and log rank-tests were calculated to evaluate the time until the first severe exacerbation. Cox's proportional hazards model was used to evaluate various variables simultaneously regarding the time until the first severe exacerbation.

Many patients had more than 1 moderate exacerbation. Therefore Poisson regression was performed as primary analysis to evaluate relations between the annual rate of moderate exacerbations during follow-up and various variables (program SAS PROC GENMOD was used, allowing for overdispersion).

Exacerbation data were analyzed up to the time of withdrawal or completion of the study.

Other analyses were performed using the SPSS for Windows statistical package. (version 11.5, SPSS Inc, Chicago, IL, US). To eliminate the influence of outlying observations for CRP, TNF- $\alpha$, STNFR55, STNFR75 and LBP, these parameters were logarithmically transformed in all analyses. Correlation coefficients ( $r$ ) given are Spearman's.

$\mathrm{P}=0.05$ (two-sided) was considered as the limit of significance in all analyses.

\section{Results}

Patient demographic data and baseline characteristics are summarized in table 1. During the one year follow-up period 69 patients withdrew. This occurred after a mean follow-up of 23 weeks. Of the total group of 314 patients, a total of 277 person years was analysed (mean follow-up: 0.88 yr per patient).

Of these 314 patients, 128 patients had neither a moderate nor a severe exacerbation during follow-up.

31 patients experienced a total of 37 severe exacerbations, with the number per patient ranging from 1 to 2 .

179 patients experienced a total of 374 moderate exacerbations, with the number per patient ranging from 1 to 10 . No differences in exacerbation rates were found between the S and SFC treatment groups with respect to severe, moderate, or total 
Table 1. Baseline characteristics of the 314 evaluated patients. Data given are mean values (SD) or median and range or numbers of patients (\%)

\begin{tabular}{lcc}
\hline Age, years & 63.2 & $(7.7)$ \\
Male, \% & 227 & $(72)$ \\
Current smoker, \% & 116 & $(37)$ \\
Prebronchodilator FEV1, L & 1.41 & $(0.47)$ \\
Prebronchodilator FEV1, \% predicted & 48.3 & $(13.2)$ \\
Postbronchodilator FEV1, L & 1.56 & $(0.50)$ \\
Postbronchodilator FEV1, \% predicted & 52.9 & $(13.6)$ \\
Reversibility FEV1, \% predicted & 4.8 & $(3.8)$ \\
FVC, L & 3.09 & $(0.88)$ \\
DLCO, \% predicted. & 66.7 & 22.1 \\
FRC, L ( $n=222)$ & 4.22 & $(1.21)$ \\
FRC, \% predicted. ( $n=222)$ & 125.9 & 31.0 \\
FEV, /FVC, \% & 47.0 & 12.4 \\
BMI, kg/m2 & 26.3 & 4.3 \\
Number of prestudy severe exacerbations & 0 & $0-3$ \\
Number of prestudy moderate exacerbations & 2 & $0-8$ \\
\hline
\end{tabular}

\# during year before entry into the study (total had to be at least 2 as inclusion criterium).

number of exacerbations. The total (moderate and severe) mean annual exacerbation rates were 1.61 and 1.36 for the $S$ and SFC treatment groups, respectively (rate ratio 1.2; $95 \% \mathrm{Cl}$ : 0.9-1.6; $p=0.23$ ). Furthermore no differences could be demonstrated between both treatment arms for the time until the first severe or first moderate exacerbation. Since there were no differences between the two groups, all further analyses were performed in the two treatment groups combined.

Smokers had a slightly higher LBP $(p=0.02)$ and lower TNF- $\alpha(p=0.03)$ than non-smokers. There were no significant differences in fibrinogen, CRP and soluble TNF receptors between smokers and non-smokers.

\section{Severe exacerbations}

\section{Univariate analysis}

Table 2 shows levels of inflammatory parameters in the total group and stratified according to whether or not a severe exacerbation had occurred during the treatment period of one year. The table shows a significantly higher median value of fibrinogen in patients experiencing a severe exacerbation. Kaplan-Meier curves with patients grouped according to median level of fibrinogen showed an increase of the exacerbation rate with a higher fibrinogen level (Figure 1). Univariate Cox- 
Increased systemic inflammation is a risk factor for COPD exacerbations

Table 2. Median levels and range of inflammatory mediators in the total group of patients and according to the presence of severe exacerbation.

\begin{tabular}{|c|c|c|c|c|}
\hline & $\begin{array}{c}\text { Total } \\
(n=314)\end{array}$ & $\begin{array}{c}\text { No severe } \\
\text { exacerbation } \\
(n=283)\end{array}$ & $\begin{array}{c}\text { Severe } \\
\text { exacerbation } \\
(n=31)\end{array}$ & $\begin{array}{c}\text { p- } \\
\text { value }^{\#}\end{array}$ \\
\hline TNF ng/ml & $\begin{array}{c}1.68 \\
(0.69-40.25)\end{array}$ & $\begin{array}{c}1.64 \\
(0.69-40.25)\end{array}$ & $\begin{array}{c}1.89 \\
(0.75-7.42)\end{array}$ & 0.7987 \\
\hline TNF R 55 ng/ml & $\begin{array}{c}842.16 \\
(168.85-4922.60)\end{array}$ & $\begin{array}{c}829.25 \\
(168.85-3794.00)\end{array}$ & $\begin{array}{c}906.57 \\
(456.73-4922.60)\end{array}$ & 0.092 \\
\hline TNF R $75 \mathrm{ng} / \mathrm{ml}$ & $\begin{array}{c}1817.40 \\
(690.47-7329.70)\end{array}$ & $\begin{array}{c}1811.10 \\
(690.47-7329.70)\end{array}$ & $\begin{array}{c}1966.00 \\
(1121.20-4054.50)\end{array}$ & 0.282 \\
\hline CRP mg/L & $\begin{array}{c}3.94 \\
(0.16-83.60)\end{array}$ & $\begin{array}{c}3.93 \\
(0.16-83.60)\end{array}$ & $\begin{array}{c}4.12 \\
(0.34-34.50)\end{array}$ & 0.3985 \\
\hline Fibrinogen $\mathrm{g} / \mathrm{L}$ & $\begin{array}{c}3.45 \\
(1.24-6.10)(n=269)\end{array}$ & $\begin{array}{c}3.45 \\
(1.24-5.81)(n=243)\end{array}$ & $\begin{array}{c}3.75 \\
(2.86-6.10)(n=26)\end{array}$ & $<0.001$ \\
\hline LBP ng/ml & $\begin{array}{c}20.2 \\
(3.03-92.50)\end{array}$ & $\begin{array}{c}20.0 \\
(3.03-92.50)\end{array}$ & $\begin{array}{c}21.5 \\
(6.69-68.50)\end{array}$ & 0.3325 \\
\hline
\end{tabular}

\# Mann-Whitney test for comparison of the severe exacerbation groups (Y vS N).

ॠ Fibrinogen data were not available in 45 patients.

Figure 1. Kaplan-Meier curves for the time until the first severe exacerbation above or below the median fibrinogen level.( $p=0.002)$. Tickmarks denote patients withdrawing or completing study.

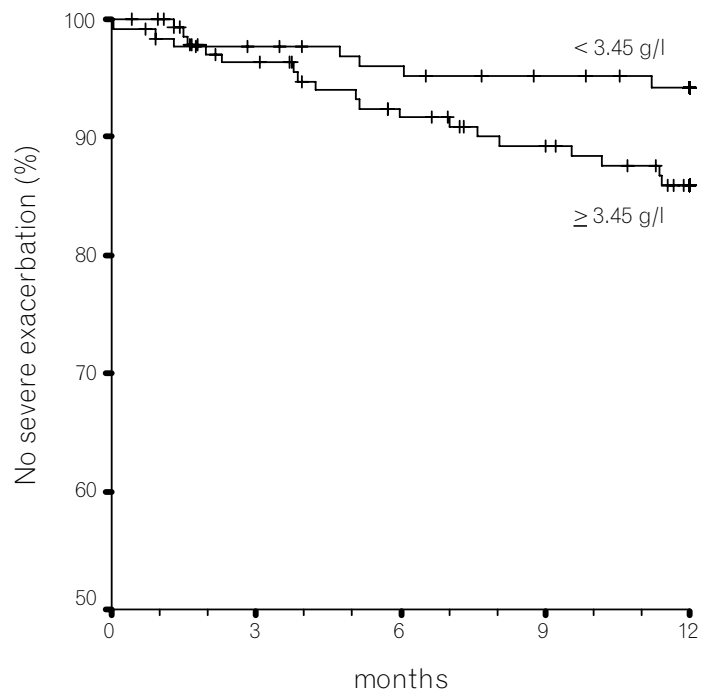


Figure 2. Kaplan-Meier curves for the time until the first severe exacerbation according to $\mathrm{FEV}_{1}$ percentage of predicted (\% pred) [below the median of $46 \%$ vs above, left panel], DLCO percentage of predicted (below the median of $65 \%$ vs above, middle panel ), and FRC percentage of predicted (below the median of $124 \%$ vs above, right panel ); $p=0.005$, $p<0.001$, and $p=0.02$, respectively.
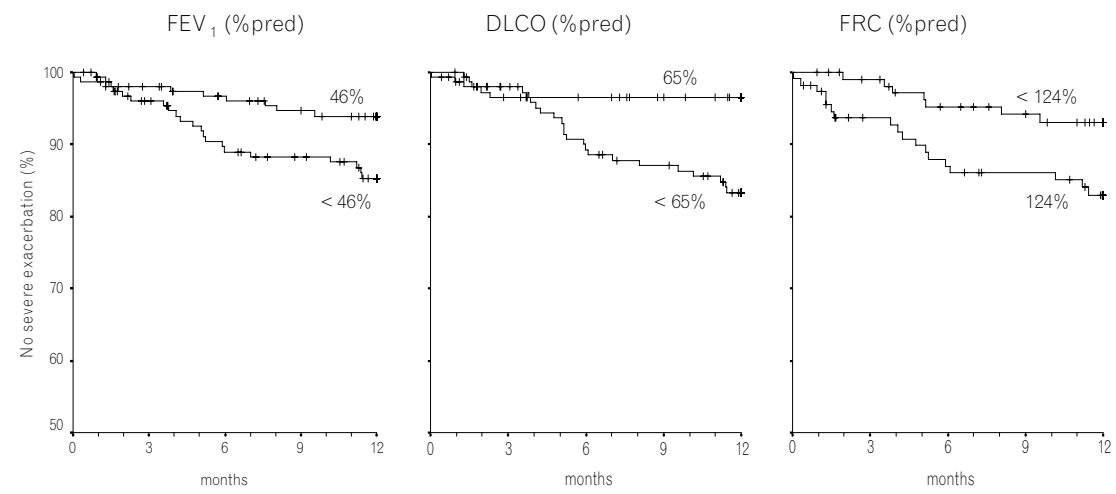

regression did not reveal any relation between severe exacerbations and the other inflammatory parameters.

Univariate analysis of the lung function parameters showed that FEV, DLCO and FRC were all significantly related to the occurrence of a severe exacerbation. Figure 2 shows Kaplan-Meier curves according to FEV, DLCO and FRC.

Univariate analysis did not show any relationship with BMI, gender, age or smoking history.

It was found that the documented occurrence of severe exacerbations during the year before entry into study was related to the occurrence of severe exacerbations during the follow-up period. Of the group of 271 patients who had no prior severe exacerbation $8 \%$ had severe exacerbations during follow-up. This percentage was $27 \%$ in the group of 43 patients who had at least 1 prior severe exacerbation. $(p<0.001)$

\section{Multivariate analysis}

In multivariate Cox-regression of the 3 lung function parameters $\mathrm{FEV}_{1}$, DLCO and FRC, it was found that $\mathrm{FEV}_{1}$ and DLCO were the two major predictive factors independently related to the occurrence of a severe exacerbation. Simultaneous evaluation of fibrinogen level, $\mathrm{FEV}_{1}$ and DLCO showed that these 3 factors were all significantly predictive. This analysis further showed that also the number of documented prior severe exacerbations was predictive (table 3 ). The number of prior moderate exacerbations was not predictive $(p=0.13)$. None of the other investigated factors, including treatment group, was of significant importance when these 4 variables were taken into account. 
Table 3. Multivariate Cox-regression analysis for prediction of a severe exacerbation during the one-year treatment period.

\begin{tabular}{llll}
\hline Variable & Hazard ratio (HR) & $\mathbf{9 5} \%$ CI HR & p-value \\
\hline $\mathrm{FEV}_{1}(\%$ pred $)$ & $0.57^{\#}$ & $0.37-0.87$ & 0.009 \\
$\mathrm{DLCO}(\% \mathrm{pred})$ & $0.73^{\#}$ & $0.57-0.92$ & 0.009 \\
Fibrinogen $(\mathrm{g} / \mathrm{L})$ & $1.77^{\pi}$ & $1.13-2.78$ & 0.012 \\
prior severe exacerbations & $2.36^{\star}$ & $1.33-4.19$ & 0.003 \\
\hline
\end{tabular}

\# per 10 percentage points increase

"per unit $(g / l)$ increase

\& Per additional occurrence in year befor entry in study

\section{Moderate exacerbations}

\section{Univariate analysis}

In univariate analysis none of the inflammatory parameters was significantly associated with the time until the first moderate exacerbation; $\mathrm{FEV}_{1}$ was the only lung function parameter associated. The percentage of patients with a moderate exacerbation within 12 months was $67 \%$ in patients below and $52 \%$ in those above the median $\mathrm{FEV}_{1}$ of $46 \%$ predicted $(\mathrm{p}=0.010)$.

None of the demographic data, except the number of documented moderate exacerbations during the year before entry into study, showed an association with the time until first moderate exacerbation. With an increasing number of prior moderate exacerbations, the percentage of patients who had a moderate exacerbation during the follow-up period increased. The percentage of patients with moderate exacerbations within one year was $56 \%$ when the number of moderate exacerbations in the previous year was $\leq 2(n=231), 68 \%$ when the number of moderate exacerbations in the previous year was $3(n=56)$ and $76 \%$ if the number of moderate exacerbations in the previous year was $\geq 4(n=27)$, with $p_{\text {trend }}=0.005$.

Of the inflammatory parameters measured only fibrinogen showed an association with the number of moderate exacerbations in the follow-up period. Univariate Poisson regression showed that the annual rate of moderate exacerbations increased with a factor $1.2(p=0.042)$ for each increase with 1 unit $(g / l)$ of fibrinogen. Of the lung function parameters, only baseline $\mathrm{FEV}_{1}$ (\%pred) was related to the number of moderate exacerbations. With each 10\% points increase, the annual rate decreased by 15 percent $(p=0.01)$. There was also a significant relation of the number of moderate exacerbations with the number of moderate exacerbations during the pre-study year $(p<0.001)$, but not with the prior number of severe exacerbations $(p=0.13)$. 
Table 4. Multivariate Poisson regression analysis for prediction of the annual rate of moderate exacerbations. Data are given as rate-ratios.

\begin{tabular}{llll}
\hline Variable & Rate ratio (RR) & $\mathbf{9 5} \%$ CI RR & p-value \\
\hline FEV $_{1}(\%$ pred $)$ & $0.82^{\#}$ & $0.72-0.93$ & 0.002 \\
Fibrinogen $(\mathrm{g} / \mathrm{L})$ & $1.19^{\pi}$ & $1.01-1.39$ & 0.039 \\
prior moderate exacerbations & $1.17^{£}$ & $1.05-1.33$ & 0.007 \\
\hline
\end{tabular}

* per 10 percentage points increase

ฯ per unit $(\mathrm{g} / \mathrm{l})$ increase

\& Per additional occurrence in year before entry into study

\section{Multivariate analysis}

Simultaneous evaluation of $\mathrm{FEV}_{1}$, fibrinogen and number of prestudy exacerbations showed that these three factors were all independently related to the rate of occurrence of moderate exacerbations (Table 4 ). The number of prestudy severe exacerbations was not predictive $(p=0.45)$.

Fibrinogen levels did not correlate with $\mathrm{FEV}_{1}(r=0.01, p=0.91)$ or number of prestudy moderate exacerbations. ( $r=0.03, p=0.63)$.

For all analyses, pre-bronchodilator $\mathrm{FEV}_{1}$ values were used. Pre- and post bronchodilator $\mathrm{FEV}_{1}$ correlated strongly $(r=0.95, \mathrm{p}<0.001)$. Similar results in the analyses for severe and moderate exacerbations were obtained when postbronchodilator $\mathrm{FEV}_{1}$ was evaluated instead of pre-bronchodilator $\mathrm{FEV}_{1}$.

\section{Discussion}

We investigated which factors predict acute COPD exacerbations and in particular the role of systemic inflammation in the occurrence of these acute events. We found that higher fibrinogen levels are significantly predictive for the occurrence of severe as well as moderate exacerbations. Further independent predictors for severe acute exacerbations were $\mathrm{FEV}_{1}, \mathrm{DLCO}$, and the number of prestudy severe exacerbations, whereas $\mathrm{FEV}_{1}$ and the number of prestudy moderate exacerbations were independent predictors for moderate acute exacerbations Besides being a measure of lung function, $\mathrm{FEV}_{1}$ is the parameter used in clinical practice to define the severity of COPD, regardless of the underlying pathophysiology. Since $\mathrm{FEV}_{1}$ reflects both disease in the airway wall and loss of alveolar attachments caused by emphysema, it is not surprising that $F E V_{1}$ is an important predictor for acute exacerbations. The occurrence of acute exacerbations

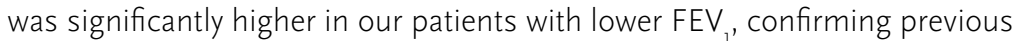
data[14]. A recent report by Pinto-Plata et al. showed that FEV, was significantly 
correlated to changes in inflammatory cytokines in patients hospitalized for an acute exacerbation[23].

The fact that the number of pre-study exacerbations is significantly predictive for an acute exacerbation is also in line with previous studies[3, 14, 24]. Interestingly, the number of severe exacerbations in the year before entry into the study predicted for the occurrence of a severe but not a moderate exacerbation, while the number of moderate exacerbations in the year before entry into the study predicted for the occurrence of a moderate but not a severe exacerbation.

Fibrinogen is an acute phase reactant and a blood clotting factor, synthesized by hepatocytes, and released into the circulation in response to IL-6. Previous studies already reported that COPD patients have higher systemic fibrinogen levels than healthy controls, independently of smoking[25]. These levels increase even further during COPD exacerbations[7]. Elevated fibrinogen levels have been associated with reduced $\mathrm{FEV}_{1}$ and increased risk of COPD[26]. Also, in a large sample of the general population in the U.S., both smoking and reduced $\mathrm{FEV}_{1}$ were related to increased systemic inflammation, measured by CRP and fibrinogen[27].

These findings fit with a shift of the hemostatic balance to favour the activation of coagulation in COPD. Different studies have suggested this pro-trombotic condition to exist in COPD. Other studies have demonstrated increased platelet activation in COPD patients[25, 28, 29]. Markers of the hypercoagulation trombinantitrombin III complex, fibrinopeptide A, and plasminogen activator inhibitor-1 have been shown to be significantly higher in COPD patients than in healthy controls [30]. This shift in the hemostatic balance can be further distorted during acute exacerbations due to increased rate of platelet aggregability as a consequence of acute disturbances in gas exchange [31, 32]. In this study, we extend the present knowledge regarding fibrinogen, by demonstrating that this clotting factor is an independent predictor of acute exacerbations.

Further prospective studies have to explore the relationship between these increased fibrinogen levels and possible exacerbation related thrombo-embolic and cardiovascular morbidity. This is of interest, since fibrinogen has been identified as an independent prognostic factor for cardiovascular morbidity[33]. At this point, the clinical implication of these results is limited, since no intervention that influences fibrinogen levels has been reported yet.

Interestingly, we found that, diffusing capacity was independently related to the occurrence of severe but not moderate exacerbations of COPD. How can we reconcile this association?

Diffusing capacity is a summative physiologic outcome parameter, reflecting parenchymal abnormalities, changes in pulmonary vascular bed or underlying cardiac function. It can be hypothesized that patients with more impaired diffusing capacity are prone to more severe worsening of the physical condition 
$[34,35]$, and thus hospitalization for acute exacerbations[36]. Diffusing capacity disturbances can be considered as an indirect marker of parenchymal destruction such as occurs in patients undergoing lung volume reduction surgery and transplantation[37]. At least in these patients, progressive inflammatory changes have been associated with more severe lung function impairment[38]. Future prospective studies need to explore differences in exacerbation pattern in COPD patients with different lung function impairment in order to better delineate specific COPD phenotypes.

A potential weakness of this study is that is that the data were originally sampled for another purpose. The study was not powered to investigate the comparison between treatment with or without ICS regarding exacerbation rates. Favorable effects of ICS cannot be excluded in view of the resulting wide $95 \%$ confidence interval for the exacerbation rate ratio. Measurement of inflammatory markers was performed when all patients were in stable state and all patients had used inhalation steroids and long acting beta 2 agonist for 3 months (Seretide). Therefore it can be assumed that our patients were maximally stable when systemic inflammatory parameters were measured.

Last but not least, it is important to realize that these results may not be applicable to all populations of COPD patients. The patients in this study were selected by 2 or more previous exacerbations in the preceding year. The results of this study may therefore be limited to a subgroup of frequent exacerbators.

This prospective study in COPD patients, initially selected based on the occurrence of at least 2 exacerbations in the year preceding entry of the study, indicates that airflow limitation as well as fibrinogen as a marker of systemic inflammation, is related to a higher number of both moderate and severe exacerbations. Patients with impaired diffusing capacity are found to be at higher risk for hospitalization for acute exacerbations.

This study demonstrates that besides lung function impairment systemic inflammation manifested by elevated fibrinogen levels is identified as an independent risk factor for acute exacerbations of COPD. Attenuation of systemic inflammation may offer new perspectives in the management of COPD patients in order to reduce the burden of exacerbations. 


\section{References}

1. Rutten van Molken MP, Postma MJ, Joore MA, Van Genugten ML, Leidl R, Jager JC. Current and future medical costs of asthma and chronic obstructive pulmonary disease in The Netherlands. Respir Med. 1999;93(11):779-87.

2. Vernooy JH, Kucukaycan M, Jacobs JA, Chavannes NH, Buurman WA, Dentener MA, et al. Local and systemic inflammation in patients with chronic obstructive pulmonary disease: soluble tumor necrosis factor receptors are increased in sputum. Am J Respir Crit Care Med. 2002 Nov 1;166(9):1218-24.

3. Seemungal TAR, Donaldson CC, Paul EA, Bestall JC, Jeffries DJ, Wedzicha JA. Effect of exacerbation on quality of life in patients with chronic obstructive pulmonary disease. Am J Resp Crit Care Med. $1998 ; 157(5)): 1418-22$.

4. Connors AF, Jr., Dawson NV, Thomas C, Harrell FE, Jr., Desbiens N, Fulkerson WJ, et al. Outcomes following acute exacerbation of severe chronic obstructive lung disease. The SUPPORT investigators (Study to Understand Prognoses and Preferences for Outcomes and Risks of Treatments) Jan;155(1):386]. Am J Respir Crit Care Med. 1996;154(4 Pt 1):959-67.

5. Saetta M, Di Stefano A, Maestrelli P, Turato G, Ruggieri MP, Roggeri A, et al. Airway eosinophilia in chronic bronchitis during exacerbations [see comments]. Am J Respir Crit Care Med. 1994;150(6 Pt 1):1646-52.

6. Dev D, Wallace E, Sankaran R, Cunniffe J, Govan JRW, Wathen CG, et al. Value of C-reactive protein measurements in exacerbations of chronic obstructive pulmonary disease. Respir Med. 1998;92(4)):664-7.

7. Wedzicha JA, Seemungal TA, MacCallum PK, Paul EA, Donaldson CC, Bhowmik A, et al. Acute exacerbations of chronic obstructive pulmonary disease are accompanied by elevations of plasma fibrinogen and serum IL-6 levels. Thromb Haemost. 2000;84(2):210-5.

8. Schols AM, Buurman WA, Staal van den Brekel AJ, Dentener MA, Wouters EF. Evidence for a relation between metabolic derangements and increased levels of inflammatory mediators in a subgroup of patients with chronic obstructive pulmonary disease. Thorax. 1996;51 (8):819-24.

9. Dentener MA, Creutzberg EC, Schols AM, Mantovani A, van't Veer C, Buurman WA, et al. Systemic anti-inflammatory mediators in COPD: increase in soluble interleukin 1 receptor II during treatment of exacerbations. Thorax. 2001 Sep;56(9):721-6.

10. Donaldson CC, Wilkinson TM, Hurst JR, Perera WR, Wedzicha JA. Exacerbations and time spent outdoors in chronic obstructive pulmonary disease. Am J Respir Crit Care Med. 2005 Mar 1;171 (5):446-52.

11. Patel IS, Seemungal TA, Wilks M, Lloyd-Owen SJ, Donaldson CC, Wedzicha JA. Relationship between bacterial colonisation and the frequency, character, and severity of COPD exacerbations. Thorax. 2002 Sep;57(9):759-64.

12. Kanner RE, Anthonisen NR, Connett JE. Lower Respiratory Illnesses Promote FEV(1) Decline in Current Smokers But Not Ex-Smokers with Mild Chronic Obstructive Pulmonary Disease. Results from the lung health study. Am J Respir Crit Care Med. 2001;164(3):358-64.

13. Donaldson GC, Seemungal TA, Patel IS, Bhowmik A, Wilkinson TM, Hurst JR, et al. Airway and systemic inflammation and decline in lung function in patients with COPD. Chest. 2005 Oct;128(4):1995-2004.

14. Garcia-Aymerich J, Monso E, Marrades RM, Escarrabill J, Felez MA, Sunyer J, et al. Risk factors for hospitalization for a chronic obstructive pulmonary disease exacerbation. EFRAM study. Am / Respir Crit Care Med. 2001;164(6):1002-7.

15. Kessler R, Faller M, Fourgaut G, Mennecier B, Weitzenblum E. Predictive factors of hospitalization for acute exacerbation in a series of 64 patients with chronic obstructive pulmonary disease. Am / Respir Crit Care Med. 1999;159(1):158-64.

16. Soler N, Torres A, Ewig S, Gonzalez J, Celis R, ElEbiary M, et al. Bronchial microbial patterns in severe exacerbations of chronic obstructive pulmonary disease (COPD) requiring mechanical ventilation. Am J Resp Crit Care Med. 1998;157(5)):1498-505.

17. Oostenbrink JB, Rutten-van Molken MP. Resource use and risk factors in high-cost exacerbations of COPD. Respir Med. 2004 Sep;98(9):883-91.

18. Wouters EF, Postma DS, Fokkens B, Hop WC, Prins J, Kuipers AF, et al. Withdrawal of fluticasone propionate from combined salmeterol/fluticasone treatment in patients with COPD causes immediate 
and sustained disease deterioration: a randomised controlled trial. Thorax. 2005 Jun;60(6):480-7.

19. Quanjer PH, Tammeling G), Cotes JE, Pedersen OF, Peslin R, Yernault JC. Lung volumes and forced ventilatory flows. Report Working Party Standardization of Lung Function Tests, European Community for Steel and Coal. Official Statement of the European Respiratory Society [see comments]. Eur Respir ] Suppl. 1993;16:5-40.

20. Cotes JE, Chinn DJ, Quanjer PH, Roca J, Yernault JC. Standardization of the measurement of transfer factor (diffusing capacity). Report Working Party Standardization of Lung Function Tests, European Community for Steel and Coal. Official Statement of the European Respiratory Society. Eur Respir ) Suppl. 1993;16:41-52.

21. Rothkrantz-Kos S, Bekers O, Gubbels A, Drent M, Schmitz MP, van Dieijen-Visser MP. Evaluation of two new high-sensitivity methods for C-reactive protein. Ann Clin Biochem. 2003 Jul;40 (Pt 4):398-405.

22. Kuijpers TW, Hakkert BC, Hoogerwerf M, Leeuwenberg JF, Roos D. Role of endothelial leukocyte adhesion molecule-1 and platelet-activating factor in neutrophil adherence to IL-1-prestimulated endothelial cells. Endothelial leukocyte adhesion molecule-1-mediated CD18 activation. J Immunol. 1991;147(4):1369-76.

23. Pinto-Plata VM, Livnat G, Girish M, Cabral H, Masdin P, Linacre P, et al. Systemic cytokines, clinical and physiological changes in patients hospitalized for exacerbation of COPD. Chest. 2007 Jan;131 (1):37-43

24. Stolz D, Christ-Crain M, Morgenthaler NG, Leuppi J, Miedinger D, Bingisser R, et al. Copeptin, Creactive protein, and procalcitonin as prognostic biomarkers in acute exacerbation of COPD. Chest. 2007 Apr;131 (4):1058-67.

25. Davi G, Basili S, Vieri M, Cipollone F, Santarone S, Alessandri C, et al. Enhanced thromboxane biosynthesis in patients with chronic obstructive pulmonary disease. The Chronic Obstructive Bronchitis and Haemostasis Study Group. Am J Respir Crit Care Med. 1997;156(6):1794-9.

26. Dahl M, Tybjaerg-Hansen A, Vestbo J, Lange P, Nordestgaard BG. Elevated plasma fibrinogen associated with reduced pulmonary function and increased risk of chronic obstructive pulmonary disease. Am J Respir Crit Care Med. 2001 Sep 15;164(6):1008-11

27. Gan WQ, Man SF, Sin DD. The interactions between cigarette smoking and reduced lung function on systemic inflammation. Chest. 2005 Feb;127(2):558-64.

28. Ferroni P, Basili S, Martini F, Vieri M, Labbadia G, Cordova C, et al. Soluble P-selectin as a marker of platelet hyperactivity in patients with chronic obstructive pulmonary disease. J Investig Med. 2000 Jan;48(1):21-7.

29. Nenci GG, Berrettini M, Todisco T, Parise P. Enhanced plasma beta-thromboglobulin in hypoxemia: effect of dipyridamole. N Engl / Med. 1981 Apr 23;304(17):1044.

30. Ashitani J, Mukae H, Arimura Y, Matsukura S. Elevated plasma procoagulant and fibrinolytic markers in patients with chronic obstructive pulmonary disease. Intern Med. 2002 Mar;41 (3):181-5.

31. Wedzicha JA, Syndercombe-Court D, Tan KC. Increased platelet aggregate formation in patients with chronic airflow obstruction and hypoxaemia. Thorax. 1991 Jul;46(7):504-7.

32. Wedzicha JA, Cotter FE, Empey DW. Platelet size in patients with chronic airflow obstruction with and without hypoxaemia. Thorax. 1988 Jan;43(1):61-4.

33. Danesh J, Lewington S, Thompson SG, Lowe GD, Collins R, Kostis JB, et al. Plasma fibrinogen level and the risk of major cardiovascular diseases and nonvascular mortality: an individual participant meta-analysis. Jama. 2005 Oct 12;294(14):1799-809.

34. Pauwels RA, Buist AS, Ma P, Jenkins CR, Hurd SS. Global strategy for the diagnosis, management, and prevention of chronic obstructive pulmonary disease: National Heart, Lung, and Blood Institute and World Health Organization Global Initiative for Chronic Obstructive Lung Disease (GOLD): executive summary. Respir Care. 2001 Aug;46(8):798-825.

35. Rodriguez Roisin R. Toward a consensus definition for COPD exacerbations. Chest. 2000;117(5 Suppl 2):398s-401s.

36. Vermeeren MA, Schols AM, Wouters EF. Effects of an acute exacerbation on nutritional and metabolic profile of patients with COPD. Eur Respir J. 1997;10(10):2264-9.

37. Park KJ, Bergin CJ, Clausen JL. Quantitation of emphysema with three-dimensional CT densitometry: comparison with two-dimensional analysis, visual emphysema scores, and pulmonary function test results. Radiology. 1999 May;211 (2):541-7.

38. Hogg JC, Chu F, Utokaparch S, Woods R, Elliott WM, Buzatu L, et al. The nature of small-airway obstruction in chronic obstructive pulmonary disease. N Engl J Med. 2004 Jun 24;350(26):2645-53. 

CHAPTER 5

Elevated plasma

homocysteine levels in stable COPD patients

Submitted

$\mathrm{KH}$ Groenewegen

| Bierau

MK Breyer

MA Spruit

JA Bakker

MA Dentener

PP Menheere

EFM Wouters

on behalf of the CIRO COPD network 


\section{Abstract}

\section{Introduction}

There is evidence for increased cardiovascular risk in chronic obstructive pulmonary disease (COPD) patients, even in stable condition, as indicated by elevated levels of C-Reactive Protein (CRP) and fibrinogen. These cytokines are also independent predictors of cardiovascular morbidity and mortality.

Furthermore, elevated plasma levels of homocysteine are considered as important markers of cardiovascular disease. A few small studies have suggested plasma levels of homocysteine may be increased in COPD patients. The aim of this study was to investigate plasma levels of homocysteine, hs-CRP and fibrinogen in a large population of stable COPD patients.

\section{Outcomes}

Primary outcomes of this study were prevalence of elevated plasma homocysteine, hs-CRP and fibrinogen levels in maximally stable COPD patients. Secondary outcome parameters were differences in homocysteine levels before and after pulmonary rehabilitation, differences in COPD patients stratified according to GOLD stages, and relation of biomarkers with clinical parameters $F E V_{1}, \mathrm{BMI}$, FFMI, $\mathrm{PaO}_{2}$ and $\mathrm{PaCO}_{2}$.

\section{Material and Methods}

85 consecutively recruited stable COPD patients were included in the study. The following data were collected before the start of a 12 week rehabilitation program: demographic data, lung function, BMI, FFMI and the plasma biomarkers total plasma homocysteine (tHcy), fibrinogen and hs-CRP. For interpretation of tHcy values, systemic levels of vitamin B 12 were determined as well as levels of methylmalonic acid for determination of functional vitamin B12 status.

After finishing the 12 week pulmonary rehabilitation program, plasma levels of tHcy were measured again in patients with elevated baseline levels..

\section{Results}

Total plasma homocysteine (tHcy) levels were elevated in 28 out of 85 patients. (32.9\%). thcy levels were not related to clinical parameters except for age, or to markers of systemic inflammation and remained stable after a 12 week pulmonary rehabilitation program.

Markers of systemic inflammation fibrinogen and hs-CRP were elevated in $20-30 \%$ of stable COPD patients and could not be correlated to $\mathrm{FEV}_{1}, \mathrm{PaO}_{2}, \mathrm{PaCO}_{2}, \mathrm{BMI}$ or FFMI.

\section{Conclusion}

It can be interpreted from these results that elevated tHcy is part of the complex systemic disease process in COPD. It may provide a link to the haemostatic system and the cardiovascular risk profile in these patients. 


\section{Introduction}

COPD is defined as a preventable and treatable disease with some significant extra-pulmonary effects that may contribute to the severity of the disease in individual patients Its pulmonary component is characterized by airflow limitation that is not fully reversible. The airflow limitation is usually progressive and associated with an abnormal inflammatory response of the lung to noxious particles or gase [1].

Next to an inflammatory response in the airways, there is evidence for increased systemic inflammation in COPD patients, even in stable condition, as indicated by elevated levels of $\mathrm{C}$-reactive protein (CRP) $[2,3]$. Furthermore, increased levels of fibrinogen have been found in COPD patients, particularly during acute exacerbations $[3,4]$.

Low grade systemic inflammation as indicated by elevated CRP and fibrinogen levels is also considered as an independent risk factor for cardiovascular morbidity and mortality [5, 6]. In COPD patients, CRP has been related to an increased cardiovascular morbidity[7].

Furthermore, increased levels of homocysteine may play an important role in cardiovascular disease via enhancement of vascular inflammation[8]. In COPD patients, limited data are available about the prevalence of increased homocysteine levels[9, 10].

The aim of this study was to investigate plasma levels of homocysteine, hs-CRP, and fibrinogen in a large population of clinically stable COPD patients. All these patients received optimal pharmacological treatment as part of the supervised medical treatment before entering the pulmonary rehabilitation program. Since there is evidence that homocysteine levels may decrease after a training program[11], plasma homocysteine levels were re-assessed after pulmonary rehabilitation in those COPD patients who had elevated baseline plasma homocysteine levels.

\section{Material and Methods}

85 Clinically stable COPD patients were included in the present study. Inclusion criteria were COPD according to the GOLD guidelines[1], and a clinically stable condition 4 weeks prior to and during the entire rehabilitation period of 12 weeks. Exclusion criteria were important co-morbid conditions as malignancies, diabetes mellitus, renal failure, thyroid and cardiovascular diseases and patients with a score $>1$ point on the Carlson index for co-morbidity [12], and the use of antibiotics and/or oral corticosteroids 4 week prior to and during the rehabilitation period. The following data were collected before the start of the rehabilitation program: demographic data, lung function, body mass index (BMI), fat free mass index 
(FFMI) and the plasma biomarkers total plasma homocysteine (tHcy), fibrinogen and hs-CRP. For correct interpretation of tHcy levels, systemic levels of vitamin B12 were determined as well as levels of methylmalonic to exclude cobalamin deficient elevation of tHcy.

After finishing the 12 week pulmonary rehabilitation program, plasma levels of tHcy were measured again, only in COPD patients with elevated baseline tHcy levels.

\section{COPD patients}

COPD patients were prospectively included from a population of COPD patients undergoing pulmonary rehabilitation at the Center for Integrated Rehabilitation of Organ failure (CIRO), Horn, the Netherlands.

COPD was defined as forced expiratory volume in one second $\left(\mathrm{FEV}_{1}\right)<80 \%$ predicted for age and height, $\beta 2$ agonist reversibility of $<11 \%$ of predicted and airflow obstruction evidenced by a ratio of FEV 1 to forced vital capacity (FVC) of < 0.70 of predicted according to GOLD criteria [1].

\section{Pulmonary rehabilitation}

Patients entered a 12 week in-patient pulmonary rehabilitation program.

Pulmonary rehabilitation has been done as described before[13]. In brief, physical training consisted of high-intensity whole-body exercises (e.g. treadmill walking and ergometry cycling), progressive high-intensity strengthening exercises of muscle groups of the upper and lower extremities and unsupported arm exercises during 5 days/week. Additionally, occupational therapy, nutritional modulation and psychosocial counseling were added if necessary.

\section{Lung function values}

$F E V_{1}$, forced vital capacity (FVC), peak expiratory flow (PEF) were calculated

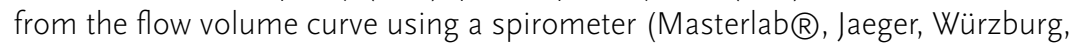
Germany). The Tiffeneau-index was calculated as FEV1/FVC. Lung function parameters were expressed as percentage of reference values[14]. After stopping of short-acting bronchodilating medication for 6 hours and long acting beta-agonists

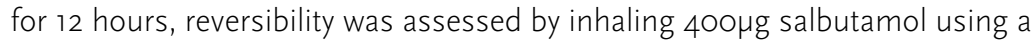
Volumatic $@$ spacer; reversibility was expressed as percentage of the predicted FEV 1 values. Dynamic lung volumes were measured before and 10 minutes after administration of salbutamol. At baseline, arterial blood gases at rest were assessed by puncture of the radial artery during room air breathing.

\section{Body composition}

Body height was determined to the nearest $0.5 \mathrm{~cm}$ (WM 715; Lameris; Breukelen, the Netherlands) with subjects standing barefoot. Body weight was measured with a beam scale (SECA; Hamburg, Germany) without shoes and in light clothing to the nearest $0.1 \mathrm{~kg}$. Body mass index (BMI) was calculated as the ratio of weight to 
height in meters squared. FFM was measured by bioelectrical impedance analysis at a frequency of $50 \mathrm{kHz}$ (Xitron 400ob; Xitron Technologies; San Diego, CA). A patient specific regression equation was used to calculate FFM in patients with COPD [15]. FFM index was calculated as the ratio of FFM to height in meters squared.

\section{Biomarkers}

Blood was collected from patients in the fasting state in an evacuated tube containing EDTA (Sherwood Medical, St Louis, Missouri, USA) and immediately placed on melting ice. Plasma was separated from blood cells by centrifugation for 10 minutes within 2 hours after collection in a refrigerated centrifuge (speed between 3000 and $5000 \mathrm{rpm}$ ), without use of the brake. The separated plasma was centrifuged for 5 minutes, with use of the brake. Plasma samples were stored at $-70{ }^{\circ} \mathrm{C}$ until analysis.

\section{Total homocysteine (tHcy)}

DL-Homocysteine, trifluoroacetic acid and DL-dithiothreitol were purchased from Sigma-Aldrich (Zwijndrecht, The Netherlands). $\mathrm{D}_{8}$-Homocysteine was purchased from Cambridge Isotope Laboratories (Andover, MA, USA). All chemicals used were of highest purity.

Frozen plasma samples were thoroughly mixed after thawing. To $50 \mu \mathrm{l}$ of plasma sample an equal volume of an internal standard solution ( $\mathrm{D}_{8}$-homocysteine) and a $14 \mu \mathrm{M}$ DTT solution were added. The sample was mixed thoroughly and incubated for 15 min at ambient temperature. The sample was deproteinized by addition of acetonitrile containing formic acid and trifluoroactetic acid, mixed thoroughly and centrifuged for $10 \mathrm{~min}$ at $4{ }^{\circ} \mathrm{C}$ at $25000 \times \mathrm{g}$. All analyses were performed using a Waters Micromass Quattro Micro Tandem Mass Spectrometer equipped with a Waters Acquity UPLC-system (Milford, MA, USA). The samples were separated by reversed-HPLC using a Waters Symmetry C18, $3.5 \mu \mathrm{m}, 2.1 \times 100 \mathrm{~mm}$ column with a gradient system of a $0.1 \% \mathrm{v} / \mathrm{v}$ ammonium formiate buffer in methanol/water (30\%/70\% v/v) acetonitrile. Homocysteine was detected in the ESI-positive mode using multiple reaction monitoring (MRM). Reference values were $10.2 \pm 3.2 \mu \mathrm{mol} / \mathrm{L}$ for females and $11.2 \pm 3.4 \mu \mathrm{mol} / \mathrm{L}$ for males [16].

\section{Methylmalonic acid}

Methylmalonic acid was purchased from Sigma-Aldrich (Zwijndrecht, The Netherlands). $D_{3}$-Methylmalonic acid was purchased from Cambridge Isotope Laboratories (Andover, MA, USA). All chemicals used were of highest purity. Frozen plasma samples were thoroughly mixed after thawing. To $100 \mu \mathrm{l}$ of plasma sample $10 \mu \mathrm{l}$ an internal standard solution ( $\mathrm{D}_{3}$-Methylmalonic acid) was added. After homogenization the sample was deproteinized by addition of formic acid/ ethylacetate ( $3 \% / 97 \% \mathrm{v} / \mathrm{v})$ under vigorous mixing. The sample was centrifuged 
for $15 \mathrm{~min}$ at $4{ }^{\circ} \mathrm{C}$ at $25000 \times \mathrm{g}$. The resulting supernatant was transferred to a clean vial and evaporated to dryness. Derivatisation was performed by butylation with $\mathrm{N}$-butanol and acetylchloride for $20 \mathrm{~min}$ at $65^{\circ} \mathrm{C}$. After evaporation of excess butylation agent, the sample was dissolved in acetonitrile/water/formic acid (65\%/35\%/1\%० v/v/v) and used for HPLC-MS/MS analysis.

All analyses were performed using a Waters Micromass Quattro Micro Tandem Mass Spectrometer equipped with a Waters Acquity UPLC-system (Milford, MA, USA). The samples were analysed by reversed-HPLC using a Waters Acquity UPLC $\mathrm{BEHC} 18,1.7 \mu \mathrm{m}, 2.1 \times 100 \mathrm{~mm}$ column. Separation was performed isocratically using acetonitrile/water/formic acid (65\%/35\%/1\% v/v/v) as the mobile phase. Methylmalonic acid was detected in the ESI-positive mode using multiple reaction monitoring (MRM).

The upper reference limit for MMA in plasma was $400 \mathrm{nmol} / \mathrm{L}$ [16].

\section{Hs-CRP}

High-sensitivity (hs) CRP was assessed by a particle-enhanced immunonephelometry on the BN Prospec from Dade-Behring (Liederbach, Germany). The detection limit for hs-CRP was $0.175 \mathrm{mg} / \mathrm{L}$, with a range of 0.175 $1100 \mathrm{mg} / \mathrm{L}$, depending on the dilution (Dade Behring, Liederbach Germany, N Hs CRP, cat no OQIY 13; supplement reagent OUMU). Reference values were 0.26$7.24 \mathrm{mg} / \mathrm{L}[17]$.

\section{Fibrinogen}

Fibrinogen was assessed on Sysmex (Dade-Behring, Liederbach, Germany) CA7000 coagulation analyzer according to the Clauss method and calculated from EDTA to citrate plasma values. The measuring range was $0.3-10.0 \mathrm{~g} / \mathrm{L}$ and the reference range was 1.7-4.0 $\mathrm{g} / \mathrm{L}[18]$.

\section{Vitamin B12 and folate}

Vitamin- $B_{12}$ and folate have been assayed using a Dualcount solid phase no boil assay (Siemens Medical Solutions Diagnostics, Los Angeles, USA). After an alkaline denaturation of endogeneous proteins in the sample, the analytes are allowed to compete for the binding places at the binders for purified vitamin $\mathrm{B}_{12}$ and folic acid immobilised on microcrystalline cellulose particles in the presence of a mix of ${ }^{57} \mathrm{Co}$ Vitamin $\mathrm{B}_{12} /{ }^{125}$ folic acid tracers. After centifugation and decantation , the remaining bound fraction has been counted in a multichannel gamma counter (Perkin Elmer-Wallac, Turku, Finland) with spill-over correction. References values for Vitamin $B_{12}$ are $150-700$ [pmol/L] and for folic acid $7-39$ [nmol/L]. Based on the manufacturer information no clinically significant interference when anticoagulants like EDTA or heparine is present. $B_{12}$ analogs don't interfere since the hog intrinsic factor binder is free of R-protein. There is equal affinity of the folic acid binder for MTHF and PCA. However, our patients didn't undergo any 
therapy with MTX or any structurally related antifolate drugs. Depending on the concentrations, the inter-assay precision varies between 3 and $9 \%$ for vitamin $B_{12}$ and for folic acid between 4 and $14 \%$.

\section{Outcomes}

Primary outcomes of this study were prevalence of elevated plasma homocysteine, hs-CRP and fibrinogen levels in stable COPD patients. Secondary outcome parameters were differences in homocysteine levels before and after pulmonary rehabilitation. Plasma levels of methylmalonic acid, vitamin B 12 and folate were measured additionally for correct interpretation of tHcy levels.

\section{Statistical analysis}

Data were analyzed using the SPSS for Windows statistical package (version 12.0, SPSS Inc, Chicago, IL, US). Data were expressed as mean ( \pm SD).

First, COPD patients were stratified according to elevated or non-elevated levels of different biomarkers. For tHcy the cut-off value was $13.4 \mathrm{mmol} / \mathrm{L}$ for females and $14.6 \mathrm{mmol} / \mathrm{L}$ for males. For CRP the cut-off value was $5 \mathrm{mg} / \mathrm{L}$. For fibrinogen the cut-off value was $4 \mathrm{~g} / \mathrm{L}$.

Second, COPD patients were stratified according to GOLD classification. Since there were only 3 patients with COPD GOLD I, patients with COLD class I and II were combined.

Comparisons between groups were conducted using ANOVA linear regression analysis.

Correlations between different biomarkers were conducted using Pearson's correlation coefficient. Correlation between tHcy at baseline and after 12 weeks was conducted using Wilcoxon's test for related samples.

Values of $p<0.05$ (two-sided) were considered statistically significant.

\section{Results}

On average, patients had moderate to severe COPD, a normal BMI and a lownormal FFMI at baseline (table 1).

Mean levels of all three biomarkers tHcy, hs-CRP and fibrinogen for all patients at baseline are shown in table 2 .

Mean tHcy levels were within the normal range. $(12.8 \pm 4.2 \mathrm{mmol} / \mathrm{l})$ Total plasma homocysteine (tHcy) levels were above the reference values in 28 out of 85 patients (32.9\%).

Clinical characteristics, lung function data and smoking habits, were not statistically significant different between both groups, stratified according to Hcy level (table 3). 


\section{Elevated plasma homocysteine levels in stable COPD patients}

Table 1. Baseline characteristics of the 85 COPD patients included in the study. Data given are mean \pm SD or numbers of patients. (\%)

\begin{tabular}{ll}
\hline Age (years) & $61.8 \pm 9.5$ \\
Gender M/F & $50 / 35(58.8 / 41.2)$ \\
FEV1 L & $1.27 \pm 0.52$ \\
FEV1 \% pred & $45.9 \pm 17.1$ \\
GOLD classification I/I/III/IV & $3 / 29 / 39 / 14 \quad(3.5 / 34.1 / 45.9 / 16.5)$ \\
$\mathrm{PaO} 2 \mathrm{kPa}$ & $9.5 \pm 1.1$ \\
$\mathrm{PaCO} 2 \mathrm{kPa}$ & $5.3 \pm 0.7$ \\
$\mathrm{BMI} \mathrm{kg} / \mathrm{m} 2$ & $24.4 \pm 4.9$ \\
FFMI kg/m2 & $16.0 \pm 2.33$ \\
Current smoker yes/no & $41 / 47(46.6 / 53.4)$ \\
Number of packyears & $35.4 \pm 13.2$ \\
\hline
\end{tabular}

Table 2. Values of plasma biomarkers at in 85 stable COPD patients.

\begin{tabular}{lccc}
\hline Biomarker & Mean & SD & Range \\
\hline tHcy baseline $\mu \mathrm{mol} / \mathrm{L}$ & 12.8 & 4.2 & $3.9-28.6$ \\
MMA nmol/L & 205.2 & 126.0 & $75.8-830.1$ \\
Vitamin B12 pmol/L & 309.5 & 125.6 & $84.0-865.0$ \\
Folate $\mathrm{nmol} / \mathrm{L}$ & 12.6 & 7.9 & $3.2-47.1$ \\
hs-CRP $\mathrm{mg} / \mathrm{L}$ & 5.27 & 6.3 & $0.0-28.1$ \\
Fibrinogen $\mathrm{g} / \mathrm{L}$ & 3.69 & 0.87 & $2.38-6.14$ \\
\hline
\end{tabular}

From those patients with tHcy levels above the reference value at baseline, a second sample was assessed after pulmonary rehabilitation. Plasma tHcy levels before and after pulmonary rehabilitation were not statistically different (mean $\mathrm{tHcy}$ before rehabilitation $=12.8 \pm 4.2 \mu \mathrm{mol} / \mathrm{L}$ and mean $\mathrm{tHcy}$ after rehabilitation $=$ $15.1 \pm 5.0 \mu \mathrm{mol} / \mathrm{L}, \mathrm{P}=0.13)$.

Methylmalonic acid concentrations were within the normal range $(205.2 \pm 126.0$ $\mathrm{nmol} / \mathrm{l})$ and correlated with tHcy levels $(\mathrm{p}=0.02, r=0.25)$.

Mean plasma levels of vitamin B12 (309.5 $\pm 125.6 \mu \mathrm{mol} / \mathrm{L})$ and folate $(12.6 \pm 7.9$ $\mu \mathrm{mol} / \mathrm{L})$ were within the normal range. Mean hs-CRP was elevated in this group of stable COPD patients $(5.27 \pm 6.3 \mathrm{mg} / \mathrm{L}$.), while mean fibrinogen levels were within the normal range in these stable COPD patients. $(3.69 \pm 0.87 \mathrm{~g} / \mathrm{L})$.

In univariate analysis, plasma tHcy was correlated with age $(r=0.25, p=0.018)$ There was no relation with $\mathrm{FEV}_{1}$, GOLD stage, smoking habits, BMI, FFMI, or with parameters of acute phase response. 
Table 3. Clinical characteristics of patients with and without elevated tHcy.

\begin{tabular}{lccc}
\hline & $\begin{array}{c}\text { Elevated tHcy } \\
(\mathbf{n}=\mathbf{2 8})\end{array}$ & $\begin{array}{c}\text { Non elevated tHcy } \\
(\mathbf{n = 5 7 )}\end{array}$ & p-value \\
\hline Age (years) & $63.0 \pm 9.6$ & $61.3 \pm 9.5$ & 0.43 \\
Gender M/F & $15 / 13$ & $35 / 22$ & 0.5 \\
FEV1 L & $1.28 \pm 0.47$ & $1.26 \pm 0.55$ & 0.86 \\
FEV1 \% pred & $47.4 \pm 16.5$ & $45.2 \pm 17.4$ & 0.58 \\
GOLD classification I/II/III/IV & $1 / 9 / 14 / 4$ & $2 / 20 / 25 / 10$ & 0.96 \\
$\mathrm{PaO}_{2}$ kPa & $9.5 \pm 1.1$ & $9.5 \pm 1.2$ & 0.8 \\
$\mathrm{PaCO}_{2} \mathrm{kPa}$ & $5.2 \pm 0.6$ & $5.3 \pm 0.7$ & 0.3 \\
$\mathrm{BMI} \mathrm{kg/m2}$ & $25.0 \pm 5.1$ & $24.1 \pm 4.9$ & 0.42 \\
FFMI kg/m2 & $16.2 \pm 2.4$ & $16.0 \pm 2.3$ & 0.73 \\
Current smoker yes/no & $13 / 15$ & $25 / 32$ & 0.82 \\
Number of packyears & $35.3 \pm 9.1$ & $35.5 \pm 14.8$ & 0.95 \\
hs-CRP mg/L & $5.78 \pm 7.27$ & $5.02 \pm 5.83$ & 0.97 \\
Fibrinogen g/L & $2.86 \pm 0.70$ & $2.87 \pm 0.61$ & 0.61 \\
\hline
\end{tabular}

\section{Discussion}

The present study reports a moderately increased total plasma homocysteine concentration in about $30 \%$ of clinically stable COPD patients.

Total plasma homocysteine levels were not related to lung function parameters or other clinical characteristics of these patients, except for age. Furthermore, tHcy levels were not related to markers of acute phase response hs-CRP and fibrinogen. Increased baseline levels of tHcy remained stable after pulmonary rehabilitation.

Homocysteine is an amino acid that is synthesized intracellularly in liver from methionine. Homocysteine has multiple fates: it may be excreted, used for the biosynthesis of proteins, catabolized to cysteine in a vitamin B6-dependent pathway or remethylated to methionine. Remethylation of homocysteine to methionine may occur via two pathways, of which the predominant pathway via methionine synthase is folate and vitamin B12 dependent (figure 1).

An excess of tHcy produces reactive oxygen species (ROS) by auto-oxidation[19]. An increase in $\mathrm{tHcy}$ and the disturbance of $\mathrm{tHcy}$ reducing pathways have been implicated in cardiovascular diseases. Case control as well as prospective studies have demonstrated that the plasma total homocysteine level is a strong, graded and independent risk factor for coronary heart disease and stroke [20, 21]. In the Framington Heart Study, Wang et al. reported that besides B-type natriuretic 


\section{Elevated plasma homocysteine levels in stable COPD patients}

Figure 1. Schematic representation of biomarkers for functional vitamin B12 status.

Panel A: Simplified scheme of homocysteine metabolism. SAM: S-adenosyl methionine, SAH: S-adenosyl homocysteine.

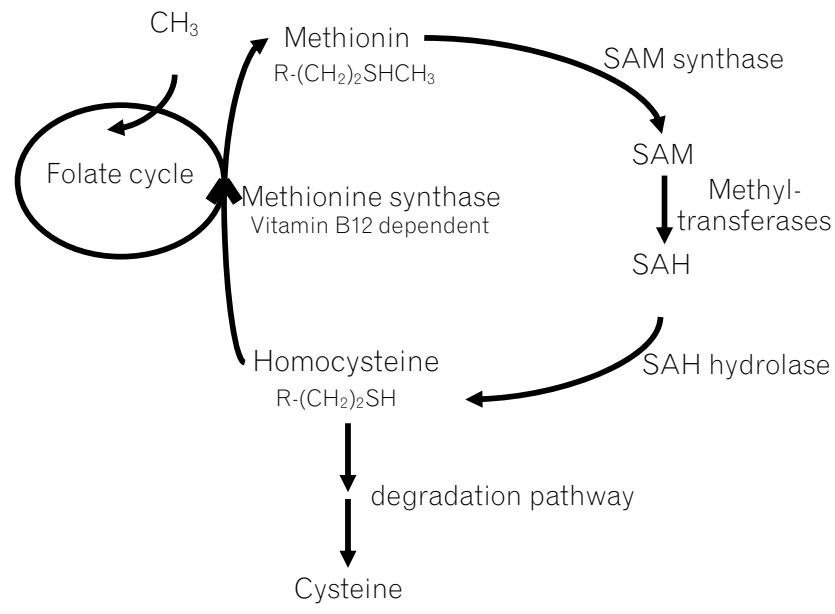

Panel B: Simplified scheme of valine and isoleucine degradation demonstrating the correlation between methylmalonic acid and vitamin B12.

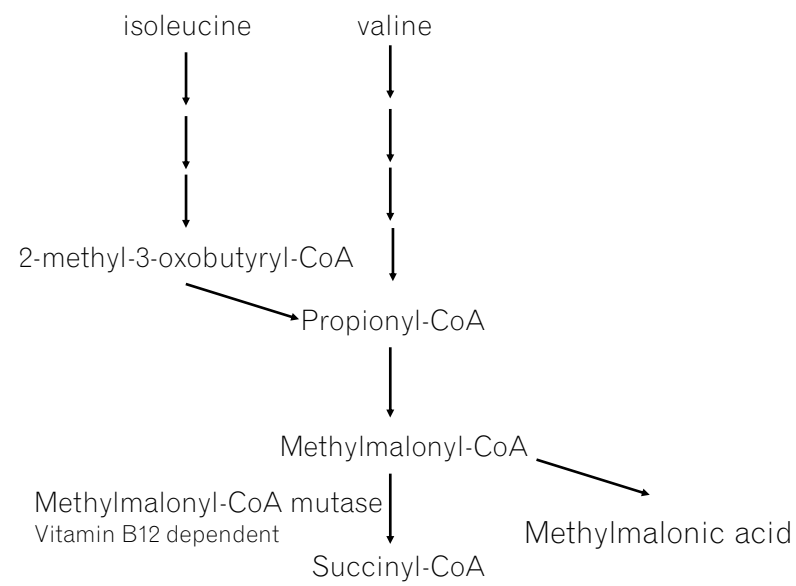


peptide, C-reactive protein level, the urinary albumin-to-creatinine ratio and rennin level, homocysteine level was a strong predictor of the risk of death[22]. Increased plasma tHcy is related to genetic, acquired and demographic factors, such as age, diabetes mellitus, folate and/or vitamin B 12 deficiencies, or renal failure [23].

Smoking also is an important factor in the elevation of plasma tHcy concentration [24].

Since smoking is also a risk factor for the development of COPD, a few small studies have investigated homocysteine levels in COPD patients[9, 10]. The report by Andersson shows elevated tHcy concentration in COPD patients, compared to healthy controls. Kai et al. found higher tHcy concentrations in COPD patients than in smoking controls with the same amount of pack-years, while tHcy values in smokers were higher than in non-smokers, suggesting that smoking might increase plasma tHcy concentration, particularly in subjects predisposed to COPD. Furthermore plasma $\mathrm{H} H \mathrm{cy}$ concentrations were correlated with $\mathrm{FEV}_{1}$ decline over 1 year, suggesting that plasma tHcy concentrations may be involved in spirometric decline, especially in the early stages of COPD [10].

The present study shows elevated tHcy levels in a subgroup of clinically stable COPD patients. Clinical characteristics of this subgroup, particularly lung function data and smoking habits were not different from patients with tHcy levels within the normal range, suggesting that elevation of $\mathrm{tHcy}$ is not related to the level of respiratory impairment in COPD. Although patients with known cardiovascular comorbidity were excluded from the study, tHcy may be a marker of unknown cardiovascular disease in this population.

Based on the measured levels of plasma MMA, vitamin B 12 and folate, it may be concluded that the mildly elevated plasma concentrations of tHcy are not caused by a functional or absolute vitamin B12 or folate deficit.

Furthermore, levels of $\mathrm{tHcy}$ in this group of COPD patients were related to age, which is in line with other reports [16].

In the present study tHcy levels remained stable after a 12 week pulmonary rehabilitation program.

Previously, one study has shown a modest decrease of tHcy levels after a training program in a population of elderly patients[25]. However, this study was performed in 43 patients and there was a small decrease of homocysteine levels (within the error margin of the assay used) in 28 patients after 6 months of low- and highintensity exercise. Furthermore, we found no correlation of tHcy levels and the acute phase proteins hs-CRP and fibrinogen.

Studies evaluating a possible correlation between increased plasma tHcy and CRP have shown inconsistent results, mostly because of heterogeneous populations and the confounding effect of comorbidities[26]. One study did show a direct relationship between plasma tHcy and CRP in elderly patients with dementia and 


\section{Elevated plasma homocysteine levels in stable COPD patients}

cardiovascular disease[26]. However, the conclusion of that study was that this association is more a reflection of a poor health status than a specific correlate of vascular inflammation.

A recent study showed a significantly elevated plasma homocysteine in COPD patients compared to healthy controls, that was related to serum CRP. In this study plasma tHcy levels were still within the normal range and even lower than in our patients.

Furthermore this study was performed in 29 patients with less severe COPD (15 patients had GOLD I-II COPD and 14 patients had GOLD III-IV COPD) and a number of patients had important co-morbidities [27].

In conclusion, we have found elevated tHcy levels in $30 \%$ of stable COPD patients. There was no relation to lung function parameters, particularly FEV 1 and smoking habits, or parameters of acute phase response.

From these results it can be considered that elevated tHcy has to be a part of the complex systemic disease process in COPD. It may provide a link to the haemostatic system and the cardiovascular risk profile in these patients.

Future studies need to unravel the exact role of tHcy in the multicomponent disease process of COPD. 


\section{References}

1. Rabe KF, Hurd S, Anzueto A, Barnes PJ, Buist SA, Calverley P, et al. Global strategy for the diagnosis, management, and prevention of chronic obstructive pulmonary disease: COLD executive summary. Am / Respir Crit Care Med. 2007 Sep 15;176(6):532-55.

2. Broekhuizen R, Wouters EF, Creutzberg EC, Schols AM. Raised CRP levels mark metabolic and functional impairment in advanced COPD. Thorax. 2006 Jan;61 (1):17-22.

3. Gan WQ, Man SF, Senthilselvan A, Sin DD. Association between chronic obstructive pulmonary disease and systemic inflammation: a systematic review and a meta-analysis. Thorax. 2004 Jul;59(7):574-80.

4. Wedzicha JA, Seemungal TA, MacCallum PK, Paul EA, Donaldson GC, Bhowmik A, et al. Acute exacerbations of chronic obstructive pulmonary disease are accompanied by elevations of plasma fibrinogen and serum IL-6 levels. Thromb Haemost. 2000;84(2):210-5.

5. Cesari M, Penninx BW, Newman AB, Kritchevsky SB, Nicklas BJ, Sutton-Tyrrell K, et al. Inflammatory markers and onset of cardiovascular events: results from the Health $A B C$ study. Circulation. 2003 Nov 11;108(19):2317-22.

6. Tracy RP. Epidemiological evidence for inflammation in cardiovascular disease. Thromb Haemost. 1999 Aug;82(2):826-31.

7. Sin DD, Man SF. Why are patients with chronic obstructive pulmonary disease at increased risk of cardiovascular diseases? The potential role of systemic inflammation in chronic obstructive pulmonary disease. Circulation. 2003 Mar 25;107(11):1514-9.

8. McKinley MC. Nutritional aspects and possible pathological mechanisms of hyperhomocysteinaemia: an independent risk factor for vascular disease. Proc Nutr Soc. 2000 May;59(2):221-37.

9. Andersson A, Ankerst J, Lindgren A, Larsson K, Hultberg B. Hyperhomocysteinemia and changed plasma thiol redox status in chronic obstructive pulmonary disease. Clin Chem Lab Med. 2001 Mar;39(3):229-33.

10. Kai S, Nomura A, Morishima Y, Ishii Y, Sakamoto T, Hegab AE, et al. The effect of smokingrelated hyperhomocysteinemia on spirometric declines in chronic obstructive pulmonary disease in elderly Japanese. Arch Gerontol Geriatr. 2006 Mar-Apr;42(2):117-24.

11. Vincent HK, Bourguignon C, Vincent KR. Resistance training lowers exercise-induced oxidative stress and homocysteine levels in overweight and obese older adults. Obesity (Silver Spring). 2006 Nov;14(11):1921-30.

12. Charlson ME, Pompei P, Ales KL, MacKenzie CR. A new method of classifying prognostic comorbidity in longitudinal studies: development and validation. J Chronic Dis. $1987 ; 40(5): 373-83$.

13. Franssen FM, Broekhuizen R, Janssen PP, Wouters EF, Schols AM. Effects of whole-body exercise training on body composition and functional capacity in normal-weight patients with COPD. Chest. 2004 Jun;125(6):2021-8.

14. Quanjer PH, Tammeling G), Cotes JE, Pedersen OF, Peslin R, Yernault JC. Lung volumes and forced ventilatory flows. Report Working Party Standardization of Lung Function Tests, European Community for Steel and Coal. Official Statement of the European Respiratory Society. Eur Respir J Suppl. 1993;16:5-40.

15. Schols AM, Wouters EF, Soeters PB, Westerterp KR. Body composition by bioelectricalimpedance analysis compared with deuterium dilution and skinfold anthropometry in patients with chronic obstructive pulmonary disease. Am J Clin Nutr. 1991;53(2):421-4.

16. Bjorke Monsen AL, Ueland PM. Homocysteine and methylmalonic acid in diagnosis and risk assessment from infancy to adolescence. Am J Clin Nutr. 2003 Jul;78(1):7-21.

17. Rothkrantz-Kos S, Bekers O, Gubbels A, Drent M, Schmitz MP, van Dieijen-Visser MP. Evaluation of two new high-sensitivity methods for C-reactive protein. Ann Clin Biochem. 


\section{Elevated plasma homocysteine levels in stable COPD patients}

2003 Jul;40(Pt 4):398-405

18. Bargnoux AS, Dupuy AM, Biron-Andreani C, Schved JF, Cristol JP. Immunonephelometric determination of fibrinogen on citrated or heparinized plasma: comparison with functional Clauss method. Clin Lab. 2005;51 (5-6):285-8.

19. Welch GN, Loscalzo J. Homocysteine and atherothrombosis. N Engl J Med. 1998 Apr 9:338(15):1042-50.

20. Nygard O, Nordrehaug JE, Refsum H, Ueland PM, Farstad M, Vollset SE. Plasma homocysteine levels and mortality in patients with coronary artery disease. N Engl I Med. 1997 Jul 24;337(4):230-6.

21. Bonaa KH, Njolstad I, Ueland PM, Schirmer H, Tverdal A, Steigen T, et al. Homocysteine lowering and cardiovascular events after acute myocardial infarction. N Engl J Med. 2006 Apr 13:354(15):1578-88.

22. Wang TJ, Gona P, Larson MG, Tofler GH, Levy D, Newton-Cheh C, et al. Multiple biomarkers for the prediction of first major cardiovascular events and death. N Engl J Med. 2006 Dec 21:355(25):2631-9.

23. Faeh D, Chiolero A, Paccaud F. Homocysteine as a risk factor for cardiovascular disease: should we (still) worry about? Swiss Med Wkly. 2006 Dec 2;136(47-48):745-56.

24. Bazzano LA, He J, Muntner P, Vupputuri S, Whelton PK. Relationship between cigarette smoking and novel risk factors for cardiovascular disease in the United States. Ann Intern Med. 2003 Jun 3;138(11):891-7.

25. Vincent KR, Braith RW, Bottiglieri T, Vincent HK, Lowenthal DT. Homocysteine and lipoprotein levels following resistance training in older adults. Prev Cardiol. 2003 Fall;6(4):197-203.

26. Ravaglia G, Forti P, Maioli F, Servadei L, Martelli M, Arnone G, et al. Plasma homocysteine and inflammation in elderly patients with cardiovascular disease and dementia. Exp Gerontol. 2004 Mar;39(3):443-50.

27. Seemungal T, Cho Fook Lun J, Davis G, Neblett C, Chinyepi N, Dookhan C, et al. Plasma homocysteine is elevated in COPD patients and is related to COPD severity. International Journal of COPD. 2007;2(3):313-21. 


CHAPTER 6

Low serum MBL levels offer no increased risk for acute exacerbations of COPD

Submitted

KH Groenewegen
WCJ Hop
DS Postma
PLML Wielders
N Schlösser
EFM Wouters
for the COSMIC study group 


\section{Abstract}

\section{Background}

Acute exacerbations of COPD are often associated with bacterial and/or viral infections. Mannose Binding Lectin (MBL) is a pattern recognition receptor that can bind to a range of pathogens, associated with COPD exacerbations.

Previous studies have suggested an association of low MBL producing genotypes, resulting in low serum MBL, with more frequent admissions for acute exacerbation.

\section{Objective}

Data of a previously published study in a well-characterized COPD cohort were analysed to determine if serum levels of MBL measured at baseline are related to the occurrence of acute exacerbations in COPD.

\section{Methods}

The occurrence of moderate (requiring oral prednisolone) and severe exacerbations (requiring hospitalisation) was prospectively recorded during one year. At the beginning of the study lung function values and serum levels of $\mathrm{MBL}$ were determined.

\section{Results}

In multivariate Cox regression analysis with category of $M B L$, gender, age, $F E V_{1}$, smoking status and the number of severe exacerbations in the year preceding the study as variables, the major independent predictors of a severe acute exacerbation were $F E V 1$ and the number of prior severe exacerbations. There was no relation of $M B L$ levels with the severe exacerbation rate.

$\mathrm{FEV}_{1}$, gender and the number of prestudy moderate exacerbations were the major variables which were independently related to the rate of occurrence of moderate exacerbations. The group of patients with very low MBL levels $(<100 \mu \mathrm{g} / \mathrm{l}) \mathrm{had}$ significantly less moderate acute exacerbations than patients with MBL levels > $100 \mu \mathrm{g} / \mathrm{l}$.

\section{Conclusion}

The major finding in this study is that low serum MBL is not a risk factor for acute exacerbations of COPD. In contrast to our hypothesis, a low serum MBL level offers no increased risk for severe exacerbations and seems to attenuate the rate and time of onset of moderate exacerbations. 


\section{Introduction}

Chronic obstructive pulmonary disease (COPD) is a disorder characterized by progressive airflow limitation that is not fully reversible and that is caused by an abnormal inflammatory response to inhaled noxious particles and gases. The pathophysiological features of COPD involve structural remodeling of the airways and a chronic inflammatory process in the wall and lumen of the small airways [1]. The course of this disease is clinically marked by acute exacerbations. Generally, acute exacerbations are characterized by varying combinations of symptoms as increase in cough, sputum production, worsening of dyspnea or changes in sputum purulence.

Exacerbations of COPD are generally considered to reflect worsening of the underlying chronic inflammation in the airways, although information is limited about the inflammatory response in the lungs in exacerbations of COPD, particularly during severe exacerbations.

During acute exacerbations, increased numbers of eosinophils, neutrophils, activated T-lymphocytes and TNF $\alpha$ positive cells have been found, compared to stable patients[2]. There is evidence for increased systemic inflammation in COPD, especially during acute exacerbations. Increased levels of systemic acute phase proteins and pro-inflammatory cytokines TNF- $\alpha$ and interleukin-6 (IL-6) have been demonstrated as well as an increase in levels of anti-inflammatory cytokine soluble interleukin -1 receptor II (sIL-1RII) during treatment, indicating that the balance between pro- and anti-inflammatory mediators is disturbed[3-5]. The relation between local and systemic inflammation is still unclear.

Although several events may lead to acute exacerbations, respiratory tract infections are often considered as the initiating event contributing to the deterioration in the clinical condition. Especially the role of bacterial infections and the value of antibiotic therapy have been a matter of debate for many decades. Bacteria and viruses are a constant challenge on the respiratory system. The upper airway and lungs have multiple complex defense mechanisms, which can detect infectious microbes and destroy them. These first line defense mechanisms constitute the innate immune system[6]. The innate immune system in the lungs includes antimicrobial peptides and the complement system, with pattern recognition receptor mediated phagocytosis. Disturbances in this system might lead to increased susceptibility to respiratory infections.

Mannose binding lectin (MBL) is a serum protein participating in innate immune defense. It belongs to the collectin family of proteins that share a similar structure and function. (together with lung surfactant proteins $A$ and D) and it acts as a pattern recognition receptor[7]. Furthermore, there is evidence that the MBL protein has at least 4 different functions: the activation of complement, the promotion of (complement-independent) opsonophagycytosis, the modulation of inflammation and the promotion of apoptosis[8]. 


\section{Low serum MBL levels offer no increased risk for acute exacerbations of COPD}

$\mathrm{MBL}$ is produced in the liver, and can bind to mannose or $\mathrm{N}$-acetyl-glucosamine carbohydrates, present on Gram positive and Gram negative bacteria and yeasts, as well as some viruses and parasites[9]. It is considered to be of importance in protection against bacterial and viral infections, particularly in newborns, before specific immune protection is established by the adaptive immune system, and in immunocompromised adults.

Several studies have suggested that MBL genetic variants, resulting in low serum concentrations of $\mathrm{MBL}$, are a risk factor for repeated respiratory tract infections[10]. Low MBL producing genotypes were also associated with more frequent admissions for acute exacerbations of COPD [11].

In this study we investigated the serum levels of mannose binding lectin (MBL) and exacerbation frequency in a group of COPD patients that was prospectively followed for frequency of acute exacerbations. Our hypothesis was that patients with lower levels of serum MBL might have more frequent acute exacerbations.

\section{Study design}

This study is a secondary study of the COSMIC (COPD and Seretide: a MultiCenter Intervention and Characterization) study, a multicenter trial to investigate the effects of steroid withdrawal in comparison with combination therapy (long acting beta-2 agonist salmeterol and inhaled steroid fluticasone) during a one year follow-up period[12].

The COSMIC study had a multi-center, randomized, double blind, parallel-group design. All patients received combined salmeterol $50 \mu \mathrm{g}$ and fluticasone $500 \mu \mathrm{g}$ (Seretide $\AA 50 / 500$ ) twice daily (in the morning and evening) via the Diskus $($ ) inhaler during a three-month run-in period. Thereafter patients were randomized to a 12-month treatment with either salmeterol/fluticasone (SFC) or salmeterol (S) alone. Inhaled salbutamol was used as relief medication and anticholinergics and methylxanthines in constant dose were allowed throughout the study. Before the 3 month run-in period at visit 1 , serum $M B L$ was measured and other assessments were performed.

\section{Patients}

Inclusion and exclusion criteria have been previously described[12]. In short, entry criteria were: age 40-75 years, established history of COPD, current or ex-smokers with at least 10 pack years, pre-bronchodilator $\mathrm{FEV}_{1} 30-70 \%$ of predicted, $\mathrm{FEV}_{1} /$ FVC $<88 \%$ for men and $<89 \%$ for women, and reversibility $400 \mu \mathrm{g}$ with salbutamol $<10 \%$ of $\mathrm{FEV}_{1}$ predicted. Importantly, as an inclusion criterium, all patients had a history of at least two documented COPD exacerbations in the year preceding the 
study inclusion. In the COSMIC study, 373 patients were randomized after the runin period. As not all centers of the COSMIC study participated in this secondary study, 327 of the randomized patients were included.

We obtained approval from ethics committees at each participating site, and all patients provided written informed consent.

\section{Measurements}

\section{Lung function}

$\mathrm{FEV}_{1}$, forced vital capacity (FVC), peak expiratory flow (PEF) were calculated from the flow volume curve using a spirometer (Masterlab $®$, Jaeger, Würzburg, Germany). The Tiffeneau-index was calculated as $\mathrm{FEV}_{7} / \mathrm{FVC}$. Lung function parameters were expressed as percentage of reference values[13]. After stopping of short-acting bronchodilating medication for 6 hours and long acting beta-agonists and study medication for 12 hours, reversibility was assessed by inhaling $400 \mu \mathrm{g}$ salbutamol using a Volumatic $@$ spacer; reversibility was expressed as percentage of the predicted $\mathrm{FEV}_{1}$ values. Dynamic lung volumes were measured before and 10 minutes after administration of salbutamol. Functional residual capacity (FRC) was determined by the closed circuit multi breath Helium dilution method.

\section{MBL}

MBL was measured by ELISA (Hbt human MBL lectin assay). Samples and standards are incubated in microliter wells coated with mannan. During this incubation the mannan binding property of functional MBL is used to capture MBL by solid bound mannan. Unbound material present in the sample is removed by washing. Biotionylated antibodies (tracer) to human MBL were added, binding to the mannan bound MBL. Excess tracer is removed by washing. Streptavudin peroxidase is applied to the wells, this conjugate reacts specifically with the biotinylated tracer antibody. Excess streptavudin peroxidase is removed by washing and substrate, tetramethylbenzidine (TMB) is added to the wells. The enzyme reaction is stopped by citric acid and the absorbance at $450 \mathrm{~nm}$ is measured by the spectrophotometer.

Although the physiologically relevant levels of $\mathrm{MBL}$ leading to clinical manifestations are likely to differ in different diseases, cut-off values for serum $\mathrm{MBL}<500 \mu \mathrm{g} / \mathrm{ml}$ are generally considered low and values $<100 \mu \mathrm{g} / \mathrm{ml}$ are considered deficient[14].

For analysis, serum MBL level was divided into 4 categories: $<100 \mu \mathrm{g} / \mathrm{l}$ (deficient, $\mathrm{n}=44$ ), $100-500 \mu \mathrm{g} / \mathrm{l}$ (low, $\mathrm{n}=70$ ). Values in the normal range were further grouped into $500-2650 \mu \mathrm{g} / \mathrm{l}(\mathrm{n}=131)$ and $>2650 \mu \mathrm{g} / \mathrm{l}(\mathrm{n}=82)$, with the latter value representing the $75^{\text {th }}$ percentile. 


\section{Low serum MBL levels offer no increased risk for acute exacerbations of COPD}

\section{Exacerbations}

All exacerbations were recorded prospectively during the 12-month follow-up period. Patients recorded symptoms and use of medication in their diaries and on each study visit, symptoms, use of additional medication and/or hospital admission was recorded in the patient's chart.

An exacerbation was defined as: worsening of the patient's symptoms of cough, sputum production and/or breathlessness requiring a change in medication. Exacerbations were classified according to severity in moderate or severe. In case of a moderate exacerbation, treatment with oral corticosteroids was indicated.

A moderate exacerbation was treated with a standardised course of prednisolone tablets of $30 \mathrm{mg} /$ day for 10 days. At the discretion of the investigator/physician a moderate exacerbation was additionally treated with a course of antibiotics. Severe exacerbations required hospitalization of the patient, based on the discretion of the physician.

\section{Statistical analysis}

The predictive value of $\mathrm{MBL}$ level, gender, age and lung function parameter $\mathrm{FEV}_{1}$ was analysed separately for severe and moderate exacerbations. Also the documented number of moderate and severe exacerbations during the year before entry into study was analysed for their predictive value. Definition of these exacerbations was the same as for the follow-up period.

As there were few patients $(n=5)$ with more than one severe exacerbation, Kaplan-Meier curves and log rank-tests were calculated to evaluate the time until the first severe exacerbation. Cox's proportional hazards model was used to evaluate various variables simultaneously regarding the time until the first severe exacerbation.

Many patients had more than 1 moderate exacerbation. Therefore Poisson regression was performed as primary analysis to evaluate relations between the annual rate of moderate exacerbations during follow-up and various variables (program SAS PROC GENMOD was used, allowing for overdispersion).

Other analyses (Chi square tests for categorical data and Mann Whitney tests for comparison of continuous data) were performed using the SPSS for Windows statistical package. (version 11.5, SPSS Inc, Chicago, IL, US).

$\mathrm{P}=0.05$ (two-sided) was considered as the limit of significance in all analyses.

\section{Results}

Patient demographic data and baseline characteristics are summarized in table 1. Table 2 gives an overview of the number of severe and moderate exacerbations per patient during the 1 year follow-up period. No differences in exacerbation 
Table 1. Baseline characteristics of the 327 patients. Data given are mean values (SD) or median and range or numbers of patients (\%).

\begin{tabular}{lll}
\hline Age, years & 63.2 & $(7.7)$ \\
Male, \% & 235 & $(72)$ \\
Current smoker, \% & 126 & $(38.5)$ \\
Number of packyears & 35.7 & 17.4 \\
Prebronchodilator FEV1, L & 1.40 & $(0.46)$ \\
Prebronchodilator FEV1, \% predicted & 48.1 & $(13.1)$ \\
Postbronchodilator FEV1, L & 1.56 & $(0.50)$ \\
Postbronchodilator FEV1, \% predicted & 52.9 & $(13.6)$ \\
Reversibility FEV1, \% predicted & 4.8 & $(3.8)$ \\
FVC, L & 3.07 & $(0.89)$ \\
FEV1/FVC, \% & 47.0 & 12.4 \\
BMI, kg/m2 & 26.3 & 4.3 \\
Number of prestudy severe exacerbations & 0 & $0-3$ \\
Number of prestudy moderate exacerbations & 2 & $0-8$ \\
\hline
\end{tabular}

\# during year before entry into the study (total had to be at least 2 as inclusion criterium).

Table 2. Cross tabulation of the number of moderate versus number of severe exacerbations per patient.

Data given are numbers of patients. 129 patients had no exacerbation.

\begin{tabular}{clllll}
\hline $\begin{array}{l}\text { Number of moderate } \\
\text { exacerbations }\end{array}$ & \multicolumn{6}{c}{$\begin{array}{l}\text { Number of severe exacerbations } \\
\text { none }\end{array}$} & $\mathbf{1}$ & $\mathbf{2}$ & $\mathbf{3}$ & Total \\
\hline none & 129 & 6 & 1 & 0 & 136 \\
1 & 77 & 9 & 0 & 0 & 86 \\
2 & 45 & 6 & 2 & 0 & 53 \\
3 & 27 & 2 & 0 & 1 & 30 \\
4 & 10 & 0 & 0 & 0 & 10 \\
$\geq 5$ & 7 & 4 & 1 & 0 & 12 \\
Total & 295 & 27 & 4 & 1 & 327 \\
\hline
\end{tabular}




\section{Low serum MBL levels offer no increased risk for acute exacerbations of COPD}

rates were found between the $\mathrm{S}$ and SFC treatment groups with respect to severe, moderate, or total number of exacerbations. Furthermore no differences could be demonstrated between both treatment arms for the time until the first severe or first moderate exacerbation. Since there were no differences between the two groups, all further analyses were performed in the two treatment groups combined.

The baseline characteristics were similar in the groups $\mathrm{MBL}<100 \mu \mathrm{g} / \mathrm{l}$ v $\mathrm{MBL}$ $>=100 \mu \mathrm{g} / \mathrm{l}$ except for gender. Comparing both MBL groups the percentage of males was $52 \%$ and $75 \%$, respectively $(\mathrm{p}=0.003)$. The difference of $\mathrm{FEV}_{1}$ (\%pred) approached significance (mean values $51.3 \%$ and $47.6 \%, p=0.052$ ).

$\mathrm{MBL}$ levels were comparable in the two treatment groups $(p=0.72)$.

\section{Severe exacerbations}

Figure 1 shows the Kaplan-Meier analysis of the time until the first severe exacerbation, stratified according to these 4 levels of MBL. There were no significant differences between the 4 groups in this univariate analysis, or when levels $<100 \mu \mathrm{g} / \mathrm{l}$ were compared with levels $\geq 100 \mu \mathrm{g} / \mathrm{l}(\mathrm{p}=0.48)$.

In multivariate Cox regression analysis with category of $\mathrm{MBL}$, gender, age, $\mathrm{FEV}$, smoking status and the number of severe exacerbations in the year preceding the study as variables, the major independent predictors of a severe acute exacerbation were $F E V_{1}$ and the number of prior severe exacerbations (table 3). There was no relation of the 4 categories of $\mathrm{MBL}$ levels with the severe exacerbation rate in this multivariate analysis $(p=0.14)$, nor when levels $<100 \mu \mathrm{g} / \mathrm{l}$ were compared with levels $\geq 100 \mu \mathrm{g} / \mathrm{l}(\mathrm{p}=0.69)$.

\section{Moderate exacerbations}

Simultaneous evaluation using Poisson regression of the 4 categories of $\mathrm{MBL}$ levels, $\mathrm{FEV}_{1}$, gender, age, smoking status and number of prestudy exacerbations showed that $\mathrm{FEV}_{1}$, gender and the number of prestudy moderate exacerbations were the major variables which were independently related to the rate of occurrence of moderate exacerbations (Table 4 ). Although overall there was no significant relation with $\mathrm{MBL}$ levels, higher levels of $\mathrm{MBL}$ are related to a higher exacerbation rate in comparison with the group of patients with $\mathrm{MBL}$ levels $<100$ $\mu \mathrm{g} / \mathrm{l}$. In comparing levels $\geq 100 \mu \mathrm{g} / \mathrm{l}$ with $<100 \mu \mathrm{g} / \mathrm{l}$ the Poisson model resulted in a lower exacerbation rate for the latter group $(R R=0.57, p=0.026)$.

Figure 2 shows the Kaplan-Meier curves for time until the first moderate exacerbation.

Overall, there was no significant difference for the time until the first moderate exacerbation between patients with deficient, low, normal or higher MBL levels. $(p=0.15)$ 
Figure 1. Kaplan-Meier analysis for time until first severe exacerbation, A: $<100$ ( $n=44), B: 100-500$ ( $n=70), C: 500-2650(n=131), D:>2650(n=82)$ Tickmarks represent patients withdrawn or completing study,

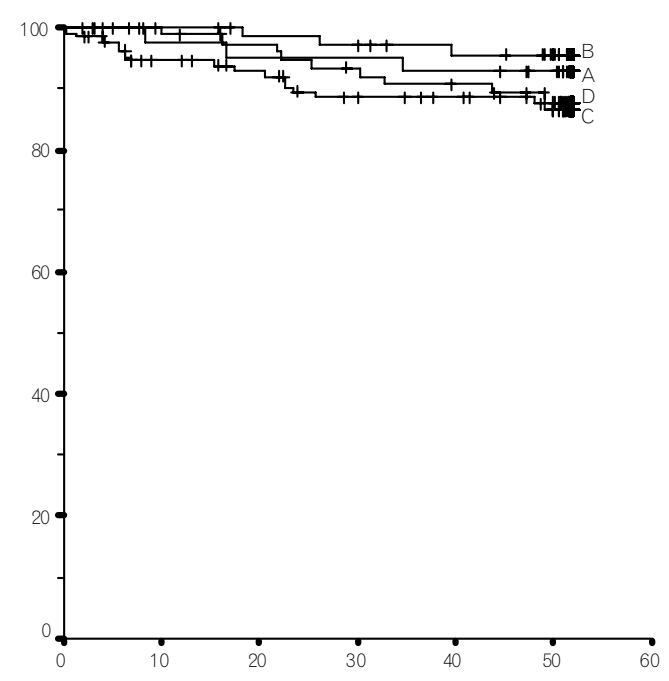

Figure 2. Kaplan-Meier analysis for time until the first moderate exacerbation. $A:<100(n=44), B: 100-500(n=70), C: 500-2650(n=131), D:>2650(n=82)$ Tickmarks represent patients withdrawn or completing study,

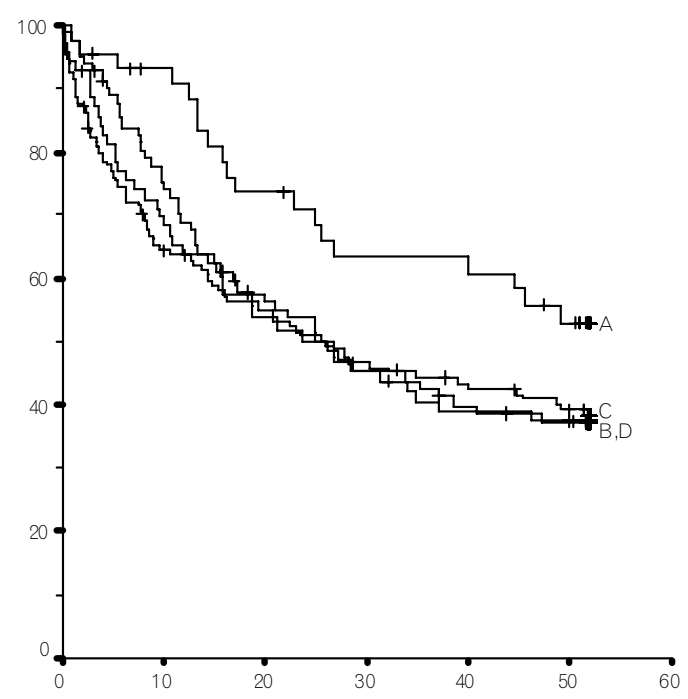




\section{Low serum MBL levels offer no increased risk for acute exacerbations of COPD}

Table 3. Cox multivariate regression analysis for prediction of a severe exacerbation during the one-year treatment period according to various factors.

\begin{tabular}{|c|c|c|c|}
\hline Factor & $\begin{array}{c}\text { Hazard } \\
\text { Ratio (HR) }\end{array}$ & $\begin{array}{l}95 \% \\
\text { CI HR }\end{array}$ & P-value \\
\hline $\mathrm{MBL}[\mu \mathrm{g} / \mathrm{l}]$ & & & 0.140 (overall) \\
\hline$<100$ & 1 & & \\
\hline$\geq 100 / 500$ & 0.52 & $0.10,2.73$ & 0.440 \\
\hline$>500 / 2650$ & 2.04 & $0.55,7.57$ & 0.280 \\
\hline$>2650$ & 1.15 & $0.30,4.40$ & 0.840 \\
\hline \multicolumn{4}{|l|}{ Gender } \\
\hline$M$ & 1 & - & \\
\hline$F$ & 2.01 & $0.89,4.56$ & 0.093 \\
\hline \multicolumn{4}{|l|}{ Current Smoker } \\
\hline N & 1 & - & \\
\hline Y & 0.95 & $0.46,2.00$ & 0.900 \\
\hline Age & $1.02 \pi$ & $0.97,1.07$ & 0.543 \\
\hline $\mathrm{FEV}_{1}$ (\% pred) & $0.49^{\#}$ & $0.34,0.72$ & $<0.001$ \\
\hline $\begin{array}{l}\text { Number of prior severe } \\
\text { exacerbations }\end{array}$ & $3.58^{\Phi}$ & $2.08,6.15$ & $<0.001$ \\
\hline
\end{tabular}

$\mathrm{HR}=1$ denotes reference category.

" per 1 year older age

* per 10 percentage points increase.

$\$$ per additional prior moderate exacerbation.

However, the group with MBL levels $<100 \mu \mathrm{g} / \mathrm{l}$ has significantly longer time until the first moderate exacerbation, compared with the other 3 groups $(p=0.04$ compared with MBL levels between 100-500 $\mu \mathrm{g} / \mathrm{l}, \mathrm{p}=0.03$ compared with $\mathrm{MBL}$ levels $500-2650 \mu \mathrm{g} / \mathrm{l}, \mathrm{p}=0.04$ compared with $\mathrm{MBL}>2650 \mu \mathrm{g} / \mathrm{l})$.

In all analyses, pre-bronchodilator $\mathrm{FEV}_{1}$ values were used. Pre- and post bronchodilator $F E V$, correlated strongly with each other. $(r=0.95, p<0.001)$. Similar results in the analyses for severe and moderate exacerbations were obtained when post-bronchodilator FEV, was evaluated instead of pre-bronchodilator FEV. 
Table 4. Multivariate Poisson regression analysis for prediction of the annual rate of moderate exacerbations according to various factors. Data are given as rate-ratios.

\begin{tabular}{lccc}
\hline Factor & $\begin{array}{c}\text { Rate ratio } \\
(\mathbf{R R})\end{array}$ & $\mathbf{9 5 \%} \mathbf{C I} \mathbf{R R}$ & P-value \\
\hline $\mathrm{MBL}[\mu \mathrm{g} / \mathrm{l}]$ & & & 0.149 (overall) \\
$<100$ & 1 & - & 0.049 \\
$\geq 100 / 500$ & 1.75 & $1.00,3.03$ & 0.022 \\
$>500 / 2650$ & 1.86 & $1.09,3.16$ & 0.086 \\
$>2650$ & 1.62 & $0.93,2.77$ & \\
Gender & & & 0.045 \\
$\mathrm{M}$ & 1 & - & \\
$\mathrm{F}$ & 1.35 & $1.01,1.80$ & 0.890 \\
Current Smoker & & & 0.340 \\
$\mathrm{~N}$ & 1 & - & 0.025 \\
Y & 0.98 & $0.73,1.32$ & 0.001 \\
Age & 1.01 & $0.99,1.03$ & \\
FEV1 (\%pred) & $0.89^{\#}$ & $0.79,0.99$ & \\
Prior moderate & $1.20^{\$}$ & $1.07,1.32$ & \\
exacerbations & & & \\
\hline
\end{tabular}

$\mathrm{RR}=1$ denotes reference category.

" per 1 year older age

* per 10 percentage points increase

$\$$ per additional prior moderate exacerbation

Note: combining 3 categories $>=100 / 500,500 / 2650$ and $>2650$

into 1 group gives $R R=1.76$ for $>100$ vs $<100(p=0.028)$.

\section{Discussion}

The major finding in this study is that low serum MBL is not a risk factor for acute exacerbations of COPD. In contrast to our hypothesis, we found that patients with lower levels of serum MBL have significantly fewer moderate acute exacerbations and a longer time to the onset of these acute exacerbations.

$\mathrm{MBL}$ is a well characterized pattern recognition receptor, and is a major component of the innate immune system[9, 15]. MBL binds to mannose or $\mathrm{N}$ acetyl-glucosamine sugar chains, present on Gram positive or Gram-negative bacteria, yeasts, and some viruses and directly enhances the phagocytosis of these micro-organisms[16]. In addition, MBL interacts with several mannose binding lection proteases (MASPs) to initiate the lectin pathway of complement[17]. Therefore, MBL is important in host defence, especially in infancy, when the 


\section{Low serum MBL levels offer no increased risk for acute exacerbations of COPD}

acquired immunity has not yet fully developed. MBL deficiency has been related to increased susceptibility for infections, both in early childhood and in adult populations[18-20]. MBL is also important when the immune system of an individual is compromised, such as when patient is receiving immunosuppressive therapy or chemotherapy.

Human MBL is derived from a single gene, located on chromosome 10, MBL2[21]. Variation within an individual over time is influenced by response to inflammatory stimuli with an acute phase response causing an increase of up to threefold[22]. There is a large inter-individual difference in the serum concentration of $\mathrm{MBL}$, caused mainly by MBL gene polymorphisms. There are 5 known single nucleotide polymorphisms (SNPs) that affect serum MBL concentration[23].

Three polymorphisms in exon 1 of MBL2 that are known as the D-, B-, and Calleles coding for structurally variant proteins in codons 52, 54 or 57 have been identified[24-26].

These components form together with two linked promoter SNPs (i.e. $-550 \mathrm{H} / \mathrm{L}$ and -221 Y/X and a 5'UTR SNP (ie. +4P/Q) seven well-characterized "secretor haplotypes", which partially account for decreased circulating levels of MBL2[27].

Patients that are homozygous for the minority alleles (B-, C-, and D- alleles) have been shown to have a higher risk of acquiring autoimmune diseases, in particular SLE[15]. The presence of MBL variant alleles (B-, C-, and D- alleles) in patients with cystic fibrosis is associated with a poor prognosis and early death in one study [28] but this finding could not be confirmed in later studies[29]. In a Japanese population, it was shown that the codon 54 variant of the MBL gene is one of the risk factors for repeated pulmonary infections, in patients without any apparent immunologic disorders[10].

There has been only one study to date exploring MBL gene polymorphism specifically in COPD patients[11]. In this study, it was found that the MBL codon $54 \mathrm{~B}$ allele reduced serum MBL in COPD patients. Furthermore, patients carrying the low MBL producing genotype had increased risk of admission for infective exacerbations, suggesting that the MBL2 gene is disease modifying in $\operatorname{COPD}[11]$. Our data are in contrast with these findings, suggesting that a low value of serum $\mathrm{MBL}$ leads to a lower moderate exacerbation rate.

At this point, we cannot offer a conclusive explanation for these findings, but several hypotheses are possible.

The present study investigated serum levels of MBL instead of genotypes.

Although a highly significant correlation has been shown between genotype and serum MBL levels in COPD patients[11], there was still some overlap in serum MBL levels between genotype groups. Part of the explanation could be that serologic methods for determination of MBL cannot distinguish between functional and non-functional protein[30].

Unfortunately, no DNA is available from our patient cohort and for this reason we cannot correlate MBL genotype and risk of acute exacerbations. 
Furthermore, the correlation between infective exacerbations of COPD and the role of $M B L$ as a pattern recognition receptor has not yet been evaluated. In vitro studies have shown that MBL can bind to a variety of pulmonary pathogens including S.aureus, various streptococci, $\mathrm{H}$. influenzae and A. fumigatus[31]. Furthermore it interacts with viral pathogens such as influenza viruses and severe acute respiratory syndrome Corona virus (SARS CoV). Results of studies on upper respiratory infections and association with $M B L$ are inconsistent[32]. High serum MBL levels levels have been associated with protection against extracellular bacterial and viral infections, especially in patients who are immunocompromised[33].

However, only in about $50 \%$ of COPD exacerbations, bacterial infections are documented[34-36]. The most commonly found micro-organisms are S. pneumoniae, $\mathrm{H}$. influenzae and $\mathrm{M}$. catarrhalis[37], while viral infections have been reported to play a role in 30 to $50 \%$ of acute exacerbations[38-41].

The protective effect of high serum MBL levels in cystic fibrosis patients may be the result of clearance or neutralization of Pseudomonas aeruginosa, or alternatively, of protection against viral infections suggested to precede P.aeruginosa colonization.[42] Colonisation with P. aeruginosa. is assumed to be infrequently present in this population, particularly during moderate exacerbations[35].

Recent studies indicate that the function of $\mathrm{MBL}$ extends beyond pathogen recognition to include recognition of self antigens. [43] In this context, MBL levels might be involved in the modulation of the systemic inflammatory response. A high $\mathrm{MBL}$ geno- and phenotype is associated with an increased risk of developing diabetic cardiovascular complications, possibly through this mechanism [43]. Furthermore, there is a modest increase in MBL levels in connection with acute phase responses. This increase is small (up to threefold) and slow (1-2 weeks after the inducing event) [22].

The relation between this acute phase response and the local function of $M B L$ as component of the innate immune system is not known. No correlation of systemic $\mathrm{MBL}$ levels and levels of C-reactive protein (a generally used marker for systemic inflammation) could be found[44].

Experimental studies have shown an effect of MBL on the production of proinflammatory cytokines that is dose-dependent: at first $\mathrm{MBL}$ induces enhancement of IL-1 $\beta$ and IL- 6 but at higher MBL concentrations, inhibition of IL-1 $\beta, I I-6$ and TNF $\alpha$ is seen[33].

In conclusion, MBL plays a complex and incompletely understood role in the systemic inflammatory response. Low MBL levels are associated with unfavorable but also with favorable effect in different disease conditions.

From our results, it seems that a low serum MBL level offers no increased risk for severe exacerbations and seems to attenuate the rate and time of onset of moderate exacerbations. 


\section{Low serum MBL levels offer no increased risk for acute exacerbations of COPD}

\section{References}

1. Fabbri L, Pauwels RA, Hurd SS. Clobal Strategy for the Diagnosis, Management, and Prevention of Chronic Obstructive Pulmonary Disease: GOLD Executive Summary updated 2003. COPD. 2004 Apr; (1):105-41; discussion 3-4.

2. Saetta M, Di Stefano A, Maestrelli P, Turato G, Ruggieri MP, Roggeri A, et al. Airway eosinophilia in chronic bronchitis during exacerbations. Am J Respir Crit Care Med. 1994;150(6 Pt 1):1646-52.

3. Bhowmik A, Seemungal TA, Sapsford RJ, Wedzicha JA. Relation of sputum inflammatory markers to symptoms and lung function changes in COPD exacerbations. Thorax. 2000;55(2):114-20.

4. Dentener MA, Creutzberg EC, Schols AM, Mantovani A, van't Veer C, Buurman WA, et al. Systemic anti-inflammatory mediators in COPD: increase in soluble interleukin 1 receptor II during treatment of exacerbations. Thorax. 2001 Sep;56(9):721-6.

5. Wedzicha JA, Seemungal TA, MacCallum PK, Paul EA, Donaldson CC, Bhowmik A, et al. Acute exacerbations of chronic obstructive pulmonary disease are accompanied by elevations of plasma fibrinogen and serum IL-6 levels. Thromb Haemost. 2000;84(2):210-5.

6. Medzhitov R, Janeway C, Jr. Innate immunity. N Engl J Med. 2000 Aug 3;343(5):338-44.

7. Sim RB, Clark H, Hajela K, Mayilyan KR. Collectins and host defence. Novartis Found Symp. 2006;279:170-81; discussion 81-6, 216-9.

8. Turner MW. The role of mannose-binding lectin in health and disease. Mol Immunol. 2003 Nov; 40 (7):423-9.

9. Turner MW. Mannose-binding lectin (MBL) in health and disease. Immunobiology. 1998 Aug;199(2):327-39.

10. Gomi K, Tokue Y, Kobayashi T, Takahashi H, Watanabe A, Fujita T, et al. Mannose-binding lectin gene polymorphism is a modulating factor in repeated respiratory infections. Chest. 2004 Jul;126(1):95-9.

11. Yang IA, Seeney SL, Wolter JM, Anders EM, McCormack JG, Tunnicliffe AM, et al. Mannosebinding lectin gene polymorphism predicts hospital admissions for COPD infections. Genes Immun. 2003 Jun;4(4):269-74.

12. Wouters EF, Postma DS, Fokkens B, Hop WC, Prins J, Kuipers AF, et al. Withdrawal of fluticasone propionate from combined salmeterol/fluticasone treatment in patients with COPD causes immediate and sustained disease deterioration: a randomised controlled trial. Thorax. 2005 Jun;60(6):480-7.

13. Quanjer PH, Tammeling G), Cotes JE, Pedersen OF, Peslin R, Yernault JC. Lung volumes and forced ventilatory flows. Report Working Party Standardization of Lung Function Tests, European Community for Steel and Coal. Official Statement of the European Respiratory Society. Eur Respir / Suppl. 1993;16:5-40.

14. Thiel S, Frederiksen PD, Jensenius JC. Clinical manifestations of mannan-binding lectin deficiency. Mol Immunol. 2006 Jan;43(1-2):86-96.

15. Tsutsumi A, Takahashi R, Sumida T. Mannose binding lectin: genetics and autoimmune disease. Autoimmun Rev. 2005 Jul;4(6):364-72.

16. Epstein J, Eichbaum Q, Sheriff S, Ezekowitz RA. The collectins in innate immunity. Curr Opin Immunol. $1996 \mathrm{Feb} ; 8(1): 29-35$.

17. Petersen SV, Thiel S, Jensenius JC. The mannan-binding lectin pathway of complement activation: biology and disease association. Mol Immunol. 2001 Aug;38(2-3):133-49.

18. Kakkanaiah VN, Shen GQ, Ojo-Amaize EA, Peter JB. Association of low concentrations of serum mannose-binding protein with recurrent infections in adults. Clin Diagn Lab Immunol. 1998 May;5(3):319-21.

19. Summerfield JA, Sumiya M, Levin M, Turner MW. Association of mutations in mannose 
binding protein gene with childhood infection in consecutive hospital series. Bmj. $1997 \mathrm{Apr}$ 26;314(7089):1229-32.

20. Summerfield JA, Ryder S, Sumiya M, Thursz M, Gorchein A, Monteil MA, et al. Mannose binding protein gene mutations associated with unusual and severe infections in adults. Lancet. 1995 Apr 8;345(8954):886-9.

21. Sastry K, Herman GA, Day L, Deignan E, Bruns G, Morton CC, et al. The human mannosebinding protein gene. Exon structure reveals its evolutionary relationship to a human pulmonary surfactant gene and localization to chromosome 10. J Exp Med. 1989 Oct $1 ; 170(4): 1175-89$.

22. Thiel S, Holmskov U, Hviid L, Laursen SB, Jensenius JC. The concentration of the C-type lectin, mannan-binding protein, in human plasma increases during an acute phase response. Clin Exp Immunol. 1992 Oct;90(1):31-5.

23. Garred P, Larsen F, Seyfarth ), Fujita R, Madsen HO. Mannose-binding lectin and its genetic variants. Genes Immun. 2006 Mar;7(2):85-94.

24. Lipscombe RJ, Sumiya M, Hill AV, Lau YL, Levinsky RJ, Summerfield JA, et al. High frequencies in African and non-African populations of independent mutations in the mannose binding protein gene. Hum Mol Genet. 1992 Dec;1 (9):709-15.

25. Madsen HO, Garred P, Kurtzhals JA, Lamm LU, Ryder LP, Thiel S, et al. A new frequent allele is the missing link in the structural polymorphism of the human mannan-binding protein. Immunogenetics. 1994;40(1):37-44.

26. Sumiya M, Super M, Tabona P, Levinsky RJ, Arai T, Turner MW, et al. Molecular basis of opsonic defect in immunodeficient children. Lancet. 1991 Jun 29;337(8757):1569-70.

27. Bernig T, Breunis W, Brouwer N, Hutchinson A, Welch R, Roos D, et al. An analysis of genetic variation across the MBL2 locus in Dutch Caucasians indicates that 3 ' haplotypes could modify circulating levels of mannose-binding lectin. Hum Genet. 2005 Dec;118(3-4):404-15.

28. Garred P, Pressler T, Madsen HO, Frederiksen B, Svejgaard A, Hoiby N, et al. Association of mannose-binding lectin gene heterogeneity with severity of lung disease and survival in cystic fibrosis. J Clin Invest. 1999 Aug;104(4):431-7.

29. Carlsson M, Sjoholm AG, Eriksson L, Thiel S, Jensenius JC, Segelmark M, et al. Deficiency of the mannan-binding lectin pathway of complement and poor outcome in cystic fibrosis: bacterial colonization may be decisive for a relationship. Clin Exp Immunol. 2005 Feb;139(2):306-13.

30. Vikingsson A, Valdimarsson $\mathrm{H}$. Mannose-binding lectin deficiency and infections in homozygous and heterozygous patients with systemic lupus erythematosus: comment on the article by Garred et al. Arthritis Rheum. 2000 Jul;43(7):1657-8.

31. Davies ), Turner M, Klein N. The role of the collectin system in pulmonary defence. Paediatr Respir Rev. 2001 Mar;2(1):70-5.

32. Ruskamp JM, Hoekstra MO, Rovers MM, Schilder AG, Sanders EA. Mannose-binding lectin and upper respiratory tract infections in children and adolescents: a review. Arch Otolaryngol Head Neck Surg. 2006 May;132(5):482-6.

33. Klein NJ. Mannose-binding lectin: do we need it? Mol Immunol. 2005 May;42(8):919-24.

34. Cabello H, Torres A, Celis R, El Ebiary M, Puig de la Bellacasa J, Xaubet A, et al. Bacterial colonization of distal airways in healthy subjects and chronic lung disease: a bronchoscopic study. Eur Respir J. 1997;10(5):1137-44.

35. Groenewegen $\mathrm{KH}$, Wouters EF. Bacterial infections in patients requiring admission for an acute exacerbation of COPD; a 1-year prospective study. Respir Med. 2003 Jul;97(7):770-7.

36. Monso E, Ruiz J, Rosell A, Manterola J, Fiz J, Morera J, et al. Bacterial infection in chronic obstructive pulmonary disease. A study of stable and exacerbated outpatients using the protected specimen brush. Am J Respir Crit Care Med. 1995;152 (4 Pt 1):1316-20.

37. Murphy TF, Sethi S, Niederman MS. The role of bacteria in exacerbations of COPD. A 


\section{Low serum MBL levels offer no increased risk for acute exacerbations of COPD}

constructive view. Chest. 2000;118(1):204-9.

38. Hurst JR, Donaldson GC, Wilkinson TM, Perera WR, Wedzicha JA. Epidemiological relationships between the common cold and exacerbation frequency in COPD. Eur Respir ). 2005 Nov;26(5):846-52.

39. Rohde G, Wiethege A, Borg I, Kauth M, Bauer TT, Gillissen A, et al. Respiratory viruses in exacerbations of chronic obstructive pulmonary disease requiring hospitalisation: a casecontrol study. Thorax. 2003 Jan;58(1):37-42.

40. Seemungal T, Harper-Owen R, Bhowmik A, Moric I, Sanderson G, Message S, et al. Respiratory Viruses, Symptoms, and Inflammatory Markers in Acute Exacerbations and Stable Chronic Obstructive Pulmonary Disease. Am J Respir Crit Care Med. 2001;164(9):1618-23.

41. Seemungal TA, Harper Owen R, Bhowmik A, Jeffries DJ, Wedzicha JA. Detection of rhinovirus in induced sputum at exacerbation of chronic obstructive pulmonary disease [In Process Citation]. Eur Respir J. 2000;16(4):677-83.

42. Bouwman LH, Roep BO, Roos A. Mannose-binding lectin: clinical implications for infection, transplantation, and autoimmunity. Hum Immunol. 2006 Apr-May;67(4-5):247-56.

43. Hansen TK. Mannose-binding lectin (MBL) and vascular complications in diabetes. Horm Metab Res. 2005 Apr;37 Suppl 1:95-8.

44. Hansen TK, Thiel S, Knudsen ST, Gravholt CH, Christiansen JS, Mogensen CE, et al. Elevated levels of mannan-binding lectin in patients with type 1 diabetes. / Clin Endocrinol Metab. 2003 Oct;88(10):4857-61. 


CHAPTER 7

\section{Systemic inflammation in COPD: the role of acute exacerbations}

Proceedings of the American Thoracic Society 2007

Dec;4 (8):626-34

EFM Wouters

$\mathrm{KH}$ Groenewegen

MA Dentener

JHJ Vernooy 


\section{Summary}

The systemic manifestations of COPD exacerbations are recognized, but our understanding of their etiology and importance is lacking largely due to the small number of systematic and longitudinal studies. Most of the systemic manifestations are likely the result of inflammatory processes. Serum biomarkers, such as various cytokines, adipokines, CRP, and coagulation factors, are elevated during exacerbations. Our understanding of the systemic manifestations can be greatly enhanced if we integrate what is known about the basic science of systemic mediators with the translational science of their role in COPD exacerbations. Many overlapping connections and promising avenues of future research come to light with such a viewpoint.

\section{Introduction}

Chronic obstructive pulmonary disease (COPD) is a major worldwide disease and exacerbations of COPD are considered the key drivers of morbidity and mortality associated with this disease. In the past, the definition of COPD has been based upon pulmonary pathophysiology - airflow limitation that is not fully reversible and usually progressive. Now it is widely recognized that this airflow limitation is associated with an abnormal inflammatory response(1) and that it is a multi-component disease $(2,3)$ with extra-pulmonary effects that contribute to disease severity(1). Thus, COPD can be considered a disease with organ-specific characteristics and systemic manifestations. Like other diseases that have an unclear etiology, there is a mosaic of processes that contribute to the pathogenesis of COPD, including variable gene expression, abnormal immune responses, the influence of hormones, and the damaging effects of factors in the environment(4). Because of the absence of an adequate conceptual frame-work and an advocacy that desires to lump different expressions of the disease together, many pieces of this complex mosaic remain unexplored. In most research on chronic inflammatory diseases, such as autoimmune disorders, environmental factors are viewed more as triggers that initiate the overt expression of an underlying disease process $(4,5)$. In COPD, research is largely focused on the effects environmental factors as the end all, both initiators and causative agents, with little attention given to underlying, or predisposing conditions.

Despite the recognition of COPD as a multi-component disease, exacerbations are defined only in terms of respiratory symptoms: worsening of dyspnea, cough, and/or sputum production that is acute in onset and may warrant a change in the regular medication regimen $(1,6)$. However, consistent with COPD being a 
systemic disease, disturbed sleeping as well as fatigue have been reported to be as important as dyspnea by patients hospitalized for an acute exacerbation of $\operatorname{COPD}(7)$.

The role of bacterial infections in exacerbations remains controversial, but at least $50 \%$ of patients have a high concentration of bacteria in their lower airways during an exacerbation(8)'(9-11). The link between bacterial infection and COPD exacerbations is further supported by the fact that immune responses that are bacterial strain specific are seen, and by the fact that bacterial exacerbations are associated with neutrophillic inflammation, as is COPD in general(12-15). Viral respiratory infections have also been associated with the severity and frequency of exacerbations (16).

\section{Systemic effects of exacerbations of COPD}

Although extra-pulmonary effects are considered to contribute to the severity of COPD, the medical literature contains for the most part only cross-sectional studies that have evaluated clinical variables, enumerated cell types and/or concentrations of inflammatory mediators. Longitudinal studies investigating potential markers as prognostic indicators, or as discriminators between different disease stages are limited in number. A recent meta-analysis showed that many clinical, cytological and biochemical variables in COPD have little or no correlation with FEV 1 -based disease staging. Only systemic concentrations of TNF- $\alpha$ and Creactive protein (CRP) showed a trend towards separation between disease stages (17).

Because it is well appreciated that there is enhancement of local airway inflammation during exacerbations $(18,19)$, more attention is also being given to the exacerbation induced enhancement of systemic inflammation. Furthermore, finding a biomarker in blood that aids in diagnosis and defines outcomes of exacerbations would be a significant clinical advance as currently diagnosis and outcome are based on symptoms and/or measures of health care utilization(1). This may prove to be difficult when one considers that reported symptoms and their interpretation are prone to interobserver variability, perhaps explaining why most variables and measures show weak relationships with the levels of exacerbation severity except for blood arterial carbon dioxide tension and breathing rate. Therefore, a more robust definition of exacerbation may be necessary before we can reliably identify objective markers of disease activity(20).

Various studies report that systemic inflammation is upregulated during exacerbations. Markers reported to be higher in blood during exacerbation compared with the baseline include CRP (21-24), IL-8 (25), TNF $\alpha(26)$, leptin(26, 


\section{Systemic inflammation in COPD: the role of acute exacerbations}

Table 1. Systemic mediators known to be elevated during COPD exacerbations.

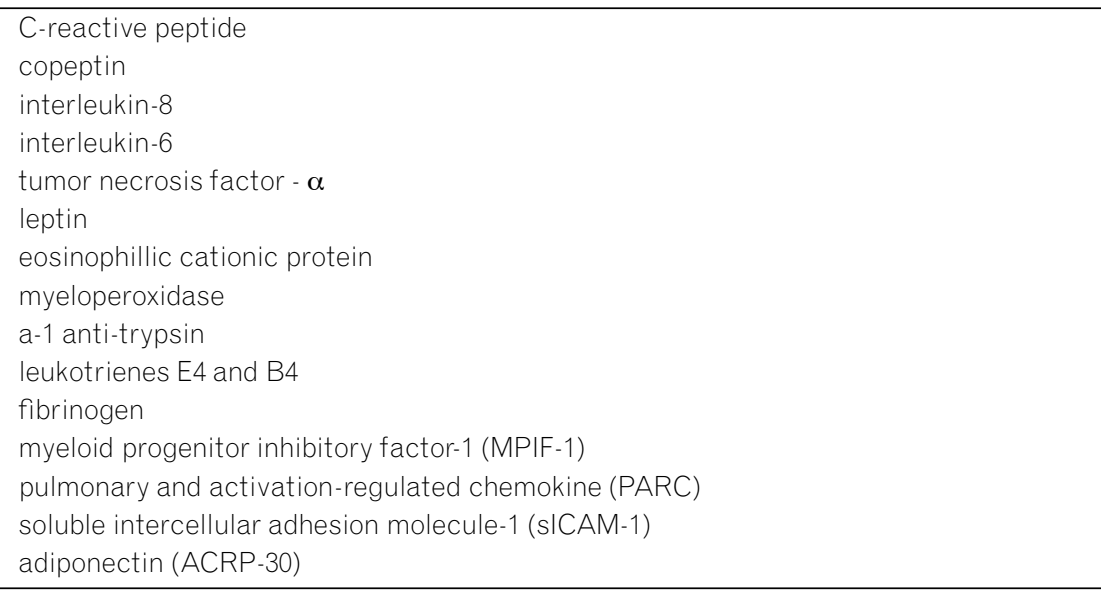

27), endothelin-1 (28), eosinophil cationic protein, myeloperoxidase(29), fibrinogen, IL-6(30), $\alpha$ 1-antitrypsin(31), and leukotriene E4(32) and leukotriene B4(25) (table 1). Moreover, serum IL- 6 and CRP concentrations during exacerbations correlate with selected markers of airway inflammation, and seem to be higher in the presence of a bacterial pathogen(33). This correlation of systemic and airway inflammation has been shown to be lower airway specific(34) suggesting that it is not simply a result of pan-systemic inflammation.

A recent study assessed the ability of 36 different biomarkers to confirm the presence of an exacerbation and predict its severity and found that CRP was the most selective(18). Besides CRP, only levels of IL-6, myeloid progenitor inhibitory factor-1 (MPIF-1), pulmonary and activation-regulated chemokine (PARC), adiponectin (ACRP-3O) and soluble intercellular adhesion molecule-1 (SICAM-1) were found to significantly vary between baseline and exacerbation. The clinical implication of these changes for confirmation of exacerbation was limited because at a cut-off value of $5 \mathrm{mg} / \mathrm{L}$, CRP sensitivity was only $76 \%$ and specificity $57.5 \%$. Elevated CRP concentrations during the recovery period of an exacerbation has been shown to be predictive of a failure to completely resolve symptoms and the recurrence of exacerbation(35). Furthermore, though CRP values are normal in nearly $50 \%$ of patients admitted for an exacerbation of COPD; they do relate to patient reported presence of increased sputum purulence(36).

Copeptin, the more stable C-terminal part of the vasopressin precursor and a 39-amino-acid-long glucosylated peptide(37) has also been studied. Copeptin 
remains stable ex vivo for several days at room temperature in serum or plasma and directly reflects levels of vasopressin. In comparison to CRP, copeptin was superior in predicting the course of exacerbation, elevated copeptin levels at hospital admission predicted in-hospital outcome and length of hospital stay. Elevated copeptin levels also predicted long-term clinical failure, including survival, independent of lung function impairment, co-morbidities, or hypoxemia.

The finding that the majority of tested biomarkers do not appear capable of improving clinical judgment, can partially be related to the selection of the panel of biomarkers and the recognized heterogeneity of acute exacerbations. Using a proteomic approach, Pinto Plata et. al. found that a panel of 24 serum biomarkers, selected from an micro array analysis of 143 biomarkers, correlated with the exacerbation rate for patients with $\operatorname{COPD}(38)$. This study demonstrates that consideration of a large number of biomarkers is important and that the relationship between systemic inflammation and COPD exacerbations is multidimensional.

\section{Adaptive and innate immunity: likely causative factors of systemic manifestations of COPD exacerbations}

Despite the acknowledgement that adaptive immunity plays an important antimicrobial role in the respiratory mucosa, the adaptive immune responses during exacerbations of COPD have been poorly studied and the mechanisms behind the to the host micro-organism defense responses in COPD are poorly understood. Nonetheless we know that inducible cell migration is triggered during respiratory infections as a result of the sensing of pathogens through pattern recognition receptors, toll-like receptors (TLRS), and thus augmenting the killing of invading pathogens (39). These events are mediated by 2 types of signals: diffusible chemotactic factors and cell surface adhesion molecules. Key inflammatory chemokines produced during acute microbial infection include interleukin(IL)-8, growth-related oncogene-alpha ( $G R O \alpha)$, monocyte chemoattractant protein 1 (MCP-1, MCP-2, MCP-3, MCP-4, macrophage inflammatory protein ralpha (MIP$1 \alpha)$, MIP-1 $\beta$ and RANTES(40-42). These chemokines bind to the luminal surface of the vascular endothelium and trigger activation of the leucocytes, inducing conformational changes in the integrins $(39,40,43,44)$. These activated integrins on the leucocytes allow firm adhesion to the vascular endothelium. Integrin ligands on the endothelium, such as the intercellular cell adhesion molecule 1 (ICAM-1), are also induced either directly by TLRs expressed on the endothelium, or indirectly, 


\section{Systemic inflammation in COPD: the role of acute exacerbations}

through TNF $\alpha$ and IL-1, which are induced by TLR-activated macrophages (40). In addition to the inflammation induced cell recruitment, most tissues of the body are interlaced with resident innate leukocytes such as dendritic cells (DCs), macrophages and mast cells. The role of DCs and the involvement of the CCL2OCCR6 receptor has been recently further elucidated in COPD. Particularly the involvement of the CCL2O-CCR6-DC axis in exacerbations of COPD is intriguing and urgently needs further evaluation $(45,46)$. CCL2O shares a high degree of structural homology with the $\beta$-defensins. In broncho-alveolar lavage from patients with cystic fibrosis, CCL2O is abundantly present and CCL2O displayed antimicrobial activity against mainly gram-negative bacteria and permeabilized bacterial membranes in a range intermediate to human $\beta$-defensin 2 and 3(46). This multivariate adaptive immune response consisting of a host of cell types, cytokines, receptors, adhesion molecules and biological factors effectively marshals systemic processes to combat local infections, and is thereby at least in part likely to be responsible for the systemic consequences of exacerbations of COPD.

\section{COPD exacerbations: lessons to be learned from current knowledge of systemic mediators}

In order to better understand the role of systemic involvement in COPD exacerbations, it is helpful to integrate some of the basic science of systemic mediators with the findings of more clinical and translational research across the disease spectrum. Below, the basic, clinical, and translational science of CRP, adipose tissue, endothelial dysfunction, and hemostasis are discussed in the context of their known and potential role in COPD exacerbations.

\section{a. C-reactive protein: the biological role of the acute-phase response}

During the last decade, there is compelling evidence that CRP is not just a marker of disease but also contributes to pathogenesis. Further expansion of our knowledge of the structure and function of CRP is crucial if we are to improve our understanding of the pathogenesis and heterogeneity of COPD.

CRP, named for its capacity to precipitate the somatic C-polysaccharide of Streptococcus Pneumoniae, is a sensitive marker of inflammation and tissue damage(47). The acute phase response comprises the nonspecific physiological and biochemical responses of endothermic animals to most forms of tissue damage, infection, inflammation, and malignant neoplasia. In particular, the synthesis of a number of proteins is rapidly upregulated, principally in 
hepatocytes under the control of cytokines originating at the site of pathology. Other acute-phase proteins include proteinase inhibitors and coagulation proteins, complement, and transport proteins (47). Plasma CRP is produced mainly by hepatocytes, predominantly under transcriptional control by the interleukin-6. The plasma half-life of CRP is about 19 hours and is constant under all conditions of health and disease, so that the sole determinant of circulating CRP concentration is the synthesis rate(48), which thus directly reflects the intensity of the pathological process stimulating CRP production. Subjects in the general population have stable CRP concentrations characteristic for each individual. CRP belongs to the pentraxin family of calcium dependent ligand-binding plasma proteins. The human CRP molecule is composed of five identical non-glycosylated polypeptide subunits, each containing 206 amino acid residues (49). Human CRP binds with the highest affinity to phosphocholine residues, but it also binds to a variety of other autologous and extrinsic ligands, and it aggregates or precipitates the cellular, particulate, or molecular structures, bearing these ligands (50). Phosphocholine is a component of many prokaryocytes and is almost universally present in eukaryocytes (51). The capacity to bind these residues may be important for both host defense and handling of autologous constituents including necrotic and apoptotic cells (50, 52-54). Autologous ligands include the native and modified plasma lipoproteins, damaged cell membranes, a number of different phosphoplipids and related compounds, small nuclear ribonucleoprotein particles and apoptotic cells $(50,52,55)$. Extrinsic ligands include many glycans, phospholipids, and other constituents of micro-organisms, such as capsular and somatic components of bacteria, fungi, and parasites, as well as plant products (50). When aggregated or bound to macromolecular ligands, human CRP is recognized by $\mathrm{C} 1 \mathrm{q}$ and potently activates the classical complement pathway $(50,56,57)$. Indeed, $C_{1 q}$ is a pattern recognition molecule that can trigger rapid enhanced phagocytosis resulting in efficient containment of pathogens or clearance of cellular debris, apoptotic cells and immune complexes. The complement system is a powerful effector mechanism, which, upon activation generates activation fragments ( $\mathrm{C}_{3} \mathrm{a}$ and $\mathrm{C}_{5}$ a) responsible for the initiation of a local inflammatory response by recruitment of leukocytes to the area of infection or injury, and results in the assembly of the membrane attack complex (MAC or C5bC9). C1q is a member of a family of proteins categorized as defense collagens. The globular carboxyl terminal portion of these proteins recognizes broad categories of molecules including PAMPs and the collagen-like N-terminal domain links the invading organism to complement-mediated or phagocyte effector mechanisms of the immune system. Membrane bound defense collagens include the type A macrophage scavengers receptors, $\mathrm{C}$ 1q, the collectins (mannose binding lectin, pulmonary surfactant $A$ and $D$, conglutinin and the more recently isolated members as the ficolin family and adiponectin (Acrp30, the adipocyte complement (C19) related protein of $30 \mathrm{kDa}(58)$. 


\section{Systemic inflammation in COPD: the role of acute exacerbations}

Few studies reported that the complement system may participate in the inflammatory process of $\operatorname{COPD}(59,60)$. One study evaluated $\mathrm{C}_{5}$ a concentrations in the induced sputum of patients with COPD. Significantly elevated levels of $C_{5}$ a were found in the induced sputum of patients with COPD. C5a concentrations in patients with COPD correlated negatively with diffusing capacity.(61)

In summary, CRP may actively participate in the pathogenesis of COPD through the complement system, an idea that is supported by evidence of complement system activation in COPD. While it has not been reported in COPD, CRP has been found in the sputum from patients with inflamed airways which means it has the potential to itself to participate in airways inflammation(62). From an integrative viewpoint, therapeutic targeting of CRP could focus on any of the above listed facets of the CRP axis.

\section{b. Fat tissue during exacerbations: a leptin/adiponectin imbalance?}

Until recently, fat was considered to function predominantly as the triglyceride reservoir of the body and was believed to have only a passive endocrine role. It is now recognized that white adipose tissue is a multifunctional organ. White adipose tissue secretes several hormones and a diverse range of protein factors that have been given the collective name "adipocytokines" or adipokines"(63). Adipocytes themselves have been found to secrete proteins involved in lipid metabolism, insulin sensitivity, the alternative complement system, vascular homeostasis, blood pressure regulation and angiogenesis, as well as the regulation of energy balance(64). Of particular interest, leptin and adiponectin have been linked to acute exacerbations and stable $\operatorname{COPD}(26,65)$. Below the complex interrelationship among leptin and adiponectin, inflammatory processes, and immune responses will be discussed with an eye toward implications for the future.

\section{Leptin}

Leptin is a peptide hormone that is produced predominantly by white adipose cells $(66,67)$. The mature protein is a $16 \mathrm{kDa}$ non-glycosylated protein and it belongs to the type I cytokine superfamily. Circulating leptin is proportional to the amount adipose tissue in any given individual. Leptin exerts most of its energy metabolism effects through effects on the central nervous system, namely the hypothalamic nuclei. These effects include decreases in food intake, increases in energy expenditure and decreases in metabolic efficiency. In addition, leptin has been shown to influence a wide spectrum of biological functions, including lipid and glucose metabolism, synthesis of glucocorticoids and insulin, regulation of the hypothalamic-pituitary-adrenal axis, maturation of the reproductive system, hematopoiesis, angiogenesis and fetal development(68-76). It is therefore not surprising that during acute exacerbations leptin concentrations have been shown 
to relate to disturbances in the energy balance and the systemic inflammatory response(27).

The leptin receptor $(\mathrm{Ob}-\mathrm{R})$ is encoded by the diabetes $(\mathrm{db})$ gene $(77,78)$. The leptin receptor (Ob-R) has at least 6 isoforms, a result of alternative splicing, that all share an identical extracellular ligand-binding domain but have cytoplasmic domains of varying lengths(79). The full-length functional isoform Ob-Rb contains intracellular motifs required for activation of the Janus-activated kinase as well as signal transduction and activation of the transcription pathway JAK/STAT (79). Furthermore the almost universal distribution of leptin receptors reflects the multitude of leptin's biological effects outside the central nervous system.

Recently published studies demonstrate that leptin has a potentiating role in the function of both innate and adaptive immunity (80). Leptin stimulates neutrophils and macrophage chemotaxis (81), and enhances their functional capacities like oxidative burst(81), phagocytosis(82) and cytokine secretion $(83,84)$. In addition, leptin exerts activating (85) and proliferating (86) effects on T-lymphocytes and promotes Thr cell differentiation(87). Furthermore, leptin enhances host responses to inflammation and infection by stimulating tissue repair via its mitogenic and angiogenic effects on epithelium and endothelium $(72,88)$.

All of the above has lead to the general consensus that leptin has a proinflammatory role in the regulation of inflammation and immunity. In patients with rheumatoid arthritis, it has been shown that fasting results in an improvement of clinical and biological measures of disease activity, and that this improvement correlates with a marked decrease in serum leptin concentration as well as a shift towards a Th2 cytokine profile (89). Interestingly, in chronic auto-immune disorders like multiple sclerosis, circulating leptin concentrations correlate significantly with the percentage of circulating CD4+CD25+ regulatory T cells (Tregs) (90). Tregs are known to dampen auto-immune responses mediated by CD4+CD25- T cells and may thereby delay the onset and dampen progression of auto-immune disorders(91). Such findings may very well have implications for improving our understanding of the pathogenesis of autoimmunity and are likely to improve future therapy of auto-immune disorders. More research is needed to better our understanding of the role of elevated concentrations of leptin during exacerbations of COPD, particularly regarding the role of leptin in local respiratory defense $(92,93)$.

To sum up, leptin does function as a pro-inflammatory cytokine and is involved in the pathogenesis of inflammatory and autoimmune diseases, including acute exacerbations of COPD.

\section{Adiponectin}

Adiponectin is the adipokine that is best known for its role in the regulation of insulin sensitivity and is found in the circulation at the highest concentration of 


\section{Systemic inflammation in COPD: the role of acute exacerbations}

any adipokine (in the microgram per millimeter range versus nanograms per millimiter for leptin) (94). The adiponectin molecule is composed of a globular and a collagenous domain and is present in the circulation as trimers and oligomers(95). The globular domain of adiponectin presents close structural similarities with TNF $\alpha(96)$. Leukocyte elastase cleaves adiponectin and generates the globular domain, which can trimerize but does not further polymerize( 96 , 97), indicating that activated leukocytes might modulate adiponectin bioactivity. Serum adiponectin levels do not increase with obesity. Adiponectin has important anti-inflammatory effects. Adiponectin reduces the production and activity of TNF- $\alpha$ and inhibits IL- 6 production and this anti-inflammatory activity is accompanied by induction of the anti-inflammatory cytokines IL-10 and IL-1 receptor antagonist(98-101). Inhibition of the nuclear factor $k B$ by adiponectin might explain these effects(101). Interestingly, increased concentrations of soluble IL-1 receptor during recovery of acute exacerbations have been reported(23). In addition, adiponectin reduces induction of the endothelial adhesion molecules ICAM-1 and vascular cell adhesion molecule $1(102,103)$. On the basis of all the above mentioned effects, it appears that adiponectin acts as an anti-inflammatory molecule.

In total, the above reported data strongly implicate both leptin and adiponectin in the inflammatory process that is part of pathogenesis of exacerbations of COPD.

Thus, we can think of adipose tissue as an important contributor to the systemic manifestations of COPD, and particularly COPD exacerbations. Indeed, the inflammatory/anti-inflammatory effects of adipokines highlight the fact that adipose tissue is more than an energy storage organ, and they also highlight the importance of body composition in the pathogenesis of COPD. This latter point is of particular interest when one considers that obesity, even in the absence of other inflammatory conditions including COPD, is associated with a low grade chronic inflammatory state. Is body composition thereby a predisposing factor for the development of COPD and/or exacerbations? This area of research is in need of a more longitudinal and systematic approach to the questions at hand. In addition, focus should not be placed upon a singular adipokine as the opposing effects of leptin and adiponectin suggest that adipokine ratios may be of greater interest.

\section{c. Endothelial dysfunction during exacerbations of COPD}

Endothelial dysfunction can be viewed as an imbalance between vaso-relaxing and vaso-constrictive substances produced by endothelial cells(104). The up-regulation of the expression of adhesion molecules in the vascular endothelium is considered to be the initiating event in atherogenesis. A number of the biochemical markers that are associated with COPD are also associated with endothelial dysfunction: C-reactive protein, S-ICAM-1, interleukin-6, TNF $\alpha$, endothelin-1, complement, and Leptin. In particular, CRP, fibrinogen, and complement will be discussed below. 
CRP is one of the strongest independent predictors of vascular death in various settings(105-107). Furthermore, while CRP was initially studied as non-contributing biomarker, CRP is now understood to be involved itself in atherogenesis(108). CRP potently downregulates endothelial nitric oxide synthase (eNOS) transcription and destabilizes eNOS mRNA, which decreases both basal and stimulated nitric oxide (NO) release(109). CRP has been shown to stimulate endothelin-1 and interleukin- 6 release, up-regulates adhesion molecules, and stimulates monocyte chemotactic protein 1 while facilitating macrophage low density lipoprotein uptake.(110). CRP has been shown to facilitate endothelial cell apoptosis and to inhibit angiogenesis and to up-regulate NF-kB(111). The pro-atherogenic effects of CRP extend beyond the endothelium to the vascular smooth muscle, where it directly up-regulates angiotensin type 1 receptors and stimulates vascular smooth muscle migration, proliferation, neo-intimal formation and reactive oxygen species production(112). CRP directly inhibits endothelial progenitor cell differentiation, survival, and function. This ability of CRP to inhibit EPC differentiation and survival may represent an important mechanism that further links inflammation to cardiovascular disease(113). Plasma fibrinogen levels are also elevated during acute exacerbations and can further predispose COPD patients to develop cardiovascular events.

Leptin exerts many potentially atherogenic effects such as induction of endothelial dysfunction, stimulation of inflammatory reactions, oxidative stress, decrease in paraoxonase activity, playing an important role in oxidative modification of plasma lipoproteins, platelet aggregation, migration and hypertrophy and proliferation of vascular smooth muscle cells(114).

An intriguing process is the cross-talk between the complement system and the endothelial cells as recently reviewed by Fischetti and Tedesco(115). Endothelial cells secrete several complement components which contribute to the circulating pool. This process is regulated by cytokines and is affected by pro-inflammatory stimuli such as hypoxia and tissue re-oxygenation. Stimulation by complement activation products causes endothelial cells to adopt a pro-inflammatory and coagulation promoting state. Expression of regulatory molecules on the cell surface provides protection against this undesired attack by complement activation products. This unrestricted complement activation may lead to structural and functional changes of the endothelium(115).

In summary, the potential exists for COPD exacerbations to initiate or promote endothelial dysfunction. It is therefore important that future studies evaluate endothelial dysfunction and vascular changes during exacerbations of COPD. 


\section{d. Systemic inflammation and haemostasis}

A pro-thrombotic condition has been documented by various studies in COPD patients. An increased rate of platelet aggregation has been found in patients with hypercapnia and or hypoxemia $(116,117)$. and a number of studies have demonstrated increased platelet activation in COPD patients(118-120). Markers of hypercoagulation, thrombin-antithrombin III complex (TAT), fibrinopeptide A and PAI-1, have been shown to be significantly higher in COPD patients than in healthy controls (121). The role of smoking in coagulation and tromboembolism in COPD has been recently extensively reviewed (122).

Blood coagulation is part of an important host defense mechanism termed hemostasis. Thrombosis is a pathological process in which a platelet aggregate and/or fibrin clot forms in the lumen of an intact blood vessel or in the chamber of the heart. Coagulation in vivo is the result of activation of the intrinsic or extrinsic pathways of the coagulation cascade. This involves coagulation protease zymogens, fibrinogen and thrombin, that are secreted by hepatocytes into the bloodstream. Fibrinogen consists of three pairs of polypeptide chains covalently linked by disulfide bonds. Thrombin (Ila) converts fibrinogen to fibrin monomers by cleaving fibrinopeptides $A$ and $B$ from the $N$-terminal ends of the $A \alpha$ and $B \beta$ chains. Removal of the fibrinopeptides allow the fibrin monomers to form a gel of long polymers. The formation of stable, fibrinolysis-resistant, cross-linked fibrin is the ultimate step in coagulation and occurs as a result of concurrent activation of factor XIII and the generation of cross-linked fibrin polymers $(123,124)$. The main fibrinolytic components of plasma are plasminogen, alpha2-antiplasmin, tissue plasminogen activator (t-PA) and urinary-type plasminogen activator. The two principal inhibitors of fibrinolysis in the circulation are plasminogen activator inhibitor type 1 (PAI-1), and alpha2-antiplasmin, a specific pasmin inhibitor that is covalently bound to polymerizing fibrin by activated factor XIII (125).

Inflammatory mechanisms shift the hemostatic balance toward a balance that favours the activation of coagulation (126). Inflammation can increase fibrinogen concentrations and such an increase has been reported stable and exacerbating COPD patients $(30,127)$. Probably the best known contribution of inflammation is the induction of tissue factor expression on the cell surface of leukocytes, particularly monocytes $(128,129)$. Inflammation also increases CRP. CRP has been shown to facilitate monocyte- endothelial cell interactions and to promote plasminogen activator inhibitor-1 (PAI-1) and tissue factor(130-132). CRP can contribute to complement activation, as outlined above, and the complement system activates the coagulation system in multiple ways (115). Inflammatory mediators, such as IL-6, increase platelet production(133). Platelet responsiveness can also be increased indirectly by inflammatory mediators and can induce expression of protease activated receptors (PARs) on the endothelium(134). In inflammatory conditions anti-thrombin inhibitory activity is decreased and this 
results in delayed inhibition of the coagulation enzymes that favour intravascular coagulation(135). In addition to decreasing anti-thrombin concentrations, the concentration of vascular heparin-like molecules can be reduced by inflammatory cytokines and neutrophil activation products(136). Of the natural anticoagulant pathways, the protein C-pathway appears to be especially sensitive to downregulation by inflammatory mediators. Endotoxin, IL-1 $\beta$ and TNF $\alpha$ all downregulate both thrombomodulin and endothelial cell protein $C$ receptor(137, 138).

Once control of thrombin and other coagulation enzymes is lost, they can participate in promoting the inflammatory response(126). Platelets contain, and are capable of releasing high concentrations of the pro-inflammatory mediator, $\mathrm{CD} 40$ ligand. This cytokine induces tissue factor synthesis and increases inflammatory cytokines, such as IL-6 and IL-8(139-142). In this way, inflammatory mediators leading to increased platelet number and responsiveness set in motion the ability to generate additional inflammatory responses(126). Thrombin is involved in many cellular and humoral responses of inflammation and cell proliferation (126). Tissue factor-factor VIIa complex can activate protease activated receptors leading to increased expression of adhesion molecules that facilitate leucocyte-mediated vessel injury $(143,144)$. Finally, fibrin can participate in regulation of different aspects of inflammation(145).

\section{Conclusions}

Exacerbations are important events in the natural history of COPD and an active field of research. However, the current research paradigm largely underestimates the importance of factors that orchestrate host responses and undervalues the interplay between the innate and adaptive immunity. Furthermore, there is more need to examine the role of systemic inflammation, as it is at the very least involved with the alterations of physical conditions observed during COPD exacerbations. In addition, a wide variety of systemic effects are seen during exacerbations: acute phase protein elevation, triggering of the complement system, changes in adipokine concentrations, endothelial dysfunction and a shift of the haemostatic balance so as to promote coagulation (figure 1). Broadening our viewpoint beyond respiratory symptoms and considering systemic factors will undoubtedly improve our understanding of the process of COPD exacerbations. In so doing, we will also improve disease management and facilitate the identification of new therapeutic targets ultimately leading to a reduction in morbidity and mortality related to exacerbations of COPD. 
Systemic inflammation in COPD: the role of acute exacerbations

Figure 1. Venn diagram illustrating the connections between systemic mediators, systemic manifestations, immune response, infection and the clinical syndrome of COPD exacerbation. Grey shading indicates an anti-inflammatory effect.

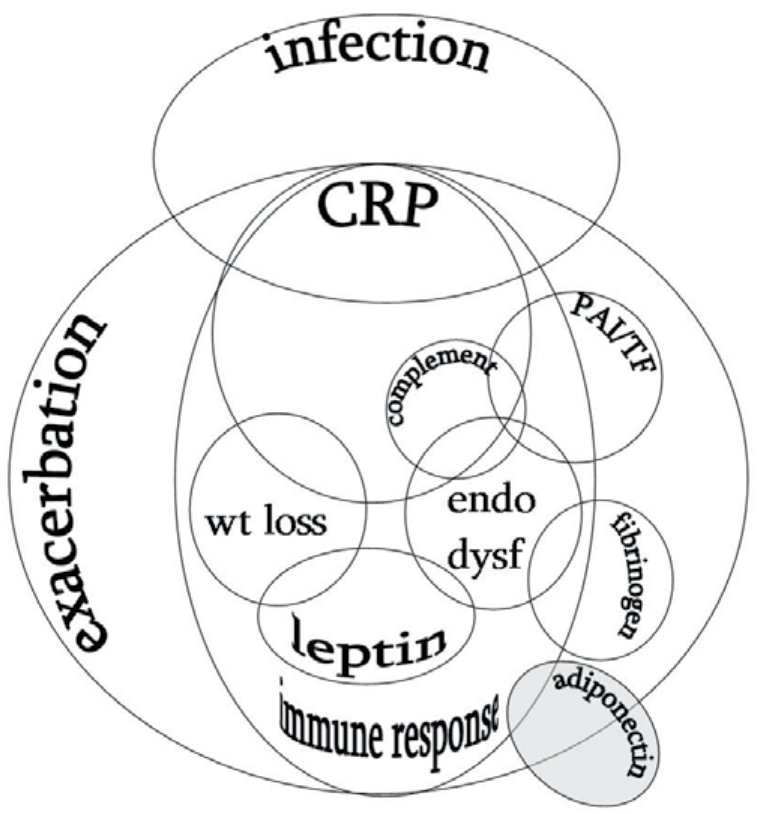

Acknowledgement

The authors thank Dr. Scott Wagers for critical reviewing this manuscript. 


\section{References}

1. Pauwels, R. A., A. S. Buist, P. M. Calverley, C. R. Jenkins, and S. S. Hurd. 2001. Global strategy for the diagnosis, management, and prevention of chronic obstructive pulmonary disease. NHLBI/WHO Global Initiative for Chronic Obstructive Lung Disease (GOLD) Workshop summary. Am J Respir Crit Care Med 163(5):1256-76.

2. Wouters, E. F. 2002. Chronic obstructive pulmonary disease. 5: systemic effects of COPD. Thorax 57(12):1067-70.

3. Agusti, A. G. 2005. COPD, a multicomponent disease: implications for management. Respir Med 99(6):670-82.

4. Molina, V., and Y. Shoenfeld. 2005. Infection, vaccines and other environmental triggers of autoimmunity. Autoimmunity 38(3):235-45.

5. Ebringer, A., and T. Rashid. 2006. Rheumatoid arthritis is an autoimmune disease triggered by Proteus urinary tract infection. Clin Dev Immunol 13(1):41-8.

6. Rodriguez-Roisin, R. 2000. Toward a consensus definition for COPD exacerbations. Chest $117(5$ Suppl 2):398S-401S.

7. Vermeeren, M. A., A. M. Schols, and E. F. Wouters. 1997. Effects of an acute exacerbation on nutritional and metabolic profile of patients with COPD. Eur Respir | 10(10):2264-9.

8. White, A. J., S. Gompertz, and R. A. Stockley. 2003. Chronic obstructive pulmonary disease . 6: The aetiology of exacerbations of chronic obstructive pulmonary disease. Thorax 58(1):7380.

9. Monso, E., J. Ruiz, A. Rosell, J. Manterola, J. Fiz, J. Morera, and V. Ausina. 1995. Bacterial infection in chronic obstructive pulmonary disease. A study of stable and exacerbated outpatients using the protected specimen brush. Am J Respir Crit Care Med 152(4 Pt 1):131620.

10. Pela, R., F. Marchesani, C. Agostinelli, D. Staccioli, L. Cecarini, C. Bassotti, and C. M. Sanguinetti. 1998. Airways microbial flora in COPD patients in stable clinical conditions and during exacerbations: a bronchoscopic investigation. Monaldi Arch Chest Dis 53(3):262-7.

11. Sethi, S., N. Evans, B. J. Grant, and T. F. Murphy. 2002. New strains of bacteria and exacerbations of chronic obstructive pulmonary disease. N Engl J Med 347(7):465-71.

12. Sethi, S., C. Wrona, B. J. Grant, and T. F. Murphy. 2004. Strain-specific immune response to Haemophilus influenzae in chronic obstructive pulmonary disease. Am J Respir Crit Care Med 169(4):448-53.

13. Sethi, S., J. Maloney, L. Grove, C. Wrona, and C. S. Berenson. 2006. Airway inflammation and bronchial bacterial colonization in chronic obstructive pulmonary disease. Am J Respir Crit Care Med 173(9):991-8.

14. White, A. J., S. Gompertz, D. L. Bayley, S. L. Hill, C. O'Brien, I. Unsal, and R. A. Stockley 2003. Resolution of bronchial inflammation is related to bacterial eradication following treatment of exacerbations of chronic bronchitis. Thorax 58(8):680-5.

15. Murphy, T. F., A. L. Brauer, B. J. Grant, and S. Sethi. 2005. Moraxella catarrhalis in chronic obstructive pulmonary disease: burden of disease and immune response. Am J Respir Crit Care Med 172(2):195-9.

16. Seemungal, T., R. Harper Owen, A. Bhowmik, I. Moric, G. Sanderson, S. Message, P. Maccallum, T. W. Meade, D. J. Jeffries, S. L. Johnston, and J. A. Wedzicha. 2001. Respiratory viruses, symptoms, and inflammatory markers in acute exacerbations and stable chronic obstructive pulmonary disease. Am J Respir Crit Care Med 164(9):1618-23.

17. Franciosi, L. G., C. P. Page, B. R. Celli, M. Cazzola, M. J. Walker, M. Danhof, K. F. Rabe, and O. E. Della Pasqua. 2006. Markers of disease severity in chronic obstructive pulmonary disease. Pulm Pharmacol Ther 19(3):189-99.

18. Hurst, J. R., G. C. Donaldson, W. R. Perera, T. M. Wilkinson, J. A. Bilello, G. W. Hagan, R. 


\section{Systemic inflammation in COPD: the role of acute exacerbations}

S. Vessey, and J. A. Wedzicha. 2006. Use of plasma biomarkers at exacerbation of chronic obstructive pulmonary disease. Am J Respir Crit Care Med 174(8):867-74.

19. Sapey, E., and R. A. Stockley. 2006. COPD exacerbations . 2: aetiology. Thorax 61 (3):250-8.

20. Franciosi, L. G., C. P. Page, B. R. Celli, M. Cazzola, M. J. Walker, M. Danhof, K. F. Rabe, and O. E. Della Pasqua. 2006. Markers of exacerbation severity in chronic obstructive pulmonary disease. Respir Res 7:74.

21. Dev, D., E. Wallace, R. Sankaran, J. Cunniffe, J. R. Govan, C. G. Wathen, and F. X. Emmanuel. 1998. Value of C-reactive protein measurements in exacerbations of chronic obstructive pulmonary disease. Respir Med $92(4): 664-7$.

22. Hill, A. T., E. J. Campbell, D. L. Bayley, S. L. Hill, and R. A. Stockley. 1999. Evidence for excessive bronchial inflammation during an acute exacerbation of chronic obstructive pulmonary disease in patients with alpha(1)-antitrypsin deficiency (PiZ). Am J Respir Crit Care Med 160(6):1968-75.

23. Dentener, M. A., E. C. Creutzberg, A. M. Schols, A. Mantovani, C. van't Veer, W. A. Buurman, and E. F. Wouters. 2001. Systemic anti-inflammatory mediators in COPD: increase in soluble interleukin 1 receptor II during treatment of exacerbations. Thorax 56(9):721-6.

24. Malo, O., J. Sauleda, X. Busquets, C. Miralles, A. G. Agusti, and A. Noguera. 2002. [Systemic inflammation during exacerbations of chronic obstructive pulmonary disease]. Arch Bronconeumol 38(4):172-6. Spanish.

25. Pinto-Plata, V. M., G. Livnat, M. Girish, H. Cabral, P. Masdin, P. Linacre, R. Dew, L. Kenney, and B. R. Celli. 2007. Systemic cytokines, clinical and physiological changes in patients hospitalized for exacerbation of COPD. Chest 131 (1):37-43.

26. Calikoglu, M., G. Sahin, A. Unlu, C. Ozturk, L. Tamer, B. Ercan, A. Kanik, and U. Atik. 2004. Leptin and TNF-alpha levels in patients with chronic obstructive pulmonary disease and their relationship to nutritional parameters. Respiration 71 (1):45-50.

27. Creutzberg, E. C., E. F. Wouters, I. M. Vanderhoven Augustin, M. A. Dentener, and A. M. Schols. 2000. Disturbances in leptin metabolism are related to energy imbalance during acute exacerbations of chronic obstructive pulmonary disease. Am J Respir Crit Care Med $162(4$ Pt 1):1239-45.

28. Roland, M., A. Bhowmik, R. J. Sapsford, T. A. Seemungal, D. J. Jeffries, T. D. Warner, and J. A. Wedzicha. 2001. Sputum and plasma endothelin-1 levels in exacerbations of chronic obstructive pulmonary disease. Thorax 56(1):30-5.

29. Fiorini, G., S. Crespi, M. Rinaldi, E. Oberti, R. Vigorelli, and G. Palmieri. 2000. Serum ECP and MPO are increased during exacerbations of chronic bronchitis with airway obstruction. Biomed Pharmacother 54(5):274-8.

30. Wedzicha, J. A., T. A. Seemungal, P. K. MacCallum, E. A. Paul, G. C. Donaldson, A. Bhowmik, D. J. Jeffries, and T. W. Meade. 2000. Acute exacerbations of chronic obstructive pulmonary disease are accompanied by elevations of plasma fibrinogen and serum IL-6 levels. Thromb Haemost 84(2):210-5.

31. Stockley, R. A., D. L. Bayley, I. Unsal, and L. J. Dowson. 2002. The effect of augmentation therapy on bronchial inflammation in alphar-antitrypsin deficiency. Am J Respir Crit Care Med 165(11):1494-8.

32. Shindo, K., Y. Hirai, M. Fukumura, and K. Koide. 1997. Plasma levels of leukotriene E4 during clinical course of chronic obstructive pulmonary disease. Prostaglandins Leukot Essent Fatty Acids 56(3):213-7.

33. Hurst, J. R., W. R. Perera, T. M. Wilkinson, G. C. Donaldson, and J. A. Wedzicha. 2006. Systemic and upper and lower airway inflammation at exacerbation of chronic obstructive pulmonary disease. Am J Respir Crit Care Med 173(1):71-8.

34. Hurst, J. R., W. R. Perera, T. M. Wilkinson, G. C. Donaldson, and J. A. Wedzicha. 2006. Exacerbation of chronic obstructive pulmonary disease: pan-airway and systemic inflammatory indices. Proc Am Thorac Soc 3(6):481-2. 
35. Perera, W. R., J. R. Hurst, T. M. Wilkinson, R. J. Sapsford, H. Mullerova, G. C. Donaldson, and J. A. Wedzicha. 2007. Inflammatory changes, recovery and recurrence at COPD exacerbation. Eur Respir ) 29(3):527-34.

36. Weis, N., and T. Almdal. 2006. C-reactive protein--can it be used as a marker of infection in patients with exacerbation of chronic obstructive pulmonary disease? Eur / Intern Med $17(2): 88-91$.

37. Stolz, D., M. Christ-Crain, N. G. Morgenthaler, J. Leuppi, D. Miedinger, R. Bingisser, C. Muller, J. Struck, B. Muller, and M. Tamm. 2007. Copeptin, C-reactive protein, and procalcitonin as prognostic biomarkers in acute exacerbation of COPD. Chest 131 (4):1058-67.

38. Pinto-Plata, V., J. Toso, K. Lee, D. Park, J. Bilello, H. Mullerova, M. M. De Souza, R. Vessey, and B. Celli. 2007. Profiling serum biomarkers in patients with COPD: associations with clinical parameters. Thorax 62(7):595-601.

39. Laudanna, C., J. Y. Kim, G. Constantin, and E. Butcher. 2002. Rapid leukocyte integrin activation by chemokines. Immunol Rev 186:37-46.

40. Iwasaki, A., and R. Medzhitov. 2004. Toll-like receptor control of the adaptive immune responses. Nat Immunol 5(10):987-95.

41. McCurdy, J. D., T. J. Olynych, L. H. Maher, and J. S. Marshall. 2003. Cutting edge: distinct Toll-like receptor 2 activators selectively induce different classes of mediator production from human mast cells. J Immunol 170(4):1625-9.

42. Mantovani, A. 1999. The chemokine system: redundancy for robust outputs. Immunol Today $20(6): 254-7$.

43. Hornung, V., S. Rothenfusser, S. Britsch, A. Krug, B. Jahrsdorfer, T. Giese, S. Endres, and G. Hartmann. 2002. Quantitative expression of toll-like receptor 1-10 mRNA in cellular subsets of human peripheral blood mononuclear cells and sensitivity to CpG oligodeoxynucleotides. I Immunol 168(9):4537-7.

44. Nagase, H., S. Okugawa, Y. Ota, M. Yamaguchi, H. Tomizawa, K. Matsushima, K. Ohta, K. Yamamoto, and K. Hirai. 2003. Expression and function of Toll-like receptors in eosinophils: activation by Toll-like receptor 7 ligand. J Immunol 171(8):3977-82.

45. Demedts, I. K., K. R. Bracke, G. Van Pottelberge, D. Testelmans, G. M. Verleden, F. E. Vermassen, G. F. Joos, and G. G. Brusselle. 2007. Accumulation of Dendritic Cells and Increased CCL2O Levels in the Airways of Patients with Chronic Obstructive Pulmonary Disease. Am J Respir Crit Care Med 175(10):998-1005.

46. Starner, T. D., C. K. Barker, H. P. Jia, Y. Kang, and P. B. McCray, Jr. 2003. CCL2O is an inducible product of human airway epithelia with innate immune properties. Am J Respir Cell Mol Biol $29(5): 627-33$.

47. Pepys, M. B., and M. L. Baltz. 1983. Acute phase proteins with special reference to C-reactive protein and related proteins (pentaxins) and serum amyloid A protein. Adv Immunol 34:141. 212.

48. Vigushin, D. M., M. B. Pepys, and P. N. Hawkins. 1993. Metabolic and scintigraphic studies of radioiodinated human C-reactive protein in health and disease. J Clin Invest 91 (4):1351-7.

49. Thompson, D., M. B. Pepys, and S. P. Wood. 1999. The physiological structure of human C-reactive protein and its complex with phosphocholine. Structure 7(2):169-77.

50. Pepys, M. B., and G. M. Hirschfield. 2003. C-reactive protein: a critical update. J Clin Invest $111(12): 1805-12$.

51. Harnett, W., and M. M. Harnett. 1999. Phosphorylcholine: friend or foe of the immune system? Immunol Today 20(3):125-9.

52. Gershov, D., S. Kim, N. Brot, and K. B. Elkon. 2000. C-Reactive protein binds to apoptotic cells, protects the cells from assembly of the terminal complement components, and sustains an antiinflammatory innate immune response: implications for systemic autoimmunity. J Exp Med 192(9):1353-64. 


\section{Systemic inflammation in COPD: the role of acute exacerbations}

53. Kushner, I., and M. H. Kaplan. 1961. Studies of acute phase protein. I. An immunohistochemical method for the localization of Cx-reactive protein in rabbits. Association with necrosis in local inflammatory lesions. J Exp Med 114:961-74.

54. Chang, M. K., C. J. Binder, M. Torzewski, and J. L. Witztum. 2002. C-reactive protein binds to both oxidized LDL and apoptotic cells through recognition of a common ligand: Phosphorylcholine of oxidized phospholipids. Proc Natl Acad Sci U S A 99(20):13043-8.

55. Pepys, M. B., I. F. Rowe, and M. L. Baltz. 1985. C-reactive protein: binding to lipids and lipoproteins. Int Rev Exp Pathol 27:83-111.

56. Volanakis, J. E. 1982. Complement activation by C-reactive protein complexes. Ann N Y Acad Sci 389:235-50.

57. Mold, C., H. Gewurz, and T. W. Du Clos. 1999. Regulation of complement activation by Creactive protein. Immunopharmacology $42(1-3): 23-30$.

58. Bohlson, S. S., D. A. Fraser, and A. J. Tenner. 2007. Complement proteins C1q and MBL are pattern recognition molecules that signal immediate and long-term protective immune functions. Mol Immunol 44(1-3):33-43.

59. Kosmas, E. N., D. Zorpidou, V. Vassilareas, T. Roussou, and S. Michaelides. 1997. Decreased $\mathrm{C}_{4}$ complement component serum levels correlate with the degree of emphysema in patients with chronic bronchitis. Chest 112(2):341-7.

6o. Chauhan, S., M. K. Gupta, A. Goyal, and D. J. Dasgupta. 1990. Alterations in immunoglobulin \& complement levels in chronic obstructive pulmonary disease. Indian J Med Res 92:241-5.

61. Marc, M. M., P. Korosec, M. Kosnik, I. Kern, M. Flezar, S. Suskovic, and J. Sorli. 2004. Complement factors $\mathrm{C3}$ a, c4a, and c5a in chronic obstructive pulmonary disease and asthma. Am J Respir Cell Mol Biol 31(2):216-9.

62. Gould, J. M., and J. N. Weiser. 2001. Expression of C-reactive protein in the human respiratory tract. Infect Immun 69(3):1747-54.

63. Trayhurn, P., and I. S. Wood. 2004. Adipokines: inflammation and the pleiotropic role of white adipose tissue. Br f Nutr 92(3):347-55.

64. Trayhurn, P., and I. S. Wood. 2005. Signalling role of adipose tissue: adipokines and inflammation in obesity. Biochem Soc Trans 33(Pt 5):1078-81.

65. Tomoda, K., M. Yoshikawa, T. Itoh, S. Tamaki, A. Fukuoka, K. Komeda, and H. Kimura. 2007. Elevated circulating plasma adiponectin in underweight patients with COPD. Chest $132(1): 135-40$.

66. Zhang, Y., R. Proenca, M. Maffei, M. Barone, L. Leopold, and J. M. Friedman. 1994. Positional cloning of the mouse obese gene and its human homologue. Nature 372(6505):425-32.

67. Ahima, R. S., and J. S. Flier. 2000. Leptin. Annu Rev Physiol 62:413-37.

68. Yu, W. H., M. Kimura, A. Walczewska, S. Karanth, and S. M. McCann. 1997. Role of leptin in hypothalamic-pituitary function. Proc Natl Acad Sci U S A 94(3):1023-8.

69. Bornstein, S. R., K. Uhlmann, A. Haidan, M. Ehrhart-Bornstein, and W. A. Scherbaum. 1997 Evidence for a novel peripheral action of leptin as a metabolic signal to the adrenal gland: leptin inhibits cortisol release directly. Diabetes 46(7):1235-8.

70. Bennett, B. D., G. P. Solar, J. Q. Yuan, J. Mathias, G. R. Thomas, and W. Matthews. 1996. A role for leptin and its cognate receptor in hematopoiesis. Curr Biol 6(9):1170-80.

71. Umemoto, Y., K. Tsuji, F. C. Yang, Y. Ebihara, A. Kaneko, S. Furukawa, and T. Nakahata. 1997. Leptin stimulates the proliferation of murine myelocytic and primitive hematopoietic progenitor cells. Blood 9o(9):3438-43.

72. Sierra-Honigmann, M. R., A. K. Nath, C. Murakami, G. Garcia-Cardena, A. Papapetropoulos, W. C. Sessa, L. A. Madge, J. S. Schechner, M. B. Schwabb, P. J. Polverini, and J. R. FloresRiveros. 1998. Biological action of leptin as an angiogenic factor. Science 281 (5383):1683-6.

73. Bouloumie, A., H. C. Drexler, M. Lafontan, and R. Busse. 1998. Leptin, the product of Ob 
gene, promotes angiogenesis. Circ Res 83(10):1059-66.

74. Harigaya, A., K. Nagashima, Y. Nako, and A. Morikawa. 1997. Relationship between concentration of serum leptin and fetal growth. J Clin Endocrinol Metab 82 (10):3281-4.

75. Koistinen, H. A., V. A. Koivisto, S. Andersson, S. L. Karonen, K. Kontula, L. Oksanen, and K. A. Teramo. 1997. Leptin concentration in cord blood correlates with intrauterine growth. I Clin Endocrinol Metab 82(10):3328-30.

76. Otero, M., R. Lago, F. Lago, F. F. Casanueva, C. Dieguez, J. J. Comez-Reino, and O. Gualillo. 2005. Leptin, from fat to inflammation: old questions and new insights. FEBS Lett 579(2):295-301.

77. Tartaglia, L. A. 1997. The leptin receptor. J Biol Chem 272(10):6093-6.

78. Tartaglia, L. A., M. Dembski, X. Weng, N. Deng, J. Culpepper, R. Devos, G. J. Richards, L. A. Campfield, F. T. Clark, J. Deeds, C. Muir, S. Sanker, A. Moriarty, K. J. Moore, J. S. Smutko, G. G. Mays, E. A. Wool, C. A. Monroe, and R. I. Tepper. 1995. Identification and expression cloning of a leptin receptor, OB-R. Cell 83(7):1263-71.

79. Fruhbeck, G. 2006. Intracellular signalling pathways activated by leptin. Biochem I 393 (Pt 1):7-20.

80. La Cava, A., C. Alviggi, and G. Matarese. 2004. Unraveling the multiple roles of leptin in inflammation and autoimmunity. J Mol Med 82:4-11.

81. Caldefie-Chezet, F., A. Poulin, and M. P. Vasson. 2003. Leptin regulates functional capacities of polymorphonuclear neutrophils. Free Radic Res 37(8):809-14.

82. Moore, S. I., G. B. Huffnagle, G. H. Chen, E. S. White, and P. Mancuso. 2003. Leptin modulates neutrophil phagocytosis of Klebsiella pneumoniae. Infect Immun 71 (7):4182-5.

83. Loffreda, S., S. Q. Yang, H. Z. Lin, C. L. Karp, M. L. Brengman, D. J. Wang, A. S. Klein, G. B. Bulkley, C. Bao, P. W. Noble, M. D. Lane, and A. M. Diehl. 1998. Leptin regulates proinflammatory immune responses. Faseb | 12(1):57-65.

84. Santos-Alvarez, J., R. Goberna, and V. Sanchez-Margalet. 1999. Human leptin stimulates proliferation and activation of human circulating monocytes. Cell Immunol 194(1):6-11.

85. Martin-Romero, C., J. Santos-Alvarez, R. Goberna, and V. Sanchez-Margalet. 2000. Human leptin enhances activation and proliferation of human circulating $T$ lymphocytes. Cell Immunol 199(1):15-24.

86. Fujita, Y., M. Murakami, Y. Ogawa, H. Masuzaki, M. Tanaka, S. Ozaki, K. Nakao, and T. Mimori. 2002. Leptin inhibits stress-induced apoptosis of T lymphocytes. Clin Exp Immunol 128(1):21-6.

87. Lord, G. M., G. Matarese, J. K. Howard, R. J. Baker, S. R. Bloom, and R. I. Lechler 1998. Leptin modulates the T-cell immune response and reverses starvation-induced immunosuppression. Nature 394(6696):897-901.

88. Frank, S., B. Stallmeyer, H. Kampfer, N. Kolb, and J. Pfeilschifter. 2000. Leptin enhances wound re-epithelialization and constitutes a direct function of leptin in skin repair. J Clin Invest 106(4):501-9.

89. Fraser, D. A., J. Thoen, J. E. Reseland, O. Forre, and J. Kjeldsen-Kragh. 1999. Decreased $\mathrm{CD}_{4}+$ lymphocyte activation and increased interleukin-4 production in peripheral blood of rheumatoid arthritis patients after acute starvation. Clin Rheumatol 18(5):394-401.

90. Matarese, G., P. B. Carrieri, A. La Cava, F. Perna, V. Sanna, V. De Rosa, D. Aufiero, S. Fontana, and S. Zappacosta. 2005. Leptin increase in multiple sclerosis associates with reduced number of $\mathrm{CD}_{4}(+) \mathrm{CD}_{25}$ + regulatory T cells. Proc Natl Acad Sci U S A 102 (14):5150-5.

91. Sakaguchi, S. 2004. Naturally arising $C_{4}+$ regulatory t cells for immunologic self-tolerance and negative control of immune responses. Annu Rev Immunol 22:531-62.

92. Bruno, A., P. Chanez, G. Chiappara, L. Siena, S. Giammanco, M. Gjomarkaj, G. Bonsignore, J. Bousquet, and A. M. Vignola. 2005. Does leptin play a cytokine-like role within the airways 


\section{Systemic inflammation in COPD: the role of acute exacerbations}

of COPD patients? Eur Respir / 26(3):398-405.

93. Broekhuizen, R., J. H. Vernooy, A. M. Schols, M. A. Dentener, and E. F. Wouters. 2005. Leptin as local inflammatory marker in COPD. Respir Med 99(1):70-4.

94. Beltowski, J. 2003. Adiponectin and resistin--new hormones of white adipose tissue. Med Sci Monit 9(2):RA55-61.

95. Fantuzzi, C. 2005. Adipose tissue, adipokines, and inflammation. J Allergy Clin Immunol 115(5):911-9; quiz 920.

96. Chandran, M., S. A. Phillips, T. Ciaraldi, and R. R. Henry. 2003. Adiponectin: more than just another fat cell hormone? Diabetes Care 26(8):2442-50.

97. Waki, H., T. Yamauchi, J. Kamon, S. Kita, Y. Ito, Y. Hada, S. Uchida, A. Tsuchida, S. Takekawa, and T. Kadowaki. 2005. Generation of globular fragment of adiponectin by leukocyte elastase secreted by monocytic cell line THP-1. Endocrinology 146(2):790-6.

98. Masaki, T., S. Chiba, H. Tatsukawa, T. Yasuda, H. Noguchi, M. Seike, and H. Yoshimatsu. 2004. Adiponectin protects LPS-induced liver injury through modulation of TNF-alpha in KKAy obese mice. Hepatology 40(1):177-84.

99. Kumada, M., S. Kihara, N. Ouchi, H. Kobayashi, Y. Okamoto, K. Ohashi, K. Maeda, H. Nagaretani, K. Kishida, N. Maeda, A. Nagasawa, T. Funahashi, and Y. Matsuzawa. 2004. Adiponectin specifically increased tissue inhibitor of metalloproteinase-1 through interleukin10 expression in human macrophages. Circulation 109(17):2046-9.

100. Wolf, A. M., D. Wolf, H. Rumpold, B. Enrich, and H. Tilg. 2004. Adiponectin induces the anti-inflammatory cytokines IL-10 and IL-1RA in human leukocytes. Biochem Biophys Res Commun 323(2):630-5.

101. Wulster-Radcliffe, M. C., K. M. Ajuwon, J. Wang, J. A. Christian, and M. E. Spurlock. 2004. Adiponectin differentially regulates cytokines in porcine macrophages. Biochem Biophys Res Commun 316(3):924-9.

102. Ouchi, N., S. Kihara, Y. Arita, K. Maeda, H. Kuriyama, Y. Okamoto, K. Hotta, M. Nishida, M. Takahashi, T. Nakamura, S. Yamashita, T. Funahashi, and Y. Matsuzawa. 1999. Novel modulator for endothelial adhesion molecules: adipocyte-derived plasma protein adiponectin. Circulation 100(25):2473-6.

103. Kawanami, D., K. Maemura, N. Takeda, T. Harada, T. Nojiri, Y. Imai, I. Manabe, K. Utsunomiya, and R. Nagai. 2004. Direct reciprocal effects of resistin and adiponectin on vascular endothelial cells: a new insight into adipocytokine-endothelial cell interactions. Biochem Biophys Res Commun 314(2):415-9.

104. Verma, S., and T. J. Anderson. 2002. Fundamentals of endothelial function for the clinical cardiologist. Circulation 105(5):546-9.

105. Ridker, P. M., C. H. Hennekens, J. E. Buring, and N. Rifai. 2000. C-reactive protein and other markers of inflammation in the prediction of cardiovascular disease in women. N Engl / Med 342(12):836-43.

106. Ridker, P. M., M. J. Stampfer, and N. Rifai. 2001. Novel risk factors for systemic atherosclerosis: a comparison of C-reactive protein, fibrinogen, homocysteine, lipoprotein (a), and standard cholesterol screening as predictors of peripheral arterial disease. Jama 285(19):2481-5.

107. Ridker, P. M. 2001. High-sensitivity C-reactive protein: potential adjunct for global risk assessment in the primary prevention of cardiovascular disease. Circulation 103(13):1813-8.

108. Szmitko, P. E., C. H. Wang, R. D. Weisel, J. R. de Almeida, T. J. Anderson, and S. Verma. 2003. New markers of inflammation and endothelial cell activation: Part I. Circulation 108(16):191723.

109. Verma, S., C. H. Wang, S. H. Li, A. S. Dumont, P. W. Fedak, M. V. Badiwala, B. Dhillon, R. D. Weisel, R. K. Li, D. A. Mickle, and D. J. Stewart. 2002. A self-fulfilling prophecy: C-reactive protein attenuates nitric oxide production and inhibits angiogenesis. Circulation 106(8):913-9. 
110. Verma, S., S. H. Li, M. V. Badiwala, R. D. Weisel, P. W. Fedak, R. K. Li, B. Dhillon, and D. A. Mickle. 2002. Endothelin antagonism and interleukin- 6 inhibition attenuate the proatherogenic effects of C-reactive protein. Circulation 105(16):1890-6.

111. Verma, S., M. V. Badiwala, R. D. Weisel, S. H. Li, C. H. Wang, P. W. Fedak, R. K. Li, and D. A. Mickle. 2003. C-reactive protein activates the nuclear factor-kappaB signal transduction pathway in saphenous vein endothelial cells: implications for atherosclerosis and restenosis. J Thorac Cardiovasc Surg 126(6):1886-91.

112. Wang, C. H., S. H. Li, R. D. Weisel, P. W. Fedak, A. S. Dumont, P. Szmitko, R. K. Li, D. A. Mickle, and S. Verma. 2003. C-reactive protein upregulates angiotensin type 1 receptors in vascular smooth muscle. Circulation 107(13):1783-90.

113. Verma, S., M. A. Kuliszewski, S. H. Li, P. E. Szmitko, L. Zucco, C. H. Wang, M. V. Badiwala, D. A. Mickle, R. D. Weisel, P. W. Fedak, D. J. Stewart, and M. J. Kutryk. 2004. C-reactive protein attenuates endothelial progenitor cell survival, differentiation, and function: further evidence of a mechanistic link between $\mathrm{C}$-reactive protein and cardiovascular disease. Circulation $109(17): 2058-67$.

114. Beltowski, J. 2006. Leptin and atherosclerosis. Atherosclerosis 189(1):47-60.

115. Fischetti, F., and F. Tedesco. 2006. Cross-talk between the complement system and endothelial cells in physiologic conditions and in vascular diseases. Autoimmunity 39(5):41728.

116. Wedzicha, J. A., D. Syndercombe-Court, and K. C. Tan. 1991. Increased platelet aggregate formation in patients with chronic airflow obstruction and hypoxaemia. Thorax 46(7):504-7.

117. Wedzicha, J. A., F. E. Cotter, and D. W. Empey. 1988. Platelet size in patients with chronic airflow obstruction with and without hypoxaemia. Thorax 43(1):61-4.

118. Nenci, G. G., M. Berrettini, T. Todisco, and P. Parise. 1981. Enhanced plasma betathromboglobulin in hypoxemia: effect of dipyridamole. N Engl J Med 304(17):1044.

119. Ferroni, P., S. Basili, F. Martini, M. Vieri, G. Labbadia, C. Cordova, C. Alessandri, and P. P. Gazzaniga. 2000. Soluble P-selectin as a marker of platelet hyperactivity in patients with chronic obstructive pulmonary disease. J Investig Med 48(1):21-7.

120. Davi, G., S. Basili, M. Vieri, F. Cipollone, S. Santarone, C. Alessandri, P. Gazzaniga, C. Cordova, and F. Violi. 1997. Enhanced thromboxane biosynthesis in patients with chronic obstructive pulmonary disease. The Chronic Obstructive Bronchitis and Haemostasis Study Group. Am-J-Respir-Crit-Care-Med 156(6):1794-9 issn: 1073-449x.

121. Ashitani, J., H. Mukae, Y. Arimura, and S. Matsukura. 2002. Elevated plasma procoagulant and fibrinolytic markers in patients with chronic obstructive pulmonary disease. Intern Med $41(3): 181-5$.

122. Tapson, V. F. 2005. The role of smoking in coagulation and thromboembolism in chronic obstructive pulmonary disease. Proc Am Thorac Soc 2(1):71-7.

123. Hemker, H. C., P. L. Giesen, M. Ramjee, R. Wagenvoord, and S. Beguin. 2000. The thrombogram: monitoring thrombin generation in platelet-rich plasma. Thromb Haemost $83(4): 589-91$.

124. Monroe, D. M., and H. R. Roberts. 2003. Mechanism of action of high-dose factor VIla: points of agreement and disagreement. Arterioscler Thromb Vasc Biol 23(1):8-9; discussion 10.

125. Kohler, H. P., and P. J. Grant. 2000. Plasminogen-activator inhibitor type 1 and coronary artery disease. N Engl J Med 342(24):1792-801.

126. Esmon, C. T. 2005. The interactions between inflammation and coagulation. Br / Haematol $131(4): 417-30$.

127. Mannino, D. M., E. S. Ford, and S. C. Redd. 2003. Obstructive and restrictive lung disease and markers of inflammation: data from the Third National Health and Nutrition Examination. Am J Med 114(9):758-62. 


\section{Systemic inflammation in COPD: the role of acute exacerbations}

128. Parry, G., and N. Mackman. 1998. NF-kB mediated transcription in human monocytic cells and endothelial cells. Trends Cardiovasc Med 8:138-142.

129. Lindmark, E., T. Tenno, and A. Siegbahn. 2000. Role of platelet P-selectin and CD40 ligand in the induction of monocytic tissue factor expression. Arterioscler Thromb Vasc Biol $20(10): 2322-8$.

130. Han, K. H., K. H. Hong, J. H. Park, J. Ko, D. H. Kang, K. J. Choi, M. K. Hong, S. W. Park, and S. J. Park. 2004. C-reactive protein promotes monocyte chemoattractant protein-1--mediated chemotaxis through upregulating CC chemokine receptor 2 expression in human monocytes. Circulation $109(21): 2566-71$.

131. Cermak, J., N. S. Key, R. R. Bach, J. Balla, H. S. Jacob, and G. M. Vercellotti. 1993. C-reactive protein induces human peripheral blood monocytes to synthesize tissue factor. Blood $82(2): 513-20$.

132. Devaraj, S., D. Y. Xu, and I. Jialal. 2003. C-reactive protein increases plasminogen activator inhibitor-1 expression and activity in human aortic endothelial cells: implications for the metabolic syndrome and atherothrombosis. Circulation 107(3):398-404.

133. Burstein, S. 1997. Cytokines, platelet production and hemostasis. Platelets 8:93-104.

134. Nystedt, S., V. Ramakrishnan, and J. Sundelin. 1996. The proteinase-activated receptor 2 is induced by inflammatory mediators in human endothelial cells. Comparison with the thrombin receptor. J Biol Chem 271(25):14910-5.

135. Levi, M., T. T. Keller, E. van Gorp, and H. ten Cate. 2003. Infection and inflammation and the coagulation system. Cardiovasc Res 6o(1):26-39.

136. Klein, N. J., G. I. Shennan, R. S. Heyderman, and M. Levin. 1992. Alteration in glycosaminoglycan metabolism and surface charge on human umbilical vein endothelial cells induced by cytokines, endotoxin and neutrophils. J Cell Sci 102 ( Pt 4):821-32.

137. Conway, E. M., and R. D. Rosenberg. 1988. Tumor necrosis factor suppresses transcription of the thrombomodulin gene in endothelial cells. Mol Cell Biol 8(12):5588-92.

138. Fukudome, K., and C. T. Esmon. 1994. Identification, cloning, and regulation of a novel endothelial cell protein C/activated protein C receptor. J Biol Chem 269(42):26486-91.

139. Pendurthi, U. R., D. Alok, and L. V. Rao. 1997. Binding of factor VIla to tissue factor induces alterations in gene expression in human fibroblast cells: up-regulation of poly $(A)$ polymerase. Proc Natl Acad Sci U S A 94(23):12598-603.

140. Miller, D. L., R. Yaron, and M. J. Yellin. 1998. CD4OL-CD40 interactions regulate endothelial cell surface tissue factor and thrombomodulin expression. J Leukoc Biol 63(3):373-9.

141. Henn, V., J. R. Slupsky, M. Grafe, I. Anagnostopoulos, R. Forster, G. Muller-Berghaus, and R. A. Kroczek. 1998. CD40 ligand on activated platelets triggers an inflammatory reaction of endothelial cells. Nature 391(6667):591-4.

142. Andre, P., K. S. Prasad, C. V. Denis, M. He, J. M. Papalia, R. O. Hynes, D. R. Phillips, and D. D. Wagner. 2002. CD4OL stabilizes arterial thrombi by a betaz integrin--dependent mechanism. Nat Med 8(3):247-52.

143. Camerer, E., J. A. Rottingen, E. Gjernes, K. Larsen, A. H. Skartlien, J. G. Iversen, and H. Prydz. 1999. Coagulation factors VIla and Xa induce cell signaling leading to up-regulation of the egr-1 gene. J Biol Chem 274(45):32225-33.

144. Isermann, B., S. B. Hendrickson, K. Hutley, M. Wing, and H. Weiler. 2001. Tissue-restricted expression of thrombomodulin in the placenta rescues thrombomodulin-deficient mice from early lethality and reveals a secondary developmental block. Development 128(6):827-38.

145. Loike, J. D., J. el Khoury, L. Cao, C. P. Richards, H. Rascoff, J. T. Mandeville, F. R. Maxfield, and S. C. Silverstein. 1995. Fibrin regulates neutrophil migration in response to interleukin 8 , leukotriene B4, tumor necrosis factor, and formyl-methionyl-leucyl-phenylalanine. J Exp Med 181 (5):1763-72. 


CHAPTER 8

Mortality and mortalityrelated factors after hospitalization for acute exacerbations of COPD

Chest 2003 Aug;124 (2): 459-467

$\mathrm{KH}$ Groenewegen

EFM Wouters 


\section{Abstract}

\section{Background}

Acute exacerbations form a major component of the socio-economic burden of COPD. Little information is yet available about the long term outcome of patients hospitalized with acute exacerbation, although high mortality rates have been reported.

\section{Study objective}

The aim of this study was to investigate prospectively the outcome for all patients admitted with acute exacerbation of COPD during admission and after one year of follow-up. Furthermore, patient characteristics related to increased mortality rate were analyzed.

\section{Design}

We investigated prospectively the one year mortality rate and potential determinants of mortality for all patients admitted with an acute exacerbation between January 1st and December 31st, 1999.

\section{Results}

171 Patients were included in the study. Mortality rate during hospital admission was $8 \%$, increasing to $23 \%$ after one year of follow-up. Despite a comparable in-hospital mortality ( $6 \%$ ) one year mortality was significantly higher for patients admitted to ICU for respiratory failure. (35\%).

The multivariate Cox proportional hazards model was used to determine independent predictors of survival. Variables included in the regression model were age, sex, $\mathrm{FEV}_{1}, \mathrm{PaO}_{2}, \mathrm{PaCO}_{2}$, $\mathrm{BMI}$, chronic use of oral corticosteroids, comorbidity index and readmissions. Maintenance use of oral glucocorticosteroids, $\mathrm{PaCO}_{2}$ and age were independently related to mortality. (Relative Risks 5.07 (2.03$12.64) ; 1.17$ (1.01-1.38); and 1.07 (1.01-1.12) respectively.)

\section{Conclusion}

We conclude that prognosis in patients admitted for acute exacerbation of COPD is poor. Chronic use of oral corticosteroids, higher $\mathrm{PaCO}_{2}$ and older age could be identified as risk factors associated with higher mortality. 


\section{Introduction}

Chronic Obstructive Pulmonary Disease is a major cause of morbidity and mortality and an important health economic problem. Since 1960 there has been an increase in mortality associated with COPD, especially in men. In recent years mortality from COPD, especially among women has further increased[1]. Worldwide COPD is the only leading cause of death that still has a rising mortality and it has been estimated that by the year 2020 COPD will be fifth among the conditions with a high burden to society[2]. Hospitalization for acute exacerbations represent a major component of the socio-economic burden related to COPD [3]. Despite the high number of COPD related hospitalizations, relatively little is known about the mortality rate and related determinants of patients hospitalized for this acute deterioration in the clinical course of COPD. The most important and largest study on survival after hospital admission for acute exacerbation was performed by Connors et al [4]. They reported high mortality rates;- in-hospital mortality was $11 \%$, mortality after one year was $43 \%$, slightly increasing to $49 \%$ after 2 years.

Among COPD patients requiring mechanical ventilation for respiratory failure, mortality is even higher as demonstrated by a recent study that reported an inhospital mortality of $24 \%$ for all patients and $30 \%$ for patients of 65 years and older, with mortality rates after discharge increasing to $59 \%$ after one year [5]. Several studies have investigated predictive factors related to an increased COPD related mortality risk. Patient characteristics that have been reported to influence survival in stable COPD patients include $\mathrm{FEV}_{1},[6-8]$, age $[7,8]$, arterial carbon dioxide tension $\left(\mathrm{PaCO}_{2}\right)[6]$, cardiac factors $[6,7]$, diffusion capacity $[6]$ and BMI [9-12].

Other studies have investigated more specifically factors related to mortality after acute exacerbations of COPD. Factors that have been reported as risk factors for mortality after exacerbation are arterial carbon dioxide tension $\left(\mathrm{PaCO}_{2}\right)$, oxygen saturation and resting oxygen consumption [13] , low body mass index (BMI) $[4,9]$, older age $[4,14,15]$, cardiac factors $[4,14,15]$ and other co-morbidity [15], severity of illness, serum albumin, functional status and arterial oxygen tension $\left(\mathrm{PaO}_{2}\right)$ [4]. The present study was designed to assess prospectively the mortality rates and potential determinants of mortality for patients admitted for an acute exacerbation of COPD during admission and after one year of follow-up. Patient characteristics related to an increased mortality rate were analyzed.

Furthermore the frequency and the determinants of readmissions were assessed. 


\section{Material and Methods}

We prospectively included all patients, admitted for an acute exacerbation of COPD to the pulmonology ward of the University Hospital Maastricht, between January 1st 1999 and December 31st 1999. Besides its academic function, the University Hospital of Maastricht has an important function as regional hospital, therefore this patient population is representative for general pulmonary practices.

Patients were included if the following criteria were met: diagnosis of COPD, according to the criteria of the American Thoracic Society[16] (all patients had $\mathrm{FEV} 1<70 \%$ predicted and reversibility $<11 \%$ ), and symptoms indicating an acute exacerbation of COPD. An exacerbation was defined by the presence of an increase in at least two of the three following symptoms: dyspnea, cough and sputum purulence, severe enough to warrant hospital admission. Each patient was included only once in the study even if hospitalized more than once. During admission, patients were treated with a standard protocol consisting of intravenous administration of corticosteroids in standardized dosage of 0.5 $\mathrm{mg} / \mathrm{kg}$, theophylline and nebulization of salbutamol and ipratropiumbromide as bronchodilating agents. $\mathrm{O}_{2}$ was titrated according to blood gas analyses.

\section{Clinical data}

For all included patients the following data were assessed: medical history, lung function measurements, blood gases, body mass index (BMI), duration of hospital stay, treatment prior to admission and use of oral corticosteroids. Medical history, previous treatment, use of oral corticosteroids and co-morbid conditions were recorded on standardized forms from the patients charts. Use and duration of oral corticosteroids were verified from outpatient records. Chronic use of corticosteroids was defined as the daily use of oral corticosteroids for at least one year in a dosage of at least $5 \mathrm{mg}$ Prednisolone or equivalent.

Co-morbidity was quantified according to the Charlson index [17]. This index has been developed to predict mortality of patients with chronic diseases. It assigns to each disease a score that is proportional to the disease related risk of death. A score of 1 is allocated to myocardial infarct, congestive heart failure, peripheral vascular disease, cerebrovascular disease, dementia, COPD, connective tissue disease, ulcer disease, mild liver disease and diabetes. A score of 2 is allocated to diabetes with end organ damage, hemiplegia, renal disease and malignancies including leukemia and lymphoma. A score of 3 is attributed to moderate or severe liver disease while AIDS and metastatic malignancies are attributed a score of 6 .

\section{Measurements}

On admission, arterial blood gases at rest were assessed by puncture of the radial artery during room air breathing. On the first day after admission, while patients were in a fasting state, body weight without clothes was measured in 
kilograms.(SECA, Germany). Body height was measured in centimeters with the patient standing barefoot (SECA, Germany). Body mass index (BMI) was determined in $\mathrm{kg} / \mathrm{m}^{2}$.

On admission and after recovery (immediately before discharge) lung function was determined with a portable pneumotachograph (Jaeger instruments, Würzburg, Germany). FEV values measured immediately before discharge were used in the analyses. FEV, values were expressed as a percentage of the reference values.

\section{Outcomes}

During their hospital stay patients were monitored and outcomes were determined: length of hospital stay, mortality and need for intubation or noninvasive ventilation. The decision to transfer a patient to ICU for mechanical or non-invasive ventilation was made on clinical grounds in case of worsening of respiratory failure.

After discharge patients were followed prospectively for at least one year. The following parameters were determined: survival time, need for readmission and number of readmissions. Only readmissions because of an acute exacerbation of COPD were counted. Survival was determined in several ways. If patients died during hospital stay, their date of death was recorded and verified by hospital records. If patients died after discharge, their date of death was verified from hospital records, general practitioners records or the death records of the city in which they lived. The status of all patients was confirmed in this way.

Mortality rates were determined for the admission period and during the follow-up period, until at least one year after discharge. Unfortunately mortality registration in the Netherlands does not allow access to actual records to determine the cause of death, so only for patients who died during their hospital stay, the cause of death was known.

\section{Data analysis}

Patients were categorized for FEV 1 according to ATS criteria [16].

All data were expressed as mean values \pm standard deviation.

All statistical analyses were performed using the Statistical Products and Service Solutions (SPSS 9.0 ; Chicago,IL,USA) for Windows Package. Nominal variables were compared using the Chi-square test. Comparisons between groups were performed using Analysis of Variance. (ANOVA) Comparisons of individual predictor variables were performed using Cox regression analysis. To determine independent predictors of mortality all predictor variables were included in a Cox proportional hazards model. Age, number of admission days, forced expiratory volume in one second ( $\left.F E V_{1}\right)$, body mass index (BMI), resting arterial blood gases $\left(\mathrm{PaO}_{2}\right.$ and $\left.\mathrm{PaCO}_{2}\right)$ and co-morbidity index were included as continuous variables in the model and chronic use of oral corticosteroids $(\mathrm{O}=\mathrm{no}, 1=$ yes), gender ( $\mathrm{O}$ $=$ males, $1=$ females $)$ and need for readmission $(\mathrm{O}=$ no, $1=$ yes $)$ as categorical 
variables. Crude and adjusted relative risks (RR) with and without adjustment for interaction between the various risk factors are shown in table 3. The RR corresponding to a risk factor in this model is the exponential of the regression coefficient. Baseline comparisons were done by unpaired student t-test with Bonferroni correction for multiple comparisons.

A two-sided value of $p<0.05$ was considered statistically significant. Survival plots for the influence of oral corticosteroid use versus no steroids were drawn and analysed using the Kaplan-Meier method.

\section{Results}

\section{Patient characteristics}

Between January 1st 1999 and January 1st 2000, 171 patients were admitted to the pulmonology ward of the University Hospital Maastricht with an acute exacerbation of COPD. Patient characteristics are listed in table 1.

Most patients were elderly and comorbid illnesses were common. About $30 \%$ of the patients had even 2 or more comorbid conditions. Hypoxia was a common condition on admission as well as hypercapnia: $85 \%$ of the patients had a $\mathrm{PaO}_{2} \leq$ $8.7 \mathrm{kPa}$ and $55 \%$ had a $\mathrm{PaCO}_{2} \geq 5.9 \mathrm{kPa}$ on admission. According to ATS criteria for COPD severity, $51 \%$ of the patients were in stage III (FEV $<35$ predicted), $35 \%$ in stage II ( $\mathrm{FEV}_{1} 35 \%$ to 49 predicted), and $14 \%$ in stage I ( $\mathrm{FEV}_{1} \geq 50 \%$ predicted), based on lung function measurements before discharge. 12 Patients were not able to perform spirometry during hospital stay; 10 of these patients were followed for an established diagnosis of severe COPD at our outpatient department and their condition during admission did not tolerate lung function tests. In the remaining 2 patients, the diagnosis of COPD was established on clinical grounds and both patients had a previous history of COPD documented by their general practitioner. 17 Patients (10\%) used daily oral corticosteroids for at least one year in a median dosage of $7.5 \mathrm{mg}$.

17 Patients had to be transferred to ICU after admission because of progressive respiratory failure. In 15 patients referral to ICU was necessary on the first (11 patients) or second (4 patients) day after admission, because of failure of conservative treatment. In the remaining 2 patients there was deterioration of their clinical condition after initial improvement.

10 Patients had to be intubated for mechanical ventilation, 4 patients received noninvasive ventilation (BiPAP) and in 3 patients ventilatory support could be avoided by intensive conservative treatment. When patient characteristics of ICU patients and non-ICU admitted patients were compared, ICU patients had higher $\mathrm{PCO}_{2}$ and lower $\mathrm{pH}$ values (table 2).

Crude and adjusted relative risks (RR) for mortality are shown in table 3. 
Table 1. Characteristics of 171 patients with acute exacerbation of COPD.

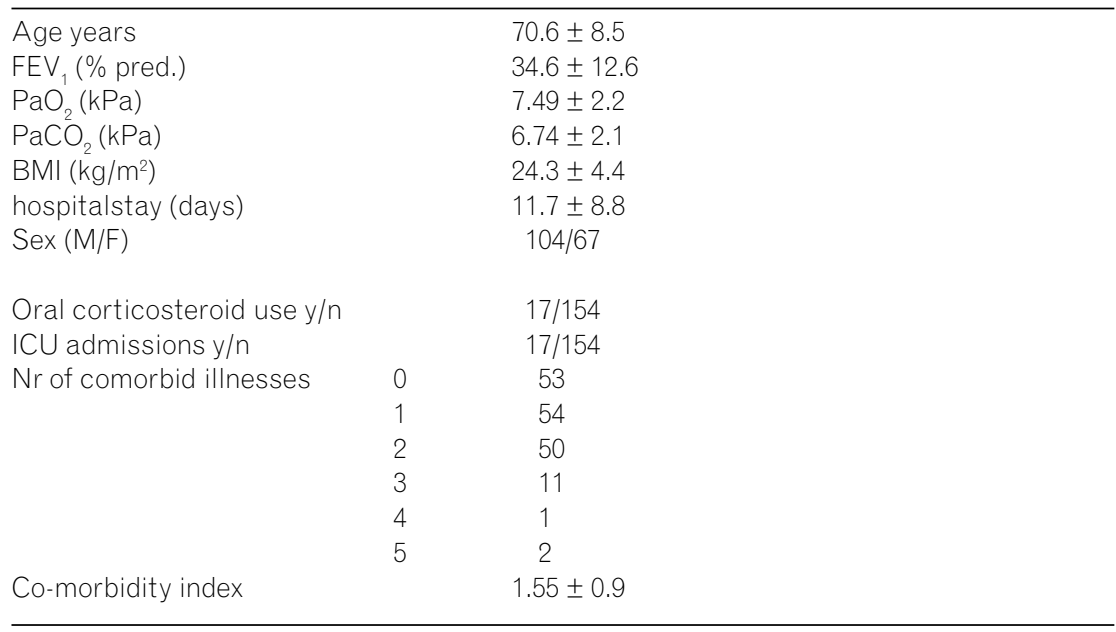

Table 2. Characteristics of patients transferred to Intensive Care.

\begin{tabular}{llll}
\hline Mean \pm SD & $\begin{array}{l}\text { ICU patients } \\
\mathbf{n}=\mathbf{1 7}\end{array}$ & $\begin{array}{l}\text { non-ICU } \\
\text { admitted patients } \\
\mathbf{n}=\mathbf{1 5 4}\end{array}$ & p-value \\
\hline Age $(\mathrm{yr})$ & $73.4 \pm 6.5$ & $0.4 \pm 8.6$ & $\mathrm{n} . \mathrm{s}$ \\
$\mathrm{FEV}_{1}(\%$ pred $)$ & $34.2 \pm 12.2$ & $39.1 \pm 15.4$ & $\mathrm{n} . \mathrm{s}$ \\
$\mathrm{PaO}_{2}(\mathrm{kPa})$ & $8.0 \pm 5.0$ & $7.4 \pm 2.7$ & $\mathrm{n} . \mathrm{s}$ \\
$\mathrm{PaCO}_{2}(\mathrm{kPa})$ & $9.3 \pm 2.7$ & $6.5 \pm 1.9$ & 0.0001 \\
$\mathrm{pH}$ & $7.31 \pm 0.9$ & $7.39 \pm 0.7$ & 0.0001 \\
$\mathrm{BMl}\left(\mathrm{kg} / \mathrm{m}^{2}\right)$ & $26.1 \pm 6.5$ & $24.1 \pm 4.2$ & $\mathrm{n} . \mathrm{s}$ \\
$\mathrm{co-morbidity} \mathrm{index}$ & $1.50 \pm 0.89$ & $1.55 \pm 0.90$ & $\mathrm{n} . \mathrm{s}$ \\
corticosteroid use & $2 / 15$ & $15 / 139$ & $\mathrm{n} . \mathrm{s}$ \\
\hline
\end{tabular}


Table 3. Multivariate Cox proportional hazards model for factors associated with mortality.

\begin{tabular}{|c|c|c|c|c|c|c|}
\hline Covariate & $\begin{array}{c}\mathbf{R R} \\
\text { crude }\end{array}$ & $95 \% \mathrm{Cl}$ & p value & $\begin{array}{c}\mathbf{R R} \\
\text { adjusted }\end{array}$ & $95 \% \mathrm{Cl}$ & p value \\
\hline Age yr & 1.0876 & $1.0424-1.1348$ & 0.0001 & 1.0648 & $1.0111-1.1214$ & 0.0175 \\
\hline Sex M/F & 1.0826 & $0.6054-1.9358$ & 0.79 & 0.9836 & $0.4604-2.1010$ & 0.9659 \\
\hline $\begin{array}{l}\text { Admission } \\
\text { days }\end{array}$ & 1.0373 & $1.0156-1.0598$ & 0.0007 & 1.0125 & 0.9801-1.0459 & 0.4558 \\
\hline $\mathrm{FEV}_{1} \%$ & 1.0221 & $1.0424-1.1348$ & 0.0001 & 1.0154 & $0.9908-1.0406$ & 0.2225 \\
\hline $\mathrm{PaO}_{2} \mathrm{kPa}$ & 1.0134 & $0.9052-1.1344$ & 0.8177 & 1.1471 & $1.0171-1.2937$ & 0.0254 \\
\hline $\mathrm{PaCO}_{2} \mathrm{kPa}$ & 1.2044 & $1.0838-1.3384$ & 0.0006 & 1.1786 & $1.0082-1.3778$ & 0.0392 \\
\hline BMI kg/m² & 0.9454 & $0.8801-1.0160$ & 0.1271 & 0.9210 & $0.8453-1.0033$ & 0.0596 \\
\hline Steroid use $y / n$ & 4.01 & $2.0803-7.7296$ & 0.0001 & 5.0684 & $2.0317-12.6422$ & 0.0005 \\
\hline $\begin{array}{l}\text { Co-morbidity } \\
\text { index }\end{array}$ & 1.3814 & $1.0615-1.7976$ & 0.0162 & 1.2176 & $0.9151-1.6202$ & 0.1767 \\
\hline $\begin{array}{l}\text { Readmissions } \\
y / n\end{array}$ & 1.3983 & $0.7977-2.4513$ & 0.2417 & 1.7274 & $0.8087-3.6895$ & 0.1581 \\
\hline
\end{tabular}

\section{Outcomes}

\section{In-hospital mortality}

Median hospital stay was 10 days. Median hospital stay was longer for patients after ICU admission (16.9 days) than in the conservatively treated group ( 9.5 days) $(p=0.005)$.

13 Patients (8\%) died during their hospital stay. One of these patients had been admitted to ICU. The other 12 patients were not admitted to ICU because the decision not to intubate them in case of respiratory failure had been made on medical grounds (in case of terminal COPD) or according to the patient's own wish.

In all in-hospital cases of mortality, progressive respiratory failure was the primary cause of death; 9 patients suffered from COPD alone while in 3 patients respiratory failure was the consequence of COPD and congestive heart failure; in 1 patient COPD treatment was complicated with a treatment refractory gastro-intestinal bleeding.

Of the surviving patients, most patients were discharged home $(147=93 \%)$; 6 patients $(=4 \%)$ were transferred to another hospital or to another ward; 3 patients $(=2 \%)$ were discharged to a nursing home and 2 patients $(=1 \%)$ were discharged to a senior citizens home. 
Figure 1. Influence of chronic corticosteroid use on survival.

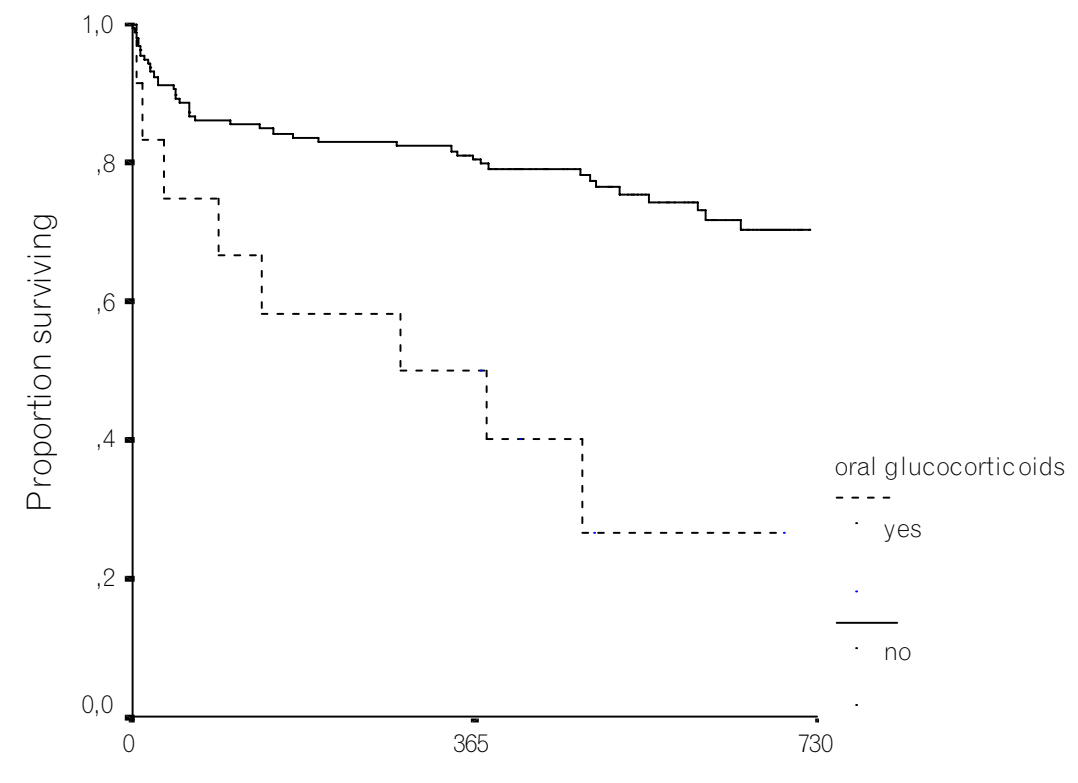

Follow up (days)

\section{Mortality during follow-up}

Mean follow-up after discharge was 571 days (ranging from 365 to 725 days). No patients were lost to follow-up.

The Kaplan-Meier survival plot for the entire study population is shown in figure 1. In the first 3 months after discharge, 13 additional patients (=8\%) died. Overall mortality rate at 3 months was $16 \%$.

3 More patients ( $2 \%$ ) died within 6 months after initial admission. Mortality rate at 6 months was $18 \%$.

In the period between 6 months and one year after study entry 8 other patients ( 5 $\%)$ died. Mortality rate after one year was $23 \%$.

Overall mortality was higher in patients requiring ICU admission for respiratory failure $(6 / 17=35 \%)$ than for patients not requiring ICU admission $(31 / 154=23 \%)$. $(p=0.045)$

Separate mortality rates for ICU and non-ICU admitted patients are shown in figure 2. 
Figure 2. Mortality for ICU and non-ICU admitted patients.

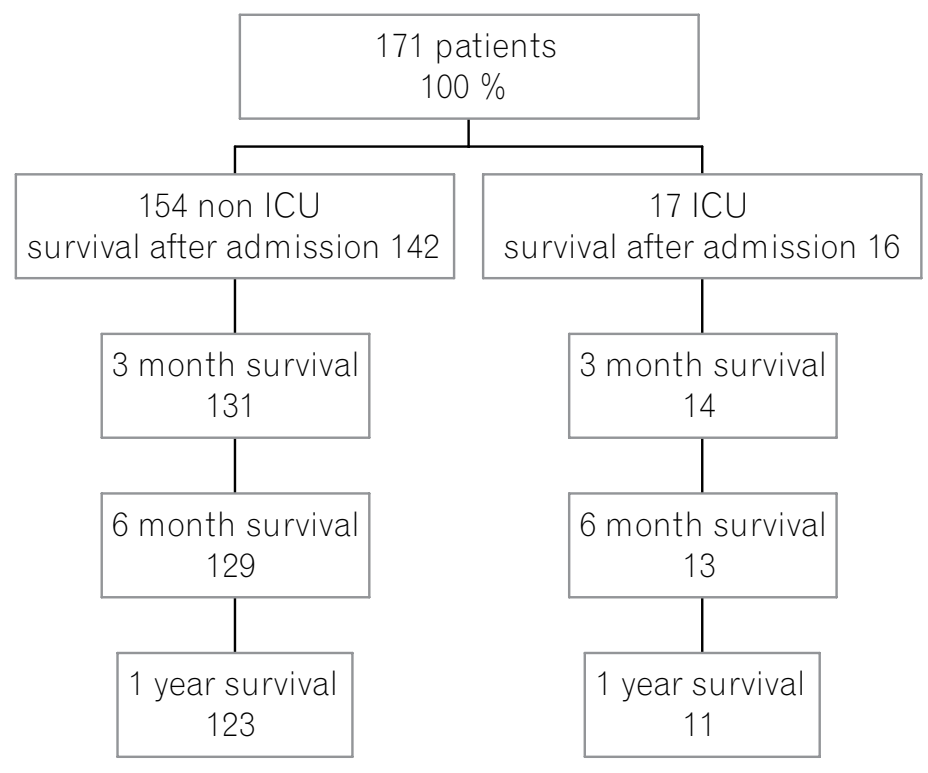

\section{Factors related to survival}

Table 3 shows the results of the bivariate analyses for influence of risk factors on survival (crude relative risk (RR)). High values for age, number of admission days and co-morbidity index, and low values for $\mathrm{FEV}_{1}, \mathrm{PaCO}_{2}$ and use of oral corticosteroids were significantly associated with increased mortality.

Table 3 also shows the results of the Cox regression analysis adjusting for the above mentioned parameters (adjusted RR)

The chronic use of oral corticosteroids, blood gas values on admission and older age had an independent adverse effect on survival after acute exacerbation of COPD, after adjusting for the influence of all other variables.

Duration of hospital stay, gender, lung function ( $\mathrm{FEV}_{1}$ in \% predicted), $\mathrm{Pa}_{2}$ and the presence of comorbidity were not independently associated with mortality. Body mass index reached borderline significance as an independent factor associated with mortality.

The subgroup of patients that were on maintenance corticosteroid treatment consisted of 17 patients of whom 9 patients died in the one year follow up period: 3 patients died during admission, 4 patients within the first 6 months after discharge 
Table 4. Characteristics of patients with and without oral corticosteroids.

\begin{tabular}{lccc}
\hline & $\begin{array}{c}\text { with } \\
\text { corticosteroids } \\
\mathbf{n = 1 7}\end{array}$ & $\begin{array}{c}\text { without } \\
\text { corticosteroids } \\
\mathbf{n = 1 5 4}\end{array}$ & p value \\
\hline $\mathrm{Age}$ & $73.3 \pm 7.3$ & $70.4 \pm 8.6$ & n.s. \\
$\mathrm{FEV}_{1}$ & $34.5 \pm 15.0$ & $34.7 \pm 12.3$ & n.s. \\
$\mathrm{PaO}_{2}$ & $7.2 \pm 1.7$ & $7.5 \pm 2.3$ & n.s. \\
$\mathrm{PaCO}_{2}$ & $7.4 \pm 2.5$ & $6.7 \pm 2.1$ & n.s. \\
$\mathrm{BMl}$ & $24.7 \pm 3.6$ & $24.3 \pm 4.5$ & n.s. \\
1 or more readmissions & $76 \%$ & $49 \%$ & 0.0026 \\
Co-morbidity index & $1.65 \pm 0.79$ & $1.54 \pm 0.91$ & n.s. \\
\hline
\end{tabular}

and 2 patients within one year after discharge.

The Kaplan-Meier plot for influence of chronic corticosteroid use on survival is shown in figure 1.

Comparisons between patients with and without oral corticosteroids are shown in table 4.

On admission, there was no difference in age, $\mathrm{FEV}_{1}, \mathrm{PaO}_{2}, \mathrm{PaCO}_{2}, \mathrm{BMI}$ or comorbidity index between patients with and without corticosteroid use. Patients with chronic oral corticosteroid use however had a higher number of readmissions in the follow-up period. $(p=0.0026)$

\section{Readmissions}

Readmissions to the hospital frequently occurred during the follow-up period: 86 patients $(=55 \%)$ had one or more readmissions in the first year after discharge. The total number of readmissions was 216 in this group. The total of days spent in the hospital because of readmission was 2052 days. Median number of readmissions was one per patient.

27 Patients (= $16 \%$ ) had one readmission, 29 patients (= $17 \%$ ) had 2 readmissions, 15 patients $(=9 \%)$ had 3 readmissions and 15 patients $(=9 \%)$ had even more than 3 readmissions. Since this is the only hospital in the region, it is highly unlikely that any of the patients was readmitted into another hospital. In the first month after discharge, 24 patients (14\%) had to be readmitted because of acute exacerbation, 12 more patients (7\%) were readmitted for the first time within 3 months after discharge, 15 patients (9\%) were readmitted within 6 months and 34 patients (20\%) had their first readmission within one year from discharge. 
Table 5. Characteristics of patients with and without readmission.

\begin{tabular}{lccl}
\hline & 1 or more readmissions & no readmission & p-value \\
\hline Age (years) & $68.7 \pm 8.8$ & $72.6 \pm 7.7$ & 0.003 \\
$\mathrm{FEV}_{1}(\% \mathrm{pred})$ & $33.8 \pm 12.5$ & $35.5 \pm 12.7$ & n.s \\
$\mathrm{PaO}_{2}(\mathrm{kPa})$ & $7.3 \pm 1.6$ & $7.5 \pm 2.2$ & n.s \\
$\mathrm{PaCO}_{2}(\mathrm{kPa})$ & $6.6 \pm 2.0$ & $6.9 \pm 2.0$ & n.s \\
$\mathrm{pH}$ & $7.38 \pm 0.8$ & $7.37 \pm 0.7$ & n.s \\
$\mathrm{BMI}\left(\mathrm{kg} / \mathrm{m}^{2}\right)$ & $24.2 \pm 4.2$ & $24.4 \pm 4.7$ & n.s \\
Comorbidity Index & $1.43 \pm 0.73$ & $1.67 \pm 1.0$ & n.s \\
Corticosteroids $\mathrm{y} / \mathrm{n}$ & $13 / 73$ & $4 / 81$ & 0.038 \\
Survived $\mathrm{y} / \mathrm{n}$ & $59 / 26$ & $63 / 23$ & n.s \\
Living alone $\mathrm{y} / \mathrm{n}$ & $27 / 58$ & $23 / 63$ & n.s \\
\hline
\end{tabular}

Patients that were readmitted one or more times were younger than patients without readmission and had more chronic corticosteroid treatment but there were no differences in $\mathrm{FEV}_{1}, \mathrm{PaO}_{2}, \mathrm{PaCO}_{2}, \mathrm{pH}, \mathrm{BMI}$ or co-morbidity index. There was no difference in survival rates between readmitters and non-readmitters.

Social status of patients (whether they were living alone or not) did not influence readmission.

These results are shown in table 5 .

\section{Discussion}

The present study confirms previous data about mortality after acute exacerbations of COPD.

Mortality during admission for an acute exacerbation of COPD was high and continued to increase after discharge.

For patients requiring ICU admission during their hospital stay, mortality was even higher.

Besides $\mathrm{PaCO}_{2}$ and age, which were previously established as predictors of mortality, the chronic use of oral corticosteroids was found to be an important independent risk factor for mortality.

Most patients were discharged home. In the study follow-up period readmissions to the hospital because of acute exacerbation were common. Patients requiring one or more readmissions because of acute exacerbation were younger and used more chronic corticosteroid medication. 
The high mortality rates we found following admission for an exacerbation of COPD are in line with other reports. In a cohort of 1016 patients, Connors et al. reported in-hospital mortality of $11 \%$, increasing to $33 \%$ after 6 months and $43 \%$ after one year. ${ }^{4}$ Fuso et al reported an in-hospital mortality of $14.4 \% .^{14}$ In a study among patients who required mechanical ventilation for respiratory failure, an in-hospital mortality rate of $24 \%$ was reported. ${ }^{5}$

In our population age, $\mathrm{PaCO}_{2}$ and use of oral corticosteroids were determining factors for mortality after an acute exacerbation. Sex, duration of hospital stay, $\mathrm{FEV}_{1}, \mathrm{BMI}$, co-morbidity index and number of readmissions had no influence on mortality.

In the past, several factors have been implied as risk factors for increased mortality in COPD, after an acute exacerbation of the disease. In a study among COPD patients comparable to our patient population, Connors et al reported severity of illness, $\mathrm{BMI}$, age, prior functional status, $\mathrm{PaO}_{2} / \mathrm{FiO}_{2}$, congestive heart failure, serum albumin and the presence of cor pulmonale to be independently related to survival, following acute exacerbation [4].

Although age and $\mathrm{PaCO}_{2}$ have been recognized in previous studies to be predictors for survival, the chronic use of oral corticosteroids as a risk factor for mortality is a new finding. This may have important implications for therapy. A possible explanation for higher mortality among patients using oral corticosteroids could be the side-effects of this medication.

Prolonged treatment with oral corticosteroids has significant side-effects [18] of which the most important are: suppression of the hypothalamic-adrenal axis, infectious complications, myopathy, diabetes, osteoporosis, gastro-intestinal effects such as peptic ulcers, hypertension, and cataract. A recent study reported a significant increase in fractures and other adverse effects in patients with lung disease using oral corticosteroids, that was strongly related to the cumulative dose taken [19].

Several studies have demonstrated a relation between respiratory and peripheral muscle strength and steroid treatment in COPD patients [20,21], negatively influencing functional status in COPD patients [22,23].

The relation between oral corticosteroid therapy and mortality has not been studied extensively. In studies among patients using long term oxygen therapy, oral corticosteroid treatment was related to increased mortality in women $[24,25]$. Recently, we demonstrated a dose-dependent increased mortality risk in COPD patients using maintenance treatment with oral corticosteroids [26]. This observation is important to consider since positive effects are not well established and discontinuation of chronic systemic corticosteroid treatment in steroid dependent COPD patients does not cause a significant increase in COPD exacerbations [27]. 
Maintenance treatment with oral corticosteroids has been estimated to offer a clinically significant improvement in only $10 \%$ of patients [28]. Systemic oral corticosteroids are often prescribed for exacerbations but according to a recent trial the effect is limited to the first two weeks of treatment [29].

Remarkable is that in our population the patients who were using maintenance treatment with oral corticosteroids were not different in clinical characteristics like age, lung function parameters, blood gas results, body mass index and presence of co-morbidity. Therefore the reason for prescribing maintenance treatment with oral corticosteroids is unclear. Possibly, continuation of oral corticosteroid treatment is related to the frequency of exacerbations, as the chronic steroid users have more frequent readmissions. On the other hand, these readmissions could also have been the result of mentioned side-effects, creating a vicious circle for these patients.

In the present study age was also an independent predictor of mortality. In a large number of other studies age has been demonstrated to be an important determinant of survival in COPD $[4,7,8,15,30]$. Age has also been associated with an accelerated decline in lung function [31]. It seems important to discover and treat symptoms of COPD in an earlier stage to try to prevent this decline.

A high arterial carbon dioxide tension was also found as a risk factor for mortality in our population. This is in line with other reports $[5,9,13,32]$. The level of hypercapnia, suggestive of chronic alveolar hypoventilation, reflects the severity of the underlying respiratory condition and patients with chronic hypercapnia, who comprised the majority of our study population, have a worse prognosis than patients with normoventilation.

In our study we did not find any influence of body mass index on survival, contrary to other reports $[4,9]$. This may be because body mass index was relatively well preserved in our study population, with mean BMI of 24. Another explanation could be that BMI was measured on admission, while some patients may have had fluid retention at that point because of concomitant right heart failure or because of decreased renal flow as a result of respiratory failure. As a consequence, BMI may have been overestimated in the analyses. Nevertheless, there was a trend to a higher mortality risk for patients with lower body mass index $(p=0.0596)$.

In the present study, there was also no influence of co-morbidity on survival in contrast to a report by Incalzi [15] which specifically investigated this factor, and other studies that have demonstrated influence of specific cardiac diseases on survival [4-14]. A possible explanation could be that we measured co-morbidity by the Charlson index, which also lacked predictive ability in the study of Incalzi. It was hypothesized that only selected diseases like cardiac failure or cor pulmonale can influence the prognosis in severe COPD patients. We have not specifically measured cardiac factors in this study and echocardiographs were not performed, unless indicated by a cardiologist. 
An important problem in the treatment of acute exacerbations is the need for readmission. In the present study the number of readmissions was high, $55 \%$ had one or more readmissions because of acute exacerbation during the follow up period.

Like for mortality, determining factors for readmission in the present study were age and use of oral corticosteroids. Remarkably, patients who were readmitted one or more times were younger than other patients; it is difficult to find an explanation for this finding.

Also readmitted patients used more frequently maintenance oral corticosteroids. The reason for the observed relationship between corticosteroid use and readmission is not clear, but it could be due to earlier mentioned side-effects of corticosteroid use .

The need for readmission was not associated with mortality in this population. This is in contrast to the findings of Connors [4], who found that patients that had to be readmitted one or more times had a higher mortality. However, in the latter study the aspect of medication was not taken into account.

Our results demonstrate that mortality after acute exacerbation is high, especially for older patients with chronic respiratory failure. This is important to realize in order to be able to offer the patient better supportive care. In a recent study, patients with severe COPD with at least one admission for hypercapnic respiratory failure were compared to patients treated for unresectable non-small cell lung cancer [33]. Results of this study showed that COPD patients had significantly worse ADL, physical, social and emotional functioning than NSCLC patients. This study confirmed that COPD patients do not receive the necessary palliative care that is appropriate in their situation.

The present study emphasizes the need for adequate care facilities in patients treated for acute exacerbations. The care needs of these patients should be considered comparable to patients with lung cancer.

The present study demonstrates clearly that mortality in patients with acute exacerbation of COPD is high and risk factors are older age, higher carbon dioxide tension and chronic use of oral corticosteroids. These results should be taken into account when making clinical decisions in patients admitted with acute exacerbations, especially when prescribing corticosteroid treatment. 


\section{References}

1 Lacasse Y, Brooks D, Goldstein RS. Trends in the epidemiology of COPD in Canada, 1980 to 1995. COPD and Rehabilitation Committee of the Canadian Thoracic Society. Chest 1999; 116:306-313

2 Hurd S. The impact of COPD on lung health worldwide: epidemiology and incidence. Chest 2000; 117:15-4S

3 Rutten van Molken MP, Postma MJ, Joore MA, et al. Current and future medical costs of asthma and chronic obstructive pulmonary disease in The Netherlands. Respir Med 1999; 93:779-787

4 Connors AF, Jr., Dawson NV, Thomas C, et al. Outcomes following acute exacerbation of severe chronic obstructive lung disease. The SUPPORT investigators (Study to Understand Prognoses and Preferences for Outcomes and Risks of Treatments). Am J Respir Crit Care Med 1996; 154:959-967

5 Seneff MG, Wagner DP, Wagner RP, et al. Hospital and 1-year survival of patients admitted to intensive care units with acute exacerbation of chronic obstructive pulmonary disease. JAMA $1995 ; 274: 1852-1857$

6 Burrows B, Earle RH. Prediction of survival in patients with chronic airway obstruction. Am Rev Respir Dis 1969; 99:865-871

7 Traver GA, Cline MG, Burrows B. Predictors of mortality in chronic obstructive pulmonary disease. A 15-year follow-up study. Am Rev Respir Dis 1979; 119:895-902

8 Anthonisen NR, Wright EC, Hodgkin JE. Prognosis in chronic obstructive pulmonary disease. Am Rev Respir Dis 1986; 133:14-20

9 Gray Donald K, Gibbons L, Shapiro SH, et al. Nutritional status and mortality in chronic obstructive pulmonary disease. Am / Respir Crit Care Med 1996; 153:961-966

10 Hospers J), Schouten JP, Weiss ST, et al. Asthma Attacks with Eosinophilia Predict Mortality from Chronic Obstructive Pulmonary Disease in a General Population Sample. Am J Respir Crit Care Med 1999; 160:1869-1874

11 Landbo C, Prescott E, Lange P, et al. Prognostic Value of Nutritional Status in Chronic Obstructive Pulmonary Disease. Am J Respir Crit Care Med 1999; 160:1856-1861

12 Schols A, Slangen J, Volovics L, et al. Weight loss is a reversible factor in the prognosis of chronic obstructive pulmonary disease. Am J Resp Crit Care Med 1998; 157:1791-1797

13 Sukumalchantra Y, Dinakara P, Williams MH, Jr. Prognosis of patients with chronic obstructive pulmonary disease after hospitalization for acute ventilatory failure: a three-year follow-up study. Am Rev Respir Dis 1966; 93:215-222

14 Fuso L, Incalzi RA, Pistelli R, et al. Predicting mortality of patients hospitalized for acutely exacerbated chronic obstructive pulmonary disease. Am J Med 1995; 98:272-277

15 Incalzi RA, Fuso L, DeRosa M, et al. Co-morbidity contributes to predict mortality of patients with chronic obstructive pulmonary disease. Eur Resp I 1997; 10:2794-2800

16 ATS. Standards for the diagnosis and care of patients with chronic obstructive pulmonary disease (COPD) and asthma. This official statement of the American Thoracic Society was adopted by the ATS Board of Directors, November 1986. Am Rev Respir Dis 1987; 136:225244

17 Charlson ME, Pompei P, Ales KL, et al. A new method of classifying prognostic comorbidity in longitudinal studies: development and validation. J Chronic Dis 1987; 40:373-383

18 McEvoy CE, Niewoehner DE. Adverse effects of corticosteroid therapy for COPD. A critical review. Chest 1997; 111:732-743

19 Walsh L), Wong CA, Oborne J, et al. Adverse effects of oral corticosteroids in relation to dose in patients with lung disease. Thorax 2001; 56:279-284.

20 Decramer M, Stas KJ. Corticosteroid-induced myopathy involving respiratory muscles in 
patients with chronic obstructive pulmonary disease or asthma. Am Rev Respir Dis 1992; 146:800-802

21 Decramer M, Lacquet LM, Fagard R, et al. Corticosteroids contribute to muscle weakness in chronic airflow obstruction. Am J Respir Crit Care Med 1994; 150:11-16

22 Gosselink R, Troosters T, Decramer M. Peripheral muscle weakness contributes to exercise limitation in COPD. Am J Respir Crit Care Med 1996; 153:976-980

23 Bernard S, LeBlanc P, Whittom F, et al. Peripheral muscle weakness in patients with chronic obstructive pulmonary disease. Am / Respir Crit Care Med 1998; 158:629-634

24 Strom K. Survival of patients with chronic obstructive pulmonary disease receiving long-term domiciliary oxygen therapy. Am Rev Respir Dis 1993; 147:585-591

25 Strom K. Oral corticosteroid treatment during long-term oxygen therapy in chronic obstructive pulmonary disease: a risk factor for hospitalization and mortality in women. Respir Med 1998; 92:50-56

26 Schols AM, Wesseling G, Kester AD, et al. Dose dependent increased mortality risk in COPD patients treated with oral glucocorticoids. Eur Respir | 2001; 17:337-342.

27 Rice KL, Rubins JB, Lebahn F, et al. Withdrawal of chronic systemic corticosteroids in patients with COPD: a randomized trial. Am J Respir Crit Care Med 2000; 162:174-178

28 Callahan CM, Dittus RS, Katz BP. Oral corticosteroid therapy for patients with stable chronic obstructive pulmonary disease. A meta-analysis [see comments]. Ann Intern Med 1991; 114:216-223

29 Niewoehner DE, Erbland ML, Deupree RH, et al. Effect of systemic glucocorticoids on exacerbations of chronic obstructive pulmonary disease. New Engl J Med 1999; 340:19411947

30 Hansen EF, Phanareth K, Laursen LC, et al. Reversible and irreversible airflow obstruction as predictor of overall mortality in asthma and chronic obstructive pulmonary disease. Am J Resp Crit Care Med 1999; 159:1267-1271

31 Kerstjens HA, Brand PL, Postma DS. Risk factors for accelerated decline among patients with chronic obstructive pulmonary disease. Am J Respir Crit Care Med 1996; 154:S266-272

32 Menzies R, Gibbons W, Goldberg P. Determinants of weaning and survival among patients with COPD who require mechanical ventilation for acute respiratory failure. Chest 1989; 95:398-405

33 Gore JM, Brophy C), Greenstone MA. How well do we care for patients with end stage chronic obstructive pulmonary disease (COPD)? A comparison of palliative care and quality of life in COPD and lung cancer. Thorax 2000; 55:1000-1006 



\section{CHAPTER 9 \\ General discussion and summary}

This chapter is partially based on

Systemic Consequences of COPD Exacerbations Wagers, Scott S, Groenewegen KH, Wouters EFM

Wedzicha/Martinez, eds. in: Exacerbations in COPD 


\section{General discussion and summary}

In this chapter the results of the research described in this thesis will be discussed from a general clinical perspective.

Acute exacerbations of COPD are a usually defined as a combination of clinical symptoms as dyspnoea, cough and sputum production [1]. The severity of these exacerbations can range from a mild transient increase in symptoms to hospitalization and acute respiratory failure.

For a long time, acute exacerbations were largely neglected in the national course of COPD, but it is now recognized that exacerbations have important clinical consequences, particularly for the morbidity and mortality associated with this disease.

There is evidence that frequent exacerbations are associated with more rapid decline in lung function[2]. Patients who have more than 2.92 exacerbations per year have a larger loss in FEV, and PEFR than patients with less frequent acute exacerbations. Besides an effect on symptoms and lung function, it has been shown that acute exacerbations of COPD have a significant impact on the patient's health related quality of life[3-8].

All COPD patients hospitalized for an acute exacerbation suffer a serious deterioration in health status, regardless of severity based on $\mathrm{FEV}_{1}[5]$.

Furthermore, the prognosis of hospitalization for acute exacerbations of COPD is reported to be unfavourable. In a large study, in-hospital mortality was around $11 \%$ and mortality after 1 and 2 years respectively was $43 \%$ and $49 \%[9]$.

The aim of the study described in Chapter 8 of this thesis was to assess mortality and risk-factors for mortality in patients admitted for an acute exacerbation of COPD. 17 Patients admitted for an acute exacerbation of COPD were included in the study. Mortality rate during hospital admission was $8 \%$, increasing to $23 \%$ after one year of follow-up. Despite a comparable in-hospital mortality (6\%) one year mortality was significantly higher for patients admitted to ICU for respiratory failure $(35 \%)$.

The multivariate Cox proportional hazards model was used to determine independent predictors of survival. Variables included in the regression model were age, sex, $\mathrm{FEV}_{1}, \mathrm{PaO}_{2}, \mathrm{PaCO}_{2}$, $\mathrm{BMI}$, chronic use of oral corticosteroids, comorbidity index and readmissions. Maintenance use of oral glucocorticosteroids, $\mathrm{PaCO}_{2}$ and age were independently related to mortality. (Relative Risks 5.07 (2.0312.64); 1.17 (1.01-1.38); and 1.07 (1.01-1.12) respectively.)

Our results demonstrate that mortality after acute exacerbation is high, especially for older patients with chronic respiratory failure. The results regarding chronic oral corticosteroid use should be taken into account when making clinical decisions in patients admitted with acute exacerbations, especially when prescribing corticosteroid treatment.

It is important to realize the unfavourable prognosis of patients admitted for acute 
exacerbations of COPD in order to be able to offer the patient the best supportive care. This study emphasizes the need for adequate care facilities in patients treated for acute exacerbations. The care needs of these patients should be considered comparable to patients with lung cancer, who have a similar unfavourable prognosis.

In addition to their impact on morbidity and mortality, acute exacerbations are also important from a health economical point of view since they generate most of the costs associated with COPD[10].

In the United States, hospital admissions account for approximately $70 \%$ of the total costs of medical care for this disease[10]. In the future, these costs are expected to rise even further [11].

Finding new strategies to prevent and treat acute exacerbations is therefore an important goal in the management of COPD for clinical as well as for healtheconomical reasons.

Chapter 1 of this thesis gives a general introduction to the subject of acute exacerbations.

The currently known risk factors for acute exacerbations are described, as well as the pathophysiological and clinical consequences. Furthermore, this chapter reviews the potential causes and the local and systemic pathophysiological changes taking place during exacerbations. Lastly, current guidelines for treatment are described.

Current treatment of acute exacerbations, as described in chapter 1 of this thesis, is mainly symptomatic and not specifically directed towards the pathophysiological local and systemic changes that take place during acute exacerbations.

Acute exacerbations are generally defined by clinical symptoms but they are very heterogeneous and there is a large variation in severity. This heterogeneity and the lack of measurable parameters in order to define severity or outcome, interfere with a systematic approach of exacerbations as well as development of adequate strategies in order to prevent or manage them.

Therefore the main focus of the research described in this thesis was to evaluate the contribution of different clinical characteristics and systemic biomarkers to the pathophysiology of acute exacerbations.

In chapter 2, the contribution of respiratory bacterial infections to acute exacerbations of COPD was assessed. The specific aims of this study were to investigate the frequency of respiratory bacterial infections in hospitalized patients, admitted for an acute exacerbation of COPD, to identify the responsible pathogens by sputum culture and to assess patient characteristics in relation to sputum culture results. We prospectively evaluated clinical data and sputum culture results of 171 patients, admitted with an acute exacerbation of COPD. 85 of these patients (50\%) had 


\section{General discussion and summary}

positive sputum cultures, indicating the presence of bacterial infection. Pathogens most frequently isolated were: H.influenzae (45\%), S. pneumoniae (27\%), and P. aeruginosa (15\%).

Patients with more severely compromised lung function had a higher incidence of bacterial infections $(p=0.026)$. There were no significant differences in age, lung function parameters, blood gas results and length of hospital stay between patients with and without bacterial infection. There were no correlations between the type of bacteria isolated and clinical characteristics.

In the future the pathogenic role of bacterial infection in exacerbations of COPD should be further investigated, especially the role of bacterial infection in relation to local and systemic inflammation.

It is becoming more and more clear that systemic inflammation is an important factor in COPD, particularly during acute exacerbations.

In chapter 7 , the current knowledge regarding systemic inflammation in the context of acute exacerbations of COPD is extensively reviewed.

Along with local pulmonary inflammation, exacerbations of COPD are associated with a wide variety of systemic effects. Systemic inflammation is upregulated during acute exacerbations and markers reported to be higher compared to the stable state include CRP, IL-8, TNF- $\alpha$, leptin, endothelin-1, eosinophil cationic protein, myeloperoxidase, fibrinogen, IL-6, $\alpha 1$ - antitrypsin, leukotriene $\mathrm{E}_{4}$ and leukotriene B4.[12-23] However, most of the literature about acute exacerbations consists of cross-sectional studies, but longitudinal data of changes in systemic biomarkers were scarce.

Therefore, the aim of the study described in chapter 3 was to evaluate the longitudinal course of several inflammatory and anti-inflammatory cytokines during hospitalization and treatment for acute exacerbation. The study was performed in the University Hospital Maastricht in 21 patients, consecutively admitted for an acute exacerbation.

Systemic inflammation was determined by measurement of the pro-inflammatory markers interleukin (IL)-6, soluble tumor necrosis factor (TNF) receptors sTNFR55 and sTNFR-75, the anti-inflammatory mediator sIL-1RII, and Bactericidal Permeability Increasing protein (BPI) as a marker of neutrophil activation. In addition, plasma level of Trolox antioxidant capacity (TEAC) was determined. Healthy age-matched controls were measured for the same markers at one timepoint. All inflammatory markers analyzed were elevated on first day of admission for exacerbation of COPD, as compared to healthy controls. During treatment, levels of IL-6, and STNFR75 rapidly decreased, whereas STNFR55 and BPI remained elevated. Moreover, sIL-1RII and TEAC increased during first 8 days of treatment. In the stable condition after 6 months, all inflammatory markers had returned to values comparable to healthy controls, with the exception of BPI which remained 
persistently elevated compared to healthy controls.

This study clearly demonstrates upregulation of systemic inflammation in acute exacerbations of COPD. Furthermore, recovery of acute exacerbations is associated with an increase in anti-inflammatory capacity. Future research could include the course of other anti-inflammatory mediators such as IL-10 in the course of acute exacerbation. Modulation of anti-inflammatory effects can contribute to fasten the recovery after acute exacerbations

Chronic stable COPD is also characterized by concurrent local pulmonary and systemic inflammation, nonetheless the direct association between these two compartments has been difficult to elucidate. Vernooy et. al. [24] studied both sputum and plasma concentrations of soluble tumor necrosis factor-receptors (sTNF-R) and interleukin-8 (IL-8) and found that both were elevated, but no direct relation between sputum and plasma concentrations could be demonstrated. Lack of a link between airway inflammation and the systemic inflammatory response in chronic stable disease has also been found by others [25]. These studies have lead to the notion that systemic and local inflammation are differentially regulated, and that invoking "spill over" of local inflammation to explain systemic inflammation is not valid. When it comes to exacerbations, however, such a conclusion is probably not justified. Indeed, Hurst et. al. [26] did find significant correlations between lower airway inflammation and the systemic inflammatory response during COPD exacerbations. They found that sputum IL-8 and leukocyte count correlated with serum C-reactive protein (CRP) and IL-6. These correlations do suggest that during an exacerbation, local pulmonary inflammation spills over into the systemic compartment. This may represent an effect from an increase in the degree of pulmonary inflammation, or it could be related to the presence of bacteria or viruses as exacerbations are often associated with infection [27]. In the same study as mentioned above, it was also found that the presence of pathogenic micro-organisms, bacteria or viruses, in sputum was associated with a significant increase in the systemic inflammatory response as shown by increased concentrations of CRP [26].

The adaptive immune responses taking place during acute exacerbations have been poorly studied. During respiratory infections, cell migration is triggered through the sensing of pathogens by pattern recognition receptors such as toll like receptors (TLR) [28]. In this process, inflammatory cytokines are released that bind to the luminal surface of the vascular endothelium and trigger activation of the leukocytes [28-31]. Most tissues of the body have resident cells such as dendritic cells (DCs), macrophages and mast cells that are triggered by CCL2O-CCR6 receptors which have recently been shown to have a role in exacerbations $[32,33]$. Thus, it is highly conceivable that the difference between chronic stable COPD and exacerbations, in terms of the local/systemic inflammation link, is the presence of a pathogen resulting in the marshalling of a system wide response through the innate immune system. 


\section{General discussion and summary}

These processes need further evaluation.

Hypoxia is a major concern during a COPD exacerbation [27] and may be an additional manner in which local pulmonary inflammation is translated to the systemic compartment. Hypoxia inducible factor - ( $1 \mathrm{HIF}-1)$ is a transcription factor that is activated in the presence of hypoxia and has a broad range of effects $[34,35]$ including the upregulation of inflammation evidenced by increases in serum concentrations of TNF- $\alpha[36]$.

It is in fact difficult to separate systemic inflammation and systemic oxidative stress. Neutrophils are known to produce reactive oxygen species and have been identified as a major source of superoxide anion in the lung [37]. As we have shown in chapter 3 of this thesis, exacerbations do increase neutrophil activation and it is therefore easy to imagine that exacerbations are associated with increased oxidant stress. Rahman et. al.[38] demonstrated that Trolox equivalent antioxidant capacity (TEAC) was low during exacerbations which is taken to mean that oxidant activity is increased. Subsequently, it was shown that this exacerbation associated oxidant/antioxidant imbalance returns to normal during the course of exacerbation treatment $[39,40]$. In this thesis we have expanded these results by showing that TEAC levels increase significantly during an acute exacerbation, thereby restoring the oxidant-antioxidant imbalance presumed to present during acute exacerbations and decrease again in the stable situation. An association between systemic inflammation and systemic oxidative stress during exacerbations has been found [40] suggesting that systemic inflammation is causing and/or perpetuating systemic oxidative stress. However, an association between physical exercise and oxidative stress has also been found [41, 42] and considering the fact that exacerbations of COPD can increase the work of breathing even leading to respiratory failure, it becomes apparent that the muscle strain that comes with a COPD exacerbation, may itself be contributing to systemic oxidative stress.

As exacerbations of COPD are of a relatively short duration in comparison to the chronic progressive course of COPD, one has to question what impact exacerbation associated consequences have on the course of disease. The answer is that systemic inflammation and oxidative stress provoked by an exacerbation are not temporary. As described in chapter 3 of this thesis, markers of neutrophil activation remain elevated for at least 6 months following an exacerbation. Thus, the impact of exacerbations likely persists longer than the exacerbation itself. In addition, even in terms of symptoms and lung function approximately a quarter of all exacerbations persist for a month or more [43].

During acute exacerbations there is upregulation of the complement system, possibly mediated through the acute phase response and more specifically through CRP release[44, 45]. Another cytokine that is probably involved in the pathogenesis of exacerbations is leptin, which is secreted by white adipose 
tissue. Leptin has a pro-inflammatory role in the regulation of inflammation and immunity and during acute exacerbations, concentrations of leptin are related to disturbances in the energy balance and the systemic inflammatory response[13]. Adiponectin seems to act as an anti-inflammatory cytokine under these circumstances. The implication of these findings in the pathogenesis of acute exacerbations of COPD needs further evaluation.

A number of the biochemical markers associated with COPD are also involved in endothelial dysfunction and it is therefore important that future studies evaluate endothelial dysfunction and vascular changes during acute exacerbations.

Furthermore, there is evidence for a prothrombotic condition in COPD, particularly during acute exacerbations there is a shift of the haemostatic balance to favour the activation of coagulation.

It is now being recognized that pulmonary emboli (PE) are frequently present during exacerbations. Tillie-Leblond et al. [46] found a prevalence of $25 \%$, using high resolution CT scanning to diagnose PEs in patients with an unexplained exacerbation. This is in accordance with autopsy studies which have found PEs up to $30 \%$ in patients who died during an COPD exacerbation [47]. Similarly, a high prevalence of deep venous thombrosis (10\%) has also been reported during COPD exacerbations in multiple studies [47, 48]. In addition, an association between acute myocardial infarctions and COPD exacerbations has been reported[49], however there was also an association with ongoing oral steroid use and the risk abated when the steroids were stopped. Thus, this association may be a consequence of steroid use. A number of factors may be responsible for this thrombotic tendency. Fibrinogen elaboration is promoted by IL- 6 and thus fibrinogen concentrations rise with IL-6 during COPD exacerbations [23]. Fibrinogen, or more specifically fibrinopeptide $A$ and $B$ are cleaved by thrombin to form fibrin which is the major structural component of a thrombus. Thus, increased concentrations of fibrinogen can result in an accentuated risk of a thrombotic event.

Leptin itself is also an independent risk factor for thrombotic disorders because of its promotion of endothelial dysfunction, platelet aggregation and oxidative stress [50]. Platelet aggregation, also an important step in thrombosis formation, has been shown to be enhanced by hypoxemia and thereby may also play a role in these thrombotic consequences[51]. Furthermore, C-reactive protein has been shown to be a predictive marker of cardiovascular disease[52] and it is not just a marker of inflammation but also contributes directly to the pathogenesis of atherosclerosis [53].

Therefore, linking parameters of systemic inflammation as well as haemostasis in the stable baseline state to the development of acute exacerbations was studied and reported in chapter 4 .

In this study, the determinants of acute exacerbations in a large population of COPD patients were investigated, particularly focussing on systemic inflammation. 
COPD patients were initially selected based on the occurrence of at least 2 exacerbations in the year preceding entry to the study. The occurrence of moderate (requiring oral prednisolone) and severe exacerbations (requiring hospitalisation) was prospectively recorded during one year and at the beginning of the study lung function values (FEV, FVC, FRC and DLCO) and serum levels of CRP, fibrinogen, LBP, TNF- $\alpha$ and its soluble receptors STNF R-55 and STNF R-75 as markers of systemic inflammation were determined.

Multivariate analyses showed that a higher initial fibrinogen level and a lower FEV , predicted a higher rate of both moderate and severe exacerbations.

Additional independent predictors of a severe exacerbation were a higher number of prestudy severe exacerbations and lower DLCO. A higher number of prestudy moderate exacerbations was the only additional independent risk factor for the rate of moderate exacerbations.

In conclusion, this prospective study in COPD patients, initially selected based on the occurrence of at least 2 exacerbations in the year preceding entry to the study, indicates that airflow limitation as well as fibrinogen as a marker of systemic inflammation, are related to a higher number of both moderate and severe exacerbations. Patients with impaired diffusing capacity are found to be at higher risk for hospitalization for acute exacerbations. Future prospective studies need to explore differences in exacerbation pattern in COPD patients with different lung function impairment in order to better delineate specific COPD phenotypes.

Moreover, this is the first study to demonstrate that besides lung function impairment systemic inflammation manifested by elevated fibrinogen levels is an independent risk factor for exacerbations of COPD.

In chapter 5, we evaluated levels of different markers of systemic inflammation and haemostasis in COPD patients in the clinically stable state. Systemic levels of total plasma homocysteine (tHcy), high sensititivy-C-Reactive Protein (hs-CRP) and fibrinogen were measured in 85 stable COPD patients, prior to an inpatient pulmonary rehabilitation program.

We found that total homocysteine levels are elevated in about $30 \%$ of stable patients, possibly providing a link between COPD and development of cardiovascular comorbidity. In this study, total plasma homocysteine levels were not related to clinical characteristics, particularly FEV 1 or smoking habits. Further identification of factors distinguishing this group of patients with elevated homocysteine levels from other COPD patients and measuring the course of homocysteine levels during acute exacerbations would be interesting topics for future research.

Furthermore systemic levels of acute phase protein C-Reactive Protein are elevated (using a cut-off value of $5 \mathrm{mg} / \mathrm{l}$ ) in $31.9 \%$ of stable COPD patients. HsCRP was not correlated to clinical parameters or to tHcy. 
Levels of tHcy and hs-CRP remained stable after a 12 week clinical rehabilitation program.

In chapter 6 , the contributing role of Mannose Binding Lectin (MBL), a key component of the innate immune system, in the development of acute exacerbations of COPD, is evaluated.

The aim of this study was to determine if serum levels of MBL measured at baseline are related to the occurrence of acute exacerbations in COPD. $\mathrm{MBL}$, a pattern recognition receptor, can bind to various pathogens associated with acute exacerbations. Previous studies have suggested an association of low MBL producing genotypes, resulting in low serum $M B L$, with more frequent admissions for acute exacerbation.

We analyzed data of a previously published study in a well-characterized COPD cohort, consisting of 327 patients. At the beginning of the study lung function values and serum levels of MBL were determined. For analysis, serum MBL level was divided into 4 categories: <100 $\mu \mathrm{g} / \mathrm{l}$ (deficient, $\mathrm{n}=44$ ), 100-500 $\mu \mathrm{g} / \mathrm{l}$ (low, $\mathrm{n}=70$ ). Values in the normal range were further grouped into $500-2650 \mathrm{\mu g} / \mathrm{l}$ $(n=131)$ and $>2650 \mu \mathrm{g} / \mathrm{l}(\mathrm{n}=82)$, with the latter value representing the $75^{\text {th }}$ percentile.

The occurrence of moderate (requiring oral prednisolone) and severe exacerbations (requiring hospitalisation) was prospectively recorded during a one year follow-up period.

In multivariate Cox regression analysis with category of $\mathrm{MBL}$, gender, age, $F E V_{1}$, smoking status and the number of severe exacerbations in the year preceding the study as variables, the major independent predictors of a severe acute exacerbation were $\mathrm{FEV}_{1}$ and the number of prior severe exacerbations. There was no relation of $\mathrm{MBL}$ levels with the severe exacerbation rate.

$\mathrm{FEV}_{1}$, gender and the number of prestudy moderate exacerbations were the major variables which were independently related to the rate of occurrence of moderate exacerbations. The group of patients with very low MBL levels $(<100$ $\mu \mathrm{g} / \mathrm{l}$ ) had significantly less moderate acute exacerbations than patients with MBL levels $>100 \mu \mathrm{g} / \mathrm{l}$.

The major finding in this study is that low serum $M B L$ is not a risk factor for acute exacerbations of COPD. In contrast to our hypothesis, a low serum MBL level offers no increased risk for severe exacerbations and seems to attenuate the rate and time of onset of moderate exacerbations.

Future research could focus on finding an explanation for this finding and on the role of $M B L$ and the innate immune system in acute exacerbations of COPD. 


\section{Conclusion}

Like chronic stable COPD the systemic consequences of exacerbations are broad, yet the pathophysiology varies from that seen in stable disease.

The results of the research described in this thesis provide more evidence for the heterogeneity and complex multicomponent character of acute exacerbations in COPD. Table 1 summarizes the results of this thesis schematically.

In the future a more differentiated strategy directed toward optimal phenotyping of COPD patients is warranted. Understanding the ongoing processes in exacerbations of COPD as a systemic disease will contribute to more optimal management than our current approach, based on respiratory symptoms. Contributing factors like systemic inflammation, involvement of the coagulant cascade and the innate immune system all have to be considered in order to find a better treatment strategy to reduce the considerable mortality and morbidity associated with acute exacerbations. 


\section{References}

1. Anthonisen NR, Manfreda ), Warren CP, Hershfield ES, Harding GK, Nelson NA. Antibiotic therapy in exacerbations of chronic obstructive pulmonary disease. Ann Intern Med.

1987;106(2):196-204.

2. Donaldson GC, Seemungal TA, Bhowmik A, Wedzicha JA. Relationship between exacerbation frequency and lung function decline in chronic obstructive pulmonary disease. Thorax. 2002 Oct;57(10):847-52.

3. Seemungal TAR, Donaldson GC, Paul EA, Bestall JC, Jeffries DJ, Wedzicha JA. Effect of exacerbation on quality of life in patients with chronic obstructive pulmonary disease. Am J Resp Crit Care Med. 1998;157(5)):1418-22.

4. Wilkinson TM, Donaldson CC, Hurst JR, Seemungal TA, Wedzicha JA. Early therapy improves outcomes of exacerbations of chronic obstructive pulmonary disease. Am J Respir Crit Care Med. 2004 Jun 15;169(12):1298-303.

5. O'Reilly J F, Williams AE, Rice L. Health status impairment and costs associated with COPD exacerbation managed in hospital. Int J Clin Pract. 2007 Jul;61 (7):1112-20.

6. Kessler R, Stahl E, Vogelmeier C, Haughney J, Trudeau E, Lofdahl CG, et al. Patient understanding, detection, and experience of COPD exacerbations: an observational, interviewbased study. Chest. 2006 Jul;130(1):133-42.

7. Doll H, Miravitlles M. Health-related QOL in acute exacerbations of chronic bronchitis and chronic obstructive pulmonary disease: a review of the literature. Pharmacoeconomics. 2005;23(4):345-63.

8. Miravitlles M, Ferrer M, Pont A, Zalacain R, Alvarez-Sala JL, Masa F, et al. Effect of exacerbations on quality of life in patients with chronic obstructive pulmonary disease: a 2 year follow up study. Thorax. 2004 May;59(5):387-95.

9. Connors AF, Jr., Dawson NV, Thomas C, Harrell FE, Jr., Desbiens N, Fulkerson WJ, et al. Outcomes following acute exacerbation of severe chronic obstructive lung disease. The SUPPORT investigators (Study to Understand Prognoses and Preferences for Outcomes and Risks of Treatments). Am J Respir Crit Care Med. 1996;154(4 Pt 1):959-67.

10. Strassels SA, Smith DH, Sullivan SD, Mahajan PS. The Costs of Treating COPD in the United States. Chest. 2001;119(2):344-52.

11. Rutten van Molken MP, Postma MJ, Joore MA, Van Genugten ML, Leidl R, Jager JC. Current and future medical costs of asthma and chronic obstructive pulmonary disease in The Netherlands. Respir Med. 1999;93(11):779-87.

12. Calikoglu M, Sahin G, Unlu A, Ozturk C, Tamer L, Ercan B, et al. Leptin and TNF-alpha levels in patients with chronic obstructive pulmonary disease and their relationship to nutritional parameters. Respiration. 2004 Jan-Feb;71 (1):45-50.

13. Creutzberg EC, Wouters EF, Vanderhoven Augustin IM, Dentener MA, Schols AM. Disturbances in leptin metabolism are related to energy imbalance during acute exacerbations of chronic obstructive pulmonary disease [In Process Citation]. Am J Respir Crit Care Med. 2000;162(4 Pt 1):1239-45.

14. Dentener MA, Creutzberg EC, Schols AM, Mantovani A, van't Veer C, Buurman WA, et al. Systemic anti-inflammatory mediators in COPD: increase in soluble interleukin 1 receptor II during treatment of exacerbations. Thorax. 2001 Sep;56(9):721-6.

15. Dev D, Wallace E, Sankaran R, Cunniffe J, Govan JRW, Wathen CC, et al. Value of C-reactive protein measurements in exacerbations of chronic obstructive pulmonary disease. Respir Med. 1998;92(4)):664-7.

16. Fiorini G, Crespi S, Rinaldi M, Oberti E, Vigorelli R, Palmieri G. Serum ECP and MPO are increased during exacerbations of chronic bronchitis with airway obstruction. Biomed Pharmacother. 2000 Jun;54(5):274-8.

17. Hill AT, Campbell EJ, Bayley DL, Hill SL, Stockley RA. Evidence for Excessive Bronchial Inflammation during an Acute Exacerbation of Chronic Obstructive Pulmonary Disease 


\section{General discussion and summary}

in Patients with alpha(1)-Antitrypsin Deficiency (PiZ). Am J Respir Crit Care Med. 1999;160(6):1968-75.

18. Malo O, Sauleda J, Busquets X, Miralles C, Agusti AG, Noguera A. [Systemic inflammation during exacerbations of chronic obstructive pulmonary disease]. Arch Bronconeumol. 2002 Apr;38(4):172-6.

19. Pinto-Plata VM, Livnat G, Girish M, Cabral H, Masdin P, Linacre P, et al. Systemic cytokines, clinical and physiological changes in patients hospitalized for exacerbation of COPD. Chest. $2007 \operatorname{Jan} ; 131(1): 37-43$.

20. Roland M, Bhowmik A, Sapsford RJ, Seemungal TA, Jeffries DJ, Warner TD, et al. Sputum and plasma endothelin-1 levels in exacerbations of chronic obstructive pulmonary disease. Thorax. 2001;56(1):30-5

21. Shindo K, Hirai Y, Fukumura M, Koide K. Plasma levels of leukotriene E4 during clinical course of chronic obstructive pulmonary disease. Prostaglandins Leukot Essent Fatty Acids. 1997;56(3):213-7.

22. Stockley RA, Bayley DL, Unsal I, Dowson L). The effect of augmentation therapy on bronchial inflammation in alphaı-antitrypsin deficiency. Am J Respir Crit Care Med. 2002 Jun $1 ; 165(11): 1494-8$.

23. Wedzicha JA, Seemungal TA, MacCallum PK, Paul EA, Donaldson GC, Bhowmik A, et al. Acute exacerbations of chronic obstructive pulmonary disease are accompanied by elevations of plasma fibrinogen and serum IL-6 levels. Thromb Haemost. 2000;84(2):210-5.

24. Vernooy JH, Kucukaycan M, Jacobs JA, Chavannes NH, Buurman WA, Dentener MA, et al. Local and systemic inflammation in patients with chronic obstructive pulmonary disease: soluble tumor necrosis factor receptors are increased in sputum. Am J Respir Crit Care Med. 2002 Nov 1;166(9):1218-24

25. Hurst JR, Wilkinson TM, Perera WR, Donaldson GC, Wedzicha JA. Relationships among bacteria, upper airway, lower airway, and systemic inflammation in COPD. Chest. 2005 Apr;127(4):1219-26.

26. Hurst JR, Perera WR, Wilkinson TM, Donaldson GC, Wedzicha JA. Systemic and upper and lower airway inflammation at exacerbation of chronic obstructive pulmonary disease. Am J Respir Crit Care Med. 2006 Jan 1;173(1):71-8.

27. Rabe KF, Hurd S, Anzueto A, Barnes PJ, Buist SA, Calverley P, et al. Global strategy for the diagnosis, management, and prevention of chronic obstructive pulmonary disease: COLD executive summary. Am J Respir Crit Care Med. 2007 Sep 15;176(6):532-55.

28. Laudanna C, Kim JY, Constantin G, Butcher E. Rapid leukocyte integrin activation by chemokines. Immunol Rev. 2002 Aug;186:37-46.

29. Iwasaki A, Medzhitov R. Toll-like receptor control of the adaptive immune responses. Nat Immunol. 2004 Oct; 5(10):987-95.

30. Hornung V, Rothenfusser S, Britsch S, Krug A, Jahrsdorfer B, Giese T, et al. Quantitative expression of toll-like receptor 1-10 mRNA in cellular subsets of human peripheral blood mononuclear cells and sensitivity to CpG oligodeoxynucleotides. J Immunol. 2002 May 1;168(9):4531-7.

37. Nagase H, Okugawa S, Ota Y, Yamaguchi M, Tomizawa H, Matsushima K, et al. Expression and function of Toll-like receptors in eosinophils: activation by Toll-like receptor 7 ligand. J Immunol. 2003 Oct 15;171 (8):3977-82.

32. Demedts IK, Bracke KR, Van Pottelberge GR, Testelmans D, Verleden GM, Vermassen FE, et al. Accumulation of Dendritic Cells and Increased CCL2O Levels in the Airways of COPD Patients. Am / Respir Crit Care Med. 2007 Mar 1.

33. Starner TD, Barker CK, Jia HP, Kang Y, McCray PB, Jr. CCL2O is an inducible product of human airway epithelia with innate immune properties. Am J Respir Cell Mol Biol. 2003 Nov;29(5):627-33.

34. Semenza GL. HIF-1: mediator of physiological and pathophysiological responses to hypoxia. ) Appl Physiol. 2000 Apr;88(4):1474-80. 
35. Yu AY, Frid MG, Shimoda LA, Wiener CM, Stenmark K, Semenza GL. Temporal, spatial, and oxygen-regulated expression of hypoxia-inducible factor-1 in the lung. Am J Physiol. 1998 Oct;275(4 Pt 1):L818-26.

36. Takabatake N, Nakamura H, Abe S, Inoue S, Hino T, Saito H, et al. The relationship between chronic hypoxemia and activation of the tumor necrosis factor-alpha system in patients with chronic obstructive pulmonary disease. Am J Respir Crit Care Med. 2000;161 (4 Pt 1):1179-84.

37. Postma DS, Renkema TE, Noordhoek JA, Faber H, Sluiter HJ, Kauffman H, et al. Association between nonspecific bronchial hyperreactivity and superoxide anion production by polymorphonuclear leukocytes in chronic air-flow obstruction

Am Rev Respir Dis. 1988;137(1):57-61

38. Rahman I, Morrison D, Donaldson K, MacNee W. Systemic oxidative stress in asthma, COPD, and smokers. Am J Respir Crit Care Med. 1996;154(4 Pt 1):1055-60.

39. Rahman I, Skwarska E, MacNee W. Attenuation of oxidant/antioxidant imbalance during treatment of exacerbations of chronic obstructive pulmonary disease. Thorax. 1997:52 (6):5658.

40. Tkacova R, Kluchova Z, Joppa P, Petrasova D, Molcanyiova A. Systemic inflammation and systemic oxidative stress in patients with acute exacerbations of COPD. Respir Med. $2007 \mathrm{Apr}$ 19.

41. Couillard A, Koechlin C, Cristol JP, Varray A, Prefaut C. Evidence of local exercise-induced systemic oxidative stress in chronic obstructive pulmonary disease patients. Eur Respir ). 2002 Nov;2O(5):1123-9.

42. van Helvoort HA, Heijdra YF, de Boer RC, Swinkels A, Thijs HM, Dekhuijzen PN. Six-minute walking-induced systemic inflammation and oxidative stress in muscle-wasted COPD patients. Chest. 2007 Feb;131(2):439-45.

43. Seemungal TA, Donaldson CC, Bhowmik A, Jeffries DJ, Wedzicha JA. Time course and recovery of exacerbations in patients with chronic obstructive pulmonary disease. Am / Respir Crit Care Med. 2000;161 (5):1608-13.

44. Pepys MB, Hirschfield GM. C-reactive protein: a critical update. J Clin Invest. 2003 Jun;111(12):1805-12.

45. Volanakis JE. Complement activation by C-reactive protein complexes. Ann N Y Acad Sci. 1982;389:235-50.

46. Tillie-Leblond I, Marquette $\mathrm{CH}$, Perez T, Scherpereel A, Zanetti C, Tonnel AB, et al. Pulmonary embolism in patients with unexplained exacerbation of chronic obstructive pulmonary disease: prevalence and risk factors. Ann Intern Med. 2006 Mar 21;144(6):390-6.

47. Ambrosetti M, Ageno W, Spanevello A, Salerno M, Pedretti RF. Prevalence and prevention of venous thromboembolism in patients with acute exacerbations of COPD. Thromb Res. 2003;112(4):203-7.

48. Erelel M, Cuhadaroglu C, Ece T, Arseven O. The frequency of deep venous thrombosis and pulmonary embolus in acute exacerbation of chronic obstructive pulmonary disease. Respir Med. 2002 Jul;96(7):515-8

49. Huiart L, Ernst P, Ranouil X, Suissa S. Oral corticosteroid use and the risk of acute myocardial infarction in chronic obstructive pulmonary disease. Can Respir J. 2006 Apr;13(3):134-8.

50. Beltowski J. Leptin and atherosclerosis. Atherosclerosis. $2006 \mathrm{Nov} ; 189(1): 47-60$.

51. Wedzicha JA, Syndercombe-Court D, Tan KC. Increased platelet aggregate formation in patients with chronic airflow obstruction and hypoxaemia. Thorax. 1991 Jul;46(7):504-7.

52. Ridker PM, Cushman M, Stampfer M), Tracy RP, Hennekens CH. Plasma concentration of C-reactive protein and risk of developing peripheral vascular disease. Circulation. 1998 Feb 10;97(5):425-8.

53. Bisoendial RJ, Kastelein JJ, Stroes ES. C-reactive protein and atherogenesis: From fatty streak to clinical event. Atherosclerosis. 2007 Dec;195(2):e10-8. 

Samenvatting 


\section{Samenvatting}

COPD is de afkorting van de Engelse term Chronic Obstructive Pulmonary Disease, wat staat voor chronisch obstructieve longziekten.

De belangrijkste symptomen van COPD zijn kortademigheid en hoesten.

Patiënten met COPD hebben af en toe last van tijdelijke verergering van deze klachten, meestal gepaard gaand met ophoesten van slijm. Deze periodes noemen we acute exacerbaties. Acute exacerbaties van COPD hebben belangrijke klinische gevolgen ten aanzien van morbiditeit en mortaliteit.

In dit proefschrift worden klinische studies beschreven die verricht zijn bij patiënten met acute exacerbaties van COPD. Het doel van dit proefschrift was om deze ziekteepisodes beter in kaart te brengen.

Hoofdstuk 1 geeft een overzicht van de huidige kennis van acute exacerbaties. Er is geen eenduidige definitie van acute exacerbaties voorhanden. In de recente COLD richtlijnen wordt een exacerbatie als volgt gedefinieerd: een gebeurtenis in het natuurlijk beloop van de ziekte, die gekarakteriseerd wordt als een verandering in de basale symptomen van kortademigheid, hoesten en sputumproductie van de patiënt, die verdergaat dan de normale dagelijkse variatie, acuut begint, en waarvoor een wijziging in medicatie noodzakelijk is, bij een patiënt met onderliggend COPD. De meer klinische definitie van een acute exacerbatie, zoals die in de praktijk wordt gebruikt, is een verergering van een combinatie van symptomen, meestal kortademigheid, hoesten en sputumproductie.

De ernst van deze exacerbaties varieert van mild waarbij het innemen van extra longmedicatie voldoende is, tot ernstig, waarbij ziekenhuis opname en soms mechanische beademing nodig zijn.

Gemiddeld heeft een patiënt met COPD 1 tot 4 acute exacerbaties per jaar. Het reduceren van acute exacerbaties is van economisch belang vanwege de hoge kosten. In Nederland wordt meer dan de helft van de directe medische kosten van COPD veroorzaakt door ziekenhuisopnames voor acute exacerbaties.

Bovendien zijn acute exacerbaties van COPD van groot klinisch belang. Het is aangetoond dat patiënten met frequente exacerbaties een verminderde kwaliteit van leven hebben. Verder leiden frequente acute exacerbaties tot een snellere achteruitgang in longfunctie en een slechtere prognose.

Het is daarom belangrijk acute exacerbaties beter te karakteriseren om uiteindelijk strategieën te kunnen ontwikkelen ter preventie en behandeling van deze episodes.

Risicofactoren voor het krijgen van een acute exacerbatie zijn weinig onderzocht. Enkele studies rapporteren dat patiënten met een slechtere longfunctie meer risico hebben op exacerbaties, dit wordt echter niet in alle studies bevestigd.

Patiënten met een voorgeschiedenis van exacerbaties hebben een hoger risico op het krijgen van een nieuwe exacerbatie.

Andere potentiële risicofactoren zijn een slechte kwaliteit van leven, spierzwakte, 
luchtverontreiniging en een laag lichaamsgewicht. Roken heeft geen duidelijke invloed, voorzover onderzocht.

Patiënten met een slechte fysieke conditie hebben een hoger risico, evenals patiënten met gaswisselingsstoornissen en patiënten die weinig lichaamsbeweging hebben.

De exacte pathofysiologische veranderingen die plaatsvinden tijdens acute exacerbaties zijn eveneens weinig onderzocht. Er wordt gedacht dat de toegenomen kortademigheid gerelateerd is aan dynamische hyperinflatie, met als gevolg een grotere ademarbeid die moet worden geleverd en verminderde spierkracht van de ademhalingsspieren met name het diafragma.

Acute exacerbaties gaan vaak gepaard met gaswisselingsstoornissen: hypoxemie en hypercapnie. De belangrijkste mechanismen hiervoor zijn een vermindering van ventilatie en een toename in ventilatie-perfusie mismatch.

Tot dusverre is geen onderzoek gedaan naar de eventuele relatie tussen de pathofysiologische mechanismen en de inflammatoire veranderingen in de luchtwegen.

De diagnose acute exacerbatie van COPD wordt meestal gesteld op grond van de klinische symptomen: dyspnoe, hoesten en sputum productie. Bijkomende symptomen als koorts, piepen en pijn op de borst kunnen voorkomen. De ernst van de exacerbatie wordt ingeschat aan de hand van de voorgeschiedenis, symptomen, lichamelijk onderzoek, longfunctieonderzoek, arteriële bloedgassen en andere laboratoriumonderzoeken. Een exacerbatie wordt als ernstig beschouwd als een patiënt geen volledige zinnen kan spreken. Andere tekenen van een ernstige exacerbatie zijn gebruik van hulpademhalingsspieren, paradoxale adembewegingen, cyanose, oedeem, hemodynamische instabiliteit, tekenen van rechter hartfalen en verminderde alertheid.

Criteria voor ziekenhuis opname zijn een belangrijke of plotselinge toename in symptomen, ernstig onderliggend COPD, nieuwe afwijkingen bij lichamelijk onderzoek zoals cyanose of oedeem, niet reageren van de exacerbatie op initiële therapie, belangrijke comorbiditeit, frequente exacerbaties, ritmestoornissen, diagnostische onzekerheid, hogere leeftijd en inadequate thuiszorg. Criteria voor opname op een Intensive Care afdeling zijn ernstige dyspnoe die niet reageert op de ingestelde therapie, veranderde mentale toestand van de patiënt, ernstige persisterende hypoxemie $\left(\mathrm{PaO}_{2}<5.3 \mathrm{kPa}, 40 \mathrm{~mm} \mathrm{Hg}\right)$ of hypercapnie $\left(\mathrm{PaCO}_{2}<8.0 \mathrm{kPa}, 60 \mathrm{~mm} \mathrm{Hg}\right)$ en/of respiratoire acidose $(\mathrm{pH}<7.25)$ ondanks zuurstoftherapie en niet-invasieve beademing, indicatie voor beademing en hemodynamische instabiliteit met indicatie voor vasopressoren.

De meeste exacerbaties van COPD worden veroorzaakt door bacteriële dan wel virale infecties, of luchtverontreiniging. Voor meer dan $30 \%$ van de exacerbaties 


\section{Samenvatting}

wordt echter geen oorzaak gevonden.

De rol van bacteriële infecties in het veroorzaken van exacerbaties is het onderwerp van veel onderzoek en discussie. Er is een aantal problemen bij het onderzoeken van de rol van bacteriën in acute exacerbaties. COPD patiënten hebben vaak bacteriën in hun luchtwegen zonder dat er sprake is van een exacerbatie, we noemen dit kolonisatie. Verder zijn zowel COPD patiënten als acute exacerbaties erg heterogeen en kunnen bacteriën en hun klinische betekenis dus verschillen van patiënt tot patiënt. Verder zijn bacteriën die in het sputum gevonden worden niet altijd een goede afspiegeling van de situatie in de lagere luchtwegen. De bacteriën die het vaakst worden gevonden tijdens acute exacerbaties, S. Pneumoniae, $\mathrm{H}$. Influenzae en M. Catarrhalis, komen alleen voor bij de mens en kunnen dus niet worden bestudeerd in diermodellen.

Patiënten met COPD hebben een verhoogde kans op bacteriële luchtweg infecties door een verminderde mucociliaire klaring van bacteriën uit de luchtwegen en veranderde afweer, met name een gestoorde functie van witte bloedcellen (neutrofiele granulocyten).

In ongeveer 50\% van acute exacerbaties worden bacteriën gevonden. Enkele studies vonden een shift in het type bacterie bij patiënten met een slechtere longfunctie, naarmate de FEV, lager was werden meer Gram negatieve bacteriën gevonden. De hypothese van een etiologische rol van bacteriën bij acute exacerbaties wordt ondersteund doordat tijdens exacerbaties waarbij bacteriele infecties worden vastgesteld, ook meer inflammatie is aangetoond in de luchtwegen. Gecombineerde longitudinale studies van bacteriën en inflammatie in de luchtwegen kunnen in de toekomst meer duidelijkheid verschaffen over de exacte rol van bacteriën in acute exacerbaties van COPD.

Waarschijnlijk spelen ook virale infecties een rol bij acute exacerbaties. In 18 tot $34 \%$ van exacerbaties wordt een virusinfectie vastgesteld, meestal griep virussen en rhinovirussen zoals influenzavirus, para-influenza virus en coronavirus.

Virusinfecties kunnen leiden tot meer frequente exacerbaties, en ook tot bacteriële infecties, waarbij in het geval van gelijktijdige infectie ook meer inflammatie in de luchtwegen aanwezig is. Patienten met een gelijktijdige virale en bacteriële luchtweginfectie hebben een slechtere longfunctie en een langere opnameduur. De rol van atypische verwekkers in acute exacerbaties is onduidelijk. Dit komt vooral door de verschillende technieken die gebruikt worden om infecties met atypische micro-organismen aan te tonen.

Ongeveer $5 \%$ van alle acute exacerbaties zou het gevolg zijn van luchtvervuiling met name door ozon, $\mathrm{SO}_{2}, \mathrm{NO}_{2}$ en PM10. (particulate matter under 10 microns = kleine deeltjes)

Verder werd in een recente studie bij $25 \%$ van de patienten met een acute exacerbatie met onbekende oorzaak longembolieën aangetroffen.

De laatste jaren is er toenemende belangstelling voor de locale en systemische inflammatie bij COPD. 
Waarschijnlijk speelt een toename in locale inflammatie in de luchtwegen een belangrijke rol bij het ontstaan van acute exacerbaties. In biopsieën van de lagere luchtwegen, verricht tijdens acute exacerbaties, is een toename zichtbaar van bepaalde vormen van witte bloedcelle, genaamd eosinofiele granulocyten, maar ook van neutrofiele granulocyten en T-lymfocyten. De toename in eosinofiele granulocyten is geassocieerd met verhoogde expressie van RANTES, (regulated upon activation, normal T-cell expressed and secreted), een chemoattractant voor eosinofielen. Tijdens exacerbaties vindt ook verhoogde expressie plaats van leukocyten adhesie moleculen zoals E-selectin, die betrokken zijn bij de recrutering van leukocyten naar plaatsen van inflammatie.

Ook in BAL vloeistof van patiënten met acute exacerbatie zijn verhoogde aantallen neutrofiele en eosinofiele granulocyten aangetroffen, evenals een verhoogde concentratie granulocyte/macrophage colony stimulating factor (GM-CSF). Dit cytokine stimuleert differentiatie van granulocyten en macrofagen en kan deze direct activeren. In sputum van patiënten met een acute exacerbatie, zijn inflammatoire cytokines als TNF-, IL-6 en IL-8 verhoogd, evenals het potente vasoconstrictieve en bronchoconstrictieve peptide endothelin-1. (ET-1)

Bovendien hebben patiënten met frequente exacerbaties hogere sputumconcentraties van IL- 6 en IL-8 dan patiënten met mindere frequente exacerbaties.

Naast een toename in locale inflammatie zijn acute exacerbaties van COPD geassocieerd met een toename in systemische inflammatie. Markers van systemische inflammatie die verhoogd zijn tijdens acute exacerbaties zijn oa. CRP, IL-6, IL-8, TNF- $\alpha$ en de soluble TNF receptoren TNFR 55 en TNFR 75, leptine, endotheline-1, ECP, MPO, fibrinogeen, $\alpha-1$ antitrypsine, leukotrieen B4, leukotrieen E4, MPIF-1, PARC, ACRP-30 en sICAM-1. Mogelijk is deze systemische inflammatoire respons geassocieerd met de locale inflammatoire respons, maar de exacte mechanismen zijn onbekend. Geen van de onderzochte biomarkers heeft een duidelijke relatie met de klinische symptomen van een exacerbatie of de prognose.

Tijdens COPD exacerbaties is er ook verhoogde oxidatieve stress aangetoond. Sigarettenrook is de belangrijkste bron van oxidanten, maar daarnaast zijn bij COPD patiënten geactiveerde neutrofielen en macrofagen in de luchtwegen aanwezig, die reactieve zuurstofradicalen produceren, leidend tot verhoogde oxidatieve stress.

Tijdens acute exacerbaties is er een toename van oxidatieve stress zoals blijkt uit een verhoogde concentratie van $\mathrm{H}_{2} \mathrm{O}_{2}$ in de uitademingslucht en een verhoogde uitscheiding van isoprostaan $\mathrm{F} 2-\alpha$, een product van de lipiden peroxidatie, in de urine. Tevens is er een reductie in antioxidatieve capaciteit in het bloed aangetoond tijdens exacerbaties die zich herstelt tijdens behandeling. 


\section{Samenvatting}

De klinische consequenties van een acute exacerbatie zijn een verslechtering van kwaliteit van leven, een verandering in het spiermetabolisme, leidend tot spierzwakte, en metabole veranderingen die leiden tot een verstoorde energiebalans, verlies aan vetvrije massa en ondergewicht.

Preventie van acute exacerbaties is een van de belangrijkste behandeldoelen van COPD. Jaarlijkse vaccinatie tegen influenza wordt aanbevolen voor COPD patiënten, maar het nut van vaccinatie tegen pneumococcen is niet aangetoond.

De onderhoudsbehandeling van COPD bestaat uit bronchusverwijdende medicatie, zowel $\beta$-2-sympathicomimetica als anticholinergica. Langwerkende $\beta$-2-sympathicomimetica zoals formoterol en salmeterol en langwerkende anticholinergica zoals Tiotropium verminderen het aantal exacerbaties ten opzichte van placebo.

De effectiviteit van inhalatiecorticosteroiden in preventie van exacerbaties is controversieel. Inhalatiesteroiden veranderen het beloop of de prognose van de ziekte niet, maar enkele studies laten wel een reductie van het aantal exacerbaties zien ten opzichte van bronchusverwijders alleen. Ook is het stoppen van inhalatiesteroiden geassocieerd met een sneller optreden van exacerbaties en een hogere frequentie.

Het effect van anti-oxidanten en mucolytica op exacerbatie frequentie is niet aangetoond.

Enkele trials met immunomodulerende medicamenten laten gunstige resultaten zien op exacerbatie frequentie, om dit beter te onderzoeken zijn meer studies nodig.

Longrevalidatie programma's hebben een gunstige invloed op het aantal exacerbaties, zowel vanuit de stabiele situatie als na opname in verband met acute exacerbatie.

Behandeling van acute exacerbaties in de klinische situatie bestaat uit zuurstof, bronchusverwijdende medicatie, orale of intraveneuze corticosteroiden, eventueel antibiotica en indien nodig ademhalingsondersteuning. De rol van methylxantines is controversieel.

Het doel van niet -invasieve ademhalingsondersteuning is het verminderen van morbiditeit en mortaliteit van acute exacerbaties en het verlichten van symptomen. Deze behandeling is bewezen effectief in het verminderen van de mortaliteit, het verminderen van de noodzaak tot invasieve beademing en het verminderen van mislukken van de behandeling.

Indicaties voor niet-invasieve ademhalingsondersteuning zijn matige tot ernstige kortademigheid met gebruik van ademhalingsspieren en paradoxale ademhaling, matige tot ernstige respiratoire acidose $(\mathrm{pH} \leq 7.35)$ en/of hypercapnie $\left(\mathrm{PaCO}_{2} \geq 6.0\right.$ $\mathrm{kPa}, 45 \mathrm{~mm} \mathrm{Hg}$ ) en ademfrequentie van meer dan 25 keer per minuut. 
Exclusie criteria hiervoor zijn ademstilstand, cardiovasculaire instabiliteit, verandering in bewustzijn of oncoöperatieve patient, hoog risico op aspiratie, opgeven van veel of taai sputum, recente craniofaciale of gastro-oesophageale chirurgie, craniofaciaal trauma, nasopharyngeale afwijkingen, brandwonden en extreme obesitas.

Over de prognose van een acute exacerbatie is weinig bekend. Als risicofactoren voor mortaliteit worden in enkele studies genoemd: hoge $\mathrm{PaCO}_{2}$, lage $\mathrm{PaO}_{2}$ en/of zuurstofsaturatie, hogere leeftijd, hartfalen, aanwezigheid van cor pulmonale, co-morbiditeit, functionele status, ernst van onderliggende ziekte, $\mathrm{FEV}_{1}$, slechte functionele status, lage BMI en laag albumine.

Een grote studie onder meer dan 1000 patiënten opgenomen met een acute exacerbatie, liet een mortaliteit tijdens opname zien van 11\%, 35\% na 6 maanden en $43 \%$ na 1 jaar. Patienten bij wie opname op een Intensive Care afdeling noodzakelijk is in verband met acute respiratoire insufficiëntie hebben een nog slechtere prognose.

In hoofdstuk 2 van dit proefschrift wordt de bijdrage van bacteriële luchtweginfecties aan opnames voor acute exacerbaties onderzocht. In de helft van alle onderzochte COPD patiënten, opgenomen in verband met een acute exacerbatie, worden bacterieën gevonden in het sputum. Deze patiënten met een aangetoonde bacteriële luchtweginfectie verschilden niet in klinische kenmerken (leeftijd, longfunctie parameters, arteriële bloedgassen, duur van ziekenhuisopname) met patienten bij wie geen bacterien in het sputum werden gevonden.

De bacterieën die het vaakst werden aangetroffen in het sputum waren Haemophilus influenzae, Streptococcus pneumoniae en Pseudomonas aeruginosa.

Verder bleek dat patienten met een slechtere longfunctie vaker een bacteriële luchtweginfectie hadden. Er werd geen verschil gevonden in de soort verwekkers van luchtweginfecties bij patienten met een slechtere longfunctie.

Hoofdstuk 3 van dit proefschrift had als doel het longitudinaal onderzoeken van het verloop van verschillende inflammatoire en anti-inflammatoire biomarkers tijdens opname en behandeling voor een acute exacerbatie, en tot 6 maanden nadien in de stabiele fase. We vonden dat bij alle 21 patiënten de inflammatoire markers IL6, sTNFR 55 en s TNFR 75 en marker van neutrofiele activatie BPI verhoogd waren bij opname ten opzichte van gezonde controle personen, terwijl anti-inflammatoire marker sIL-1 RII gelijk was aan gezonde controles. Tijdens behandeling van de acute exacerbatie was er een snelle daling van IL- 6 en sTNF R 75 terwijl BPI en S TNF R55 verhoogd bleven. Er was een stijging van het anti-inflammatoir sIL-1 RII tijdens behandeling evenals van de anti-oxidatieve capaciteit van het plasma 


\section{Samenvatting}

(TEAC). In de stabiele situatie, 6 maanden na de acute exacerbatie, waren alle biomarkers teruggekeerd naar het niveau van gezonde controle personen, behalve $\mathrm{BPI}$, dat verhoogd bleef.

Deze studie laat een duidelijke verhoging zien van systemische inflammatie tijdens acute exacerbaties van COPD. Verder is herstel van de exacerbatie geassocieerd met een stijging in anti-inflammatoire en anti-oxidatieve capaciteit.

$\mathrm{Er}$ is persisterende activatie van neutrofiele granulocyten zowel tijdens exacerbatie als in de stabiele fase zoals blijkt uit de persisterende verhoging van BPI.

Modulatie van systemische inflammatie zou kunnen bijdragen aan het klinisch herstel na een acute exacerbatie.

De studie beschreven in hoofdstuk 4 was erop gericht om te bekijken of parameters van systemische inflammatie in de stabiele fase gemeten, voorspellend kunnen zijn voor het optreden van acute exacerbaties.

In een grote groep patiënten werd het optreden van matig ernstige (waarvoor extra orale steroiden moesten worden voorgeschreven) en ernstige (waarvoor ziekenhuisopname noodzakelijk was) prospectief geregistreerd. Aan het begin van de studie werden longfunctie waarden ( $F E V$, FVC, FRC en DLCO) gemeten en systemische inflammatoire parameters CRP, fibrinogeen, LBP, TNF- $\alpha$, sTNFR 55 en sTNF R75 werden bepaald. In de totale groep traden 411 exerbaties op in 186 patienten, waarvan 374 matig ernstige exacerbaties en 37 ernstige exacerbaties. De gemiddelde follow-up was 0.88 jaar per patiënt.

Onafhankelijke voorspellende factoren voor een ernstige exacerbaties waren een lage $F E V_{1}$, lage DLCO, hoger fibrinogeen en hoger aantal ernstige exacerbaties in het jaar voorafgaand aan de studie.

Onafhankelijke voorspellende factoren voor een matig ernstige exacerbatie waren een lage $\mathrm{FEV}_{1}$, hoger fibrinogeen en een hoger aantal matig ernstige exacerbaties in het jaar voorafgaand aan de studie.

Uit deze studie blijkt dat naast longfunctiebeperkingen systemische inflammatie voorspellend is voor het optreden van zowel ernstig als matig ernstige exacerbaties van COPD.

In hoofdstuk 5 hebben we gekeken naar verschillende markers van systemische inflammatie en hemostase bij klinische stabiele COPD patiënten. In het bloed werden totaal plasma homocysteine ( $\mathrm{tHcy}$ ), hsCRP en fibrinogeen gemeten, voorafgaand aan een klinisch longrevalidatieprogramma. We vonden dat bij ongeveer $30 \%$ van stabiele COPD patiënten tHcy verhoogd was. Er bestond geen relatie tussen deze verhoogde tHcy waarden en klinische kenmerken zoals longfunctie, leeftijd, arteriële bloedgaswaarden, rookgewoonten of BMI. Waarden van tHcy bleven stabiel na een klinisch longrevalidatieprogramma.

Acute fase-eiwitten hs-CRP en fibrinogeen waren verhoogd in 20-30 \% van de stabiele COPD patiënten en waren eveneens niet gecorreleerd aan klinische parameters of aan $\mathrm{tHcy}$. 
Deze studie laat zien dat COPD patiënten een heterogene groep zijn, niet alleen qua klinische parameters maar ook qua waarden van systemische mediatoren $\mathrm{tHcy}$, hsCRP en fibrinogeen. Uit de cardiovasculaire literatuur is bekend dat verhoogd CRP, fibrinogeen en tHcy onafhankelijke risicofactoren zijn voor mortaliteit ten gevolge van hart-en vaatziekten. Gezien de verhoogde waarden van tHcy, CRP en fibrinogeen in een subgroep van patienten bestaat er een mogelijke link tussen COPD en cardiovasculaire aandoeningen.

In hoofdstuk 6 van dit proefschrift werd de bijdrage van MBL, een belangrijke component van het aangeboren immuunsysteem, aan acute exacerbaties van COPD onderzocht. De functie van MBL binnen het immuunsystem is complex en multifunctioneel. MBL kan complement activeren en het bevordert fagocytose en apoptose en moduleert inflammatie.

MBL is een receptor die bepaalde delen van bacterieën en virussen kan herkennen en hieraan kan binden, onder andere aan verschillende pathogenen, die geassocieerd worden met acute exacerbaties. De relatie tussen MBL en het ontstaan van acute exacerbaties is weinig onderzocht maar enkele studies suggereren dat bepaalde genetische varianten, die resulteren in een laag serum $M B L$, een verhoogd risico op luchtweginfecties en acute exacerbaties hebben.

Wij onderzochten het verband tussen serum $\mathrm{MBL}$, verdeeld in 4 categorieën: deficient (< 100 microg/L), laag (100-500 microg/L), normaal (500-2650 microg/ $L$ ) en hoog (> 2650 microg/L) en het optreden van matig ernstig en ernstige exacerbaties.

Een laag serum MBL gehalte had geen relatie met het voorkomen van ernstige exacerbaties. De groep met deficient $\mathrm{MBL}(<100$ microg/L) had zelfs minder matige ernstig exacerbaties dan de groep met MBL waardes $>100$ microg/L. Uit deze studie blijkt dat een laag serum $M B L$ geen verhoogd risico vormt op het optreden van acute exacerbaties en juist het aantal matig ernstige exacerbaties lijkt te verminderen.

Verder onderzoek zal de exacte rol van het MBL en het immuunsysteem in acute exacerbaties van COPD moeten ophelderen.

In hoofdstuk 7 van dit proefschrift wordt verder ingegaan op de systemische manifestaties tijdens COPD exacerbaties.

Naast locale inflammatie in de long gaan acute exacerbaties van COPD gepaard met een scala aan systemische effecten. Systemische inflammatie is toegenomen tijdens exacerbaties zoals blijkt uit diverse parameters die verhoogd worden gevonden, onder andere CRP, IL-8, TNF- $\alpha$, leptine, endotheline-1, ECP, MPO, fibrinogeen, IL-6, $\alpha-1$ antitrypsine, en leukotrienen B4 en E4. De meeste data echter zijn cross-sectioneel verzameld, en er zijn weinig longitudinale studies verricht. De relatie tussen locale en systemische inflammatie bij COPD is ook nog niet duidelijk. Verschillende studies suggereren dat beide compartimenten afzonderlijk 


\section{Samenvatting}

gereguleerd worden, in elk geval in stabiele COPD patiënten. Tijdens exacerbaties is er mogelijk wel een correlatie tussen locale en systemische inflammatie, mogelijk door de aanwezigheid van bacteriën en/of virussen in de luchtwegen. Hierdoor worden allerlei immunologische processen in gang gezet, zoals migratie van inflammatoire cellen. Toll Like Receptors (TLR's) zoals MBL kunnen onderdelen van bacterieën en andere microorganismen herkennen, waardoor deze migratie in gang wordt gezet. Hierdoor komen inflammatoire cytokines vrij die binden aan het endotheel van de bloedvaten en aldaar leukocyten activeren. Ook dendritische cellen, macrofagen en mestcellen spelen een rol in dit inflammatoire proces. Ook de hypoxemie die frequent optreedt tijdens acute exacerbaties, kan via transcriptie factor HIF-1 zorgen voor een toename van inflammatie, via een toename in TNF- $\alpha$.

Verder zijn de geactiveerde leukocyten, die aanwezig zijn tijdens exacerbaties een bron van oxidatieve stress. In hoofdstuk 3 hebben we laten zien dat neutrofiele granulocyten persisterend geactiveerd zijn tijdens acute exacerbaties. Verder hebben we aangetoond dat herstel van acute exacerbaties gepaard gaat met een afname in oxidatieve stress door toename van plasma TEAC.

Tijdens acute exacerbaties is er ook activatie van het complement systeem, mogelijk gereguleerd via de acute fase response, en meer specifiek door afgifte van CRP. Ook vetweefsel is betrokken in de pathogenese van exacerbaties, door productie van adipokines:leptine en adiponectine. Leptine wordt beschouwd als een antiinflammatoir cytokine. Leptine wordt in verhoogde concentraties gevonden tijdens exacerbaties en is verantwoordelijk voor verstoring van de energiebalans. Adiponectine wordt beschouwd als een anti-inflammatoir cytokine door reductie van TNF-aproductie via NFKB.

Verder zijn er tijdens exacerbaties aanwijzingen gevonden voor endotheliale dysfunctie en een pro-thrombotische neiging, onder andere door verhoging van fibrinogeen en aggregatie van bloedplaatjes. Exacerbaties zijn geassocieerd met een verhoogde incidentie van thrombo-embolische gebeurtenissen zoals longembolieën en myocardinfarcten. Ook CRP is hier een bijdragende factor omdat het direct invloed heeft op de vorming van atherosclerose.

Samenvattend worden tijdens acute exacerbaties vele systemische effecten gezien: toename van systemische inflammatie, toename van acute fase-eiwitten, activatie van complement en andere onderdelen van het immuun systeem, veranderingen in concentratie van adipokines zoals leptine en adiponectine, endotheliale dysfunctie en activatie van het stollingssysteem. Het bewustzijn van al deze processen die verder gaan dan alleen de respiratoire symptomen is het centrale thema van dit hoofdstuk. Door deze overkoepelende visie kunnen we een beter begrip ontwikkelen van acute exacerbaties en uiteindelijk mogelijk betere strategieën ontwikkelen ter preventie en behandeling. 
Hoofdstuk 8 beschrijft de resultaten van een onderzoek naar de prognose van COPD exacerbaties wat betreft mortaliteit en risicofactoren voor mortaliteit. We hebben 171 patiënten die opgenomen waren in verband met een acute exacerbatie prospectief vervolgd. De mortaliteit tijdens opname was $8 \%$ en nam toe tot 23 $\%$ na 1 jaar follow-up. Bij patiënten die op de Intensive Care moesten worden opgenomen in verband met respiratoire insufficiëntie was de mortaliteit tijdens opname vergelijkbaar (6\%) maar na 1 jaar significant hoger (35\%).

De onafhankelijke voorspellende factoren voor mortaliteit waren : hogere leeftijd, hogere $\mathrm{PaCO}_{2}$ en chronisch gebruik van orale corticosteroiden. $\mathrm{FEV}_{1}$, geslacht, $\mathrm{PaO}_{2}$, comorbiditeit en aantal heropnames waren niet van invloed op de mortaliteit.

Deze resultaten laten zien dat de mortaliteit na acute exacerbaties hoog is, vooral bij oudere patienten met respiratoire insufficiëntie. Het is belangrijk voor de behandelaars zich dit te realiseren met betrekking tot de palliatieve zorg en beslissingen over het levenseinde in het eindstadium van COPD.

\section{Conclusie}

De resultaten van de studies beschreven in dit proefschrift leveren meer bewijs voor de heterogeniteit en het complexe multifactoriële karakter van acute exacerbaties van COPD. In de toekomst zal een meer gedifferentieerde aanpak nodig zijn, die gericht is op optimale karakterisatie van COPD exacerbaties. Begrip van de vele processen die zich afspelen tijdens een exacerbatie van COPD zoals systemische inflammatie, betrokkenheid van het immuunsysteem en de stollingscascade en endotheliale dysfunctie is essentieel voor het ontwikkelen van een betere behandeling dan de huidige symptomatische therapie. 



\section{Abbreviations}

ACRP-30

AECOPD

APACHE

ATS

BAL

BDI

$\mathrm{BMI}$

$\mathrm{BPI}$

COPD

CNS

CRP

CRQ

DC

$\mathrm{DH}$

DLCO

ECG

ECP

ELISA

ET-1

FEV

FVC

FFMI

FRC

GM-CSF

GOLD

HIF-1 $\alpha$

IL-6

IL-8

LBP

LPS

IVC

LTB4

$\mathrm{LTE}_{4}$

$M B L$

MCP-1

MPIF-1

$M P O$

$N F K B$

PARC

PE
Adipocyte Complement Related Protein of $30 \mathrm{kDa}$ (adiponectin)

Acute Exacerbations of COPD

Acute Physiology And Chronic Health Evaluation

American Thoracic Society

BronchoAlveolar Lavage

Baseline Dyspnea Index

Body Mass Index

Bactericidal Permeability Increasing protein

Chronic Obstructive Pulmonary Disease

Central Nervous System

C-Reactive Protein

Chronic Respiratory Questionnaire

Dendritic Cells

Dynamic Hyperinflation

Diffusion capacity of the Lung for Carbon monoxide (CO)

ElectroCardioGram

Eosinophilic Cationic Protein

Enzyme Linked Immunosorbent Assay

Endothelin-1

Forced Expiratory Volume in one second

Forced Vital Capacity

Fat Free Mass Index

Functional Residual Capacity

Granulocyte and Macrophage Colony Stimulating Factor

Global initiative for chronic Obstructive Lung Disease

Hypoxia Inducible Factor $1 \alpha$

Interleukin 6

Interleukin 8

Lipopolysaccharide Binding Protein

LipoPolySaccharide

Inspiratory Vital Capacity

Leukotriene b4

Leukotriene E4

Mannose Binding Lectin

Monocyte chemotactic protein-1

Myeloid Progenitor Inhibitory Factor-1

Myeloperoxidase

Nuclear Factor kappa B

Pulmonary and Activation Regulated Chemokine

Pulmonary Embolism 


$\begin{array}{ll}\text { PM10 } & \text { Particulate Matter under } 10 \text { micron } \\ \text { RANTES } & \text { Regulated upon Activation, Normal T-cell Expressed and } \\ & \text { Secreted } \\ \text { RSV } & \text { Respiratory Syncytial Virus } \\ \text { RT-PCR } & \text { Real Time Polymerase Chain Reaction } \\ \text { S } & \text { Salmeterol } \\ \text { SFC } & \text { Salmeterol-fluticasone } \\ \text { SICAM-1 } & \text { Soluble Intercellular Adhesion Molecule-1 } \\ \text { SIL-1 RII } & \text { Soluble InterLeukin-1 Receptor II } \\ \text { SGRQ } & \text { Saint Ceorge Respiratory Questionnaire } \\ \text { STNF R55 } & \text { Soluble Tumor Necrosis Factor Receptor } 55 \\ \text { STNF R75 } & \text { soluble Tumor Necrosis Factor Receptor 75 } \\ \text { TEAC } & \text { Trolox Equivalent Antioxidant Capacity } \\ \text { tHcy } & \text { total homocysteine } \\ \text { TLR } & \text { Toll Like Receptors } \\ \text { TNF- } \alpha & \text { Tumor Necrosis Factor- } \alpha\end{array}$




\section{Curriculum vitae}

Karin Groenewegen-Sipkema werd geboren op 16 augustus 1969 in Leeuwarden. In 1987 behaalde zij haar VWO diploma aan het Christelijk Gymnasium te Leeuwarden. Na uitloting voor de studie Geneeskunde vertrok zij naar de Verenigde Staten voor een uitwisselingsprogramma van 1 jaar. Daarna begon zij met de studie Geneeskunde aan de Universiteit Utrecht.

Tijdens haar studie werden enkele stages en co-schappen in het buitenland gevolgd, onder andere in Turkije, Indonesië, Canada en Zimbabwe.

In 1996 behaalde Karin haar artsdiploma. De belangstelling voor de Longziekten en met name voor COPD ontwikkelde ze tijdens haar eerste baan als AGNIO Interne Geneeskunde, Cardiologie en Longziekten in het Groene Hart Ziekenhuis te Gouda en werd daarna versterkt tijdens een arts-assistentschap in Astmacentrum Heideheuvel te Hilversum. In 1998 begon zij in het Academisch Ziekenhuis Maastricht als AGNIO Longziekten en aan het einde van dat jaar werd begonnen met het in dit proefschrift beschreven onderzoek.

De opleiding tot longarts werd gevolgd van oktober 2001 tot 1 juni 2007 in het Academisch Ziekenhuis Maastricht en nadien werd dit proefschrift voltooid. Karin is gehuwd met Paul Groenewegen en zij hebben 2 zoons, Pieter (2001) en Karel (2002).

Per 1 juli 2008 gaat zij werken als longarts in het Deventer Ziekenhuis. 


\section{Dankwoord}

Geen klinische studie is mogelijk zonder patiënten want daar gaat het allemaal om. Allereerst wil ik de patiënten die aan dit onderzoek hebben meegewerkt van harte danken voor hun inspanningen. Het is ongetwijfeld niet gemakkelijk voor patiënten die ziek en kortademig worden opgenomen ook nog eens deel te nemen aan een "onderzoekje". Voor diegenen die deze extra inspanning wel hebben opgebracht, heb ik grote bewondering. Helaas zal het grootste gedeelte van "mijn" patiënten de publicatie van dit proefschrift niet meer meemaken, hetgeen niet alleen iets zegt over de prognose van deze patiëntenpopulatie, maar ook over de tijd die nodig is geweest voor het voltooien van dit boekwerk...

Geen promotie zonder promotor. Mijn promotor professor Wouters was de drijvende kracht achter het onderzoek, en heeft mij met zijn enorme kennis en visie steeds geïnspireerd en gemotiveerd.

Mieke Dentener hielp mij met vele praktische en inhoudelijke zaken, variërend van het delen in haar grote kennis betreffende inflammatoire mediatoren en het leren pipetteren en wegwijs maken op het laboratorium, tot het schrijven van een goed diplomatiek antwoord naar de reviewers, zodat weigering geen optie meer was.

Wim Hop was mijn steun en toeverlaat in de statistiek van de COSMIC bestanden en toverde onvermoeibaar steeds nieuwe getallen en correlaties tevoorschijn. En dat ook op de meest onmogelijke tijden, als ik weer eens iets met spoed nodig had.

Martijn Spruit coördineerde het verwerken van de samples en patiëntgegevens op Hornerheide en stond altijd klaar met goede adviezen en suggesties.

Marie Breyer zocht alle patiëntensamples bij elkaar en trotseerde keer op keer de ijskoude vriezer en dat ook nog in recordtijd.

De medewerkers van het lab op Hornerheide, het klinisch chemisch lab, het lab Immunologie en het lab Klinische Genetica van het azM, hartelijk dank voor het verrichten van alle bepalingen.

Alle co-auteurs van de verschillende artikelen, hartelijk dank voor jullie bijdrage, ieder artikel is het resultaat van een gezamenlijke inspanning!

Collega-researchers Pulmonologie, teveel om allen bij naam te noemen, en bovendien een steeds wisselende en groeiende groep, dank voor de adviezen, suggesties en hulp op diverse terreinen, met name in het begin toen ik van onderzoek en alles wat daarbij komt kijken geen kaas gegeten had. 
Longartsen en collega- arts-assistenten van de afdeling Longziekten van het azM, dank voor de gezellige werksfeer, waarin dit proefschrift tot stand kwam, ondanks de hectiek van de dagelijkse patiëntenzorg.

Het secretariaat Longziekten, met name Manon Hijnens, hartelijk dank voor alle praktische ondersteuning bij het samenstellen van het manuscript en de officiële correspondentie.

De beoordelingscommissie, bestaande uit Prof. Dr. A. Masclee, Prof. Dr. H.A.M. Kerstjens, Prof. Dr. R. Louis, Dr. E. Stobberingh en Dr. G.P.M. ten Velde wil ik hartelijk danken voor het doorlezen van het manuscript. Guul, ik vind het leuk dat je naast je grote bijdrage aan mijn opleiding, ook aan dit proefschrift je bijdrage hebt geleverd.

Mijn paranimfen: Jet Beijer en Ank Sonnenberg.

Jet, je herinnerde me er pas nog aan dat wij elkaar al 20 jaar kennen, en ook al spreken wij elkaar niet dagelijks, we kunnen de draad altijd meteen weer oppakken. Op naar de volgende 20 jaar!

Ank, ook al weer sinds vele jaren vriendin en collega (in die volgorde), bedankt voor alle gezelligheid van de afgelopen jaren, bij jou realiseerde ik me altijd dat er meer in het leven is naast werk en onderzoek!

Mijn familie en schoonfamilie, eindelijk zien jullie een tastbaar resultaat van waar ik de afgelopen jaren mee bezig ben geweest. Vanaf nu heb ik meer tijd voor jullie. Als laatste mijn mannen, Paul, Pieter en Karel, jullie brachten de grootste offers. Als gezin hebben wij altijd meer quality time gehad dan quantity time, alles wordt nu anders! Ik houd van jullie.

Karin 
